\title{
WestVirginiaUniversity
}

THE RESEARCH REPOSITORY @ WVU

Graduate Theses, Dissertations, and Problem Reports

2012

\section{A Novel Approach To Residence Time Distribution}

Jackson W. Wolfe

West Virginia University

Follow this and additional works at: https://researchrepository.wvu.edu/etd

\section{Recommended Citation}

Wolfe, Jackson W., "A Novel Approach To Residence Time Distribution" (2012). Graduate Theses, Dissertations, and Problem Reports. 467.

https://researchrepository.wvu.edu/etd/467

This Thesis is protected by copyright and/or related rights. It has been brought to you by the The Research Repository @ WVU with permission from the rights-holder(s). You are free to use this Thesis in any way that is permitted by the copyright and related rights legislation that applies to your use. For other uses you must obtain permission from the rights-holder(s) directly, unless additional rights are indicated by a Creative Commons license in the record and/ or on the work itself. This Thesis has been accepted for inclusion in WVU Graduate Theses, Dissertations, and Problem Reports collection by an authorized administrator of The Research Repository @ WVU. For more information, please contact researchrepository@mail.wvu.edu. 


\title{
A Novel Approach To Residence Time Distribution
}

\author{
Jackson W. Wolfe \\ Thesis Submitted to the \\ Benjamin M. Statler College \\ of Engineering and Mineral Resources \\ At West Virginia University \\ in partial fulfillment of the requirements \\ for the degree of \\ Master of Science \\ in \\ Mechanical Engineering \\ Eric K. Johnson, Ph.D, Chair \\ Bruce S. Kang, Ph.D. \\ Larry Shadle, Ph.D. \\ Department of Mechanical Engineering
}

Morgantown, West Virginia

2012

Keywords: Fluidized Bed, Riser, Residence Time Distribution, Solids Tracing 


\section{Abstract \\ A Novel Approach to Residence Time Distribution}

\section{Jackson W. Wolfe}

An increased knowledge in the solids flow in multiphase flow systems can be applied in the design of industrial systems used for power generation, gasification, pneumatic transport of material, drying, and various other tasks. An instrument was constructed for the activation, injection, and measurement of phosphorescent tracer particles in a fluidized bed riser to determine the Residence Time Distribution (RTD) of solids flow within a fluidized bed riser. The instrument was implemented in a dual-stage transparent scale model fluidized bed riser. Testing of the instrument system validated the functionality of the instrument. It was proven to be capable of determining both localized and total Residence Time Distribution in a fluidized bed riser operated in the pneumatic transport flow regime with relatively short RTD. The determination of localized RTD was also achieved in the fluidized bed riser operated in the coreannular flow regime. 


\section{Acknowledgements}

I would firstly like to express my gratitude to Dr. Eric Johnson. Without his mentorship, I would have never been able to complete such a project. His unique views and old-school methods has positively shaped the way in which I approach a problem.

I would like to express thanks to Dr. Bruce Kang for giving other insightful opinions and solutions to problems experienced within this work. I would also like to give thanks to my last committee member, Dr. Larry Shadle. He has provided useful information crucial to this project. His expressed interest in the project also helped renew my own enthusiasm to the field of fluidization research. Thanks must also be given to Dr. Gary Morris for providing assistance with signal filtering and instrumentation.

My gratitude cannot be expressed enough for the help I have received from my fellow Graduate Researchers: Steve, Eric, and Femi. Without them I would be lost. I would also like to thank Cliff Judy for his exceptional machining and fabrication of parts.

I would like to thank my family for the support they have always provided, for always being positive, and for forcing me into graduate school. Without my loving father and mother, I would not be the person that I am today. I would lastly like to express my gratitude to a very special person in my life. Her amazing presence makes me feel the need to better myself, and her work ethic gave me the motivation to complete my work. 


\section{Table of Contents}

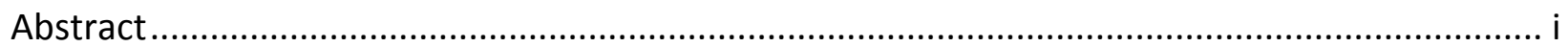

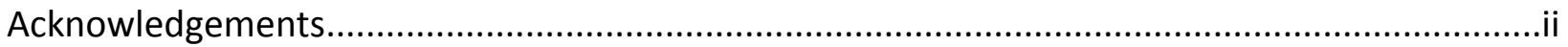

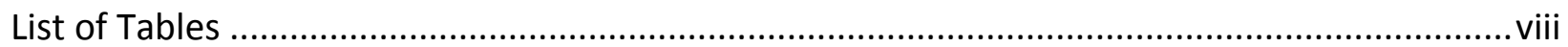

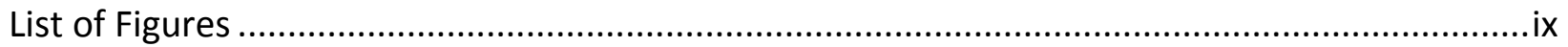

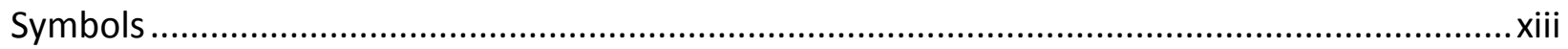

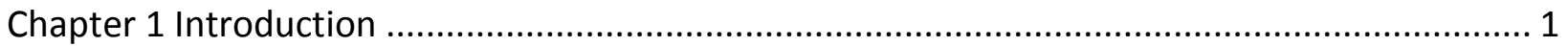

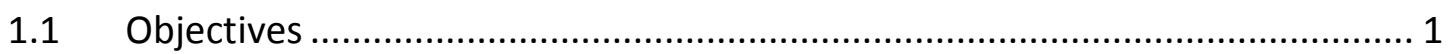

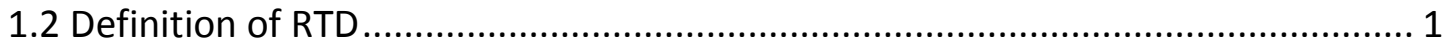

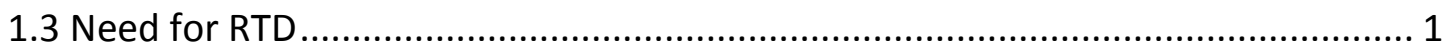

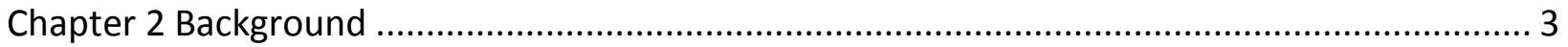

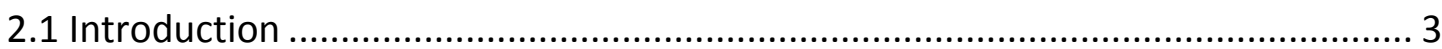

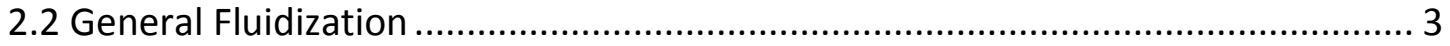

2.2.1 Dense Phase …....................................................................... 3

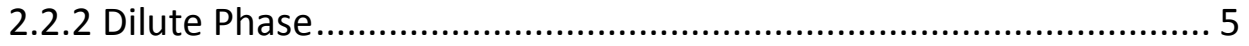

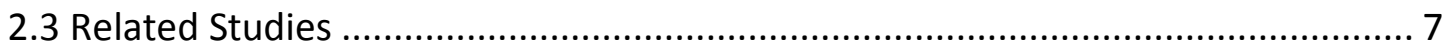

2.3.1 Radioactive/PEPT Tracer ..................................................... 7

2.3.2 Chemically Different Tracers .................................................... 8

2.3.3 Thermal Tracers................................................................... 9 
2.3.5 Phosphorescent Tracers ........................................................ 10

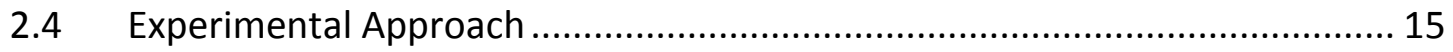

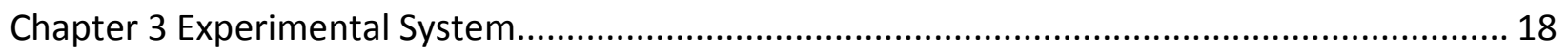

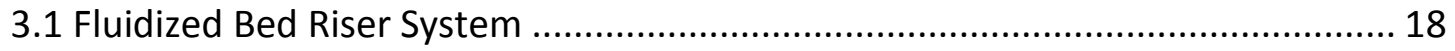

3.1.1 Feed Hopper ......................................................................... 20

3.1.2 Pneumatic Transport System ............................................. 20

3.1.3 Bottom distributor.......................................................... 21

3.1.4 Bottom Riser Stage ............................................................... 22

3.1.5 Secondary Air Injection Ring .................................................. 22

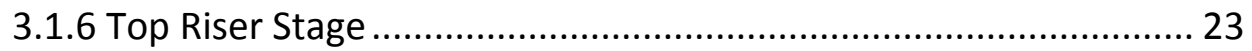

3.1.7 Cyclone ........................................................................... 23

3.1.8 Product Hopper ..................................................................... 24

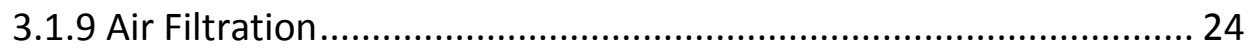

3.1.10 Compressed Air Feed System ............................................ 24

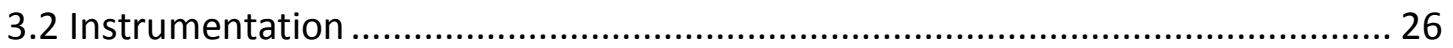

3.2.1 Data Acquisition System .................................................... 26

3.2.2 Pressure Transducers .................................................................. 26

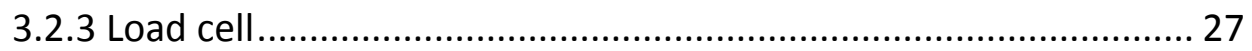




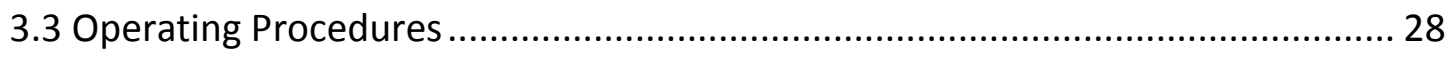

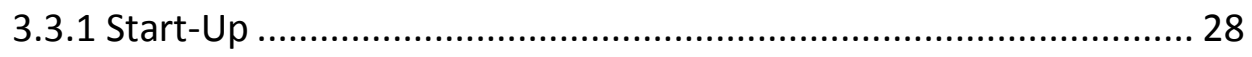

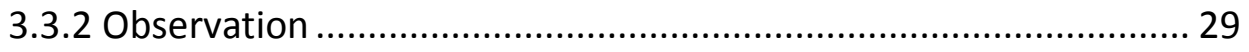

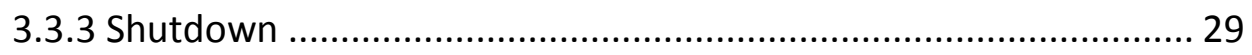

3.3.4 Emergency Shutdown............................................................... 29

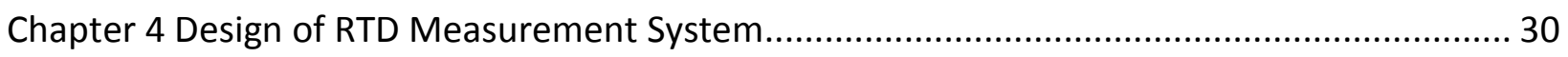

4.1 Tracer Irradiation System Design ................................................................. 30

4.2 Design of Tracer Injection Unit ...................................................................... 40

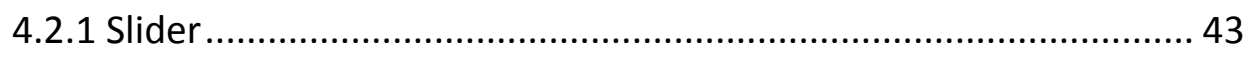

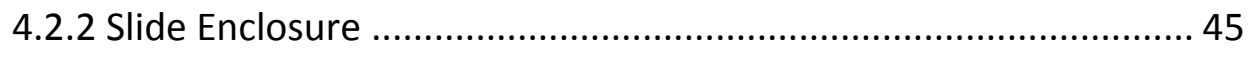

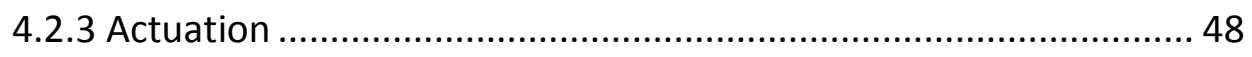

4.2.4 Sealing Provisions/Modifications ................................................ 50

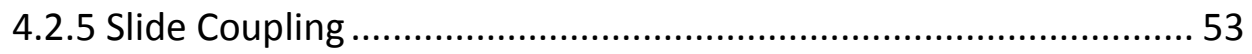

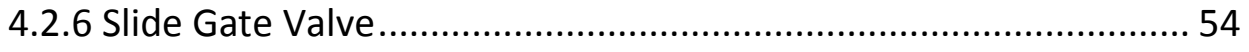

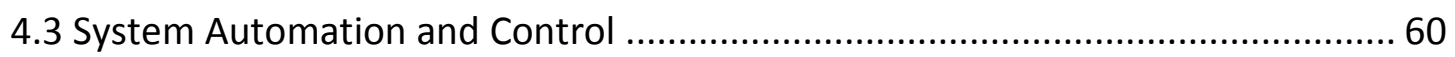

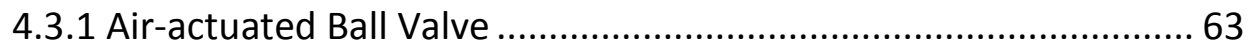

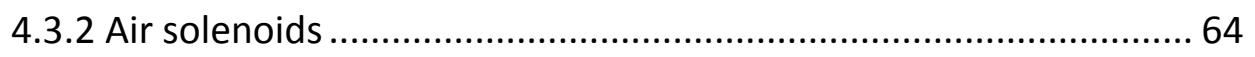

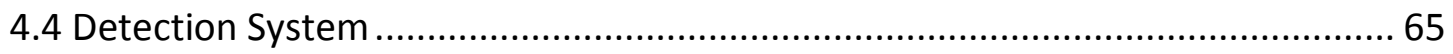

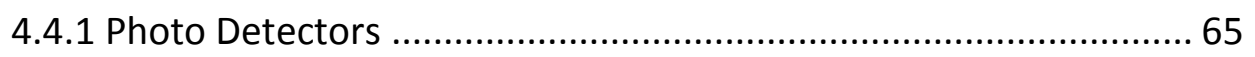




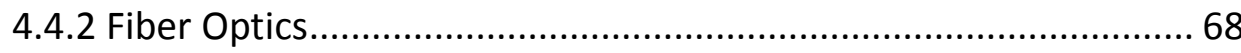

4.4.3 Fiber Optic Connection ............................................................ 72

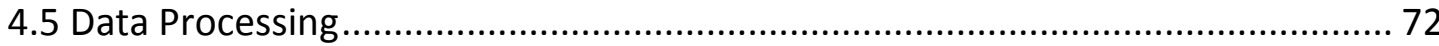

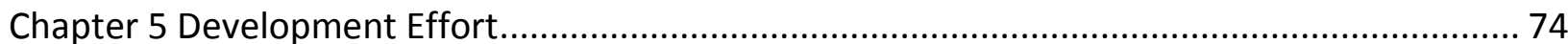

5.1 Illumination Wavelength Study ...................................................................... 74

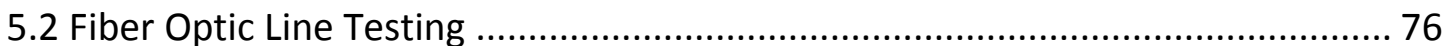

5.3 Fiber Line Angle of Acceptance Study............................................................... 79

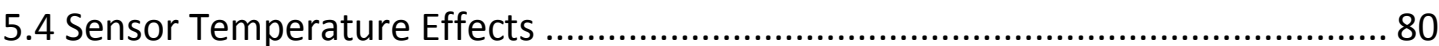

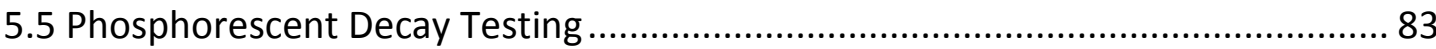

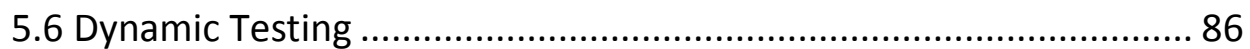

5.7 Effect of Signal Noise on Concentration Curves .................................................. 96

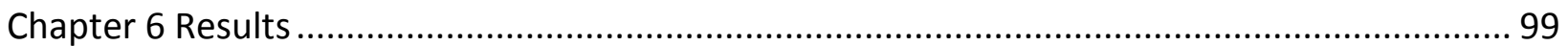

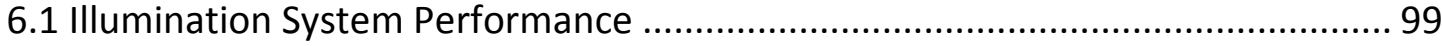

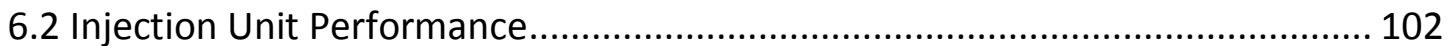

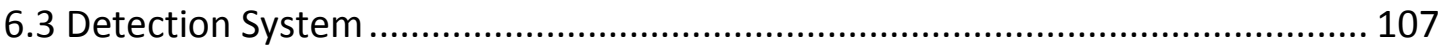

Chapter 7 Conclusions and Recommendations ............................................................... 129

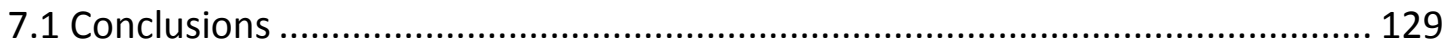

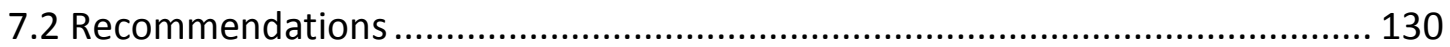

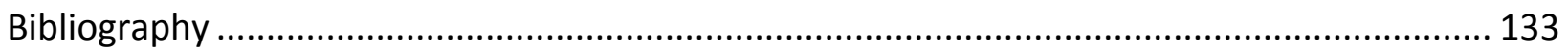




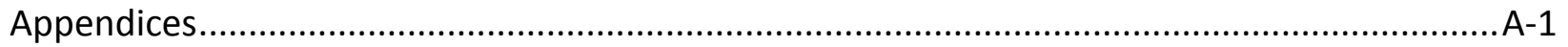

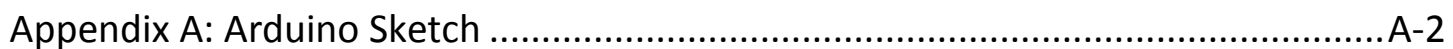

Appendix B: Thermochromic Tracers .......................................................... 


\section{List of Tables}

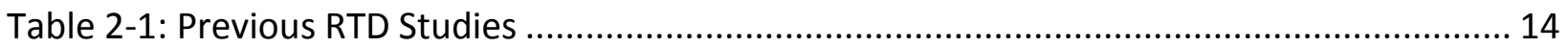

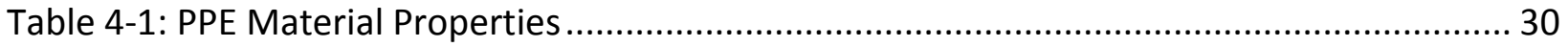

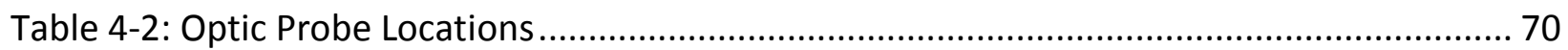

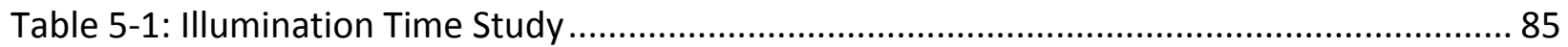

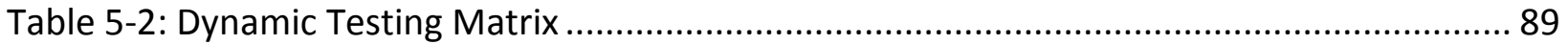

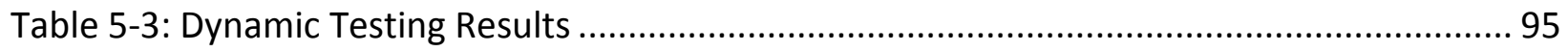

Table 6-1: Illumination Uniformity Test Results .............................................................. 101

Table 6-2: Slide Actuation Time. No Tracer Particles. 60 psi Pressurization ........................... 103

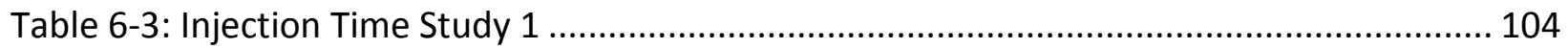

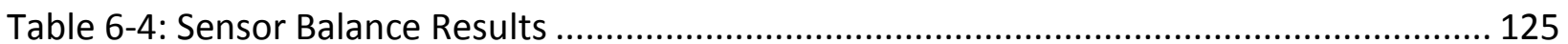




\section{List of Figures}

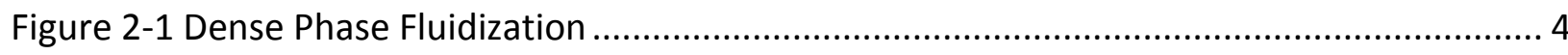

Figure 2-2 Expected Irradiation and Decay of Phosphorescent Particles................................ 15

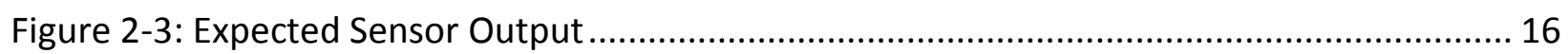

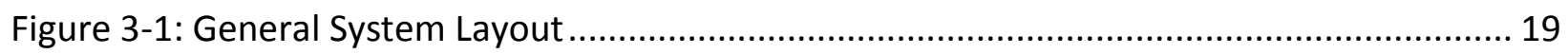

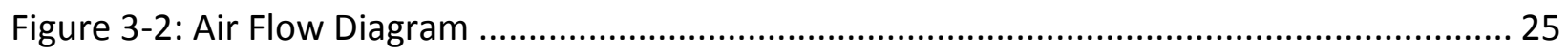

Figure 3-3: Instrument Placement Diagram ............................................................... 28

Figure 4-1: General Layout of Tracer Illumination System ............................................. 32

Figure 4-2: Clear Illumination Hopper Section .................................................................... 36

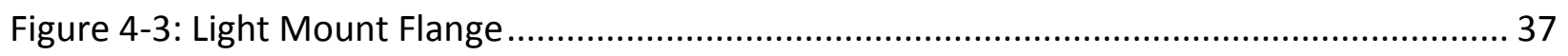

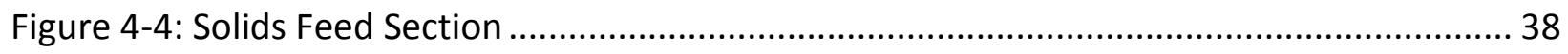

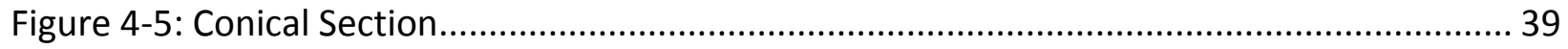

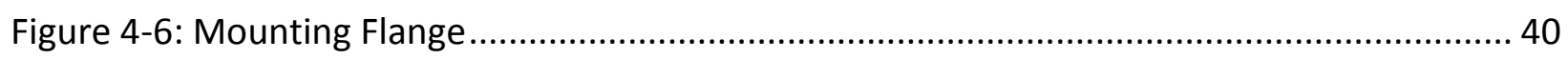

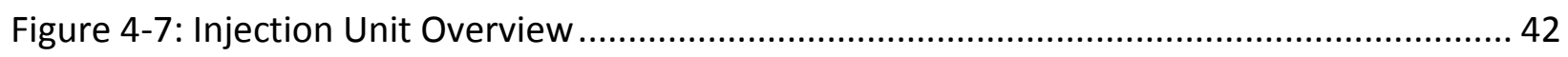

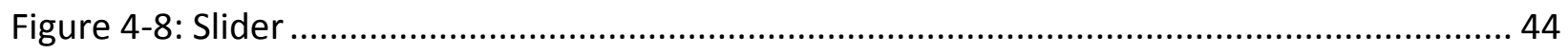

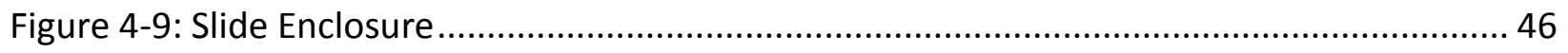

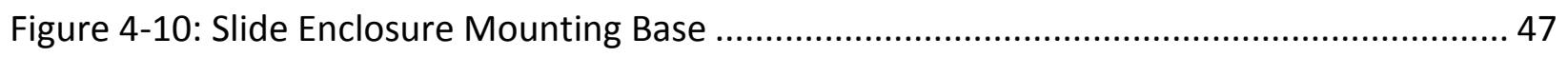

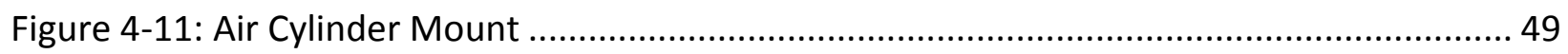

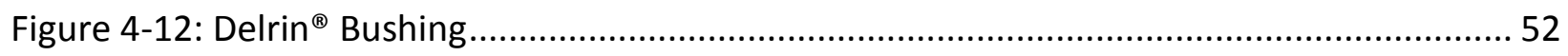

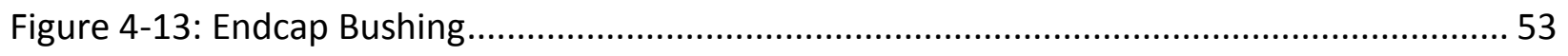

Figure 4-14: Slide Gate Valve Exploded View ................................................................ 56

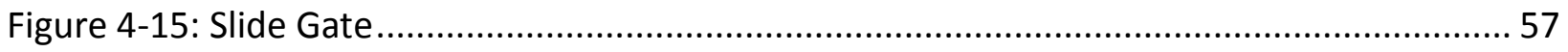


Figure 4-16: Slide Gate Valve Body 58

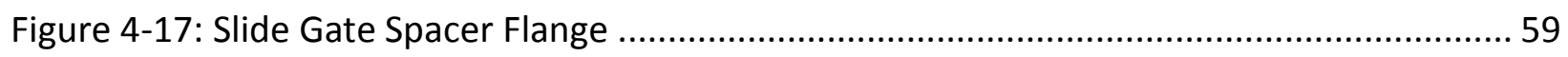

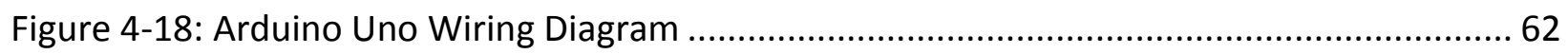

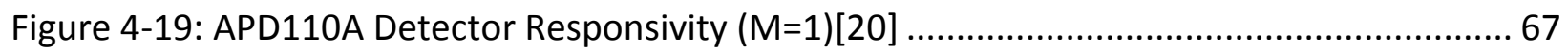

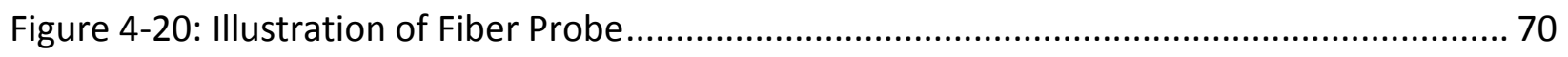

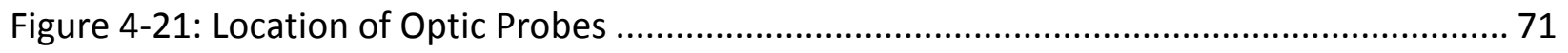

Figure 4-22: Orientation of Fiber Detection Probes and Pressure Transducers, Top View ......... 72

Figure 5-1: General Layout of Illumination Study........................................................... 75

Figure 5-2: Preliminary Particle Illumination Study, Raw Data............................................ 75

Figure 5-3: General Layout of Apparatus for Fiber Optic Line Testing .................................. 77

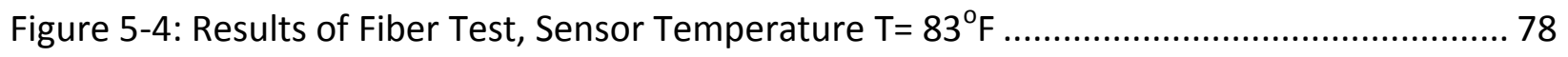

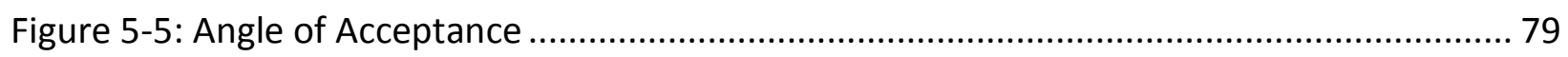

Figure 5-6: General Layout of Apparatus for Angle of Acceptance Test ................................ 80

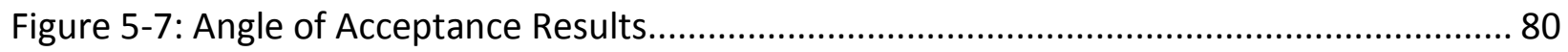

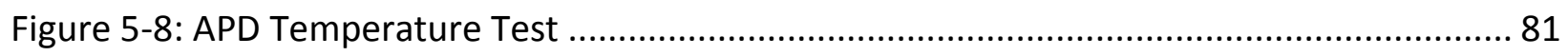

Figure 5-9: Performance Variation Due to Temperature ..................................................... 83

Figure 5-10: General Layout of Apparatus for Phosphorescent Decay Test ............................ 84

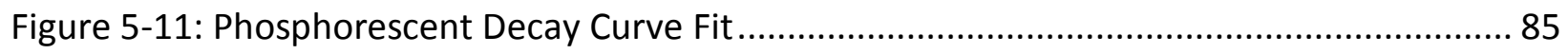

Figure 5-12: General Layout of Apparatus for Dynamic Testing ........................................ 88

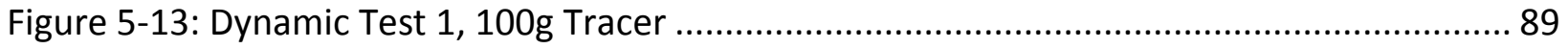

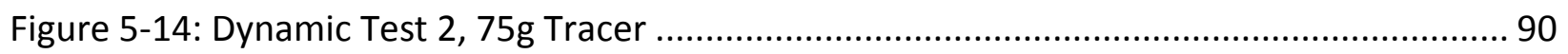

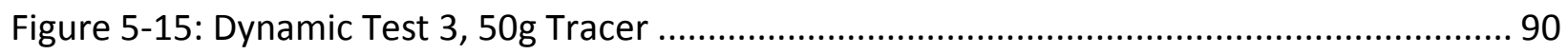


Figure 5-16: Dynamic Test 4, 25g Tracer

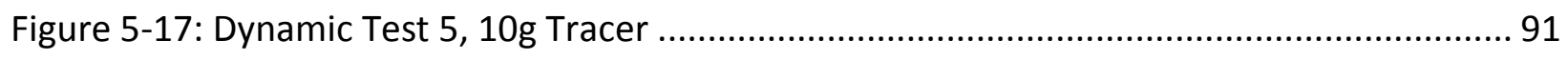

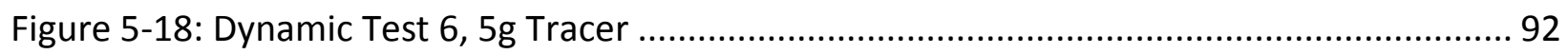

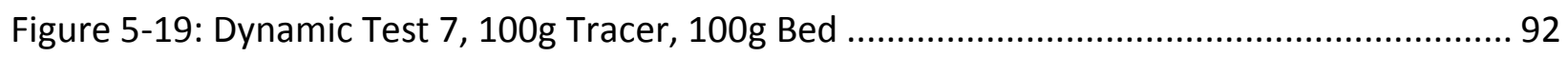

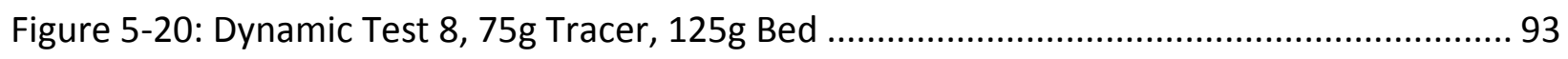

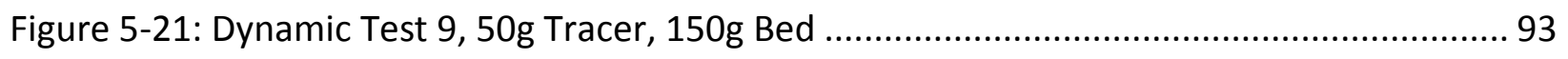

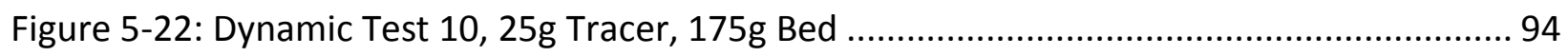

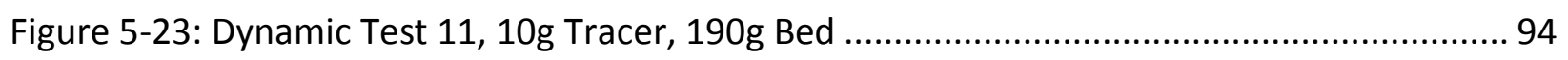

Figure 5-24: Dynamic Test 12, 5g Tracer, 195g Bed ..................................................... 95

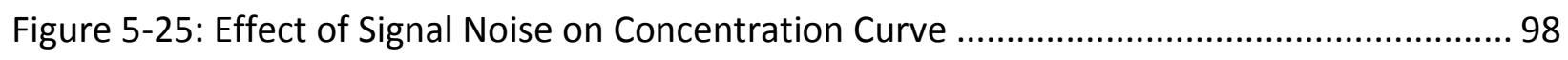

Figure 6-1: General Layout of System for Illumination Uniformity Test .............................. 100

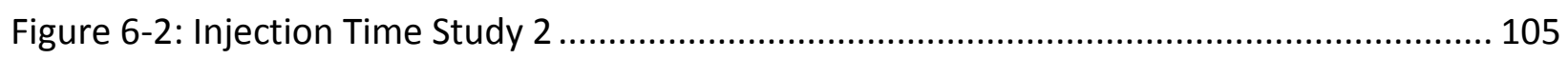

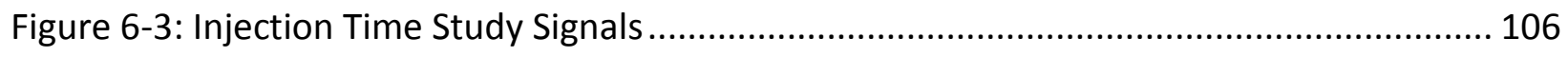

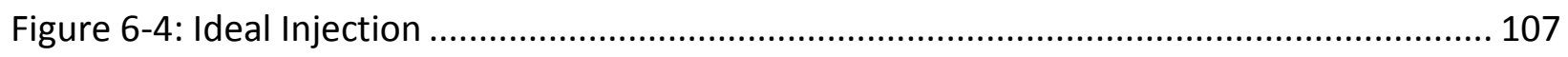

Figure 6-5: Probe Locations in Exit Crossover............................................................. 108

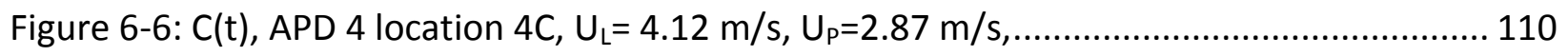

Figure 6-7: PMT APD Comparison, Strobe Light Test .................................................... 112

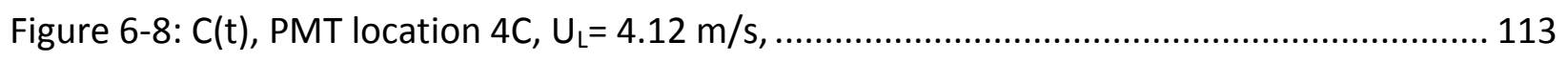

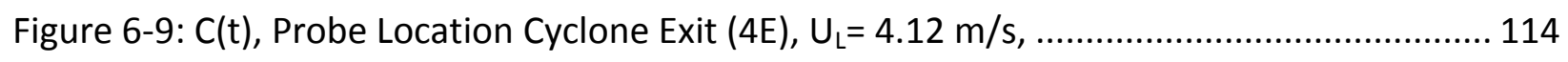

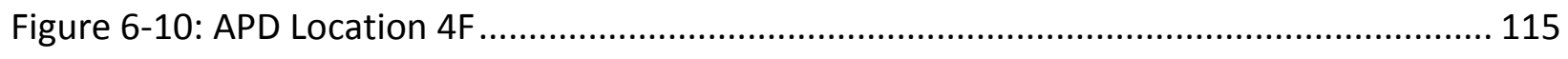

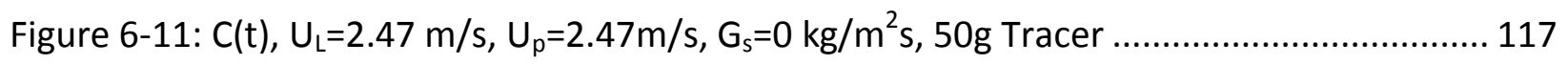

Figure 6-12: $C / C_{0}(t), U_{L}=2.47 \mathrm{~m} / \mathrm{s}, \mathrm{U}_{\mathrm{p}}=2.47 \mathrm{~m} / \mathrm{s}, \mathrm{G}_{\mathrm{s}}=0 \mathrm{~kg} / \mathrm{m}^{2} \mathrm{~s}, 50 \mathrm{~g}$ Tracer ...................... 118 
Figure 6-13: $C(t), U_{L}=2.47 \mathrm{~m} / \mathrm{s}, U_{p}=2.47 \mathrm{~m} / \mathrm{s}, G_{s}=2.94 \mathrm{~kg} / \mathrm{m}^{2} \mathrm{~s}, 50 \mathrm{~g}$ Tracer

Figure 6-14: $C / C_{0}(t), U_{L}=2.47 \mathrm{~m} / \mathrm{s}, U_{p}=2.47 \mathrm{~m} / \mathrm{s}, G_{s}=2.94 \mathrm{~kg} / \mathrm{m}^{2} \mathrm{~s}, 50 \mathrm{~g}$ Tracer 120

Figure 6-15: $C(t), U_{L}=4.12 \mathrm{~m} / \mathrm{s}, U p=2.87 \mathrm{~m} / \mathrm{s}$, 121

Figure 6-16: $C / C_{0}(t), U_{L}=4.12 \mathrm{~m} / \mathrm{s}, U p=2.87 \mathrm{~m} / \mathrm{s}$, 122

Figure 6-17: $C(t), U_{L}=4.12 \mathrm{~m} / \mathrm{s}, U p=2.87 \mathrm{~m} / \mathrm{s}$, 123

Figure 6-18: $C / C_{0}(t), U_{L}=4.12 \mathrm{~m} / \mathrm{s}, U p=2.87 \mathrm{~m} / \mathrm{s}$, 124

Figure 6-19: Sensor 1 Performance Analysis, Decay Test...... 126

Figure 6-20: Sensor 2 Performance Analysis, Decay Test. 127

Figure 6-21: Sensor 3 Performance Analysis, Decay Test. 127 


\section{Symbols}

\begin{tabular}{|c|c|}
\hline Symbol & Meaning \\
\hline A & Area \\
\hline $\operatorname{Ar}$ & Archimedes Number \\
\hline $\mathrm{cV}$ & Flow Factor \\
\hline D & Diameter \\
\hline$d_{p}$ & Diameter of Particle \\
\hline g & Gravitational acceleration \\
\hline $\mathrm{G}_{\mathrm{s}}$ & Solid Mass Flux in the Riser \\
\hline L & Length \\
\hline $\mathrm{m}$ & Mass \\
\hline M & Magnification Factor \\
\hline$P$ & Pressure \\
\hline $\mathcal{R}$ & Responsivity \\
\hline $\mathrm{R}$ & Radius \\
\hline $\operatorname{Re}_{t}$ & Reynolds Number at the Terminal Velocity \\
\hline $\operatorname{Re}_{\mathrm{tr}}$ & Reynolds Number at the Transport Velocity \\
\hline s & signal standard deviation \\
\hline$t_{1}$ & Time at Which Tracers are First Detected \\
\hline$t_{2}$ & Time at Which Tracers are No Longer Detected \\
\hline U & Superficial Air Velocity in Riser \\
\hline$U_{f d}$ & Upper Gas Velocity Bound for Core/Annulus Flow \\
\hline$U_{\mathrm{L}}$ & Superficial Air Velocity in the Lower Riser Stage \\
\hline$U_{p}$ & Superficial Air Velocity in the upper Riser Stage \\
\hline$U_{p t}$ & Particle Terminal Velocity \\
\hline
\end{tabular}




$\begin{array}{ll}U_{t} & \text { Terminal Velocity of the Particle } \\ U_{t f} & \text { Lower Gas Velocity Bound for Core/Annulus Flow } \\ V_{\text {air }} & \text { Velocity of Air } \\ W & \text { Weight } \\ \text { Greek } & \\ \varepsilon & \text { Voidage in Riser } \\ \mu & \text { Viscosity } \\ \rho & \text { Density } \\ \rho_{g} & \text { Density of Gas } \\ \rho_{p} & \text { Density of Particle } \\ \rho_{s} & \text { Density of Solid }\end{array}$




\section{Chapter 1 Introduction}

\subsection{Objectives}

The objective of this research effort was to develop a system for the measurement of Residence Time Distribution, RTD of solids within a fluidized bed riser by constructing a system for the activation, injection, and detection of a phosphorescent tracer material. A secondary objective was to conduct preliminary testing of the RTD measurement system implemented into a fluidized bed riser to evaluate the performance of the RTD system.

\subsection{Definition of RTD}

The definition of Residence Time Distribution (RTD) is somewhat vague. In the literature RTD is defined as a probability density function that is characterized by a histogram [1]. The probability density function describes the amount of time an element spends within a system. It is important to measure and examine RTD in a continuous flow system.

There are terms for total RTD and local RTD. Total RTD applies to the entire system with the measurement being taken as the particles exit the system. Local RTD is measured inside the system and is usually more difficult to determine since this measurement can be considered as an open system where the boundaries are not well defined.

\subsection{Need for RTD}

The measurement of Residence Time Distribution (RTD) of solids is of particular interest in the field of multi-phase flow. RTD is basically a study of the period in which selected elements are contained within a system. The study of RTD results in more accurate modeling of the 
hydrodynamics and the interaction between solids and gas contained within a fluidized bed system. These products models are applied in the design of industrial systems used for power generation, gasification, applying coating to particles such as medicine tablets, pneumatic transport of material, drying, and separation.

One possible outcome of increased knowledge pertaining to multiphase flow by the use of RTD measurements is the increased efficiency and the decreased pollution of coal-fueled fluidized bed reactors. Effectiveness of a circulating fluidized bed (CFB) combustor or reactor depends on the ability to adequately mix the incoming flows of reactants: fuel, sorbent and air [2]. Devolatilization or pyrolisis is a crucial step of coal combustion or gasification. Devolatilization of coal is a process in which coal is transformed at elevated temperatures to produce gases, tar, and char. These products can have a negative impact on the pollutants released from a fluidized bed coal reactor. Although devolatilization is foremost a function of composition and structure of the coal, reaction conditions also play a major role. Reaction conditions include heating rate, residence time, temperature, pressure, gas atmosphere, and most significantly particle size [3]. Knowing how solids move within a system allows designers to make more efficient designs. 


\section{Chapter 2 Background}

\subsection{Introduction}

There have been over a dozen types of tracers used in previous studies which include ferromagnetic [4], thermal [2], phosphorescent [5-9], radioactive [10,11], salt [10], sawdust[10], color [12], carbon loaded tracers[13], and solid $\mathrm{CO}_{2}$ tracers [14]. Each tracer type and measurement systems have distinct advantages and disadvantages. Some range from the simplicity of adding sawdust as a tracer material and collecting samples at even time increments at the system exit [10]. Other are more complex such as using a single radioactive tracer that is continuously tracked within the system providing tracer position, velocity, and trajectory with high resolution $[10,11]$. The following section details general fluidization concepts before expanding on previous studies examining the topic of RTD and solids movement.

\subsection{General Fluidization}

There are many aspects of fluidization of gas/solids that must be understood. The two main regimes of fluidization are dense phase and dilute phase. Each of these regimes has multiple subsets. These are classified by the state of solids motion [7].

\subsubsection{Dense Phase}

There are many fluidization regimes encompassed by dense fluidization. The first regime is where suitable solids are in a fixed bed state where the gas flow is so minimal that it permeates between the solids without causing motion of solids [15]. As the gas velocity increased, particles begin to move apart and become suspended. This dense suspension is usually 
characterized by visible bubbles traveling upwards through the solids bed. Some solids entrainment occurs as the bubbles rupture at the surface and throw solids upwards into the freeboard. A further increase in gas velocity causes greater solids entrainment and bubbles become less distinguishable. This is commonly known as the turbulent regime. It occurs at the transition between dense to dilute phase fluidization. A phenomena known as slugging occurs when the bubble diameters approaches the diameter of the riser. This fluidization regime is usually avoided. As the gas velocity increases higher, the particles become fully entrained and the fluidization regime transitions to a lean phase. Figure 2-1 is a visual representation of the dense fluidization regimes.

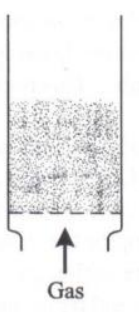

(a)

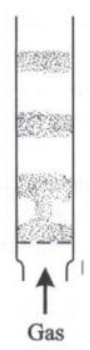

(d)

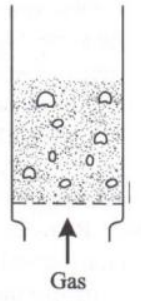

(b)

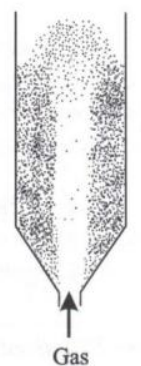

(e)

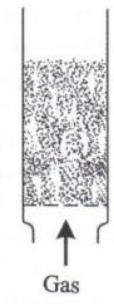

(c)

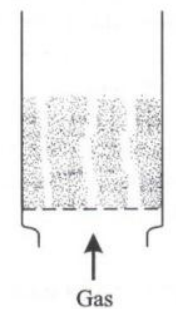

(f)

Figure 2-1 Dense Phase Fluidization (a) Particulate (b) Bubbling

(c) Turbulent (d) Slugging (e) Spouting (f) Channeling [16] 


\subsubsection{Dilute Phase}

Lean phase fluidization is characterized by total entrainment of solids within gas flow. The dense bed expands further and becomes indistinguishable. The constant addition of solids to the riser is required as particles evacuate the riser. This type of fluidization is the primary regime of a circulating fluidized bed (CFB). Within dilute fluidization there are two flow regimes: fast fluidization and dilute transport. Dilute transport is characterized by almost non-existent recirculation of the solids [16]. Fast fluidization is characterized by particle movement referred to as core-annular flow regime. This regime has an upward flow of solids in the center, the core, and a downward flow of solids near the wall, the annulus. Both dilute phase regimes are used for the verification of this study. The dilute transportation phase was utilized so that the injected tracers would pass each sensor location without recirculation to mimic the bounds of a closed system. The second set of testing was done in the core-annulus flow regime to further study the capability of the detection system within the riser as there is solids recirculation.

There are three main variables in the comparison of fluidized bed operation: superficial air velocity $(U)$, voidage $(\varepsilon)$, and solids flux $\left(G_{s}\right)$. The velocity of air within a riser containing solids is difficult to predict or calculate. Instead the superficial air velocity, $U$, is calculated. This is accomplished by dividing the volumetric air flow rate by the cross sectional area of the riser without solids. For this study using a two stage riser, the cross sectional area of the lower stage is used.

$$
U=\frac{V_{A I R}}{A}
$$


Solids flux rate denotes the mass flow rate of solids into the riser divided by the cross sectional area of the riser. This makes for easier comparison of systems of different geometries and cross sectional areas.

$$
G_{S}=\frac{d W}{d t} /_{A}
$$

$\operatorname{Voidage}(\varepsilon)$ is the ratio of the volume of the riser occupied by gas to the total volume of the riser. A riser containing no solids has a voidage of 1 . Monazam and Shadle [17] supplied an equation relating the average pressure drop across the riser to voidage which is given as:

$$
\frac{d P}{d z}=\rho_{s}(1-\varepsilon) g
$$

where $\rho_{s}$ is the density of the solids and $\mathrm{g}$ is the gravitational constant.

For operation in the dilute fluidization regime, many parameters are essential to predict velocities at which transitions of the regimes occur. The first variable to be calculated is the Reynolds number for the transport velocity of the particle, which is expressed as [16]:

$\operatorname{Re}_{\mathrm{tr}}=2.28 \mathrm{Ar}^{0.419}$

where

$$
A r=\frac{\rho\left(\rho_{p}-\rho\right) g d_{p}^{3}}{\mu^{2}}
$$

The Reynolds number corresponding to the particle terminal velocity was from the following equation [15]: 
$R e_{t}=\frac{\rho U_{p t} d_{p}}{\mu}$

Where $U_{p t}$ is the terminal velocity found from the following equation:

$U_{p t}^{1.4}=0.072 \frac{d_{p}^{1.6}\left(\rho_{p}-\rho\right) g}{\rho_{g}^{0.4} \mu^{0.6}} \quad 2<R e_{t}<500$

The lower bound for the gas velocity for the fast fluidization regime $\left(U_{t f}\right)$ is found using [16]:

$U_{t f}=39.8 \sqrt{g d_{p}}\left(\frac{G_{s}}{\rho U_{t f}}\right)^{0.311} R e_{t}^{-0.078}$

Finally the upper bound for the gas velocity for fast fluidization can be found by

$U_{f d}=21.6 \sqrt{g d_{p}}\left(\frac{G_{s}}{\rho U_{f d}}\right)^{0.542} A r^{0.105}$

\subsection{Related Studies}

\subsubsection{Radioactive/PEPT Tracer}

Valden et al. [10] used Positron Emission Particle Tracking (PEPT) to continuously track individual particles which results in real time particle positions and velocities. A radioactive isotope was prepared in a cyclotron and was incorporated into the tracer by direct activation, ion-exchange or surface modification techniques. A radioactive isotope was introduced into the system and detected by pairs of gamma-rays arising from annihilation of the positrons emitted by beta-decay. The tracer is located by triangulation from the sensors many times per second. This provided trajectory and velocity information of the particle in real time. This method results in the most accurate representation of a particle path through a riser providing the size and density of the tracer is equivalent to the bed material. This method is, however, 
one of the most costly and difficult methods. To complicate matters, there are many hazards and safety protocols associated with using radioactive isotopes.

\subsubsection{Chemically Different Tracers}

Salt and sawdust tracers have been used previously using sand as the bed material by Velden et al. [10] in conjunction with the radioactive isotope tracer study to compare accuracy. This method is very simple in nature. The tracer samples were injected into the riser while a sampling probe in the riser exit was opened simultaneously. The sampling probe filled with the combination of the base material and tracer until full. The samples were progressively emptied into dishes. The concentration of the salt tracer was measured by dissolving the sample in water and measuring the electrical conductivity. The conductivity of the solution was transformed into a salt concentration using a premeasured calibration curve. Sand does not affect the conductivity of the sample. This resulted in the concentration of the tracer material at the time of sampling. The sawdust tracer samples were heated to burn off the combustible sawdust and the loss of weight was measured. Accuracy was calculated to be within $10 \%$ for tracers used.

There are obvious problems associated with this method. The bed material must either be cleaned or replaced as the concentration of the tracer material contained within the bed material increases to the point of distorting accuracy. This method does not provide real time measurement, and the time step resolution for measurement was relatively slow. The maximum resolution generated by these methods is 0.5 second intervals. 


\subsubsection{Thermal Tracers}

Thermal techniques have also been applied to the measurement of RTD. Westphalen et al. [2] used a thermal technique where some of the bed material was heated and injected into the fluidized system to measure lateral dispersion. The tracers at elevated temperatures were then detected by thermistors measuring localized temperatures. The temperature reading from the thermistors rose when exposed to the plume of heated tracer particles.

This method was advantageous because data was measured real time, the system was easy to implement, and the tracer does not pollute the bed material. This allowed for tests to be conducted with minimal downtime between test runs which eliminated the need to clean or replace the bed material.

The main disadvantage of this study was the response time of the sensors used, 0.4 seconds. The slow detection of tracers can have strong effects on the measured outcome. Also, this type of study does not directly measure the solids. It is also difficult to verify what the sensors are measuring. It is assumed that the upward gas velocities are higher than that of the particles. Heat transfer occurs from the particles to the gas coming into contact. This elevated temperature gas plume may reach upper sensors before the tracer particles. Assumptions were made that neglected axial diffusion and heat transfer to other solids within the riser.

\subsubsection{Solid $\mathrm{CO}_{2}$ Tracer}

Bellgardt et al. [14] used cylindrical-shaped solid carbon dioxide pellets as a tracer in a bed of quartz sand to measure RTD. The pellets with a uniform diameter of $10 \mathrm{~mm}$ and a mean length of $10 \mathrm{~mm}$ were introduced into the system using a screw feeder injection system. The tracer 
particles were detected using two differing techniques. $\mathrm{CO}_{2}$ concentration was measured at localized areas as the $\mathrm{CO}_{2}$ pellets sublimated into gaseous form. The second method measured the localized temperature to detect the lower temperatures in the presence of the $\mathrm{CO}_{2}$ tracer. This study was not ideal due to it not having a pulse injection resembling a step input. As with the thermal tracer technique, the flow of solids and gases are not directly coupled. This can cause inaccuracies in measurement.

\subsubsection{Phosphorescent Tracers}

The technique of phosphorescent tracers have been used by Brewster et al.[5], Roques et al. [8], Kojima et al.[6], and Harris et al.[7]. This method uses visible light radiation to excite tracer particles coated with phosphorescent pigments or tracers made entirely of a phosphorescent pigment. After activation, these excited tracers emit light for a measurable time during which

light can be detected using optical sensors. The intensity of the visible radiation decays with time and eventually the particles cease to emit light. This effectively eliminates the problem of the tracers polluting the bed material if the particles are the same as the bed material. The high sensitivity and fast response make some optical light detection ideal for RTD measurements.

Brewster et al. [5] used this technique to measure particle residence times in particle transport system used for the pneumatic transport of coal. Phosphorescent pigments were glued to tracer particles, illuminated, and injected into the system. Optical sensors downstream detected the passing tracer particles which were traveling at velocities between $14-41 \mathrm{~m} / \mathrm{s}$. This method was found to be more cost effective compared to a radioactive tracer. There was some 
uncertainty about this measurement due to the effect of a relatively high tracer injection pressure in comparison to the pressure in the transport system.

Roques et al. [8] used phosphorescent particles to measure the RTD in a down flow transport reactor. This system used the phosphorescent pigments as the bed material as well as the tracer. Activation of the tracer was accomplished by a $4 \mathrm{~ms}$ duration high-intensity flash. Tracer particles were measured using five sensors located along the length of the system. The decay of the intensity of the light emitted from the excited pigment was measured and fit to a hyperbolic decay function to correct the measured RTD curves. Mean residence time ranged from $140 \mathrm{~ms}$ to 1.5 seconds.

Kojina et al. [6] used the phosphorescent tracer technique to research axial dispersion in a circulating fluidized bed unit. The system featured a pulsed injection of tracer directly into the riser. Ultraviolet light was transmitted into the bed using optical fibers. The reflected light was detected by photomultiplier tube sensors coupled to fiber optic probes which were placed at various heights. The detection probes were placed $0.10 \mathrm{~m}$ apart which allowed the axial dispersion coefficient to be calculated from the difference in the RTD curves. The pulsed air injection of tracer particles in this study could have imparted disturbances into the riser and distorted the measurements.

Harris et al. [7] used a modified version of previous studies to come up with an RTD measurement system with the following advantages:

i. The immediate activation of tracer by a light pulse with no disturbance to the bed hydrodynamics

ii. Nonintrusive real-time detection of the tracer by a light detector 
iii. The tracer is identical to the rest of the bed material

iv. There is no tracer accumulation in the bed

v. Low cost compared to radioactive tracer studies.

The study was completed in a circulating fluidized bed, CFB, with a height of $5.8 \mathrm{~m}$ and a square cross section of $0.14 \times 0.14 \mathrm{~m}$. This riser was operated at a superficial velocity of $1.8 \mathrm{~m} / \mathrm{s}$ and a mass flux of $8.6 \mathrm{~kg} /\left(\mathrm{m}^{2} \mathrm{~s}\right)$. A commercially available phosphorescent pigment was used as the both the bed material and tracer. The mean diameter of this particle was measured at 25 microns. Particles were activated just above the solids feed by fiber optic lines connected to dual-head photographer grade flash units. The amount of bed material exposed to the excitation light was calculated from the estimate of solids concentration. Solids concentration was calculated from a function relating the pressure drop across a known distance by using pressure transducers located in the illumination section. A single photo multiplier tube detector was placed in an inline jet mixer unit downstream of the riser exit bend. This provided a well mixed sample for detection and a closed boundary condition. The inline jet mixer had the disadvantage of causing a dune of solids to form at its entrance.

The advantages of using a phosphorescent tracer technique are many. Depending on how the tracer is introduced into the system, downtime between test runs can be minimal. Flash bulbs located at wall of the riser irradiated particles in the system without imparting hydrodynamic disturbances within the riser. The problems associated with this method are as follows: the amount of tracer activated cannot be directly controlled, and the center of a dense fluidized bed will receive less illumining light resulting in non-uniform tracer activation. Other schemes have been used where particles where illuminated in a separate fluidized bed to ensure equal 
illumination. The pulsed injection of these activated particles directly into the riser could disturb the bed hydrodynamics and do not exactly replicate the solids flow within the system.

Table 2-1 highlights the riser geometry, bed material, tracer material, and operating conditions of the studies previously discussed. 
Table 2-1: Previous RTD Studies

\begin{tabular}{|c|c|c|c|c|c|c|c|}
\hline Author & $\begin{array}{l}\text { Syste } \\
\text { m } \\
\text { Type }\end{array}$ & Geometry & $\begin{array}{l}\text { Bed } \\
\text { Material }\end{array}$ & Tracer & $\begin{array}{l}\text { Location } \\
\text { of } \\
\text { Injection }\end{array}$ & Detection & $\begin{array}{l}\text { Operating } \\
\text { Conditions }\end{array}$ \\
\hline Yan et al. & CFB & $\begin{array}{l}H=10 \mathrm{~m} \\
D=0.186 \mathrm{~m}\end{array}$ & $\begin{array}{l}78 \mu \mathrm{m} \text { sand } \\
1225 \mathrm{~kg} / \mathrm{m}\end{array}$ & Phosphorescent & $\begin{array}{l}0.5 \mathrm{~m} \\
\text { above } \\
\text { entrance }\end{array}$ & $\begin{array}{l}1.0 \mathrm{~m}, 4.0 \mathrm{~m}, \\
9.4 \mathrm{~m} \\
\text { Above } \\
\text { injection }\end{array}$ & $\begin{array}{l}\mathrm{U}=3.156 \text { to } \\
5.989 \mathrm{~m} / \mathrm{s} \\
\mathrm{Gs}=40.8-229.4 \\
\mathrm{~kg} / \mathrm{m}^{2} \mathrm{~s}\end{array}$ \\
\hline Harris et al. & CFB & $\begin{array}{l}H=5.8 m \\
D=0.14 x .14 m\end{array}$ & $\begin{array}{l}25 \mu \mathrm{m} \\
\text { Pigment } \\
3060 \mathrm{~kg} / \mathrm{m} 3\end{array}$ & $\begin{array}{l}\text { Phosphorescent } \\
\text { pigment }\end{array}$ & $\begin{array}{l}\text { Flash at } \\
\text { base of } \\
\text { riser }\end{array}$ & $\begin{array}{l}\text { PMT in riser } \\
\text { exit }\end{array}$ & $\begin{array}{l}\mathrm{U}=1.8 \mathrm{~m} / \mathrm{s} \\
\mathrm{Gs}=8.6 \mathrm{~kg} / \mathrm{m}^{2} \mathrm{~s}\end{array}$ \\
\hline Patience et al. & CFB & $\begin{array}{l}H=5 \mathrm{~m} \\
D=0.083 \mathrm{~m}\end{array}$ & $\begin{array}{l}\text { Sand } \\
277 \mu \mathrm{m}\end{array}$ & $\begin{array}{l}\text { Radioactive } \\
\text { Argon Gas }\end{array}$ & $\begin{array}{l}0.1 \mathrm{~m} \mathrm{\&} \\
1.8 \mathrm{~m} \\
\text { Above } \\
\text { distributor }\end{array}$ & $\begin{array}{l}\text { Scintillators } \\
1 \mathrm{~m} \& 4 \mathrm{~m} \\
\text { above } \\
\text { distributor }\end{array}$ & $\begin{array}{l}\mathrm{U}=3-9 \mathrm{~m} / \mathrm{s} \\
\mathrm{GS}=23-87 \\
\mathrm{~kg} / \mathrm{m}^{2} \mathrm{~s}\end{array}$ \\
\hline Velden et al. & CFB & $\begin{array}{l}H=6.5 \mathrm{~m} \\
D=0.1 \mathrm{~m}\end{array}$ & Sand & $\begin{array}{l}\text { Salt, } \\
\text { Sawdust, } \\
\text { PEPT }\end{array}$ & $\begin{array}{l}0.3 \mathrm{~m} \\
\text { above } \\
\text { distributor }\end{array}$ & $\begin{array}{l}\text { Sample } \\
\text { probe in } \\
\text { exit, }\end{array}$ & $\begin{array}{l}\mathrm{U}=1-10 \mathrm{~m} / \mathrm{s} \\
\mathrm{Gs}=22-632 \\
\mathrm{~kg} / \mathrm{m}^{2} \mathrm{~s}\end{array}$ \\
\hline Winaya et al. & & & & $\begin{array}{l}\text { Carbon loaded } \\
\text { tracer }\end{array}$ & & $\mathrm{CO}_{2}$ sensor & \\
\hline $\begin{array}{l}\text { Westphalen } \\
\text { et al. }\end{array}$ & CFB & $\begin{array}{l}H=7 m \\
D=0.2 m\end{array}$ & $\begin{array}{l}\text { Quartz } \\
\text { Sand } \\
180 \mu \mathrm{m} \\
2350 \mathrm{~kg} / \mathrm{m}^{3}\end{array}$ & Thermal & & $\begin{array}{l}\text { Thermistor } \\
\text { probes, } 10- \\
90 \mathrm{~cm} \text { above } \\
\text { injection }\end{array}$ & $\begin{array}{l}\mathrm{U}=3-5 \mathrm{~m} / \mathrm{s} \\
\mathrm{Gs}=0-30 \mathrm{~kg} / \mathrm{m}^{2} \mathrm{~s}\end{array}$ \\
\hline
\end{tabular}




\subsection{Experimental Approach}

The method to determination of local and total RTD was to measure the radiation from irradiated particles moving past a detector. A collection of particles were irradiated by an energy source to their full potential and then injected into the solids feed for the riser system as a step input. The particles then radiate the energy slowly as shown in Figure 2-2. The phosphorescent particles will be initially irradiated by light energy and then these particles then slowly radiate this energy in the form of light of a different wavelength. This slow decay of particle intensity allows for the use of the phosphorescent material as both the bed and tracer material. Pollution of the bed material is not tracer particles eventually return to a ground state.

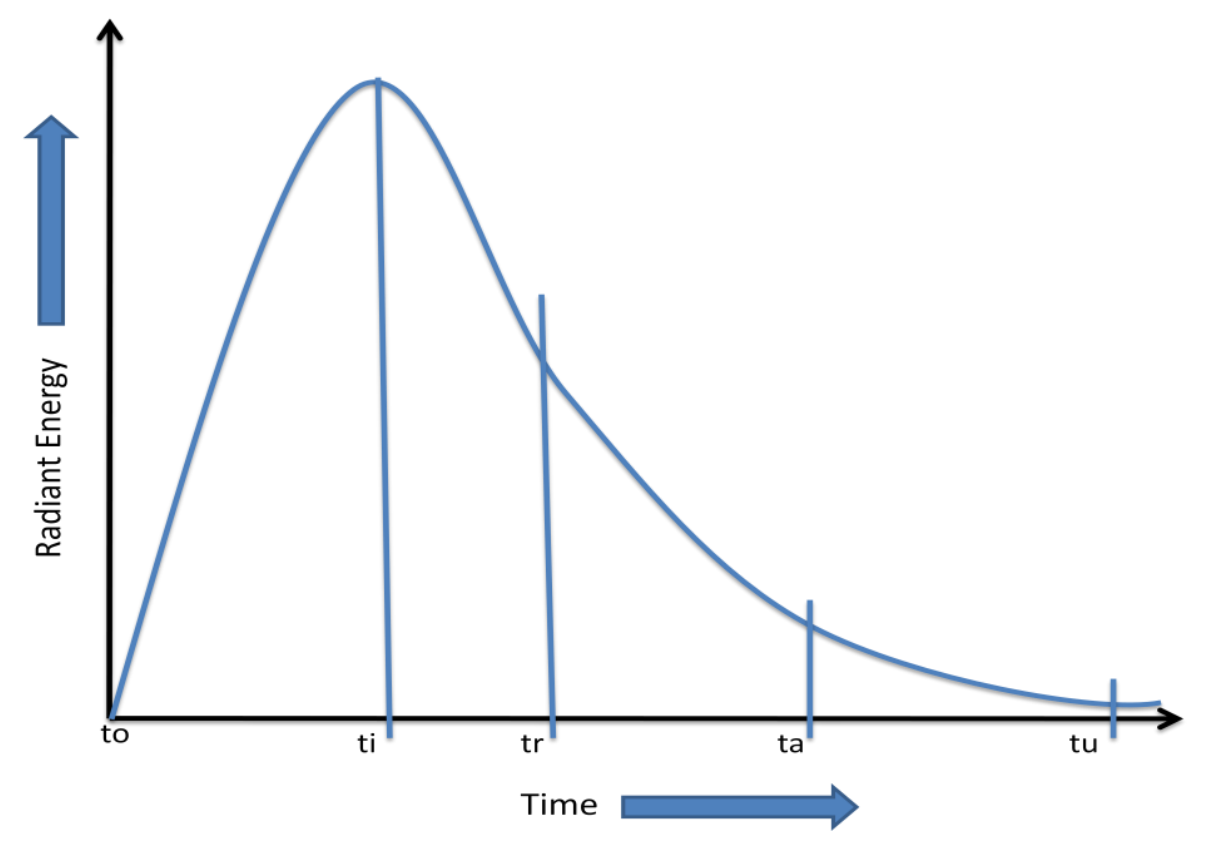

Figure 2-2 Expected Irradiation and Decay of Phosphorescent Particles

The time from $t_{0}$ to $t_{i}$ represents the irradiation process of particles exposed to a radiation source. When peak illumination is experienced at $t_{i}$ the tracer particles are rapidly injected into 
the system. The time $t_{u}$ represents the time at which particles have returned to a ground state too low for detection. The time interval between $t_{i}$ and $t_{u}$ is referred to as the useful life.

It was believed the signal from the detector would have the general shape as shown in Figure 2-2. This signal will be from the particles irradiated at time $\mathrm{t}_{0}$. The signal $\mathrm{C}(\mathrm{t})$ at a fixed location will be proportional to the local mass flux of the radiating particles $\dot{m}_{p}^{(t)}$ and the luminescence $C_{0}(t)$. Consequently,

$$
C(t) \sim \dot{m}_{p}^{(t)} C_{0}(t)
$$

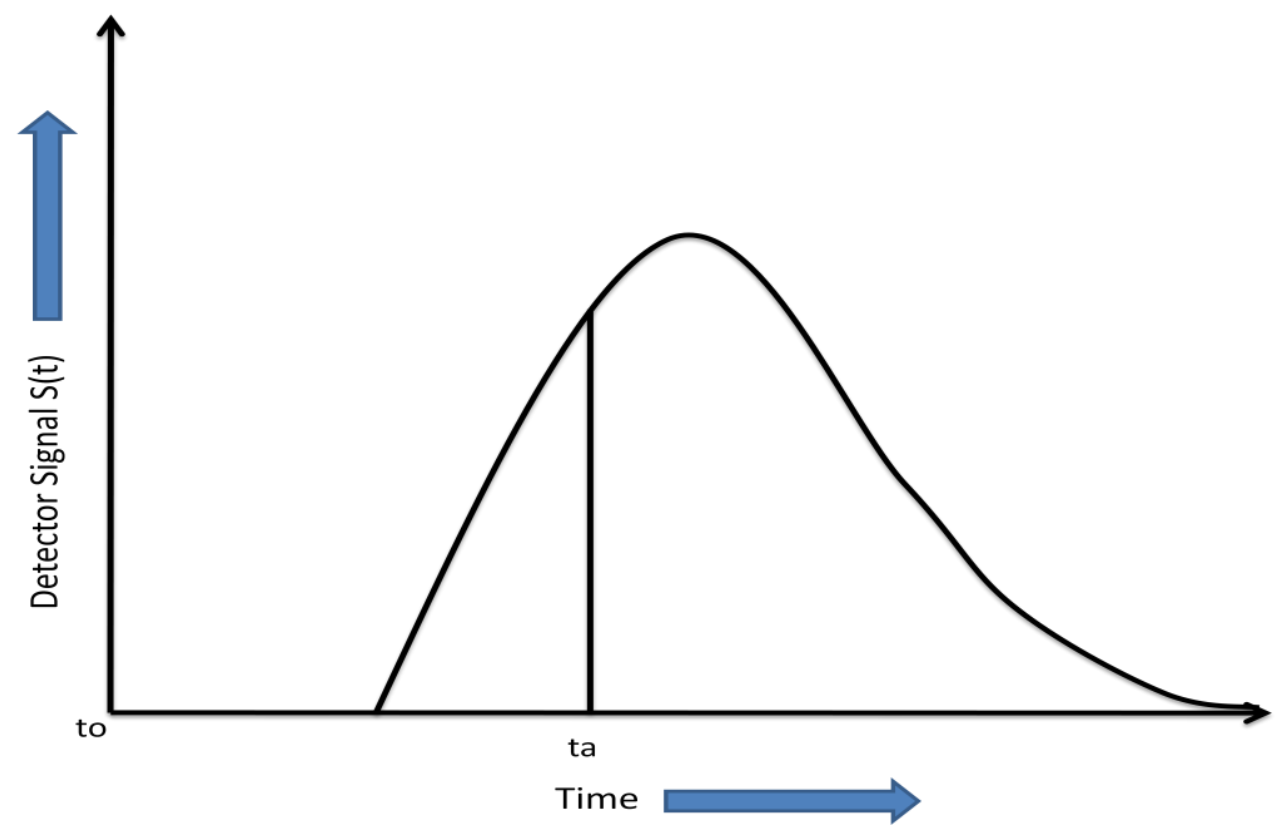

Figure 2-3: Expected Sensor Output

Figure 2-3 shows the expected detector response to radiating particles passing within sight of the detector; note that time $t_{a}$ corresponds to an arbitrary time in Figure 2-2 and Figure 2-3. The signal from the sensor is divided by the sensor measurement of the decay curve to result in a dimensionless concentration curve representing the ratio sensor signal to the maximum signal that can be measured at that specific time. 
$\dot{m}_{p}^{(t)} \sim \frac{C(t)}{C_{0}(t)}$

Other statistical analysis of the resulting RTD curve can include the mean $\left(t_{m}\right)$, variance $\left(\sigma^{2}\right)$, and skewness $\left(s^{3}\right)$ :

$t_{m}=\frac{\int_{0}^{\infty} t C(t) d t}{\int_{0}^{\infty} C(t) d t}$

$\sigma^{2}=\int_{0}^{\infty}\left(t-t_{m}\right)^{2} C(t) d t$

$s^{3}=\int_{0}^{\infty}\left(t-t_{m}\right)^{3} C(t) d t$

Testing was conducted in three phases. Phase 1 of testing focused on the phosphorescent properties of the PPE particles to get an estimate of the most efficient illumination wavelength, particle life, and the decay curve. This phase was necessary to determine if the existing tracer material could theoretically be used dependent on the useful particle life. Phase 2 of the testing involved the design a particle illumination system, detection system, and particle injection system. Phase 3 was the integration of the systems into a fluidized bed riser and verifying the functionality of the system.

The following are attributes considered in the design of the RTD measurement system:

i. Uniformly irradiate tracer particles

ii. Induce minimum disturbance to the riser system during tracer injection

iii. Introduce the tracer material into the system as a step function

iv. Introduce tracer before riser entrance to maintain entrance flow effects

v. Provide accurate detection of tracer material

vi. Possess the ability for detector to move radially across the riser

vii. Impart minimal flow disturbances within the riser by the detector 


\section{Chapter 3 Experimental System}

\subsection{Fluidized Bed Riser System}

The fluidized bed riser system used for experimentation is a modified version of the small-scale Warm Air Dryer for Fine Particles (WADFP). It is a 2:1 scale model of the unit primarily used for coal drying. It features a dual stage riser where an intermediary air injection ring serves as a transition for a larger diameter upper riser section. This allows for the addition of supplementary air to increase drying without increasing superficial air velocity, or for the possible operation the upper and lower stages at different fluidization regimes. Rowan [18] conducted testing on the small scale transparent system to verify fluidization regimes. His work concluded that the fluidization regime in the upper part of the riser forced the lower stage to match flow regimes [18]. The tracer injection system was initially designed to be integrated in different scale test system used for separation by density. Figure 3-1 is a simple representation of the system with integrated RTD measurement system. 


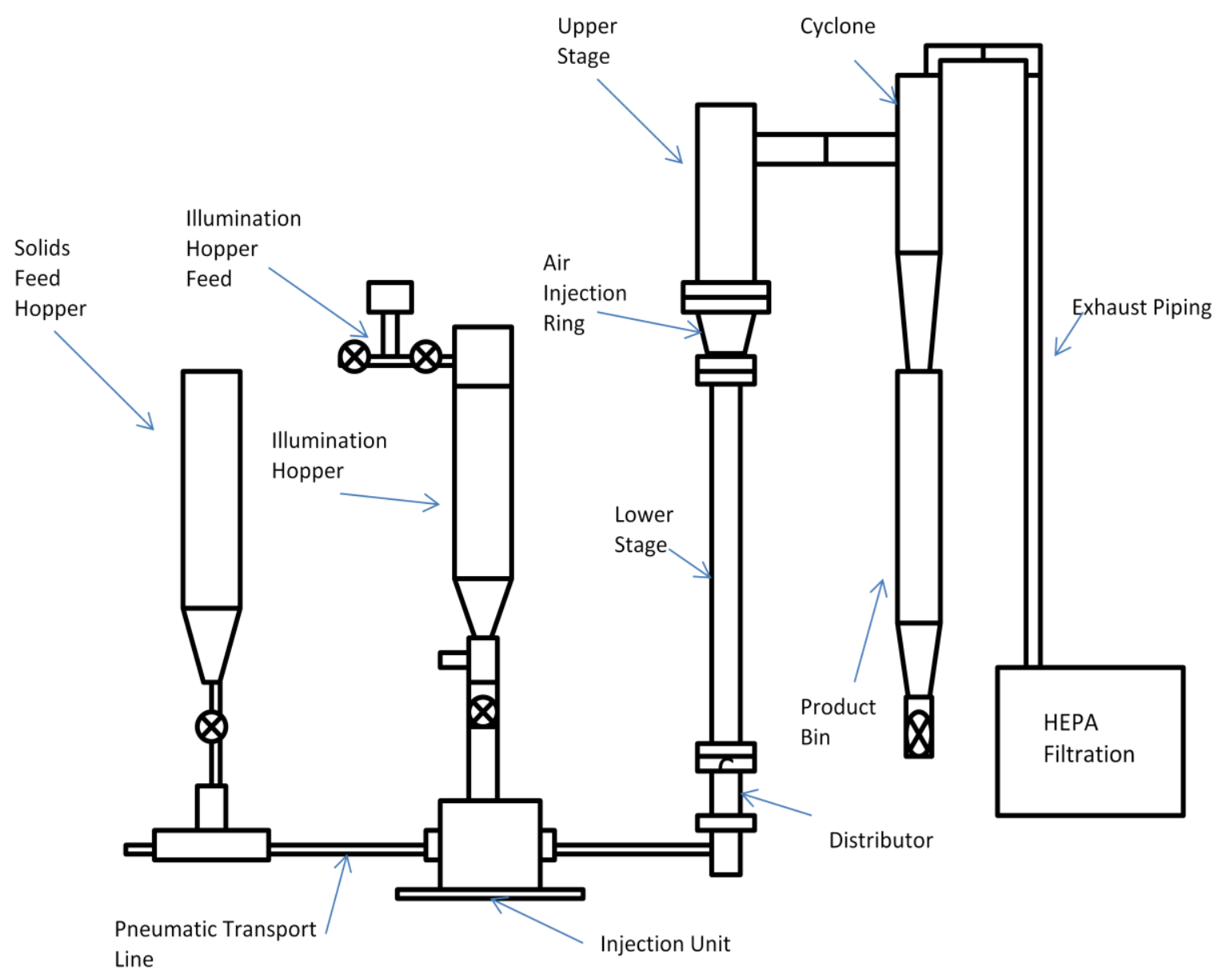

Figure 3-1: General System Layout

The particle injection unit is placed in-line with the pneumatic transport system, between the solids feed hopper and the riser system. The particles are normally transported pneumatically through the crossover section without obstruction. The particle injection unit was designed to allow normal function of the crossover but also quickly inject tracer particles with minimal disturbance to both the air and solids flow. The tracer illumination system is located directly above the particle injection unit so the particles, after illumination in the fluidized hopper, can fall into the injection system by means of gravity. During assembly of the system, thread tape 
was used on all threaded gas connections, and paper gaskets were used between all mounting flanges unless otherwise noted.

\subsubsection{Feed Hopper}

The solids feed stock is contained in a clear acrylic hopper with an outer diameter of 5.5" and a length of $36 "$. The top of the hopper is sealed with a clear acrylic plate bolted to a flange rigidly bonded to the hopper. The top plate also has a provision for a $3 / 4$ " NPT plug for introducing solids into the system. Opposing ends of a chain are bolted through the top flange to suspend the hopper from a load cell. The hopper also contains a 0-15 PSIG gauge and a 3/8" NPT hole located near the top flange to mount an air fitting for the pressurization of the feed hopper. The lower portion of the feed hopper is connected to the solids feed crossover line by means of intermediary rubber adapters fastened by hose clamps and PVC adaptors resulting in a final connector size of $1 / 2$ " NPT female. Connected to this NPT female section is a horizontal Tee fitting which accepts the solids flow from the vertical side and air injection from one of the horizontal portions.

\subsubsection{Pneumatic Transport System}

The horizontal pneumatic transport system conveys the solids feed from the hopper to the riser system. It consists of a PVC Tee fitting with $3 / 4 "$ NPT female fittings in a horizontal arrangement. The vertical component of the Tee fitting is attached to feed hopper with an intermediary $3 / 4 "$ PVC ball valve for the control of solids flow. One horizontal component is supplied with the air through a $3 / 8^{\prime \prime}$ rubber air hose attached through a $3 / 8^{\prime \prime}$ hose barb to $3 / 4$ " NPT male fitting. The other horizontal component of the Tee is aligned with and connected to the port located on the side of the bottom distributor and connected with a clear $3 / 4$ ID rubber hose attached to $3 / 4 "$ 
hose barb to $3 / 4$ " NPT male fittings at both ends. This system was operated at elevated gas velocities to mitigate the buildup of solids and the resulting dune flow to ensure tracer particles would be quickly and uniformly introduced into the riser.

\subsubsection{Bottom distributor}

The bottom distributor is manufactured from carbon steel. The lower section of the distributor is a thick-walled Schedule 80 steel Tee fitting arranged vertically. During operation, air and solids enter the horizontal portion of the Tee, make a sharp $90^{\circ}$ upward turn, and are directed into the lower stage of the riser through a conical section. The lower portion Tee fitting is threaded and plugged which allows for the evacuation of solids from the system when necessary. The conical section has a $3 / 4$ " opening at the bottom and expands to $2.29^{\prime \prime}$ at the top. A cylindrical section surrounds the conical section forming an air jacket supplied by a $3 / 4$ " NPT female gas port. There are three rows of 0.07 " diameter holes drilled in the conical section. The bottom, middle, and top rows containing 8,16 , and 32 holes respectively. The air supplied from the gas port flows around the conical section in the air jacket and through the holes into the riser system. This acts as the distributor plate for the riser system. The holes in the conical section are arranged so that they are placed directly across each other to negate the horizontal force from the pairs to ensure the vertical jet formed by the lower solids/gas injection is maintained. A $1 / 4 "$ thick steel flange matching the lower riser stage flange dimensions is welded to the top portion of the distributor. A $1 / 4$ " NPT port was added to the cylindrical outside wall section for the measuring of air pressure in the air jacket of the distributor so that the pressure drop across the distributor plate could be calculated. 


\subsubsection{Bottom Riser Stage}

The smaller bottom stage of the original system was constructed of three sections of clear acrylic tube with flanges at each end so that they could be easily mounted, and sections could either be interchanged or omitted depending on the desired setup. The lower stage was remanufactured with a single section with the appropriate length to simplify assembly and alleviate misalignment.

The new bottom riser section was fabricated from a single 2-1/4" ID clear cast acrylic tube with $1 / 4$ " wall thickness. The length of the bottom riser stage was changed to 49.5 "from $55.125^{\prime \prime}$ to better satisfy the scaling constrains of the large system as recommended by Rowan [18]. Flanges were bonded to each of the tubular section. These flanges were milled from $1 / 2$ " thick cast acrylic sheet with outer diameters of 5-1/4" and six 3/8" holes bored at equal separation 2 $1 / 8^{\prime \prime}$ from the center. These flanges were bolted to the lower air distributor and the lower part of the secondary air injection ring with paper gaskets used to promote a good seal.

\subsubsection{Secondary Air Injection Ring}

The carbon steel injection ring provides additional air to the upper part of the system and creates the transition from the 2.29 " ID of the lower stage to the 4" ID of the upper stage with a height of 4-1/4". The inner and outer portions are made of conical sections with clearance of $1 / 4$ " between to provide a pathway for the gas injection entering through a $3 / 4$ " NPT female port on the outer conical portion. The inner conical section is perforated with two rows near the top each containing 30 holes $3 / 16^{\prime \prime}$ in diameter. Steel flanges at opposite ends connect the injection ring to the upper and lower stages of the riser. The injection ring is supported by an " $\mathrm{L}$ " bracket connected to the Unistrut support structure. 


\subsubsection{Top Riser Stage}

The top section of the riser originally consisted of two separate sections bolted together, each $18 \% 4^{\prime \prime}$ length with an inner diameter of $4 "$. One of the top sections was removed due to vertical constraints caused by the integration of the particle injection system. The remaining upper section with the exit port was remanufactured with dimensions matching the original section. The new top section of the riser consists of a single 4" ID clear cast acrylic tube with a 2-1/4" exit placed approximately $3.5^{\prime \prime}$ from the top. The riser section is attached to the top distributor by a $0.5^{\prime \prime}$ thick acrylic flange 7 " in diameter with an 8 -hole bolt pattern on a 3 " radius.

The exit crossover was redesigned as two separate sections connected by a rubber collar allow for some misalignment between the riser section and the cyclone. The first section of the riser exit is rigidly bonded to the top riser section and measures $3-1 / 2$ " in length. The other section, $4-1 / 2^{\prime \prime}$ in length, is bonded to a clear acrylic flange matching the dimensions of both the lower riser stage flanges and the cyclone separator flange.

\subsubsection{Cyclone}

Air and solids exiting the riser through the crossover encounter a cyclone separator for the division of the product stream. The mixture enters the cyclone from a 2-1/2" diameter tube section placed tangential to the inner wall of the cyclone to induce a spinning action. The solids, which have higher density, are forced along the wall. These solids eventually fall downward into the product hopper. The gas exits through a smooth radius port at the top of the cyclone. The upper section of the cyclone has a $5^{\prime \prime} I D$ at the top and tapers down to $1.5^{\prime \prime} I D$ at the bottom with a total length of $24^{\prime \prime}$. 


\subsubsection{Product Hopper}

The solids captured by the cyclone separator are gathered in the product hopper. The hopper is made of 4" PCV pipe with a length of 50". The hopper was designed with a 10 gallon volume to exceed the capacity of the solids feed hopper. It is attached to the cyclone by a 4"to 2-1/2" PVC reducer and a reducing rubber collar and hose clamps. A $2-1 / 2$ "PVC ball valve is affixed to the lower end with the use of a PVC reducer. The ball valve remains closed during normal operation and is opened to evacuate the particles when required.

\subsubsection{Air Filtration}

The air exiting the cyclone is transported through 2" PVC pipe to a filtration unit to remove any leftover solids. A HEPA filter of size $35^{\prime \prime}$ by 22 " captures fine particles not removed by the cyclone. The HEPA filter is rated to remove $99.97 \%$ of all particles that are 0.3 microns in size or larger.

\subsubsection{Compressed Air Feed System}

All compressed air requirements were handled by a compressor in the NRCCE Highbay that was capable of approximately 450 SCFM of airflow. Air output from the compressor was regulated to 120 psi. The air is tapped from ridged house plumbing and passes through a main shutoff valve and an air filter before reaching the test system regulator and shutoff valve attached to the Unistrut frame housing the experimental setup. The air flow diagram is depicted in Figure 3-2. The first manifold contains three 0-100 SCFM Omega piston style flow meters with ball valves for flow control. The first flow meter supplies air to the tracer illumination hopper. The second flow meter supplies air to a secondary air manifold which distributes air into three separate flows. The first flow path from the manifold supplies air to a manifold where the air 
flow is further split into a 0-60 SCFM rotometer, a 0-8 SCFM rotometer, and a second 0-60SCFM rotometer which supplies the lower air distributor, the pneumatic transport line, and the upper air injection, respectively. The second flow path supplies air to a 0-15 PSIG regulator which is used for the feed hopper pressurization air and the 0-200SCFH regulator for the aeration air port at the lower end of the feed hopper. The third flow path is regulated by a 0-100 PSIG regulator that is connected to the air solenoid that controls the air actuators for the particle injection system. Figure 3-2 is a representation of the air feed system.

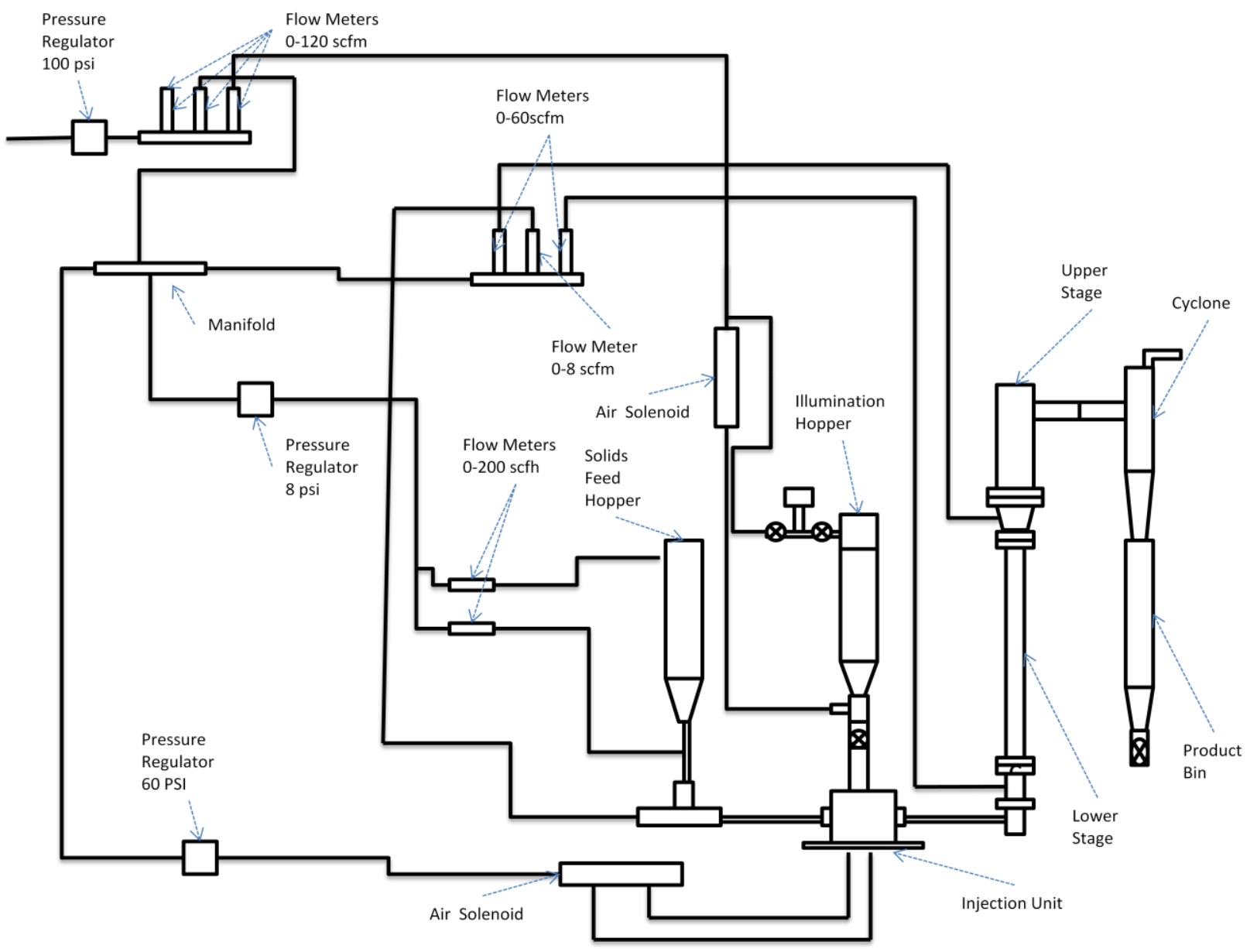

Figure 3-2: Air Flow Diagram 


\subsection{Instrumentation}

\subsubsection{Data Acquisition System}

Data is collected by an Omega OMB-DAQ-3000 USB interfaced data acquisition system with an OMB-PDQ30 expansion module connected to a Dell GX270 computer containing a $2.87 \mathrm{GHz}$ processor and $3070 \mathrm{MB}$ of memory. The data acquisition system can handle a maximum of a million data points per second combined from up to 64 single-ended or 32 differential inputs. It can measure bipolar $10 \mathrm{~V}$ analog, bipolar $31 \mathrm{mV}$ analog, thermocouple, and digital inputs. It also has two analog outputs.

The Omega Engineering Personal Daqview software interfaces the data acquisition system with the user. It allows for the setup of channels and offers a wide range of settings that include sample rate, oversampling, automatic triggering, and $50 / 60 \mathrm{~Hz}$ noise cancellation. It saves the data in a .TXT file format which then can be imported into Microsoft Excel or Matlab for data processing.

All tests were conducted at a sample rate of $1000 \mathrm{~Hz}$ unless otherwise noted. The $50 / 60 \mathrm{~Hz}$ noise cancellation was not utilized to maintain the required sample rate for the number of channels recorded. The oversample function was set to the highest allowable setting dependent on the number of channels being recorded.

\subsubsection{Pressure Transducers}

Pressure measurements throughout the system are made with a series of Omega pressure transducers. The sensors include four OMEGA PX-309-030AV (0-30 PSIA) and one Omega PX309-100AV(0-100 PSIA).The 30 PSIA sensors use a silicon sensor protected by a fluid filled 
stainless steel diagram to provide high accuracy and durability. The 100PSIA sensor uses a silicon strain gauge attached to a stainless steel diaphragm. This sensor is placed in the lower air distributor to measure the plenum pressure. The lower stage of the riser has three of the 030PSIA pressure transducers located 3", 23-1/2", and 46-1/2" above the distributor. The final 030PSIA pressure transducer is located in the upper stage of the riser 13-1/4" above the secondary air injection ring. All sensors are connected to their respective measurement locations with the use of quick disconnects that thread into the $1 / 8^{\prime \prime}$ NPT female ports on the riser sections.

A manifold fitted with 8 quick connect ports and a digital pressure gauge was used in the calibration of the sensors. Sensor output was recorded for five pressure points which resulted calibration curves for each sensor. These calibration curves were then input in the DAQview software.

\subsubsection{Load cell}

The feed hopper is suspended from an Omegadyne LC101-200 load cell connected to a crossbeam of a support frame. It has a maximum capacity of 200 pounds, and a maximum output of $36 \mathrm{mV}$ when connected to the 12 VDC power source. The load cell is calibration is scaled for a zero weight with the empty feed hopper and associated hardware being supported. This results in a measurement of zero pounds when the feed hopper is empty; only the weight of solids contained in the feed hopper is measured. The feed rate into the riser is calculated from the rate change of weight over time. The approximate locations of sensors can be seen in Figure 3-3. 


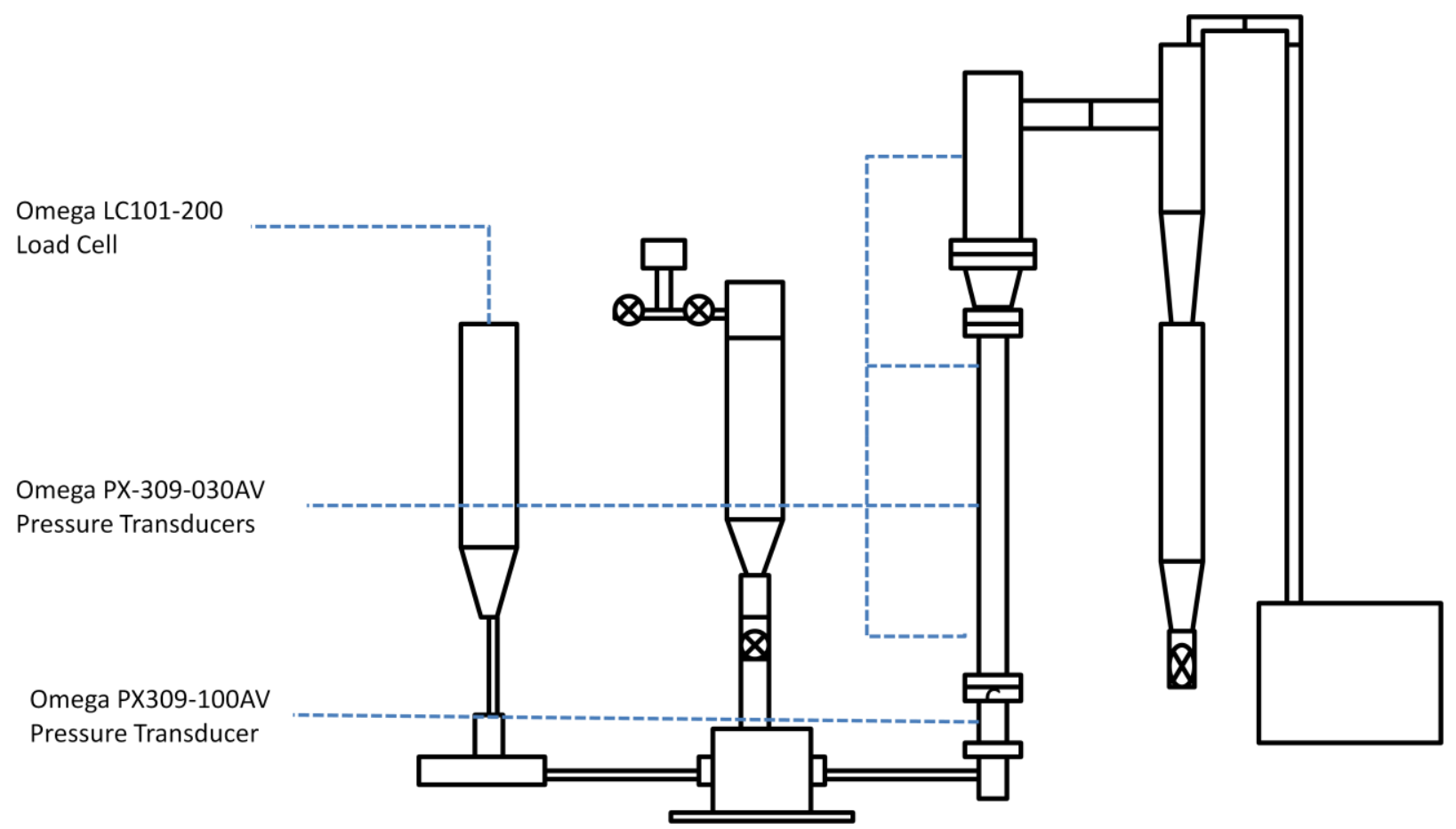

Figure 3-3: Instrument Placement Diagram

\subsection{Operating Procedures}

The following operating procedures were created for the use of the fluidized bed riser system with integrated RTD measurement.

\subsubsection{Start-Up}

1. Close all air valves

2. Turn on 12 Power Source for sensors

3. Open Data acquisition software

4. Open valve for HEPA Filter and check for other obstructions

5. Empty Solids Collection Bin

6. Power on Arduino Uno control unit

7. Open Main Air Valve at pressure regulator

8. Verify pressure is set at 100 PSI

9. Fill solid feed hopper with a maximum of 10 Lbs of solids

10. Set air flow meters to required flow rates

11. Open feed hopper valve

12. Set feed hopper and aeration air pressure and flow for desired feed rate 


\subsubsection{Observation}

1. Close all Valves associated with Tracer Injection System

2. Set Switch on control panel to OFF position

3. Set illumination hopper air flow rate

4. Open air actuator air valve and verify regulator is set to required pressure

5. Fill illumination hopper feed section with required amount of tracer

6. Open both valves on horizontal feed system to inject particles into illumination hopper

7. Close both valves when all particles are transported

8. Set Control Switch to On Position

9. Set $D A Q$ software to start recording with trigger signal

10. After cycle completion return control panel switch to off position

\subsubsection{Shutdown}

1. Increase air flow rates in the system to evacuate particles

2. Power off injection controls and automation

3. Close Hopper pressurization valves

4. Close air flow valves

5. Turn off Air Manifold

\subsubsection{Emergency Shutdown}

1. Depress red STOP button near door

2. Turn off air at the system manifold, the main air valve attached to the large dryer, or at the compressor unit 


\section{Chapter 4 Design of RTD Measurement System}

\subsection{Tracer Irradiation System Design}

The selected solids material for use as both the bed and tracer material was Polyphenylene Ether (PPE) particles coated with a phosphorescent pigment laden dye. PPE is an engineered thermoplastic with resistance to high temperatures. The PPE particles were coated with a phosphorescent dye through a fluidized bed coating process. The pigment used in the PPE coating is Phoshorescent Pigment 2330MBW Green from USR Optonix Inc [19]. The excitation wavelength for the pigment is listed at $365 \mathrm{~nm}$, and the peak emission wavelength is listed at 530nm. The material properties of the PPE particles are listed in Table 4-1.

Table 4-1: PPE Material Properties

\begin{tabular}{|l|r|l|}
\hline \multicolumn{3}{|c|}{ Material Properties } \\
\hline Material & \multicolumn{1}{|c|}{ PPE } & \\
\hline Mean Particle Size & 871 & $\mathrm{um}$ \\
\hline Sphericity & 0.92 & \\
\hline Particle Density & 0.86 & $\mathrm{~g} / \mathrm{cc}$ \\
\hline Bulk Density & 0.52 & $\mathrm{~g} / \mathrm{cc}$ \\
\hline Minimum Fluidization Velocity & 0.174 & $\mathrm{~m} / \mathrm{s}$ \\
\hline
\end{tabular}

The first objective was to design the illumination hopper for of the phosphorescent particles. The goal was that all the particles be uniformly illuminated to their maximum radiation state before the quick injection into the riser. Several studies used a rapid light impulse emitted from commercial-grade camera flashes $[5,7]$. The disadvantage of the method was that the particles subjected to the flash were in an open system where the quantity of tracer particles could not be directly determined. 
It was decided that illuminating the particles in a fluidized bed would ensure the uniform illumination of the tracer particles and result in the maximum particle useful life. The initial design specified a clear fluidized bed with a circular cross section and an illumination light with the required wavelength output. Preliminary testing revealed that illumination of the particles through a curved transparent section decreased effectiveness. The illumination hopper was designed with the illumination light source contained within the fluidized bed hopper for direct impingement of the illumination light on the tracer particles.

The phosphorescent dye coating the PPE beads require irradiation between $365-385 \mathrm{~nm}$ for maximum life and intensity as shown by the illumination wavelength study in section 5.1 . These wavelengths fall into the category of long wave UVA spectrum often referred to as black light. Black lights are commercially available and economical. The most common type of black light is constructed in the same method as normal fluorescent light tubes, except a different phosphor is used for the emission of UVA light, and the glass is covered in a deep-purple colored coating that blocks the light emission in the visible spectrum [20]. The clear glass tube of an incandescent light may be replaced by a dark-purple glass called Wood's glass. This nickel-oxide doped glass blocks almost all visible light above $400 \mathrm{~nm}$. This does not emit a higher intensity of light in the desired frequency range. However, a fluorescent black light produces a higher intensity of UVA light compared to a common filament light bulb produced with Wood's glass. A fluorescent black light produces a peak wavelength of around 368-385 nanometers which coincides with the optimal illumination wavelength required by the phosphorescent particles. For these reasons, the florescent black light source was selected. 
The particle illumination hopper was designed to house a standard 24" fluorescent black light in its center while still maintaining an equivalent length to diameter ratio in the appropriate range by selecting the inner diameter of the illumination hopper of 3 ". Other design considerations included a tracer feed system, air injection, and particle collection. The general layout of the tracer illumination system can be seen in Figure 4-1.

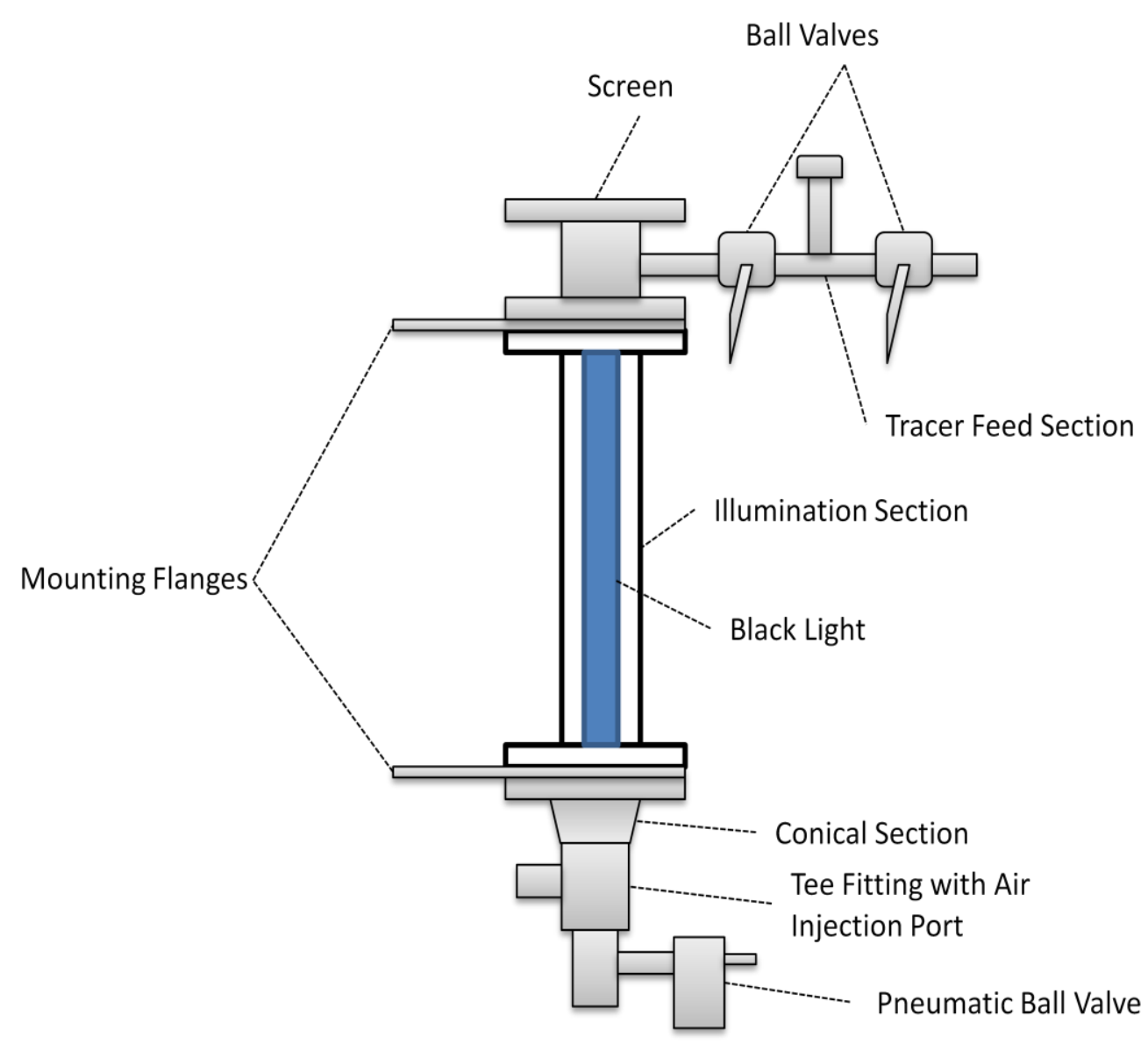

Figure 4-1: General Layout of Tracer Illumination System

The feed system is assembled with brass ball valves connected to on either aligned end of a 1" NPT Tee pipe fitting. One ball valve is connected to the upper section of the illumination hopper 
while the other is connected to the air supply. The Tee is arranged so that the perpendicular leg is aligned vertically. A pipe nipple and cap was fitted in the vertical section of the Tee fitting. To operate both ball valves are set to the closed position. The cap is removed from the vertical pipe nipple and the particles poured into the cavity. The cap is securely tightened, and then both ball valves are simultaneously opened; pneumatically transporting the particles into the illumination hopper. When all particles are evacuated from the feed system, both ball valves are returned to the closed position. This arrangement allows for the introduction of particles while the fluidization air is applied to the air distributor beneath the illumination section.

The illumination hopper, depicted in Figure 4-2, is constructed from clear cast acrylic with and inner diameter of $3 "$, a wall thickness of $1 / 4^{\prime \prime}$, and a length of $24 "$. Flanges machined from $1 / 2 "$ thick polycarbonate with an outer diameter of $6^{\prime \prime}$, an inner diameter of $3.5^{\prime \prime}$, and six $3 / 8^{\prime \prime}$ bolt holes equally spaced on a 2.25 " radius were bonded to each end of the tubular section. A second illumination hopper was manufactured as a backup, and to be used in a small system used in preliminary testing of the tracer particles and detection system. The length and diameter was chosen to house a standard $18^{\prime \prime}$ tubular black light 1 " in diameter within the illumination hopper and retain an acceptable equivalent length to area ratio.

A commercially available fluorescent light housing was modified for mounting the black light in the illumination hopper. The housing was disassembled, and the major components including wiring, ballasts, mounts, and switches were utilized in making the power source for the black light tube. The mounting provisions for the two-pin ends of the black light were placed on specially designed flanges of with the same dimensions of the illumination hopper flanges but 
with the addition of a rectangular tab protruding into the center. The light mount flanges can be seen in Figure 4-3. The light mounts sourced from the light house were bonded to the tabs so that the light would align with the center of the illumination hopper. The wiring harness from the black light housing was extended to reach the light mounts inside of the illumination hopper. The wiring from the external power source was passed through $1 / 4^{\prime \prime}$ thick rubber gaskets and sealed with silicon. Replacement of the light can be completed by removing the mounting flange from either side of the illumination hopper.

The feed section is connected with NPT fittings to an upper feed section through a 1" NPT female side port, which can be seen in Figure 4-4. The carbon steel upper feed section consists of a 3" ID pipe 5" length with flanged ends matching the dimensions of the acrylic section flanges. A steel mesh screen blocking the passage of particles larger than 500 microns is mounted to the top flange.

A traditional distributor plate is designed for the equal injection of air into a fluidized bed riser. This arrangement, however, is not necessary for the fluidized illumination hopper. An arrangement was designed so that when the fluidizing airflow is stopped the particles can be transported downward into the injection system. The falling tracer particles pass through a conical section of reducing diameter and through a vertical Tee coupling of which the horizontal leg serves as the port for air injection. This arrangement allows for unsteady fluidization in the riser to ensure equal illumination of the tracer particles while still allowing all the particles to be quickly transported into the injection mechanism. 
The conical section is made of $1 / 4$ " steel with a diameter of 3 " at the top and reducing to 1 " at the bottom with a $1 / 4$ " thick flange at the top mating the flange of the acrylic illumination section. The exit of the conical section is a 1" NPT threaded male fitting. The conical section can be seen in Figure 4-5. Connected to the bottom of the conical section is a common 1" NPT Tee female fitting in the vertical arrangement. A 3/8" NPT male to 1"NPT female bushing is fitted with a $3 / 8^{\prime \prime}$ hose barb adapter and inserted into the horizontal portion of the Tee. The lower section of Tee is connected to the air-actuated ball valve with a short 1" NPT pipe nipple.

Mounting flanges, which can be seen in Figure 4-6, were constructed from $1 / 4$ " thick carbon steel sheet with a 3 " bore with a matching bolt hole pattern to that of the illumination section on one end and two hole on the other end matching the dimensions of the bolt hole pattern of Unistrut $90^{\circ}$ " $\mathrm{L}$ " brackets. The length of the mounts was designed to align the illumination hopper with the centerline of the particle injection system. 

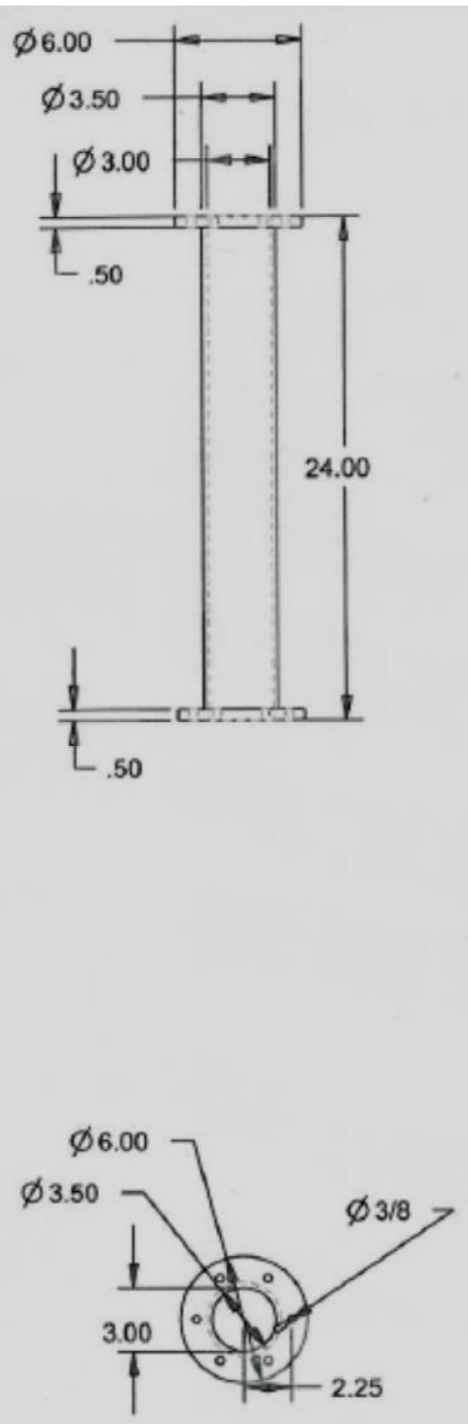

Figure 4-2: Clear Illumination Hopper Section 


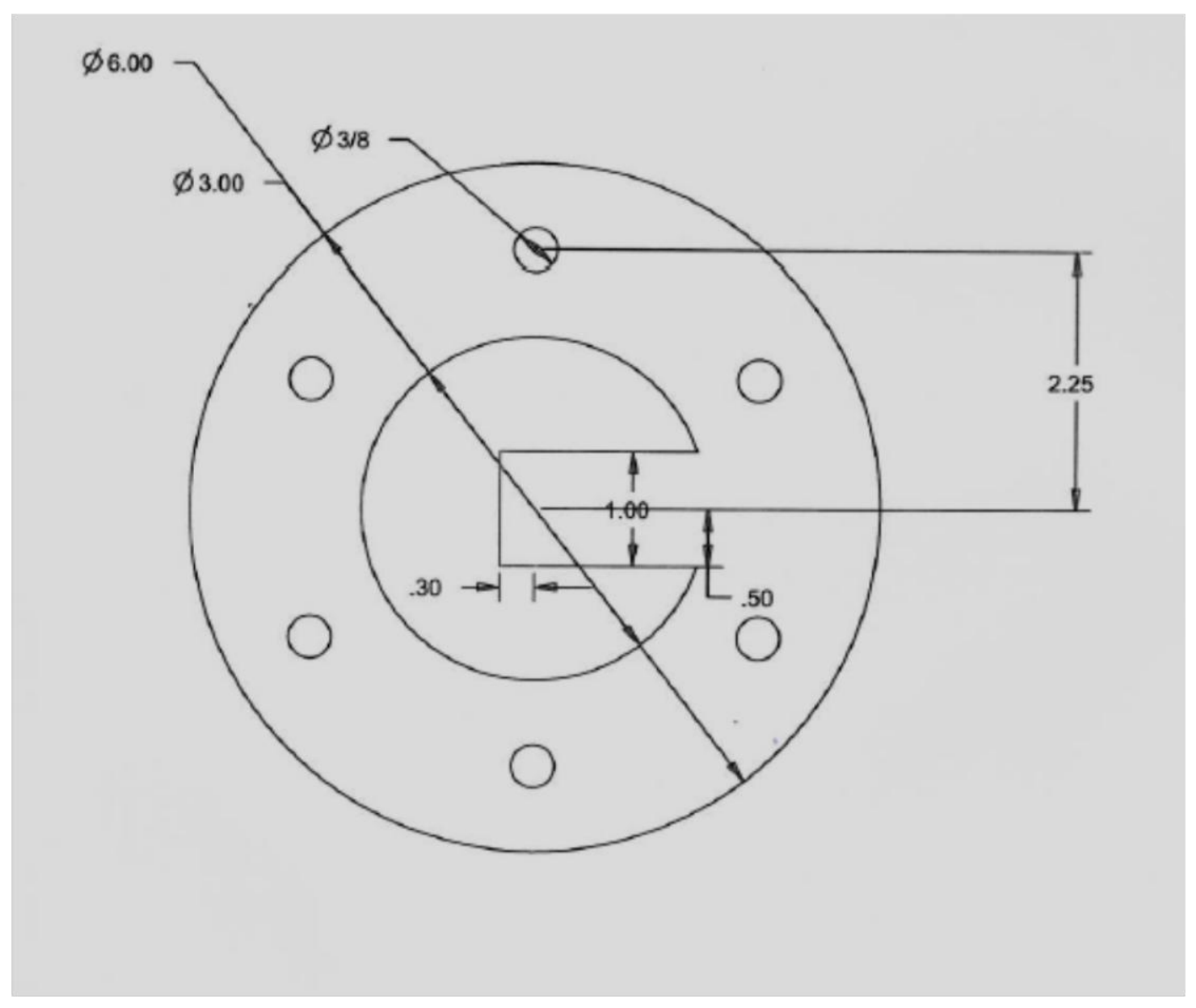

Figure 4-3: Light Mount Flange 


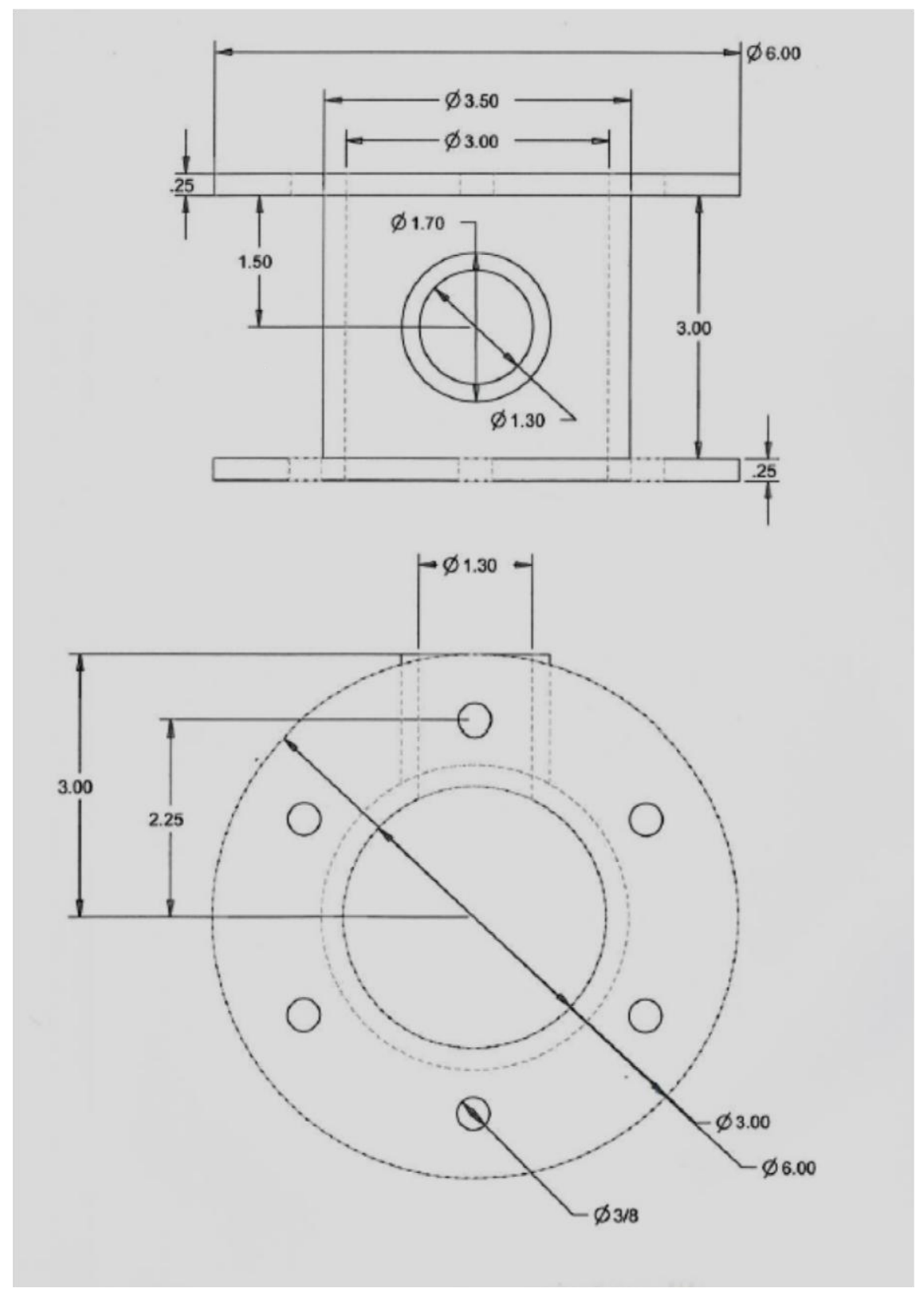

Figure 4-4: Solids Feed Section 


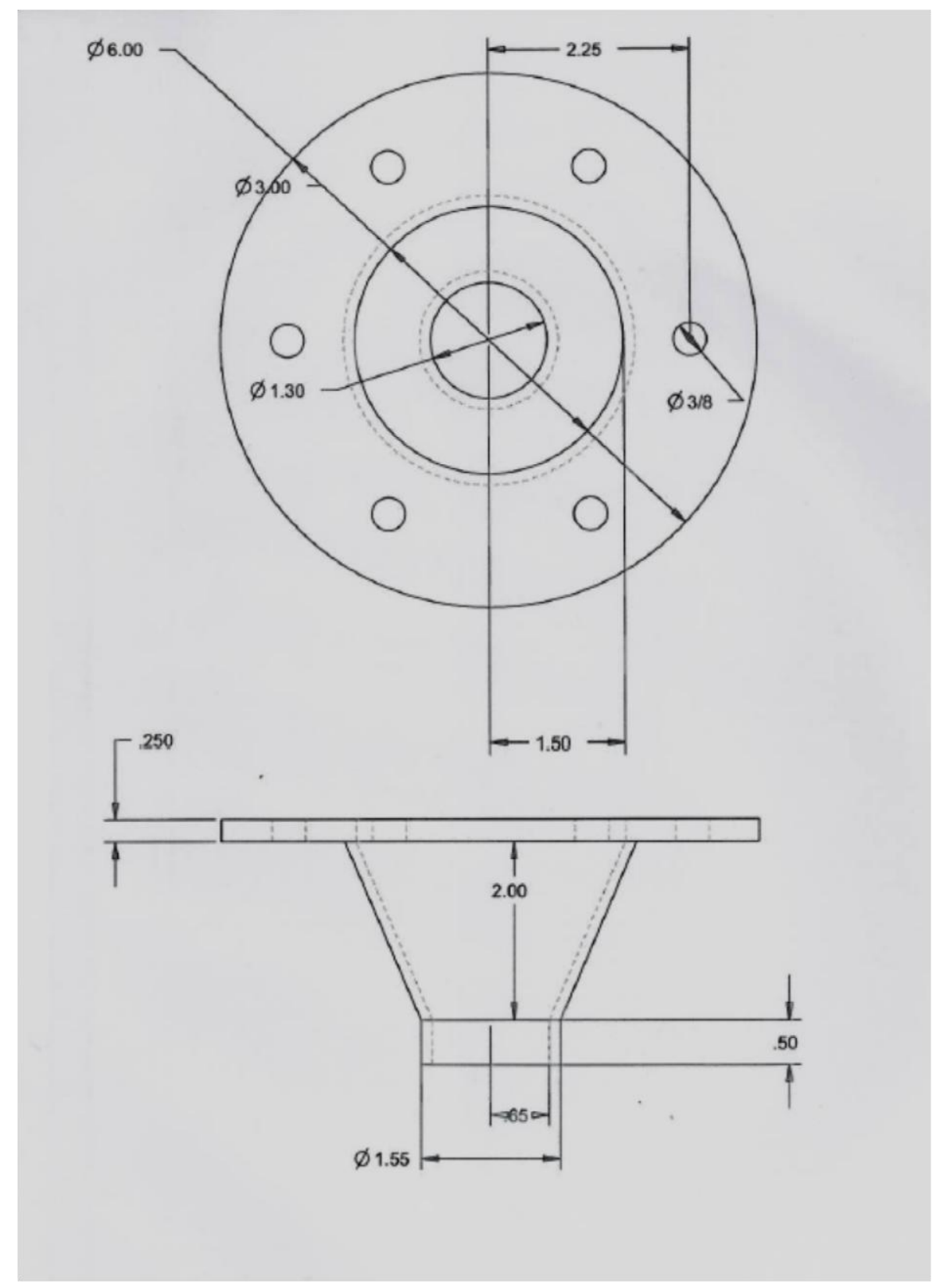

Figure 4-5: Conical Section 


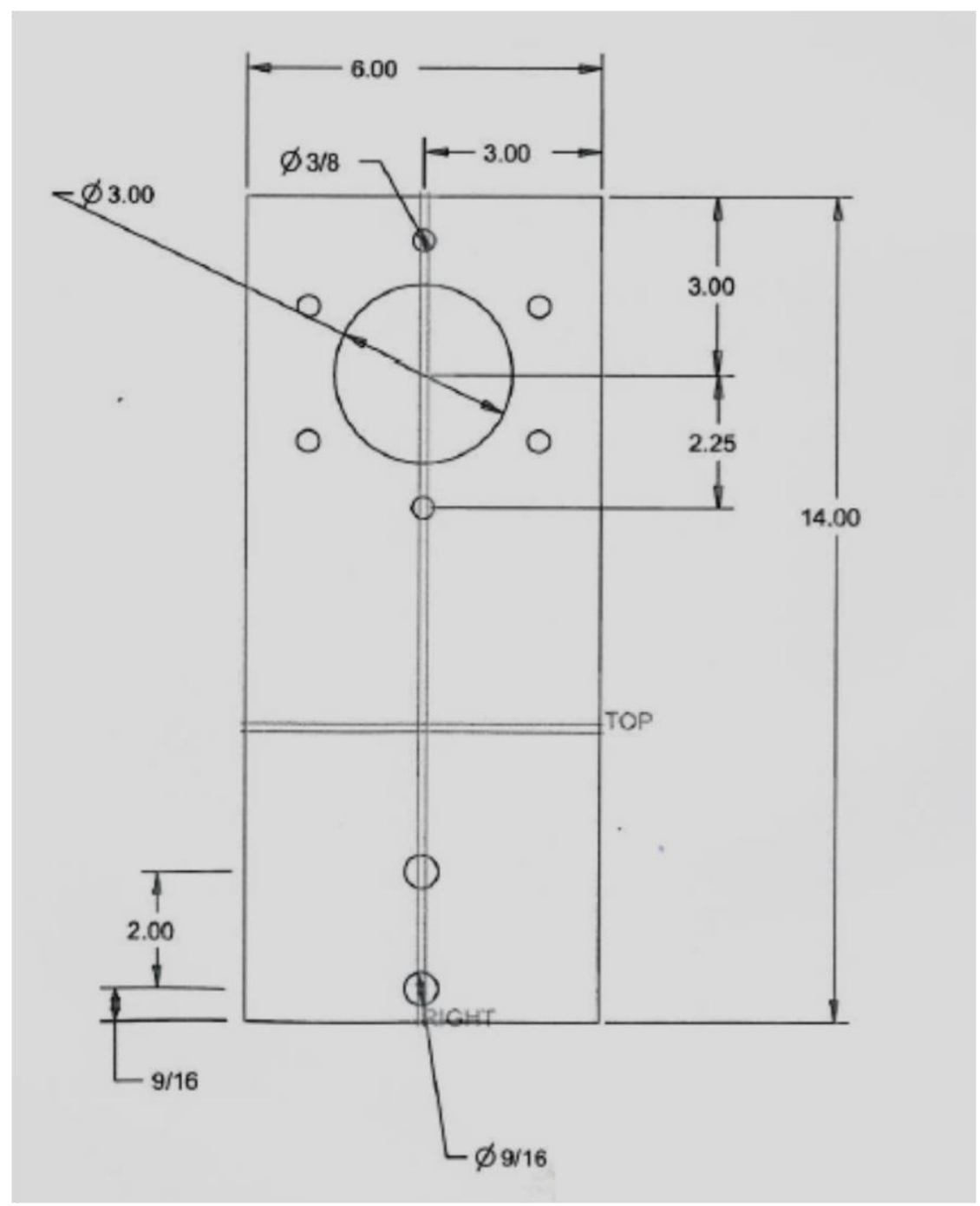

Figure 4-6: Mounting Flange

\subsection{Design of Tracer Injection Unit}

The introduction of the tracer media into the system must have a minimal effect on the hydrodynamics of the system to be studied. In previous studies, the most minimally invasive method is to illuminate particles at the bottom of the riser through clear section. Due to previously discussed limitations associated with this, it was not the method chosen for this work. Another method injects tracer particles into the riser with a blast of air through a probe. 
This method can be very intrusive with the injection probe and the air blast required to propel the tracer. It also does not accurately recreate the entrance effects of the riser.

The goal of the tracer injection system is to introduce the tracer particles in the active horizontal feed system in a batch mimicking a step input while being minimally intrusive. To accomplish the batch injection, a mechanism was designed to quickly actuate a slider mechanism aligning a cylindrical passageway containing tracer particles with the existing solids feed system.

The slider is constructed like a box with two horizontal passageways. For a visual reference, refer to Figure 4-8. The bottom passage is a cylindrical bore that allows the particles to pass through as if it were going through the original feed crossover. The passage located vertically above the bottom passage collects the tracer particles through an opening in the top. The quick downward actuation of the slider aligns the top passage with the pneumatic transport line where then the tracer particles are pushed into the system. This mimics the condition of unimpeded flow because additional air is not needed for injection, and the injection source is sufficiently far enough from the riser system so that the injected particles accelerate to approximately the same velocity as the particles from the feed hopper before entering the riser. The slider is then quickly returned to the original position after the tracer particles are ejected into the crossover line so that the cycle can be repeated. The vertical distance between the passages are minimized to reduce actuation time and minimize pressure fluctuations that occur during actuation when neither passageway is fully aligned with the pneumatic transport line. 
The first concern with the system is the integration into the existing fluidized bed riser. Measurements of the existing feed system were taken as the first step of design to determine the diameter of the passages through the slider. The length of the slider was determined by the maximum volume of tracer particles required for a batch injection which is proportional to the feed per unit time under operational conditions. The volume of the passageway of the slider was calculated to be the equivalent volume of particles required for two seconds of feed at the expected maximum feed rate. The original design was based on the injection unit being used with a larger fluidized bed system used for separation. The crossover feed line was 2" ID. The passages in the slide unit were designed to match the diameter. Sealing of the slide unit inside of its enclosure was originally designed as grooves machined into the face of the slider around the passages in which to place O-rings. A visual representation of the tracer injection unit can be seen in Figure 4-7.

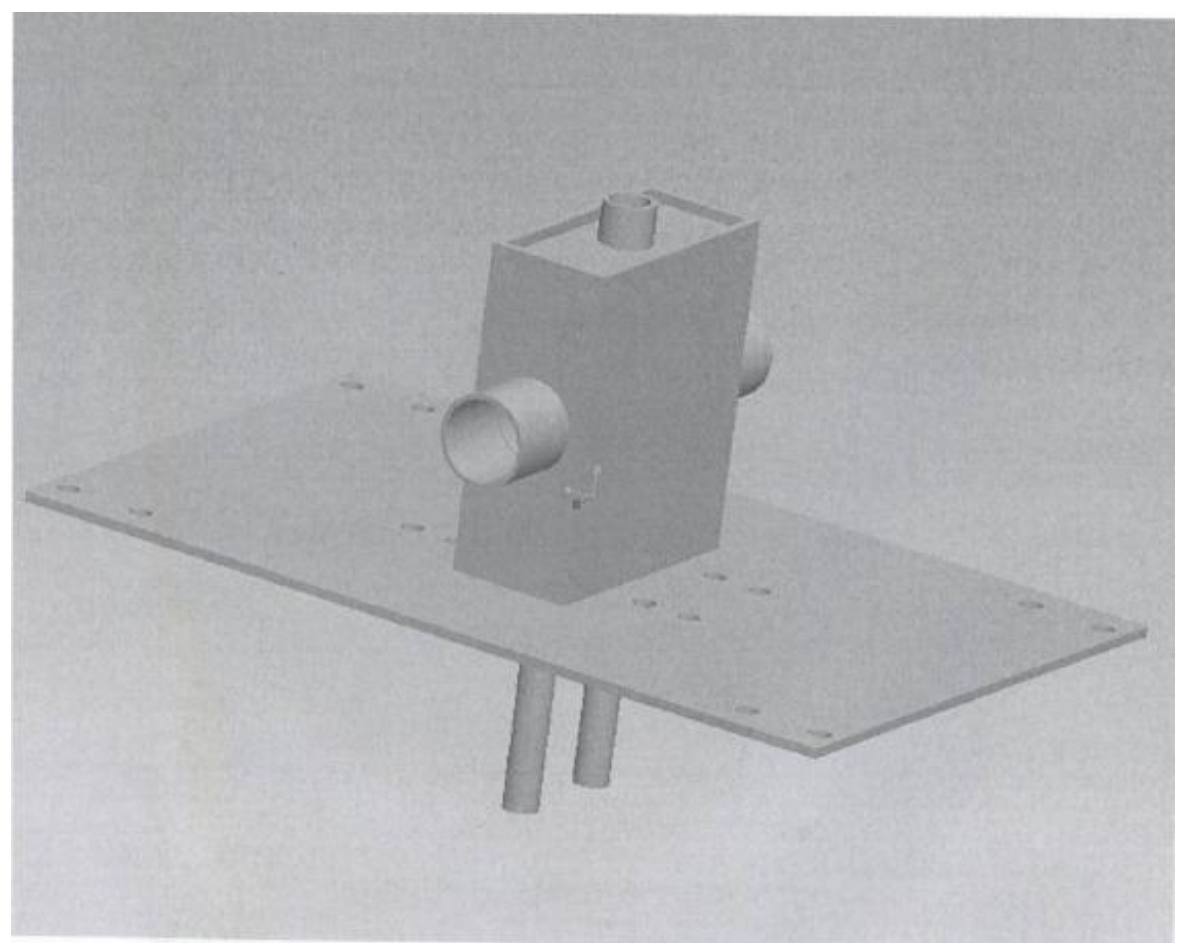

Figure 4-7: Injection Unit Overview 


\subsubsection{Slider}

The slider dimensions required 2" diameter bores to match that of the pneumatic transport feed line diameter. The length of the bores were calculated by setting the volume of the passage to the maximum expected volumetric feed rate for a two second time period. Aluminum was selected for its lower density compared to steel so that the required actuation force and associated momentum of the sliding unit would be minimized. Machinable plastics such as Delrin ${ }^{\circledR}$ were considered for the construction of the slider due to a lower density than common metals, high toughness, and low coefficient of friction. These plastics were rejected because of the difficulty of attaching provisions for the actuation air cylinders while maintaining a compact size. Another design for the slider, made of tubes welded into an enclosure made of sheet metal, was reviewed but was rejected because manufacturing methods would not allow dimensional tolerances to be satisfied.

A solid block of aluminum was milled to the dimensions of 6 " $\times 2.5^{\prime \prime} \times 5$ ". An engineering drawing of the slider can be seen in Figure 4-8. The 2 " bores were milled $2.5^{\prime \prime}$ from their respective centerlines through the vertical centerline of the $2.5^{\prime \prime} \times 5^{\prime \prime}$ face and offset equal distance from the horizontal centerline of the face. The upper passage had a 1 " hole drilled into it from the top side of the slider in the center of the surface. An aluminum pipe threaded internally with 1 NPT threads, a length of 1 " and a thickness of $1 / 4$ " was welded then welded in-line with the bore. Cylindrical standoffs $1 / 2^{\prime \prime}$ in diameter and $1 / 2^{\prime \prime}$ in length were welded to the bottom of the slider 3" apart measured from their respective centerlines. The standoffs were drilled and tapped with $1 / 4^{\prime \prime}-20$ pitch threads for the attachment of the air cylinder rods. 


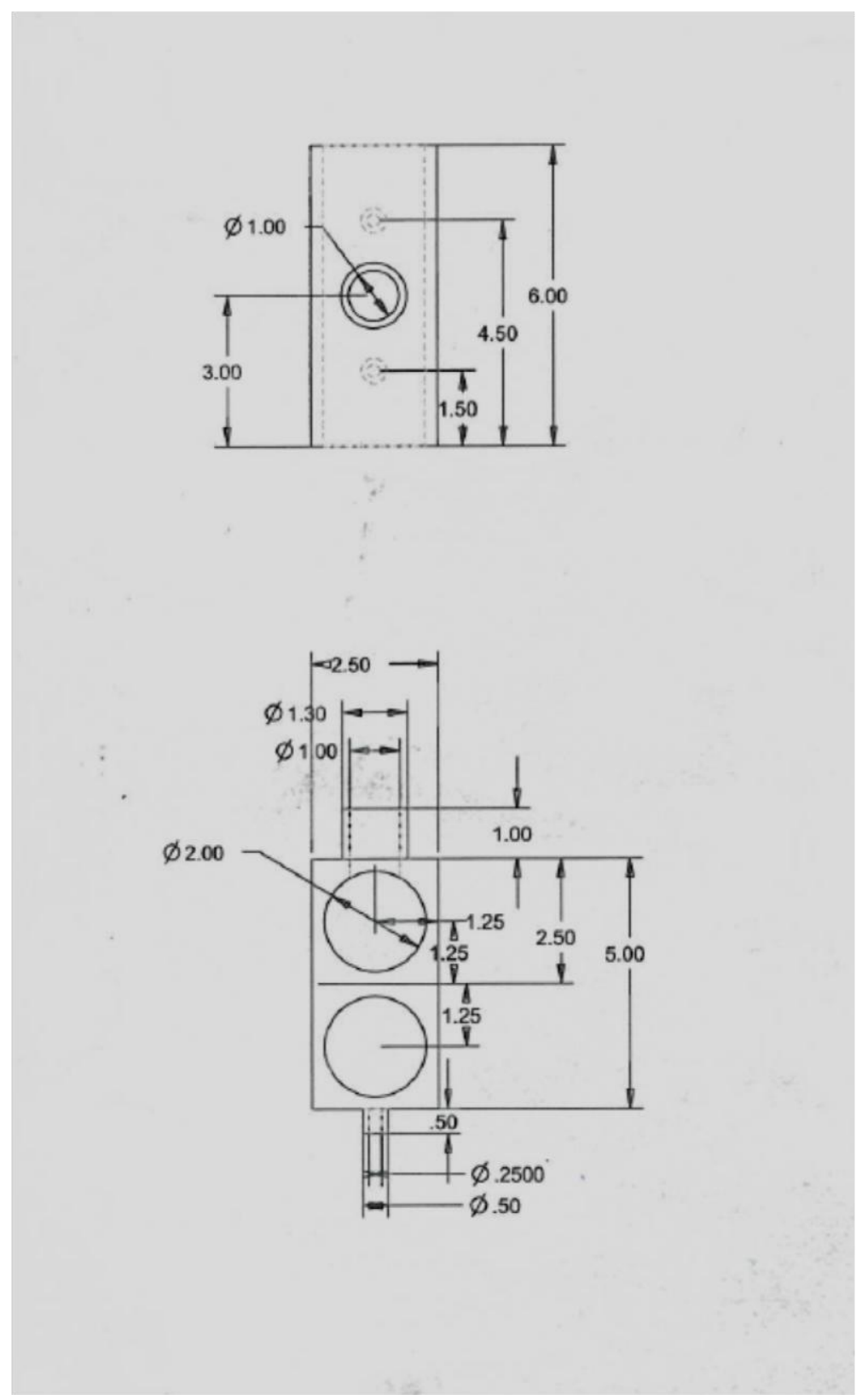

Figure 4-8: Slider 


\subsubsection{Slide Enclosure}

An enclosure was designed to contain and guide the slider, provide a ridged location to mount air actuators and provide mounting locations for Unistrut hardware. The size and thickness of the enclosure was selected to provide stability and sufficient weight to minimize the momentum effects of the slider being quickly actuated. Many revisions of the design were considered until a final design was constructed. In a previous version, the slider was to be mounted to the slide enclosure by a rail system. This design was eliminated due to the complexities of fabrication.

Instead, a rectangular enclosure, open on the top and bottom ends, was designed with inner dimensions matching the outer dimensions of the slider but with a 0.05 " clearance on all sides. The slide enclosure is depicted in Figure 4-9. The height of the enclosure was chosen so that no part of the slider protrudes from the top to minimize safety hazards. Two 2" bores were placed on opposite sides of the enclosure in a position that aligns with the passages in the slider when it is fully actuated in either position. Cylindrical standoff pipes 2 " in both length and diameter with a wall thickness of $1 / 4$ " was welded in-line with the bores. These standoffs were initially designed to attach to the rubber lines of pneumatic transport line by means of hose clamps. These were later repurposed when the design was modified for the smaller pneumatic transport line of the WADFP scale model.

The slide enclosure was welded to a base which can be seen in Figure 4-10. The base was constructed of $1 / 4^{\prime \prime}$ steel plate. It was designed with sufficient mass to mitigate the effects of momentum from the actuation of the slider. Holes were bored on both sides of the slide 
enclosure to interface with the air actuator mounts. Holes were also placed in each corner of the base matching the dimension of Unistrut ${ }^{\circledR}$ " $\mathrm{L}$ " brackets. The slide enclosure base was mounted to a Unistrut ${ }^{\circledR}$ support frame which allowed for the proper positioning of the slide enclosure relative to the riser system.
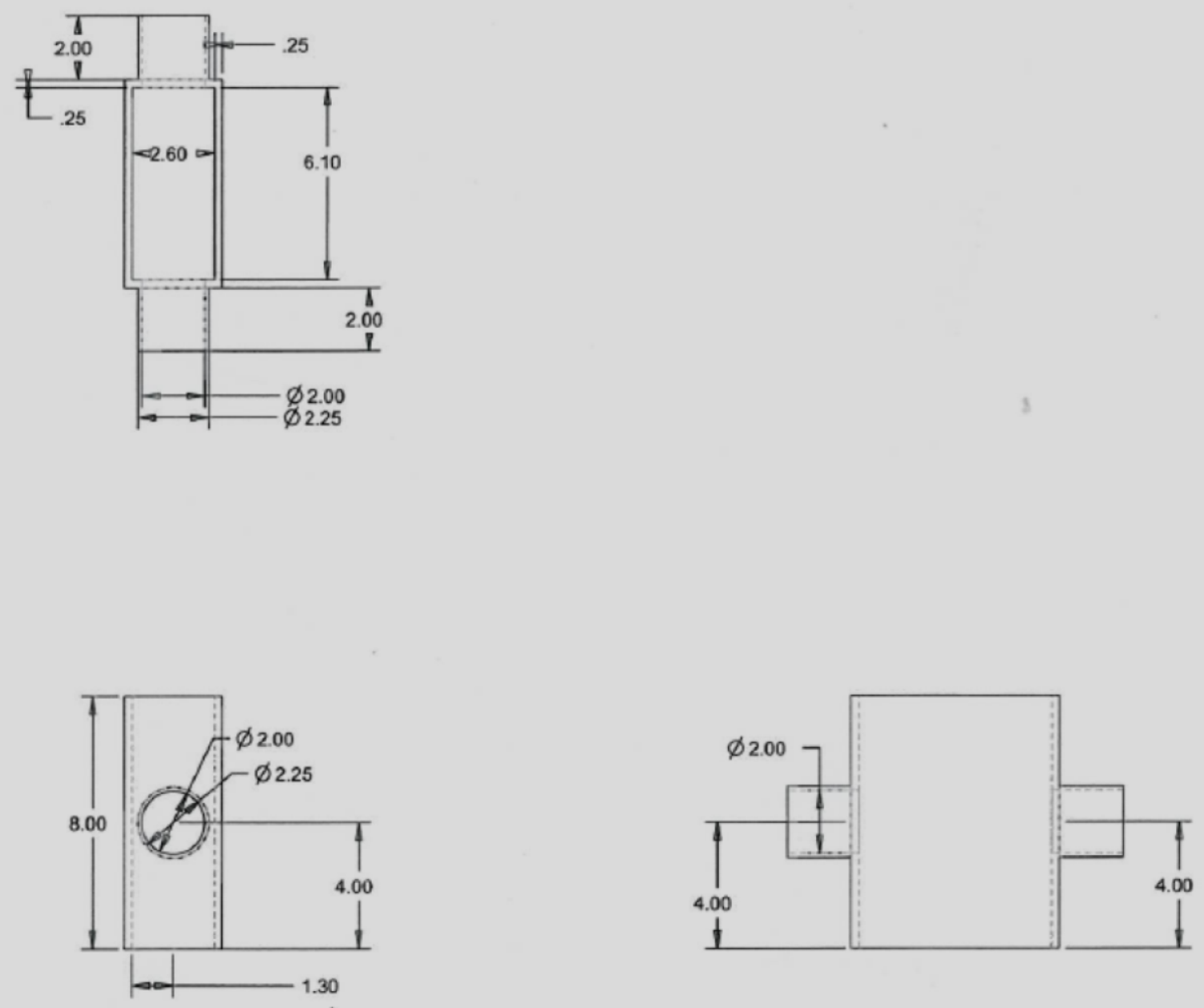

Figure 4-9: Slide Enclosure 


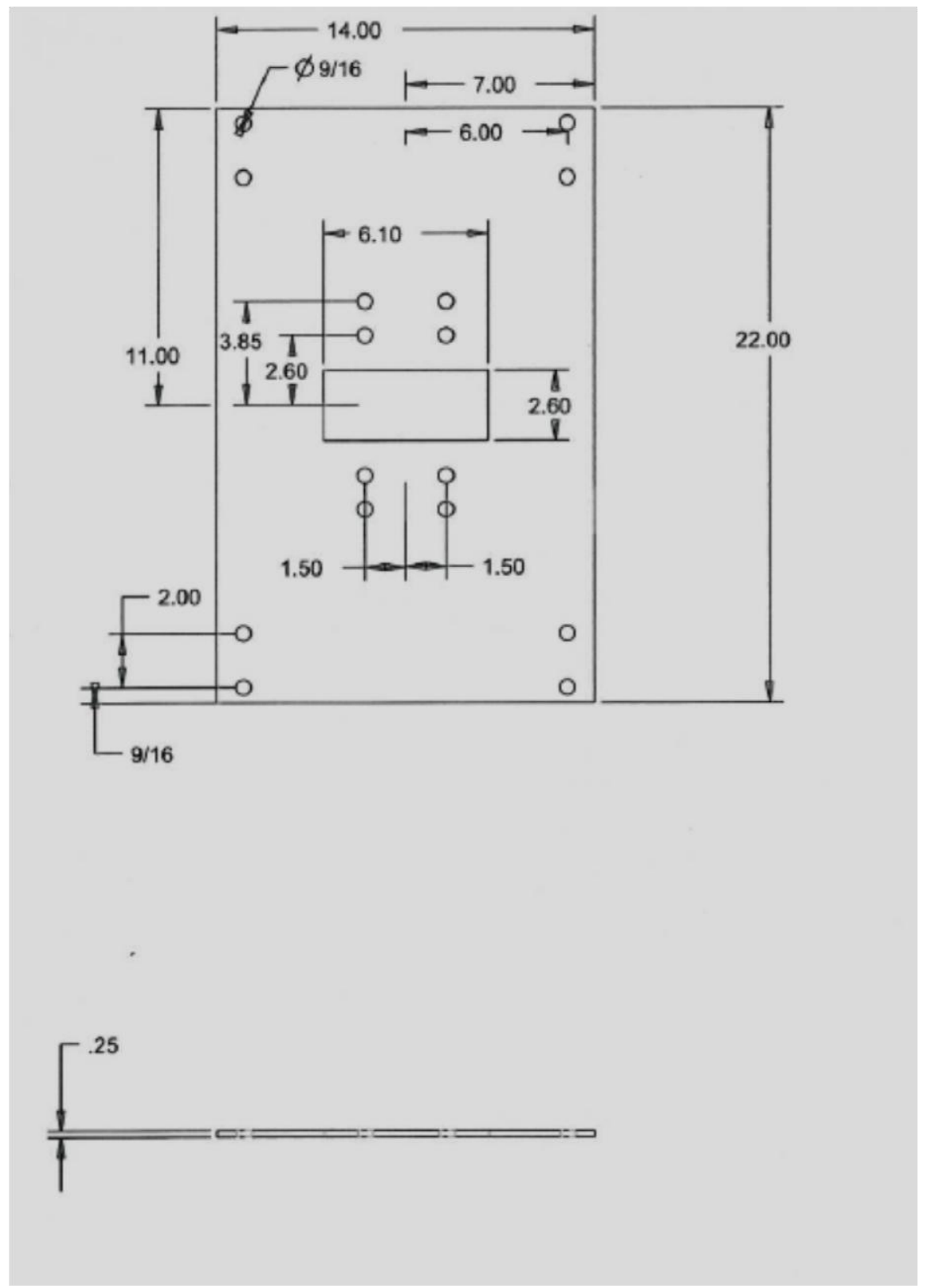

Figure 4-10: Slide Enclosure Mounting Base 


\subsubsection{Actuation}

Two nose-mount air double acting air cylinders provided the force for the actuation of slider. The $3 / 4$ " bore, $2-1 / 2$ " stroke stainless steel actuators are rated for a force of $35 \mathrm{lb}$ each when pressurized at $100 \mathrm{psi}$ and are rated for a maximum pressure of $250 \mathrm{psi}$. The nose mount portion of the air cylinder was threaded with a 5/8"-18 thread pitch and the end of the rod has $1 / 4^{\prime \prime}-20$ threads. The nose threaded into the air cylinder mounts that were rigidly bolted to the slide enclosure. The cylinder mounts can be seen in Figure 4-11. This arrangement was preferential for the reason that the bolts could be undone, and the slider, still attached to the air actuators and mount, could be removed through the bottom portion of the slide enclosure. Washers placed between the air cylinder mount and slide enclosure provide vertical adjustment of the slider to align the bores of the slider with the crossover. The rod portion of the air cylinder threads into the standoffs on the lower part of the slider. Thread locking compound was applied to the threads to prevent threads from backing out and to reduce the chances of the threads permanently locking together due to galling of the aluminum. 

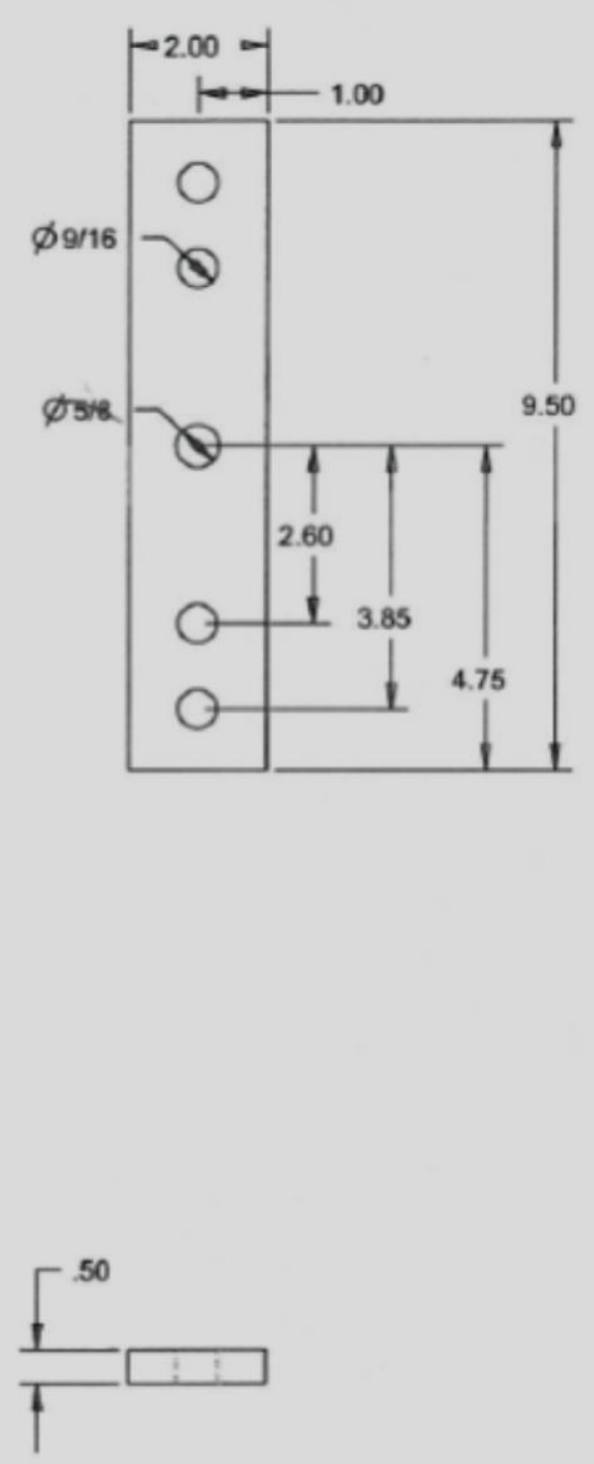

Figure 4-11: Air Cylinder Mount 


\subsubsection{Sealing Provisions/Modifications}

Wilson works was contracted to manufacture the injection unit, illumination hopper, slide gate valve, and the rest of the associated hardware. They did not, however, include any provisions for sealing the slide unit as ordered. The enclosure was constructed with a clearance of approximately $1 / 16^{\prime \prime}$ which is not conducive for the proper sealing of the system. Gas and solids would escape from the excessive clearances and cause multiple major problems which would compromise the functioning of the feed crossover and the riser itself.

The original design for the injection unit was changed from the separation riser system with a 2 " crossover to the small to the scale WADFP unit with a $3 / 4$ " crossover. The injection unit was modified for the integration into the smaller crossover system and to provide provisions for creating an airtight seal. A Delrin ${ }^{\circledR}$ rod was machined to the dimensions of the $2^{\prime \prime}$ bore and 6 " length for the slider, but with an inner diameter of $3 / 4$ " to match the dimension of pneumatic transport line. The upper bore bushing had an additional hole drilled in it for the acceptance of the tracer material through the top of the slider. The bushings can be seen in Figure 4-12. The bushings were affixed in the slider with epoxy so they did not move and cause jamming.

End bushings were made out of the same material to accept 3/4" NPT pipe nipples at one end and to protrude into the slide enclose at the other. The end bushings are depicted in Figure 4-13. Flat steel plates with dimensions of $5^{\prime \prime} \times 4^{\prime \prime} \times 0.1^{\prime \prime}$ were fabricated with a hole in the center through which to fit and weld $3 / 4^{\prime \prime}$ NPT pipe nipples. Holes of $1 / 8^{\prime \prime}$ diameter were drilled along the sides of the plate to attach the ends of tension springs. 
Delrin ${ }^{\circledast}$ was selected for its properties of low coefficient of friction, high machinability, and toughness. When assembled, the Delrin ${ }^{\oplus}$ bushings with the $3 / 4^{\prime \prime}$ NPT pipe nipples and spring mounting provisions are inserted into the tubular standoffs on each side of the slide box enclosure and then joined by coil springs. The springs are 7" in length with a spring constant of $6 \mathrm{lb} / \mathrm{in}$. The total deflection of the spring experienced while mounted is $2.2^{\prime \prime}$ which results in a force of 12.4 pounds for each spring. It was observed that two springs generated the necessary force to create a satisfactory seal against the slider without causing binding of the slide action. 


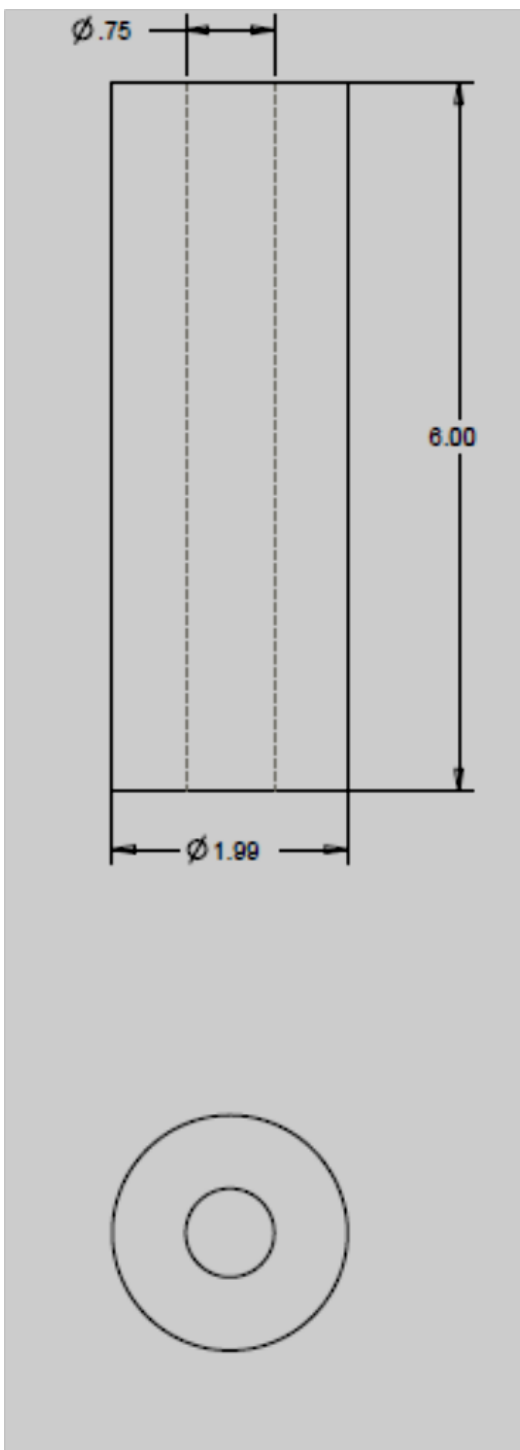

Figure 4-12: Delrin ${ }^{\circledR}$ Bushing 


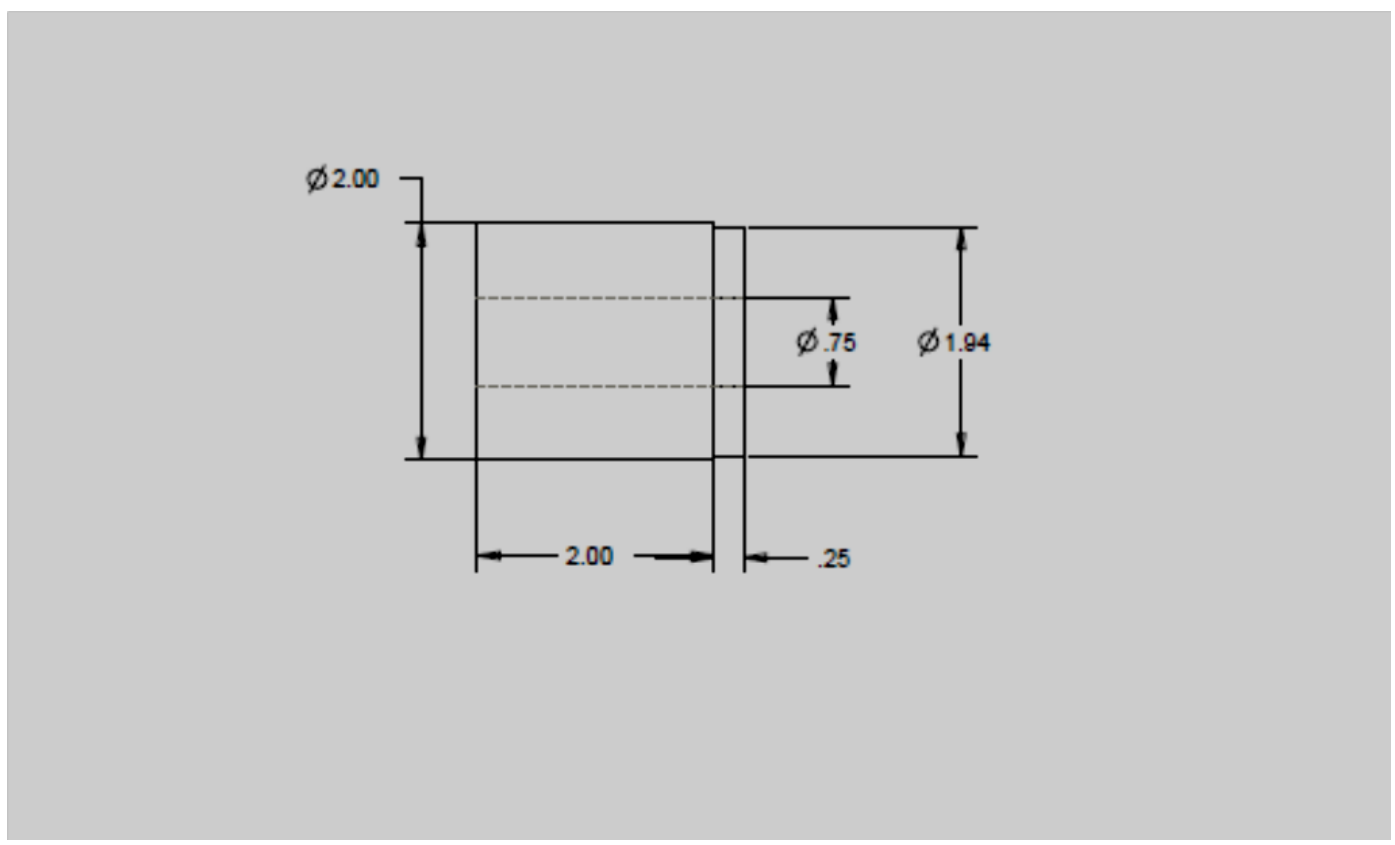

Figure 4-13: Endcap Bushing

\subsubsection{Slide Coupling}

The slider was attached to the ball valve on the illumination section via a slide coupling consisting of PVC pipe and end connectors. The upper section consists of $3 / 4$ " PVC pipe milled to an outer diameter of $1.050 "$ and 6" in length. A 3/4"PVC pipe socket end to 1" NPT treaded male end coupler was bonded to one end to connect to the air-driven ball valve. The lower section is made of 1 " PVC pipe $4.5^{\prime \prime}$ in length and honed to an inner diameter of 1.060 ". Attached to a 1"PVC socket end to 1" NPT threaded male end coupler which is then attached to the slide unit. The lengths were chosen so that the minimum overlap would be 2 " when the coupling is extended during actuation. The length of the slide coupling was a tradeoff between minimizing the amount of air and solids loss, the possibility of jamming, the force required for actuation, and the vertical distance particles between the illumination hopper and the slider 
In practice, this slide coupler configuration did not function properly. A secondary design was fabricated to provide reliable feeding without jamming. The slide coupling was replaced by a flexible plastic hose. The hose has an inner diameter of 1-3/4" and a maximum outer diameter of 1-7/8". The wall of the hose is formed in an "accordion" style shape which allows for compression and expansion. The hose with a free length of 6 " was connected to the slider and illumination system with 1"NPT pipe nipples and held in place with pipe clamps. With the slider in the upper position the length of hose was compressed to $5-1 / 2^{\prime \prime}$. The hose expanded to 8 " in length when the slider was actuated to the lower position. The only notable shortcoming to this system is that during the compression phase of actuation the hose occasionally bend into a slight " $\mathrm{S}$ " shape which required the operator to manually straighten the hose between runs.

\subsubsection{Slide Gate Valve}

For the preliminary testing of sensors and particles, an idea was discussed that it would be advantageous to utilize the illumination hopper as a small test system. It was also discussed that having a second acrylic section located below the illumination hopper separated by a gate valve with a screen to mix illuminated and non-illuminated particles would allow for observation in a more controlled environment than in the dual stage fluidized bed riser. This arrangement allowed for the determination of the minimum tracer quantity for accurate detection in varying conditions. The slide gate valve between the two cylindrical sections was designed with a flat slide gate with two holes milled in it, with one hole being covered with a screen of sufficient mesh size to block the flow of PPE particles. The theory was that nonilluminated bed particles could be placed in the lower section while tracer particles were illuminated in the upper section. Actuation of the slide gate combined with the modulation of 
fluidization air would then allow for the tracer particles to drop into the lower section for intermixing of the particles while measuring the light signal with the detection system.

An exploded view of the slide gate valve assembly can be seen in Figure 4-14. The slide gate was constructed from 1/4" thick steel plate. The slide gate can be seen in Figure 4-15. A recess was machined in one of the bores of the slide gate in which to place the screen. The slide gate valve body which was constructed of two matching parts was constructed of $1 / 4$ " steel plate and 3" ID steel pipe. The slide gate valve body can be seen in Figure 4-16. The top and bottom portions are identical. The valve bodies are separated by a $1 / 4$ " flange of which the outer dimensions match those of the valve bodies and the inner dimensions match those of the slide gate valve with a clearance of $0.01 "$. The spacer flange can be seen in Figure 4-17. This allowed for the gate valve to slide between the outer plates while maintaining proper alignment and provided adequate sealing so that the particles are not expelled from the system. The parts are bolted together with a $0.05^{\prime \prime}$ thick paper shim matching the dimensions of the spacer flange to provide clearance for actuation. The manufactured slide gate was not satisfactorily flat due to warping caused by welding. It was then remanufactured from aluminum. 


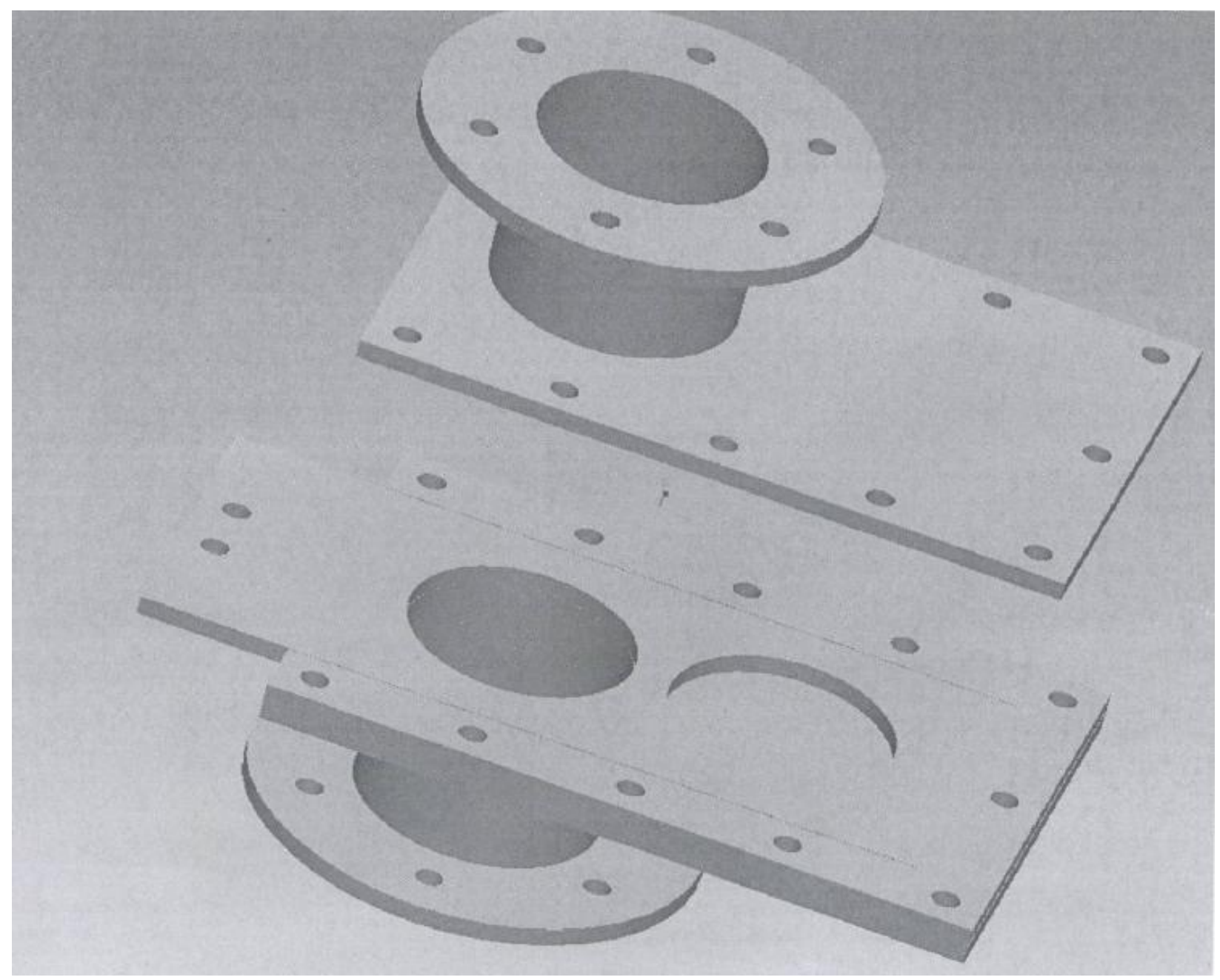

Figure 4-14: Slide Gate Valve Exploded View 


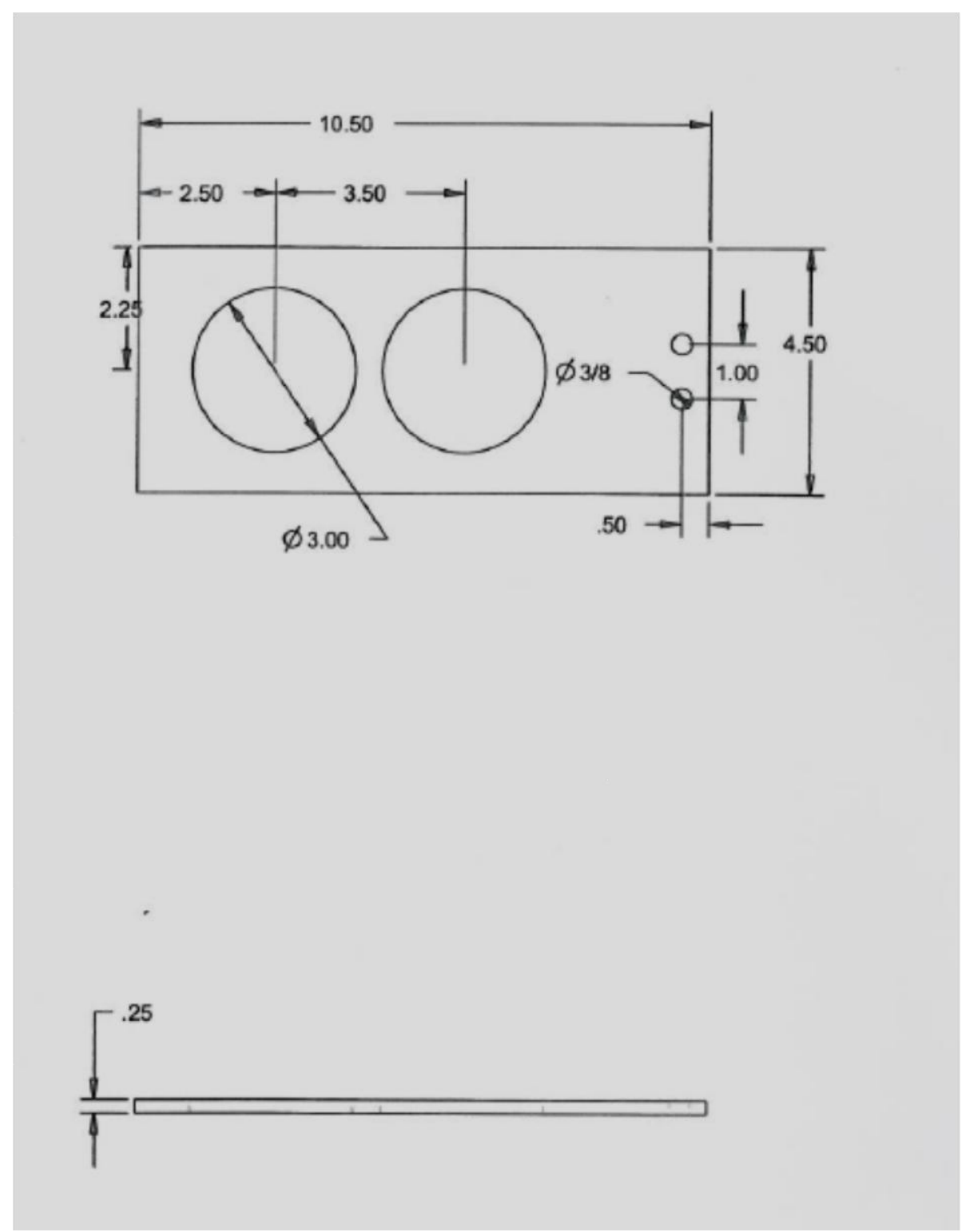

Figure 4-15: Slide Gate 


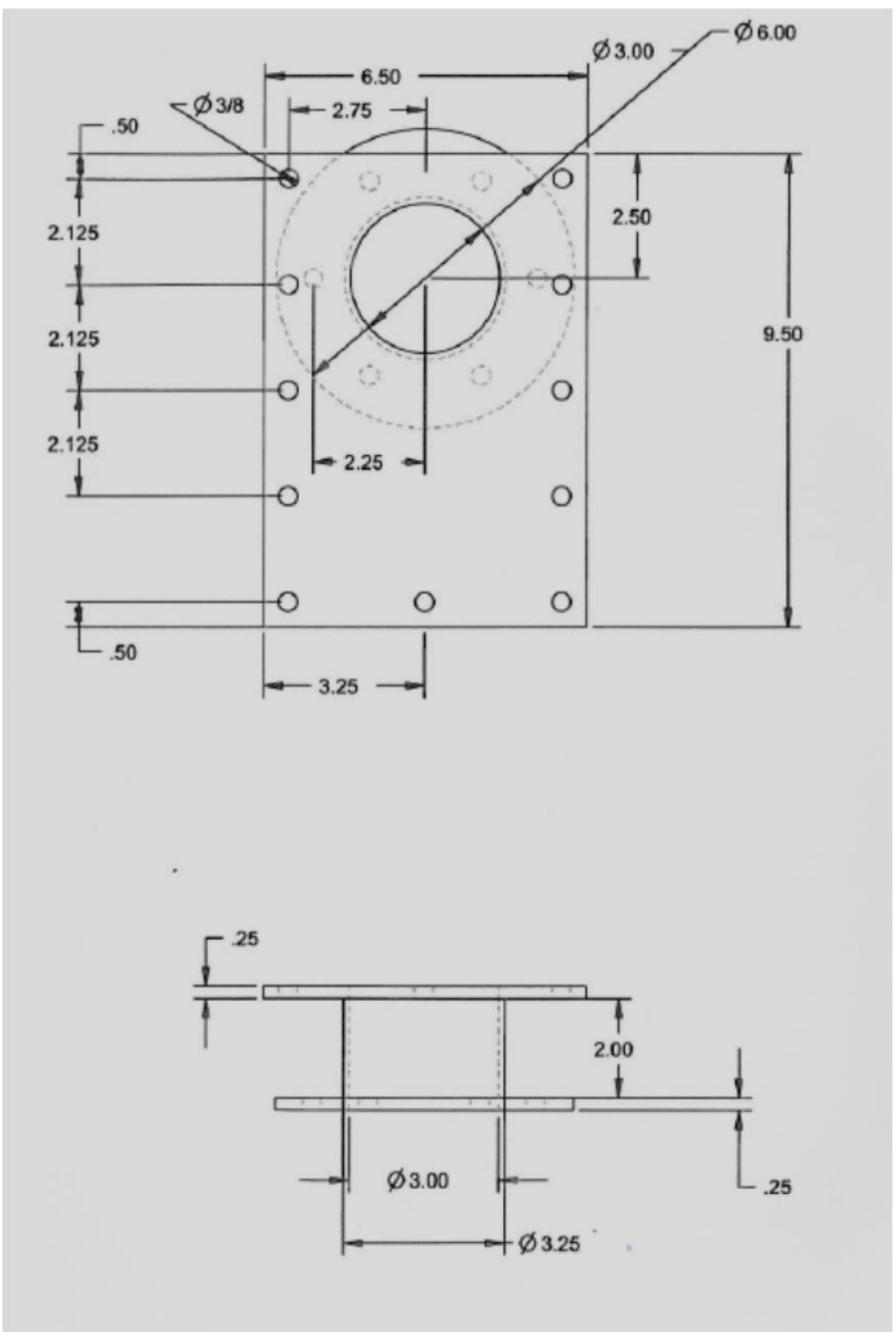

Figure 4-16: Slide Gate Valve Body 

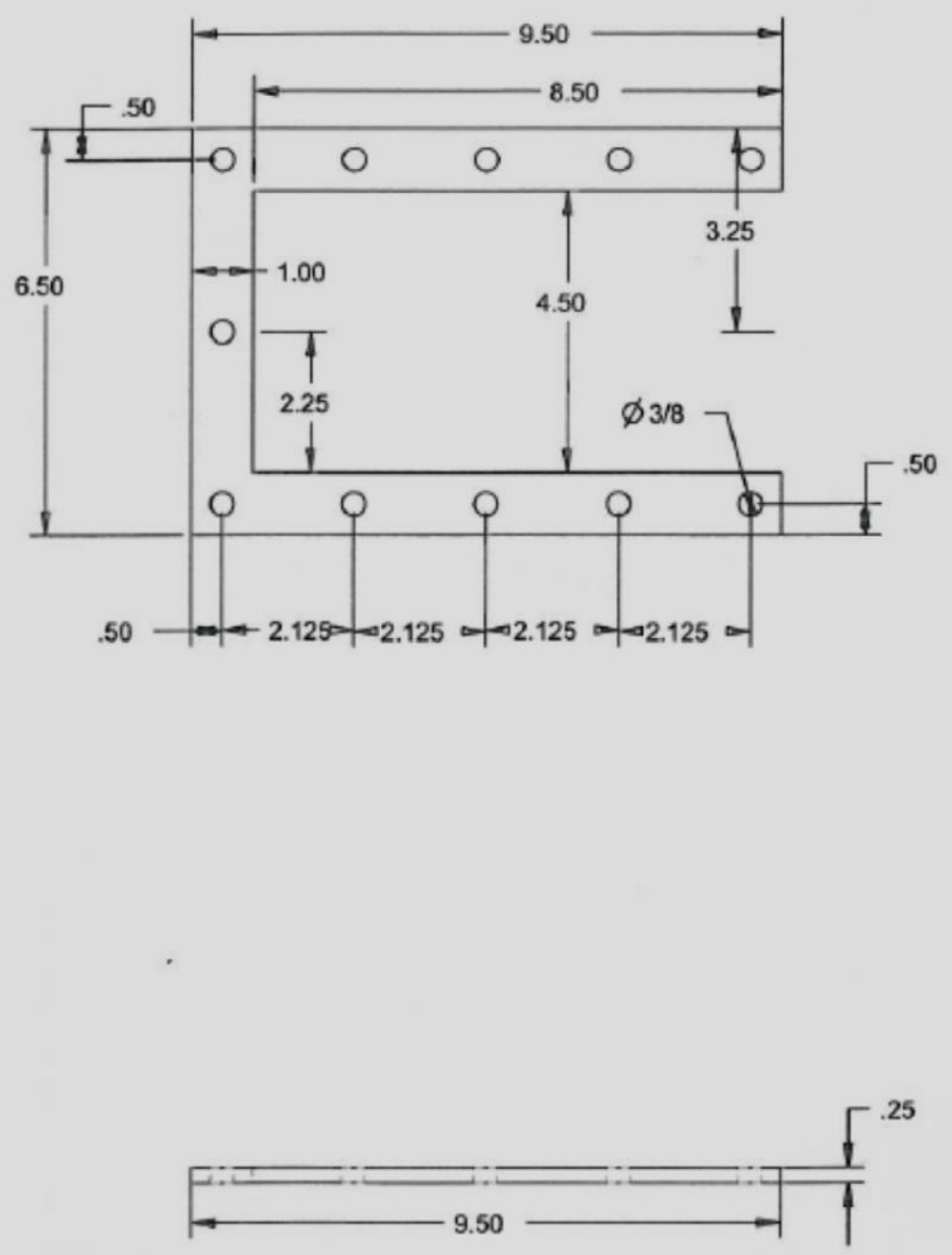

Figure 4-17: Slide Gate Spacer Flange 


\subsection{System Automation and Control}

Automation of the system is handled by an Arduino Uno, a microcontroller board based on the open-source Arduino language. It features 14 digital inputs/outputs of which six can be used for 8-bit Pulse Width Modulation (PWM) outputs, 6 analog inputs, 32 KB of flash memory, a clock speed of $16 \mathrm{MHz}$, and a USB connection for communication with a computer. Its physical dimensions are $2.7^{\prime \prime} \times 2.1^{\prime \prime} \times 0.6^{\prime \prime}$ and it has an operational voltage of $5 \mathrm{~V}$ with a recommended input voltage of 7-12V. The required power can be supplied from either a USB connection or an external power source. A maximum current of $40 \mathrm{~mA}$ can be output by each pin. Each digital pin can be used as either an input or output. The analog inputs measure voltage in a range of 0-5V with 10-bit resolution. Additionally it has a reset button and has protection for USB overcurrent conditions by means of a resettable poly fuse.

The programming language is a simplified version of the $\mathrm{C} / \mathrm{C}++$ language. Many of the same functions apply. A program in the Arduino language is referred to as a Sketch. The computer software required for programming is available directly from the Arduino website. Both the hardware and software are open-source.

The output limitations do not allow direct interfacing between the Arduino Uno board and the relays solenoids used for the system control. Intermediary relays are required to send the higher voltage and current to the objects needing controlled. A relay shield specifically designed for the direct integration Arduino Uno was acquired. The Seedstudio Relay Shield features 4 mechanical relays with a rated switching power of 35 VAC or 70W DC. The Relay Shield module is constructed with electrical pins that are positioned in such a way that they are pressed into 
the input/output pin receptacles on the Arduino Uno. It is powered by a $9 \mathrm{~V}$ external power source which is also shared by the Arduino Uno. Screw terminals are provided for the easy connection to the relay channels. Each relay has a common line, a Normally Open (NO) line, and a Normally Closed (NC). When the relay is not energized the common line is connected to the NC line. When the relay is energized, the common line is disconnected from the NC line and connected to the NO line. The action of the relays is controlled by the digital output pins from the Arduino Uno.

The Arduino Uno with the attached Relay Shield was housed in a plastic box. An external power supply of $12 \mathrm{~V}$ was connected to the common lines of the relays to meet the power requirements of the air solenoids and relays. The box was mounted on an aluminum panel with an LED to signal to signal the status of the control system. Two switches were also affixed to the panel which provide an input to the Uno to control the actuation program. The program created for the control of the system can be seen in Appendix A. One switch controls the mode in which the program operates; automatic or manual mode. The automatic mode has a counting function which when activated will delay the system actuation for a programmed amount of time. The manual mode allows for the system to be actuated immediately. The wiring diagram of the Arduino Uno and connected components can be seen in Figure 4-18. 
The general operation of the actuation system control is as follows:

1. Start Time to illuminate of tracer for 5 minutes

2. Open ball valve and stop fluidizing air simultaneously

3. Output a trigger signal to initiate data recording

4. Delay allowing for particles to fall past valve

5. Close ball valve

6. Actuate slider mechanism down

7. Delay for particle injection

8. Actuate slider mechanism up

9. Turn on fluidizing air

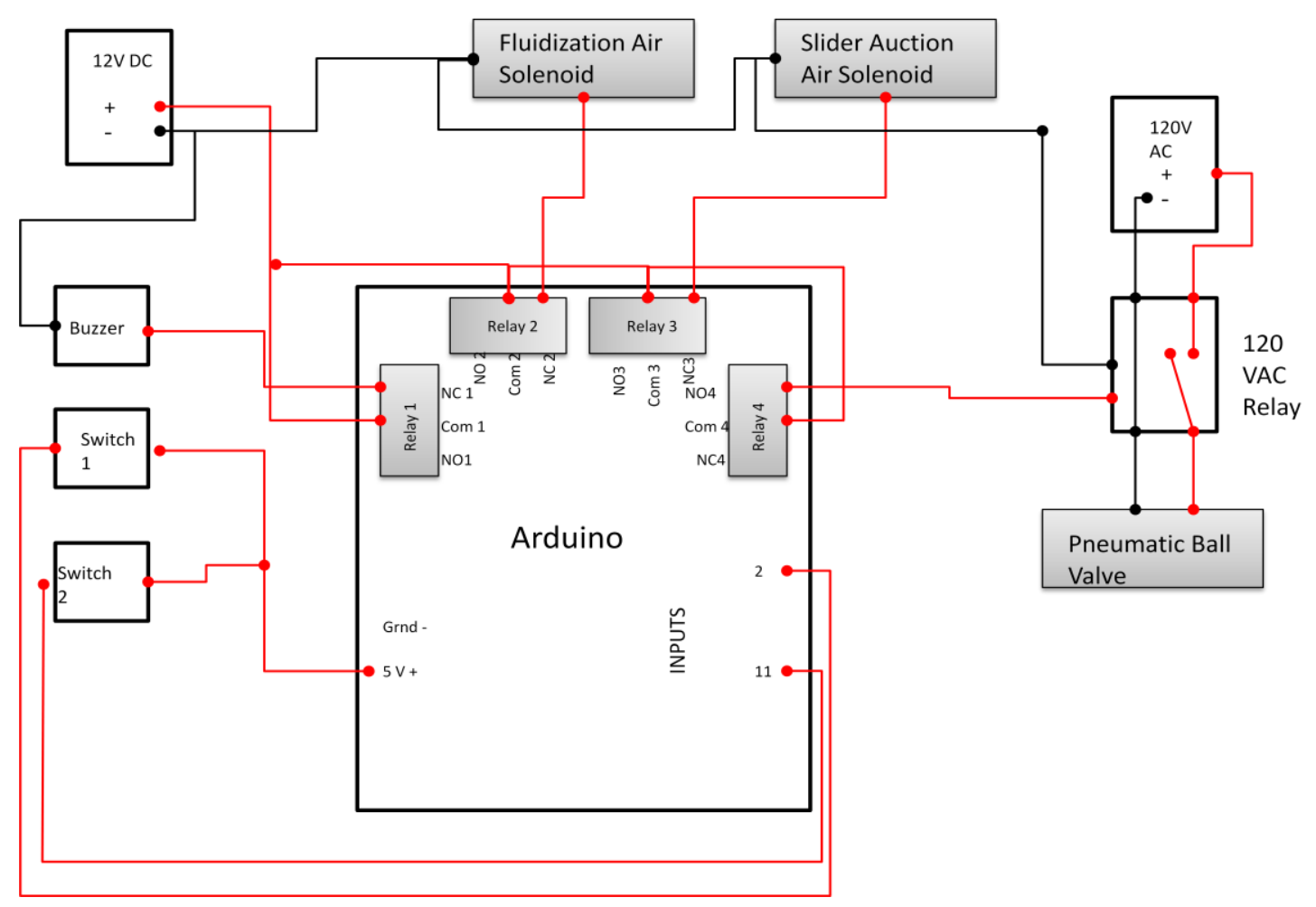

Figure 4-18: Arduino Uno Wiring Diagram 


\subsubsection{Air-actuated Ball Valve}

A valve is required between the fluidization air injection of the illumination hopper and the injection unit. This serves two functions; the first of which is to prevent particles from falling past the fluidizing air port as the particles are being introduced into the system. The second function is to prevent tracer particles from being expelled upward back into the illumination hopper during the injection process. The requirements for the valve are that it must be fast acting, be able to interface with the fluidization air Tee and slide coupling, and be controllable by the Arduino Uno. The Rub Valve Model VTN4-2S5 was selected to meet the stated requirements. It is an air powered ball valve with 1" NPT fittings and actuated with compressed air between 40-120 PSI. It has an attached air solenoid valve controlled by 120VAC. No suitable valves could be found that would operate on the same 12 VDC power source common to the other solenoids in the system. An intermediary relay was used to control the switching of the 120VAC power source with a switching voltage of 12 VDC. The valve also features a spring return for closing the valve when not pressurized. The solenoid is wired such that the valve is Normally Open. Application of the electrical signal to the solenoid causes the valve to close. The relay used in conjunction is wired Normally Closed so that when the 12 VDC signal is sent from the control unit, the relay will switch off and the ball valve will open. Testing has shown that the ball valve actuates from both open to closed and closed to open positions in well under one second. The actuation time could be varied with a change in air pressure which allowed for system optimization. 


\subsubsection{Air solenoids}

The air cylinders for the slider actuation require an air control valve to interface with the system controls. A 4-way 2-position single solenoid valve was selected to control the nose mount air actuators responsible for the slider movement. It has $1 / 8^{\prime \prime}$ NPT ports and is controlled by a 12VDC electric solenoid. The valve moves position when electric current is applied. An internal spring moves the valve back to the original position in the absence of current.

At the default position air is applied to the air actuators causing the slide mechanism to be at the upper default position. When the 12VDC excitation current is applied to the solenoid, the position of the internal air valve changes and causes the air pressure to be applied to the opposite port of each air cylinder while simultaneously venting the other port to atmosphere. This drives the actuator rod inward to move the slide mechanism to the lower position.

The fluidizing air for the illumination hopper also must be controlled by a solenoid valve so that the airflow can be temporarily interrupted to allow particles to drop into the injection section of the slide mechanism. A high flow 3-way 2-Position single solenoid valve was selected. It has 3/8" NPTF ports and actuates with a 12 VDC electric solenoid. It also has a flow factor of cV=1.7 to satisfy the high flow requirement. It was installed so that the valve is normally closed and opens when electric current is applied. 


\subsection{Detection System}

There are many requirements for the detection system to accurately represent the tracer flow within a fluidized bed riser system. The detection system must be as minimally intrusive as possible, provide accurate and repeatable detection, and be easily repositioned radially within the riser. The ability to move the point of detection radially across the riser is advantageous when the system is operating in a core-annular flow pattern. It would allow for the detection of the tracers moving upward within the core without the tracers being shielded by annular section of particles flowing downward along the wall by moving the probe inward. It was determined that using a system of a probe and optical fiber lines to transfer light emission from the tracer particles to the light detector would satisfy the requirements of the detection system. The detection system required the photo-detection sensors to have a high gain, a low signal to noise ratio, and provisions for the coupling of optical fibers

\subsubsection{Photo Detectors}

In previous works for optical measuring of RTD, the sensors chosen for measurement of light emission from illuminated particles are of the Photo Multiplier Tube (PMT) type. PMT's use a high voltage bias to amplify the small electrical signal generated when a photon comes into contact with the detection surface [21]. These types of sensor provide the highest resolution and amplification. PMT's are highly delicate sensors which can be permanently damaged from even minor exposure to ambient light. The PMT section of the tube is also fragile to vibration and impact. PMT's require the use of high voltage power sources in the range of 2000-5000 VDC. This presents increased danger of possible shock if handled improperly. The power sources must be precisely calibrated for multiple sensors to output the same signal when 
exposed to the same light intensity. To further decrease the appeal of these sensors, the price of two PMT sensors with a precision balanced dual-outlet power source can be in excess of $\$ 10,000$ (USD 2012).

At the lower end of the sensor spectrum, photodiodes provide light measuring capability at a low cost. For the illumination wavelength study in Section 5.1, a Thorlabs R220 photodiode was used to measure the intensity after the particles were exposed to various wavelengths. While this sensor provided acceptable results for that particular test, the lack of amplification and relatively slow detection speed prevented it from being useful for high speed detection of illuminated tracer particles through fiber optic lines.

Avalanche Photodiodes (APD's) exhibit comparable performance of a PMT without the most significant drawbacks. The sensor element of the APD is not permanently damaged by ambient light and operates on a much lower voltage (12V). The selected sensors were four Thorlab Model APD110A sensors with a silicon detection element tuned for the detection of light wavelengths in the range of $400-1000 \mathrm{~nm}$. The sensors featured a specially designed amplifier with active low-pass filtering for a high signal to noise ratio. The sensors had a high transimpendence gain for fast low-light level detection. Recommended applications include fluorescence, spectroscopy, and laser radar measurements.

The active detector diameter was $1 \mathrm{~mm}$. The sensor had a transimpedence gain of $\mathrm{G}=100 \mathrm{~V} / \mathrm{A}$, and a maximum conversion gain of $2.5 \times 10^{\wedge} 6 \mathrm{~V} / \mathrm{W}$. The maximum response speed was $50 \mathrm{MHz}$ which far exceeds required specifications. There were also a variety of optional fiber adapters 
available and accessories to attach a wide range of optical fibers and filters directly to the sensor housing. The corresponding power supplies output $12 \mathrm{VDC}$ at $200 \mathrm{~mA}$.

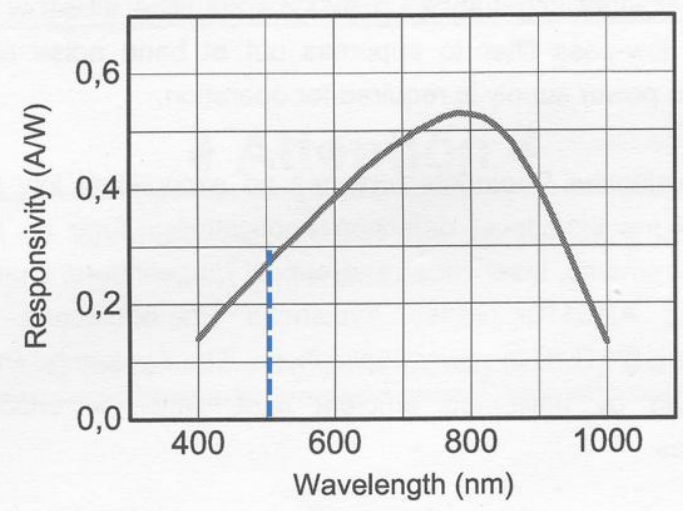

Figure 4-19: APD110A Detector Responsivity (M=1)[20]

The responsivity of the APD sensors is shown in Figure 4-19 as a function of wavelength.

The electrical output of the sensor is given by [22]:

$$
V_{O U T}=P_{O P T} \cdot \mathcal{R}(\lambda) \cdot M \cdot G
$$

Where $\mathrm{P}_{\mathrm{OPT}}$ is the incident light power, $\mathcal{R}$ is the responsivity found from Figure $4-19, \mathrm{M}$ is the magnification factor $(M=50)$ and $G$ is the transimpendence gain. With a given voltage output and light wavelength, the equation can be rearranged to find the incident light power.

Even with all the advantages of this sensor over a PMT, there are some drawbacks. The selected sensor did not have a circuit to compensate for thermal changes, which results in the magnification factor expressed in Equation 15 being temperature dependent. Testing of the sensors can be seen in Section 5.4. It was observed that it necessary to house the sensors in a thermally controlled unit to produce a more uniform data between testing. 
An Emerson compact refrigerator model CR175W was modified for the containment and temperature control of the Thorlabs APD's. It featured a 1.8 cubic foot internal capacity and an adjustable thermostat. The compact refrigerator contains the condenser coils underneath the thin metal enclosure on the sides. For this reason all fiber optic lines, sensor power sources, and sensor output wires are directed through the front hinged door of the unit. A 1" hole bored through the door was jacketed with PVC pipe and allowed the passage of all the electrical wires and sealed with silicon sealant.

A rack for the sensors was made of an $1 / 8^{\prime \prime}$ aluminum plate with dimensions 13 "x3-3/4". It was securely fastened to the door. Sensors are placed with a spacing of 2-3/8" and secured with 832 machine screws. The sensor rack was fabricated from aluminum to promote sensor cooling and to help maintain a thermal balance between the sensors. Other modifications to the refrigerator unit include the removal of all the racks and the cover on the evaporator which formed the freezer portion for better temperature uniformity throughout the unit. Silicone media was used to absorb moisture. The sensors were cooled to $50^{\circ} \mathrm{F}$ with an accuracy of $+/-2^{\circ}$ $\mathrm{F}$ with a maximum variance of $1^{\circ} \mathrm{F}$ between the sensors.

\subsubsection{Fiber Optics}

Light from the location of the probe is transmitted to the avalanche photodiodes through fiber optic lines. Two different fiber optic cables were purchased for preliminary testing. The largest factor in light transmission through fiber optic lines was believed to be the number of fibers [23]. Both fiber optic lines used in this study are made of Polymethyl Methacrylate Fluorinated polymer. This type of optical fiber is less prone to breaking than fiber optics composed of glass 
while still retaining similar transmission properties. This type of fiber was offered in larger diameters than found in fiber optics composed of glass. The first fiber line tested was constructed of 32 fibers each of which being $0.5 \mathrm{~mm}$ in diameter contained in a jacket $4.2 \mathrm{~mm}$ in diameter. The factory specifications list this multiple strand fiber optic cable having an attenuation of approximately 0.2 decibels per mile. The second fiber tested was of an unjacketed single strand fiber cable $3.0 \mathrm{~mm}$ in diameter. The factory specifications listed this fiber cable of having attenuation less than or equal to 0.20 decibels per mile also. The single strand cable has a detection area of $7.07 \mathrm{~mm}^{2}$ while the 32 strand cable only had a total detection area of $6.26 \mathrm{~mm}^{2}$.

Cutting the polymer fiber optic lines created a jagged end condition not conducive to directing light into and out of the fiber lines. After being cut, the end of the fiber lines were abraded at a right angle with sandpaper starting with 120 grit and ascending numerically to 2000 grit. The resulting scratches from each sandpaper step were removed by each successive step in size. The minute grooves left by the 2000 grit sandpaper were removed by buffing the surface with a polish compound.

Results of the in Section 5.2 showed that the single fiber line resulted in a higher voltage output of the APD sensors than the 32 strand line. Single strand fiber lines were cut to required length. Probes were constructed by inserting the measurement end of the fiber line into 8 " long $1 / 4$ " OD stainless steel tubes with an inner diameter of $0.12^{\prime \prime} A$ thin coating of silicon sealant was applied to the fiber optic line as it was being inserted into the tubing to bond the items together and create an air-tight seal. A depiction of the assembled fiber probe can be seen in 
Figure 4-20. The exposed lengths of the unjacketed fiber optic lines were wrapped tightly with black electrical tape to prevent ambient light from permeating through the surface and falsely inflating the sensor output values. Table 4-2 provides the length of fiber lines and location of probes. Figure 4-21 shows the approximate locations of the fiber probes. Figure 4-22 shows the orientation of the fiber probes in the lower stage in reference to the pneumatic transport line and pressure transducers.

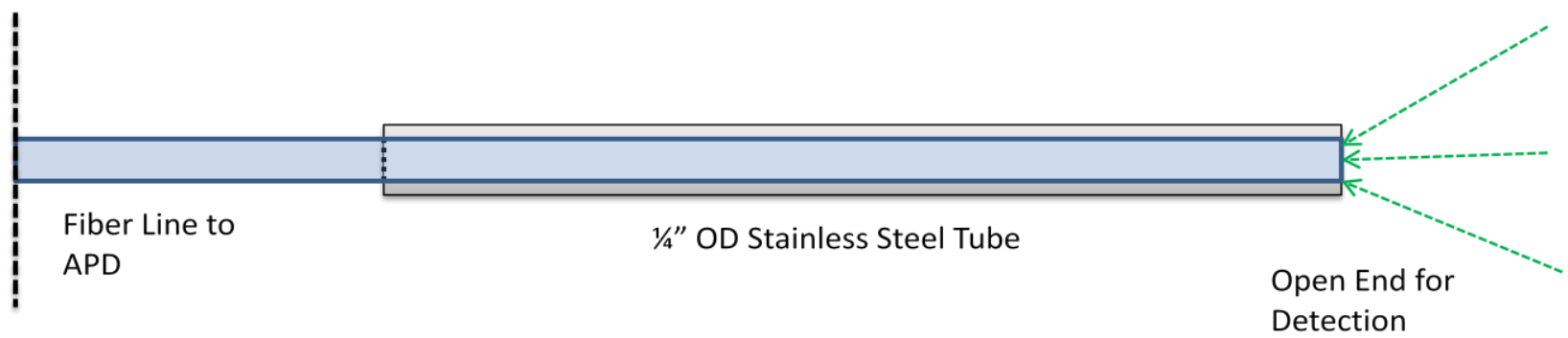

Figure 4-20: Illustration of Fiber Probe

Table 4-2: Optic Probe Locations

\begin{tabular}{|l|l|l|l|l|}
\hline Probe & 1 & 2 & 3 & 4 \\
\hline Fiber Length & $65 "$ & $86 "$ & $104 "$ & $151^{\prime \prime}$ \\
\hline Location & $\begin{array}{l}\text { Pneumatic } \\
\text { Transport Line, } \\
\text { 3" from riser } \\
\text { centerline }\end{array}$ & $\begin{array}{l}\text { Lower Riser } \\
\text { Section, 6" } \\
\text { Above Lower } \\
\text { Distributor }\end{array}$ & $\begin{array}{l}\text { Lower Riser } \\
\text { Section, 30" } \\
\text { Above Lower } \\
\text { Distributor }\end{array}$ & $\begin{array}{l}\text { Exit Crossover } \\
2.75 " \text { from riser } \\
\text { wall, 69" Above } \\
\text { Lower } \\
\text { Distributor }\end{array}$ \\
\hline
\end{tabular}




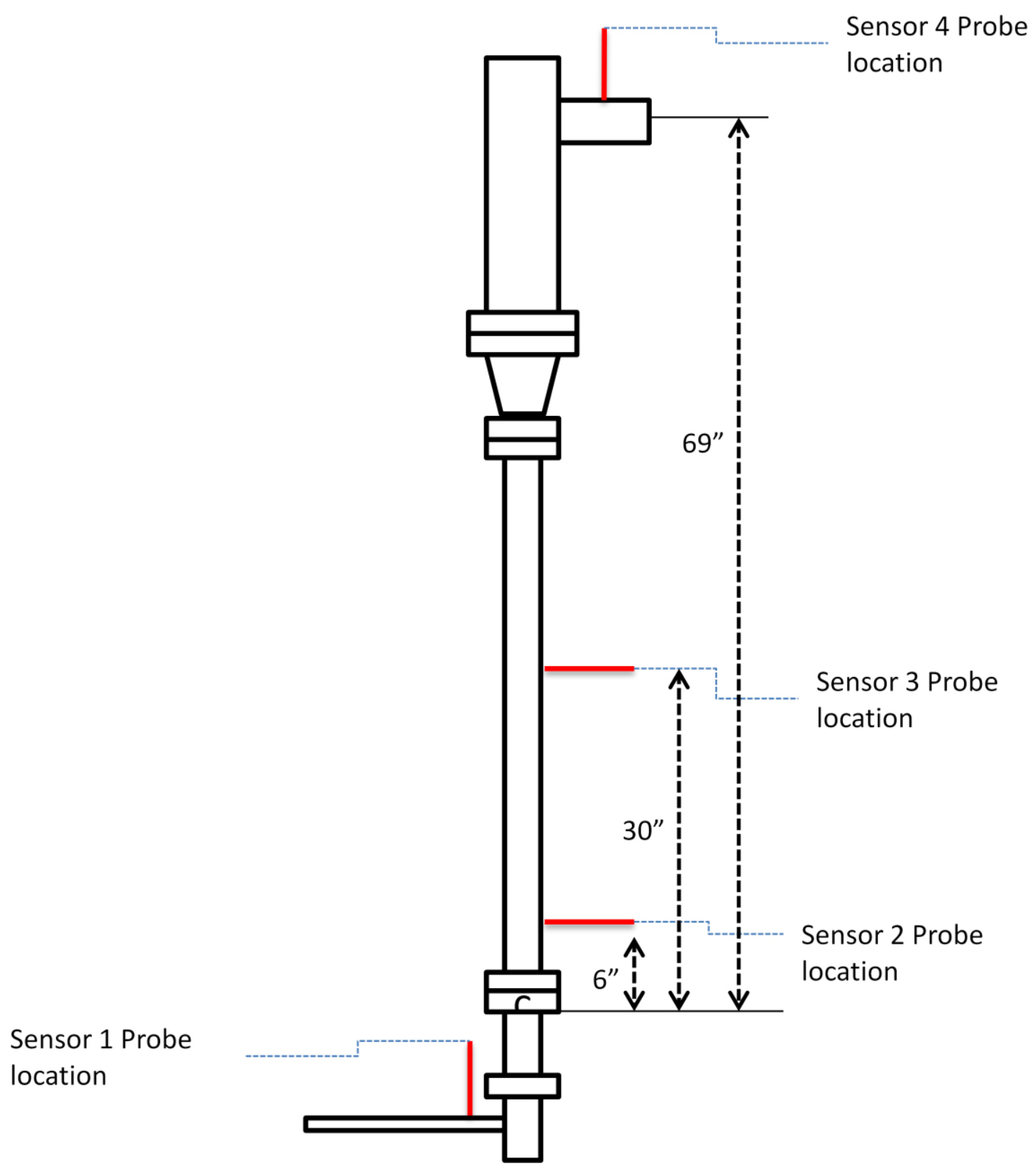

Figure 4-21: Location of Optic Probes 


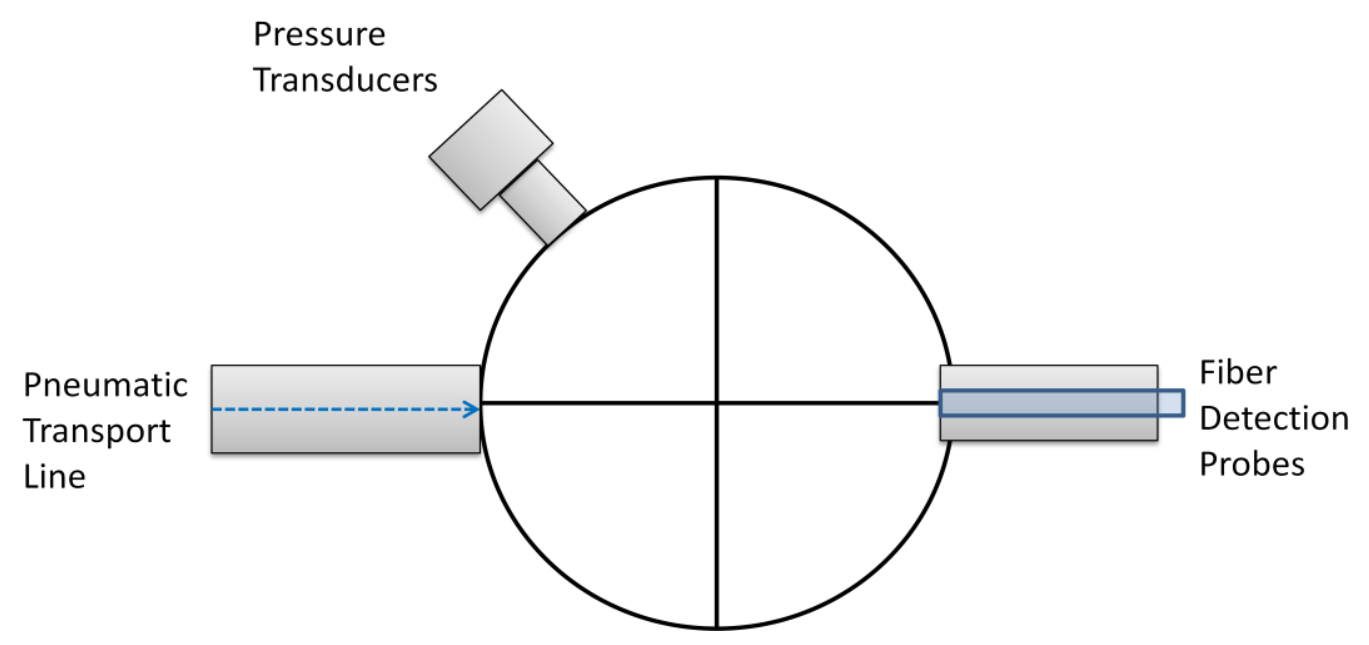

Figure 4-22: Orientation of Fiber Detection Probes and Pressure Transducers, Top View

\subsubsection{Fiber Optic Connection}

The fiber optic cable was terminated into a SMA fiber adapter connected to the threaded portion of the APD sensor body. The alignment of the fiber and sensor element can cause coupling losses. These losses were minimized by exposing the free end of the fiber optic to a light source while measuring the sensor output with a multi-meter. The fiber optic line was rotated within the fiber adapter until the signal output was maximized. This process was repeated whenever it was necessary to reconnect the fiber lines.

\subsection{Data Processing}

MATLAB was chosen to handle the extensive amount of data from accrued from each test. Microsoft Excel 2007 was not capable of handling data sets in excess of 31,000 points which limited it from being useful with the 70,000 data point length sets generated from some parts 
of the testing. Microsoft Excel was used for the creation of tables and some figures shown within this document.

A program was created for MATLAB to read the data files, process the data, and output selected figures. The MATLAB program first imported the txt files and sorted each signal data set into individual arrays. The arrays corresponding to the APD's were processed to remove the voltage offset. This was accomplished by averaging the first portion of the data set for each sensor before the occurrence of tracer detection in order to compensate for the offset voltage for the sensor. Data corresponding to the first 1.5 seconds of each array was averaged and then subtracted from the array. The program then searched for all the values in each array at which the signal exceeded the minimum threshold for detection $(0.1 \mathrm{mv})$, and created an array of the corresponding times for each point above the threshold. The time at which the signal first passes the threshold is recorded as $t_{1}$. The time corresponding to the last point in each array is recorded as $t_{2}$. The mean time was calculated by the numerical approximation of Equation (12). An array was created from Equation (16) in which the value for $C_{0}$ is calculated for each time in the array. The sensor signal arrays were then divided by the $C_{0}$ array to create the dimensionless concentration curves for each sensor when necessary. Plots were then generated from the data. 


\section{Chapter 5 Development Effort}

\subsection{Illumination Wavelength Study}

Preliminary study of the illumination properties of the PPE beads was completed in a dark room operated by the Electrical Engineering Department in the Engineering Science Building. It was performed before the design of the illumination, injection, and detection system. A computer controlled monochromator was used to bombard the PPE particles with selected light wavelength ranges to determine the most effective excitation wavelength. This study also provided an approximate estimate of useful particle life and the decay characteristics of the phosphorescent particles.

A sample of PPE particles was placed in a small glass vile and was aligned with the light source. The light source projected a square area with an area of $1 \mathrm{~cm}^{2}$. A Thorlabs $\mathrm{R} 220$ photodiode sensor was placed approximately 5 inches from the sample and was aligned so the sensor element was exposed to direct light emission from the samples. A problem was immediately noted with the arrangement. The curved glass surface of the sample container reflected the light preventing maximum exposure to the particles. This observation ultimately lead to the design of the illumination hopper with the light source contained within the fluidized bed for direct impingement of illumination light on the tracer particles.

The test arrangement was then modified so that the sample was placed in a dish, and the light from the source was reflected onto the sample with a high-grade mirror. This arrangement is depicted in Figure 5-1. The size of the projected light area was not affected. The light spectrum was varied throughout the tests to determine the wavelength range which resulted in the 
highest intensity of particle illumination. The PPE beads were exposed to the excitation light for 60 seconds while data was being taken at a sample rate of $1 \mathrm{~Hz}$. Data was collected for an additional 60 seconds after the light source was blocked.

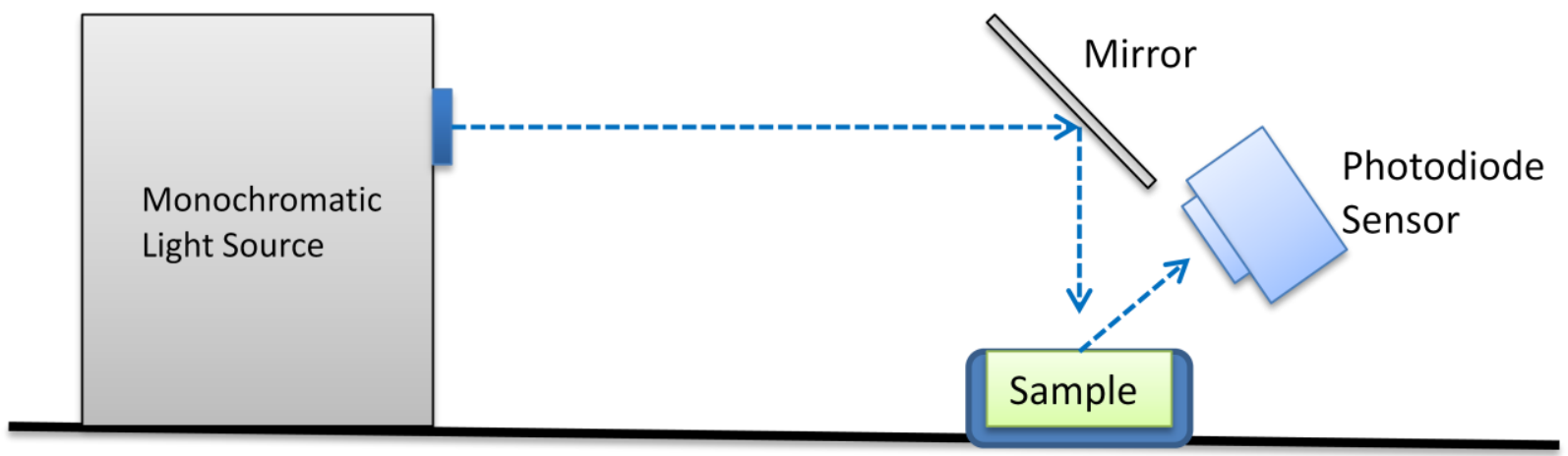

Figure 5-1: General Layout of Illumination Study

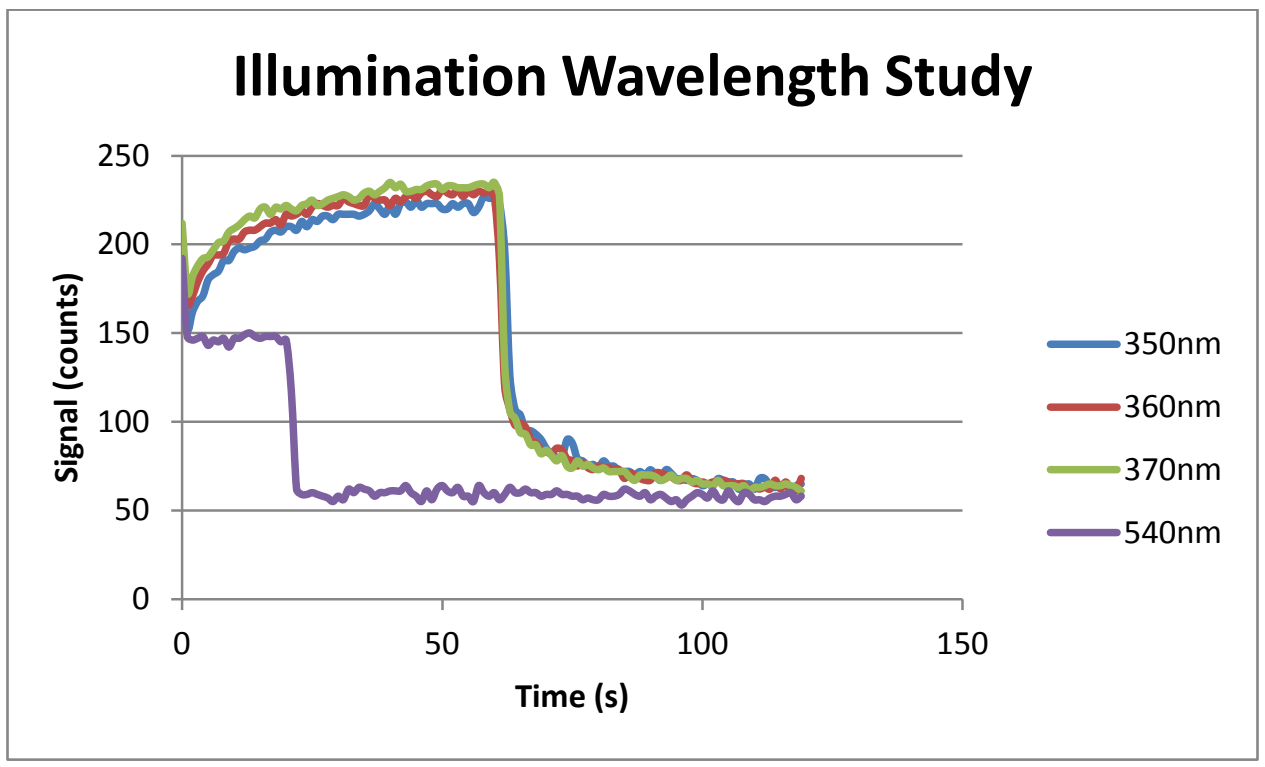

Figure 5-2: Preliminary Particle Illumination Study, Raw Data

Figure 5-2 shows the unedited data from the testing; showing both the illumination process and particle decay curve for several wavelengths. Certain wavelengths tested were omitted from 
the Figure 5-2. These wavelengths did not induce any response from the PPE particles; they resulted in same curve as the $540 \mathrm{~nm}$ spectrum shown. The first portion of the light intensity curve represents the illumination of the particles. This section of the curve is the combination if the reflected illumination light and the light emitted from the charge particles.

The second portion of the curve represents the decay of the particle afterglow when the illumination source was blocked. This part of the curve shows a drastic decrease in the measured light intensity followed by an exponential decay curve. It can be seen from this Figure 5-2 that the majority of the decay happens in the first 15 seconds and that the particles exhibit light emission above ground state for above 40 seconds. The test results confirm the illumination wavelength specifications of the phosphorescent pigment supplied by the manufacture [19].

\subsection{Fiber Optic Line Testing}

Two sets of fiber optics were selected for possible use for light detection and transmission in the RTD detection system. Both Polymethyl Methacrylate Fluorinated polymer optic cables have similar specifications for light attenuation, approximately $0.2 \mathrm{~dB} / \mathrm{M}(@ 650 \mathrm{~nm})$. Both fibers fit the size requirements imposed by the probe diameter limits and sensor fiber line adaptors. The first fiber is a single strand filament measuring $3.0 \mathrm{~mm}$ in diameter. The second optic cable is composed of 32 strands of $0.5 \mathrm{~mm}$ filament contained within a black jacketing. The single strand cable has a detection area of $7.07 \mathrm{~mm}^{2}$ while the 32 strand cable only has a detection area of $6.26 \mathrm{~mm}^{2}$, which is an $11 \%$ difference in area. 
Probes containing each fiber were constructed from 1/4" OD stainless steel tubing. Both measured 12 in length. One side of the fiber extends into the fiber attachment cap for the sensor. The fibers pass through a 12 inch long steel tube of 0.25 inch outer diameter and terminate flush with end of the tube. A 3V 20mA green LED was placed in the end of a $1 / 4$ " pipe compression fitting which securely attaches to the steel probe. The LED was connected to a battery power source consisting of two AA batteries. The batteries were replaced frequently to suppress the effects of voltage degradation of discharging batteries. The arrangement seen in Figure 5-3 allows for the precise attachment of the light source to the exposed end of the fiber probe for repeatable results.

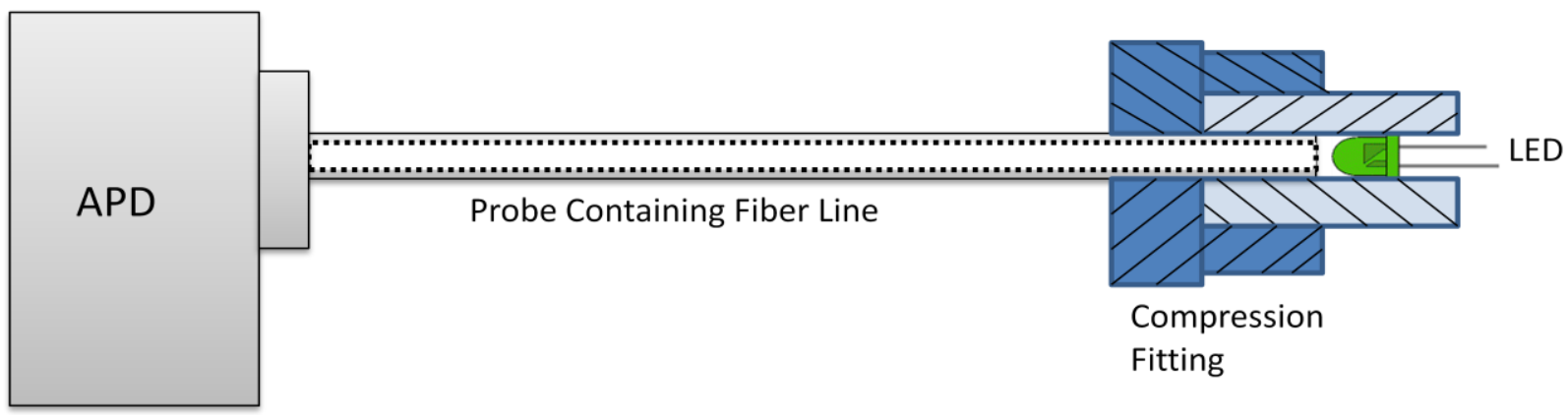

Figure 5-3: General Layout of Apparatus for Fiber Optic Line Testing

The sensors were given adequate time to reach a thermal equilibrium before testing was performed. The temperature at the start of each test was documented to ensure that the results were not affected by the temperature dependent multiplication factor of the sensor. The sensor output was measured an averaged over 18,000 data points. The probes were switched between each run for a total of 3 test points for each fiber probe. The probes were switched between each test to eliminate the potential light intensity degradation caused by the battery power source discharging. A second sensor was used to replicate the results. The test 
procedure was also followed for a second sensor. The results for the test can be seen in Figure 5-4. The single strand fiber probe resulted in the signal output $28 \%$ higher than that of the 32 strand fiber probe. The offset in output voltage between the sensors was attributed to the decay of the light battery source.

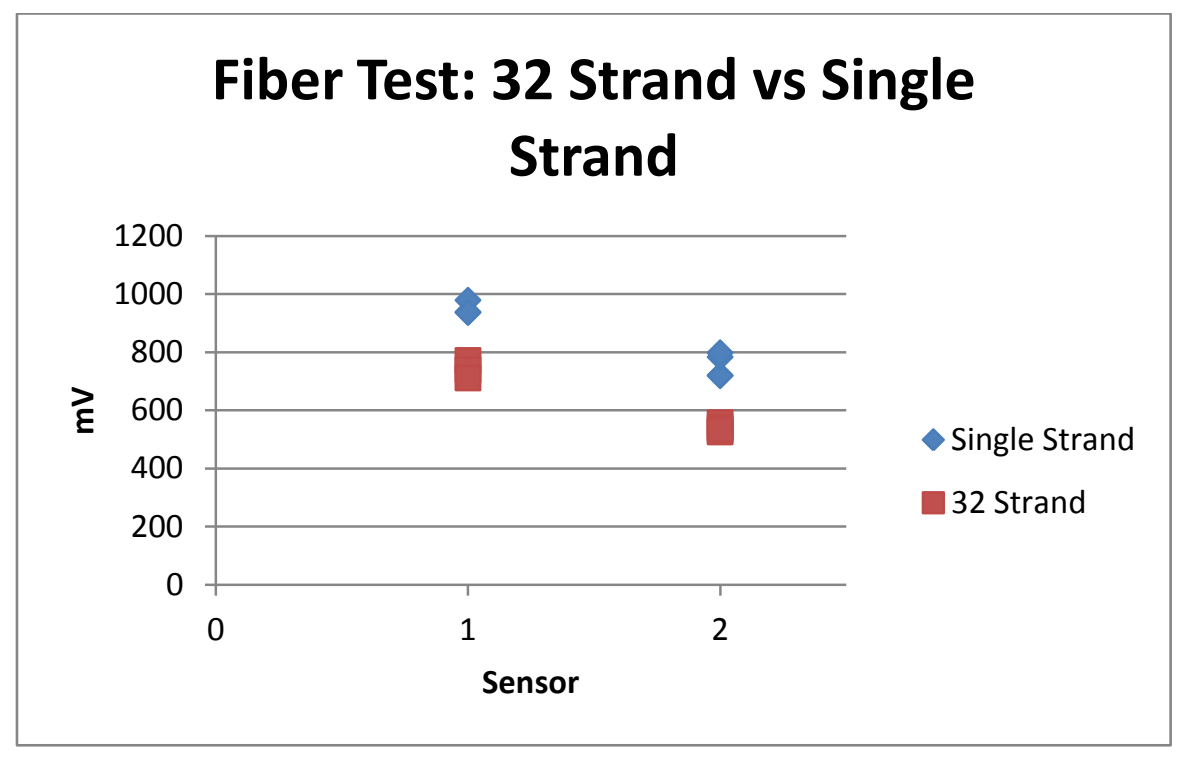

Figure 5-4: Results of Fiber Test, Sensor Temperature $\mathrm{T}=83^{\circ} \mathrm{F}$ 


\subsection{Fiber Line Angle of Acceptance Study}

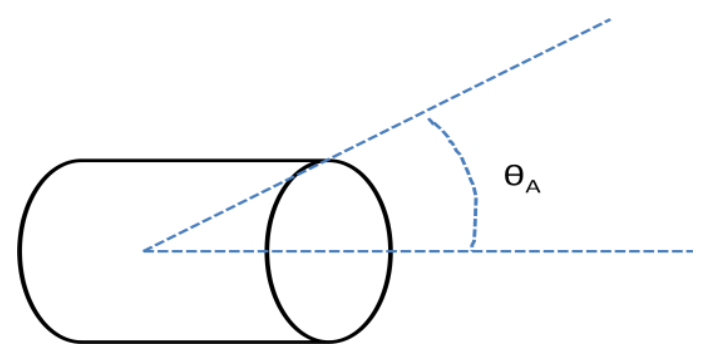

Figure 5-5: Angle of Acceptance

A test apparatus constructed for the purpose of determining the angle of acceptance $\left(\theta_{A}\right)$, depicted in Figure 5-5, for the single strand fiber optic line. The test system shown in Figure 5-6 consisted of a light source and a fiber line mount attached to a swivel. Both were rigidly attached to a precision rail mount. The fiber line mount rotated to vary the angle in relation to the light source while maintaining a set distance. A baffle with a pin-hole aperture was placed between the light source and the fiber to ensure direct impingement of light onto the fiber optic probe and to minimize the occurrence of stray light from being measured. As seen in Figure 5-7, the signal intensity begins to decrease at an angle of 20 degrees and then drastically plummets as the angle is further increased. It was concluded the angle of acceptance for this particular fiber optic is approximately $\theta_{A}=20^{\circ}$. Light striking the fiber surface at an angle greater than $20^{\circ}$ from perpendicular will not pass into the optic line and, instead, will be reflected. 


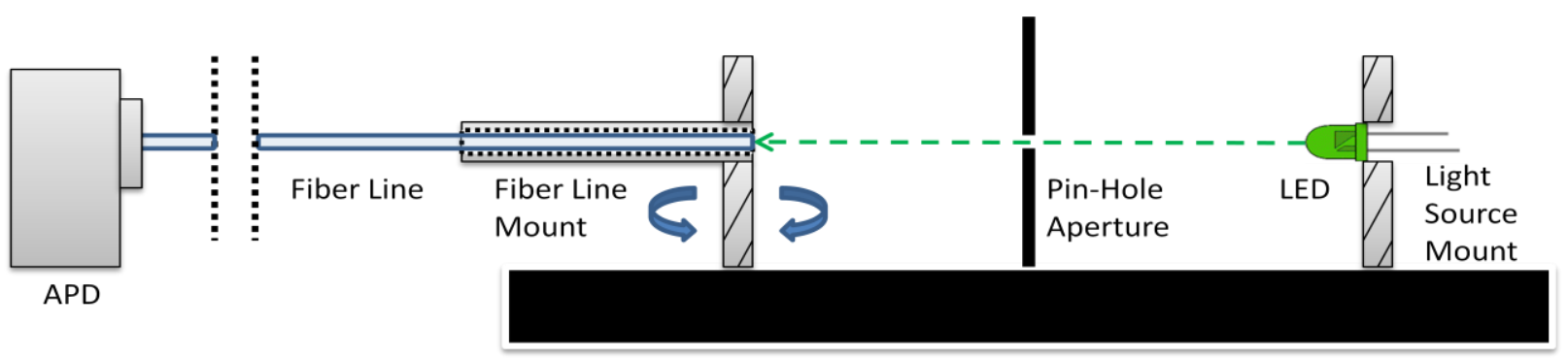

Precision Rail Mount

Figure 5-6: General Layout of Apparatus for Angle of Acceptance Test

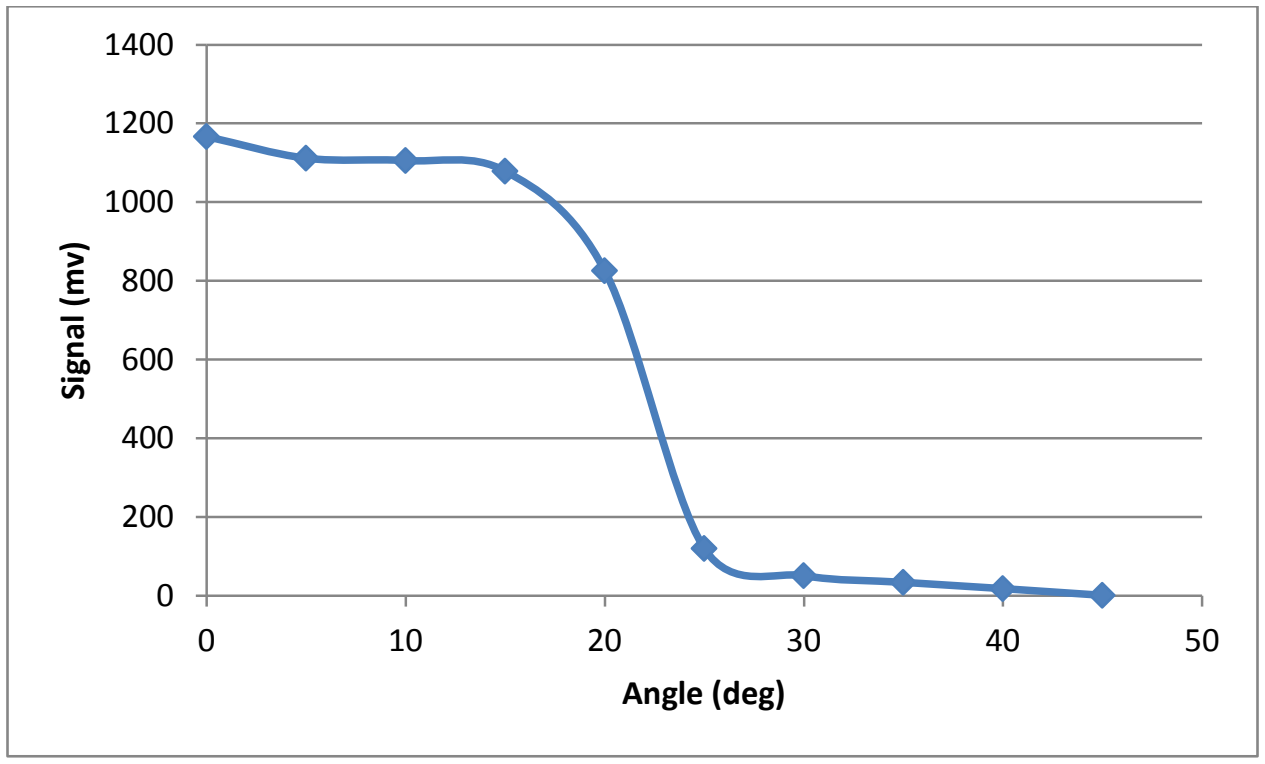

Figure 5-7: Angle of Acceptance Results

\subsection{Sensor Temperature Effects}

A wide variation in signal output, correlated to the ambient temperature measured in the test area, was observed during the particle decay testing which is described in Section 5.5. The product manual for the APDs stated the magnification factor is dependent on temperature with a magnification value of $M=50$ at an ambient temperature of $73^{\circ} \mathrm{F}$ [22]. The product manual did not, however, provide a performance curve based on temperature. When the need to 
classify the performance of the sensors in relation temperature arose, a small test box was constructed from black plastic. A sensor with a blackout cap installed over the sensor element was mounted in the test enclosure. The required power source and signal output wires were installed into the enclosure through black foam material to block ambient light. The output signal from the sensor was recorded and averaged over a 10 minute span. The sensor surface temperature as measured by a noncontact infrared thermometer before and after each test point to ensure accuracy. Figure 5-8 depicts the results from the testing.

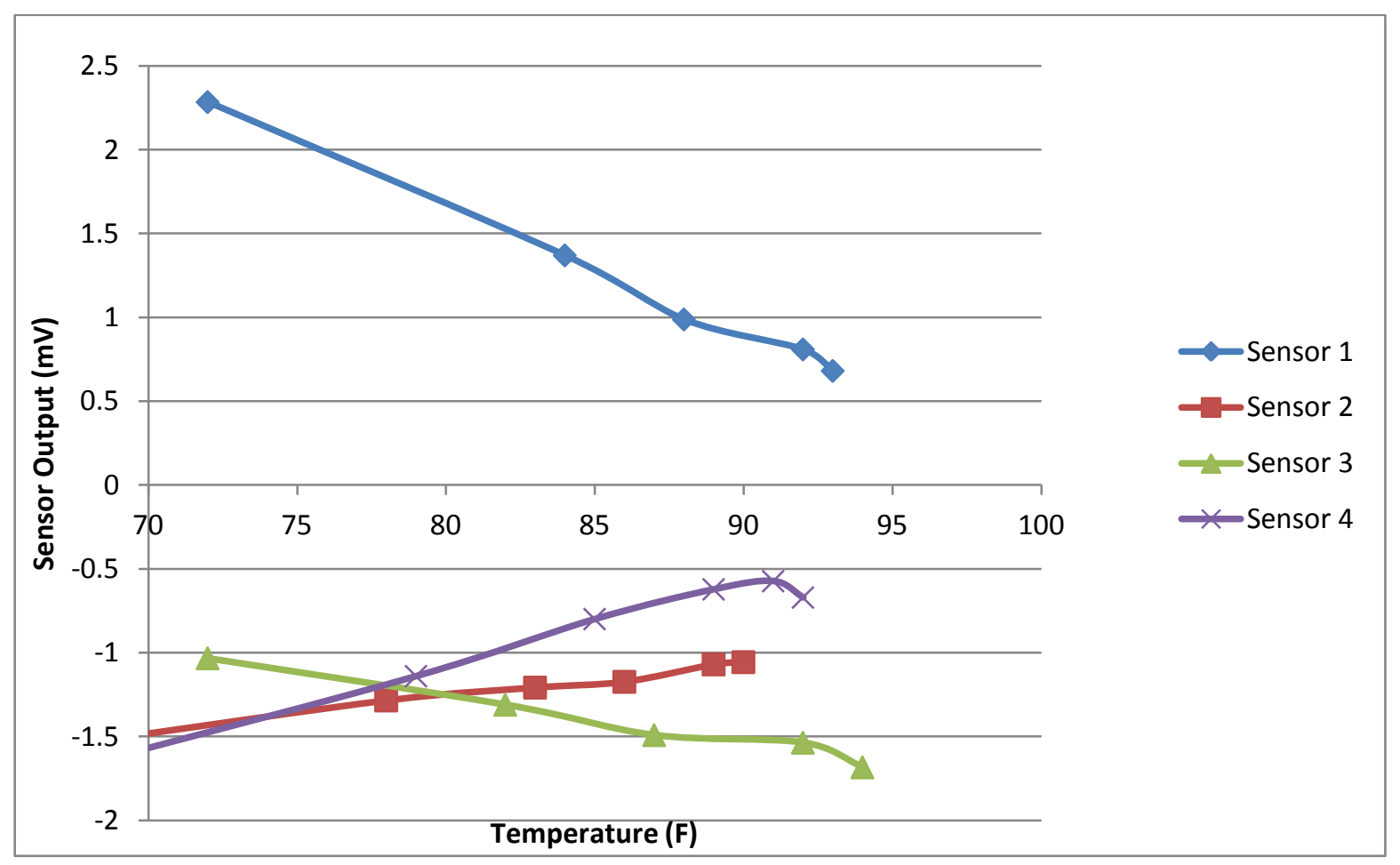

Figure 5-8: APD Temperature Test

As shown in Figure 5-8, the offset voltage of the sensors is greatly affected by temperature. Sensors 2,3, and 4 had a negative offset voltage while Sensor 1 had a positive offset voltage. Some of the results from this test were not expected. Two of the sensors exhibited an increase 
in offset voltage proportional to temperature while the other two sensors show the opposite result. The result in which the data points did not align into a linear trend line was not expected. It was concluded from this testing that strict control of the air temperatures surrounding the sensors was necessary minimize run to run variation.

Data from the decay testing performed with a sensor temperature of $50^{\circ} \mathrm{F}$, which is discussed in Section 5.5, was compared to the data acquired with sensor temperature of $90^{\circ} \mathrm{F}$. The maximum output voltage from a sensor with a surface temperature of $50^{\circ} \mathrm{F}$ exposed to fully irradiated tracer particles was approximately $40 \%$ higher than the same sensor with a surface temperature of 90F. This result is seen in Figure 5-9. Equation 15 was rearranged to create an expression relating the ratio in voltage output to the ratio of the $M$-factors. The $M$-factor for a sensor at $50^{\circ} \mathrm{F}$ was approximated to be $\mathrm{M}=70$. 


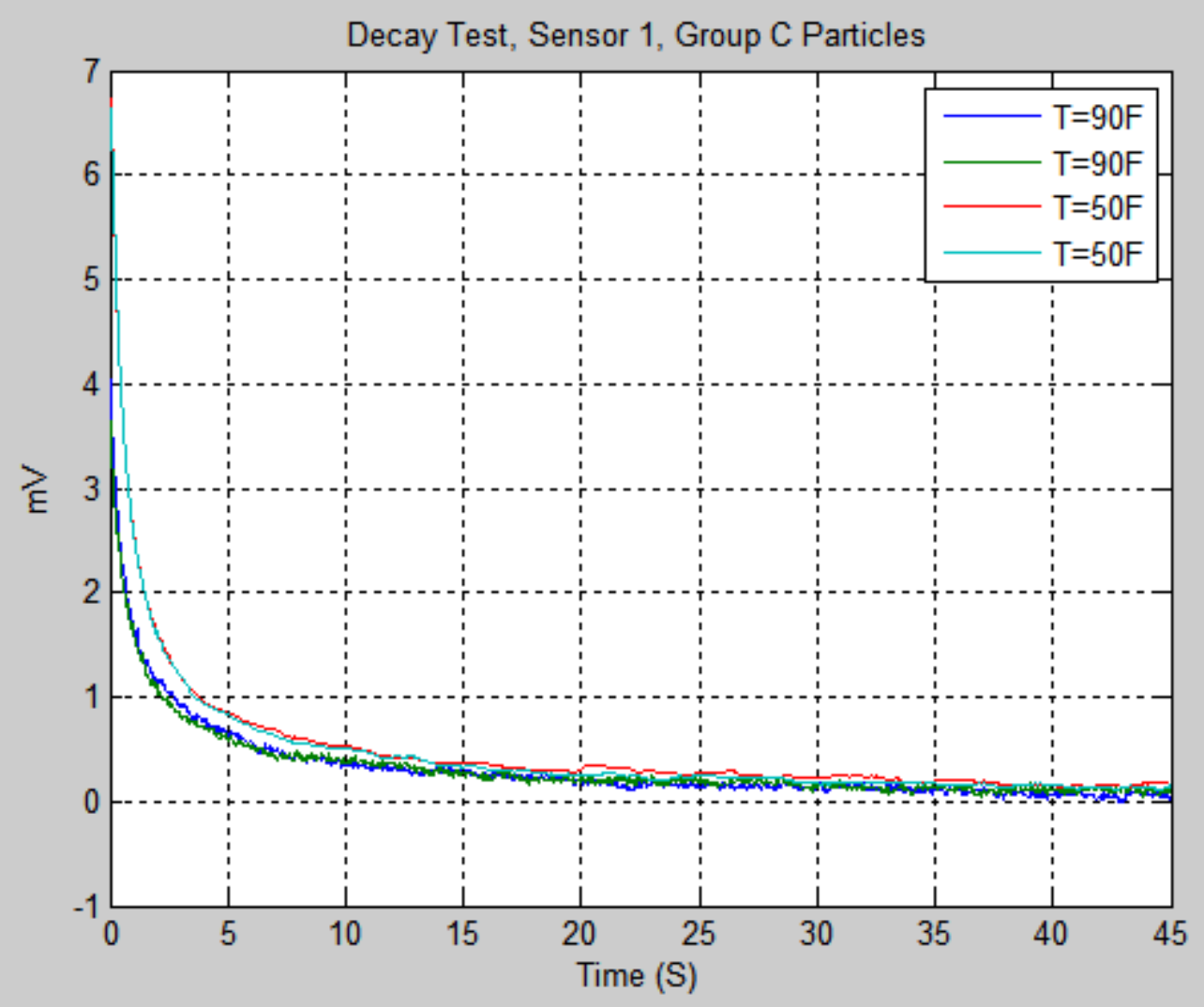

Figure 5-9: Performance Variation Due to Temperature

\subsection{Phosphorescent Decay Testing}

Testing was conducted to determine the decay curves, particle life, and necessary illumination time for the maximum irradiation of the phosphorescent particles. The fluidized illumination hopper was attached to a small support structure. The arrangement included the clear acrylic section, the tracer feed section, the conical section, the Tee pipe fitting with fluidization air port, manual ball valves, and the measurement chamber. The measurement chamber is constructed of a cylindrical threaded pipe section with a removable cap. A hole was bored into the side of the measurement chamber to insert a fiber probe coupled to an APD. This arrangement can be seen in Figure 5-10. Tracer particles were illuminated for a predetermined 
time and then dropped into the measurement chamber by stopping the fluidization air with a valve while simultaneously opening the manual ball valve located below the fluidization air port. The data acquisition started recording a few seconds before the particles were introduced into the measurement chamber.

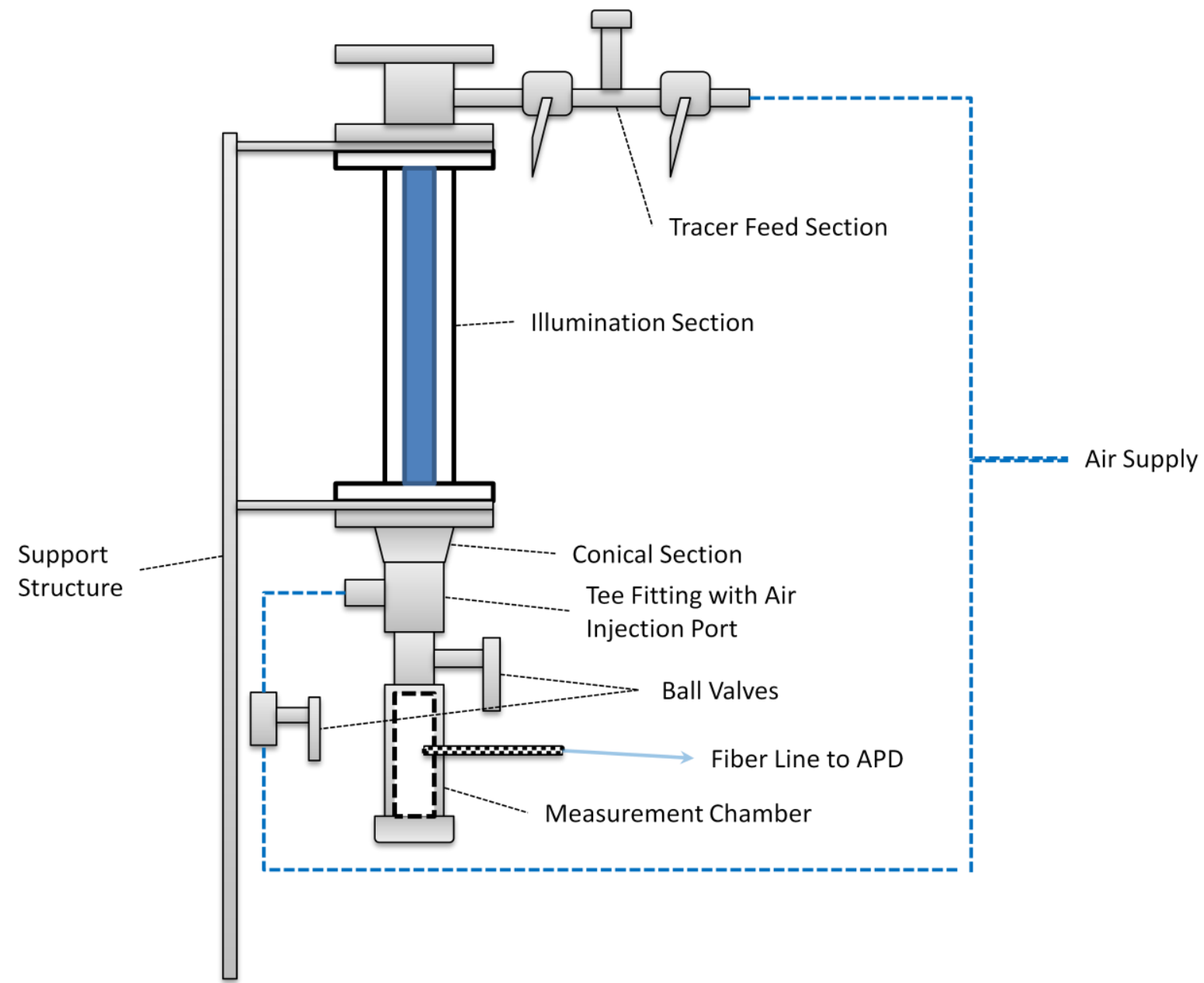

Figure 5-10: General Layout of Apparatus for Phosphorescent Decay Test

The time of illumination was varied to determine the optimal illumination time. Results can be seen in Table 5-1. Peak irradiation of the PPE particles occurred by 120 seconds. 


\section{Table 5-1: Illumination Time Study}

\begin{tabular}{|r|r|}
\hline \multicolumn{2}{|c|}{ Illumination Time Study } \\
\hline $\begin{array}{l}\text { Time } \\
\text { (s) }\end{array}$ & Peak Intensity (mV) \\
\hline 30 & 8.1 \\
\hline 60 & 9.66 \\
\hline 120 & 12.09 \\
\hline 300 & 11.81 \\
\hline 600 & 11.91 \\
\hline
\end{tabular}

The decay curve shown in Figure 5-11 was an averaged curve generated from the decay testing using all four sensors with a surface temperature of $50^{\circ} \mathrm{F}$. The curve fit toolbox of MATLAB was used to generate an appropriate curve fit.

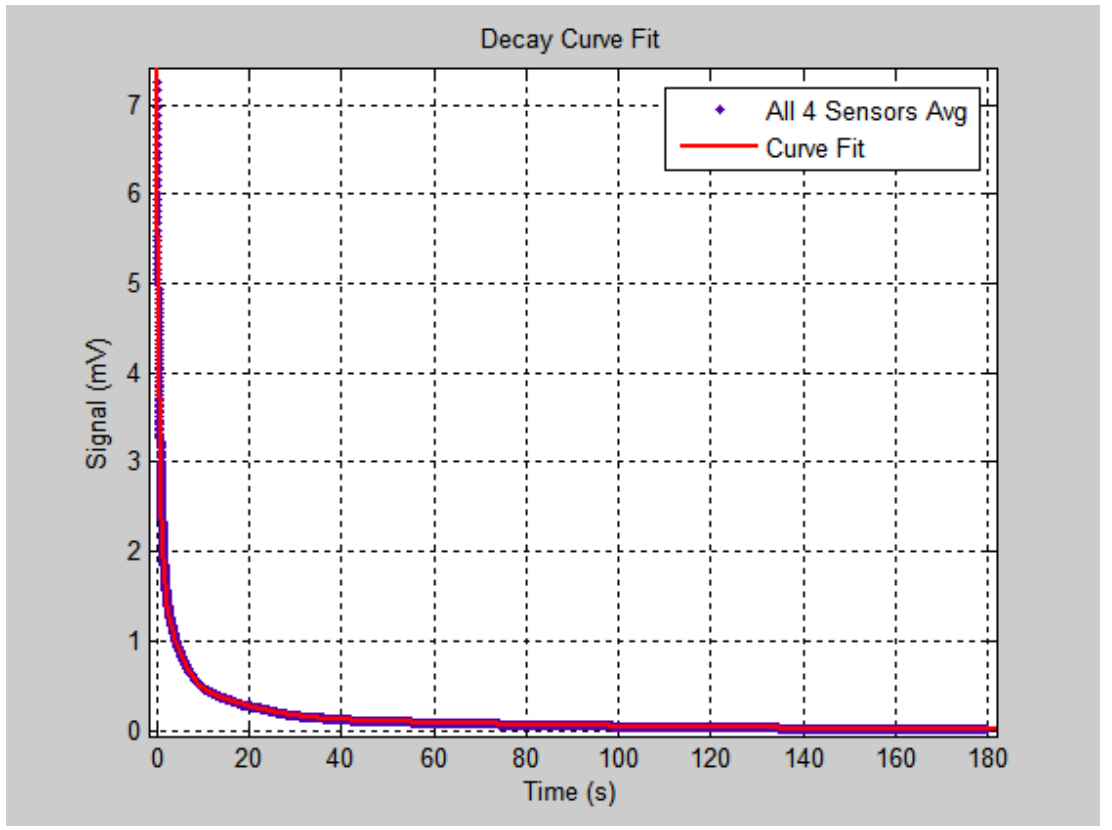

Figure 5-11: Phosphorescent Decay Curve Fit

The following curve fit was generated from the curve fit toolbox of MATLAB: 


$$
\begin{aligned}
& \operatorname{Co}(x)=a 1 * \exp \left(-\left(\frac{x-b 1}{c 1}\right)^{2}\right)+a 2 * \exp \left(-\left(\frac{x-b 2}{c 2}\right)^{2}\right)+a 3 * \exp \left(-\left(\frac{x-b 3}{c 3}\right)^{2}\right)+ \\
& a 4 * \exp \left(-\left(\frac{x-b 4}{c 4}\right)^{2}\right)+a 5 * \exp \left(-\left(\frac{x-b 5}{c 5}\right)^{2}\right)
\end{aligned}
$$

where:

$$
\begin{aligned}
& a 1=7.397 e+010 \\
& b 1=-27.76 \\
& c 1=5.744 \\
& a 2=2.04 \\
& b 2=-5.708 \\
& c 2=0.631 \\
& a 3=0.2712 \\
& b 3=4.097 \\
& c 3=18.35 \\
& a 4=0.1363 \\
& b 4=-0.3238 \\
& c 4=2.337 \\
& a 5=0.447 \\
& b 5=-167.8 \\
& c 5=175.1
\end{aligned}
$$

Many types of curve fits were applied. The curve fit expressed by Equation 16 most accurately recreated the decay curve of the fully illuminated PPE particles. It was expected that an exponential curve fit would provide the most accurate fit, but the Gaussian fit resulted in an $\mathrm{R}^{2}$ value of 0.999 .

\subsection{Dynamic Testing}

A system shown in Figure 5-12 was assembled to determine conditions in which the detection system would be able to detect tracer particles. Two scenarios were considered. The first condition tests the minimum quantity of illuminated tracer particles in the absence of bed material that is required for an adequate signal to be produced by the detection system. The second test considers the minimum ratio of tracer to bed particles that can be effectively 
detected. This particular case simulates the condition of intermixing tracer and bed particles within a fluidized bed system.

A second clear acrylic section and the slide gate valve were installed between the illumination section and the conical distributor section. The operation of the system required that the bed particles to be injected into the system while the slide gate valve was set to the open position. This allows the bed particles to be introduced into the lower section. The slide gate valve was then actuated so that the screen portion of the gate valve separates the acrylic sections allowing for the transfer of gas while blocking the passage of solids. Tracer particles were illuminated in the upper section for 5 minutes and then introduced into the lower section by actuating the slide gate valve to the open position and temporarily lowering the fluidization air flow rate. Fiber probes coupled to APD's were placed $1.5^{\prime \prime}$ and $12^{\prime \prime}$ above the conical section. 


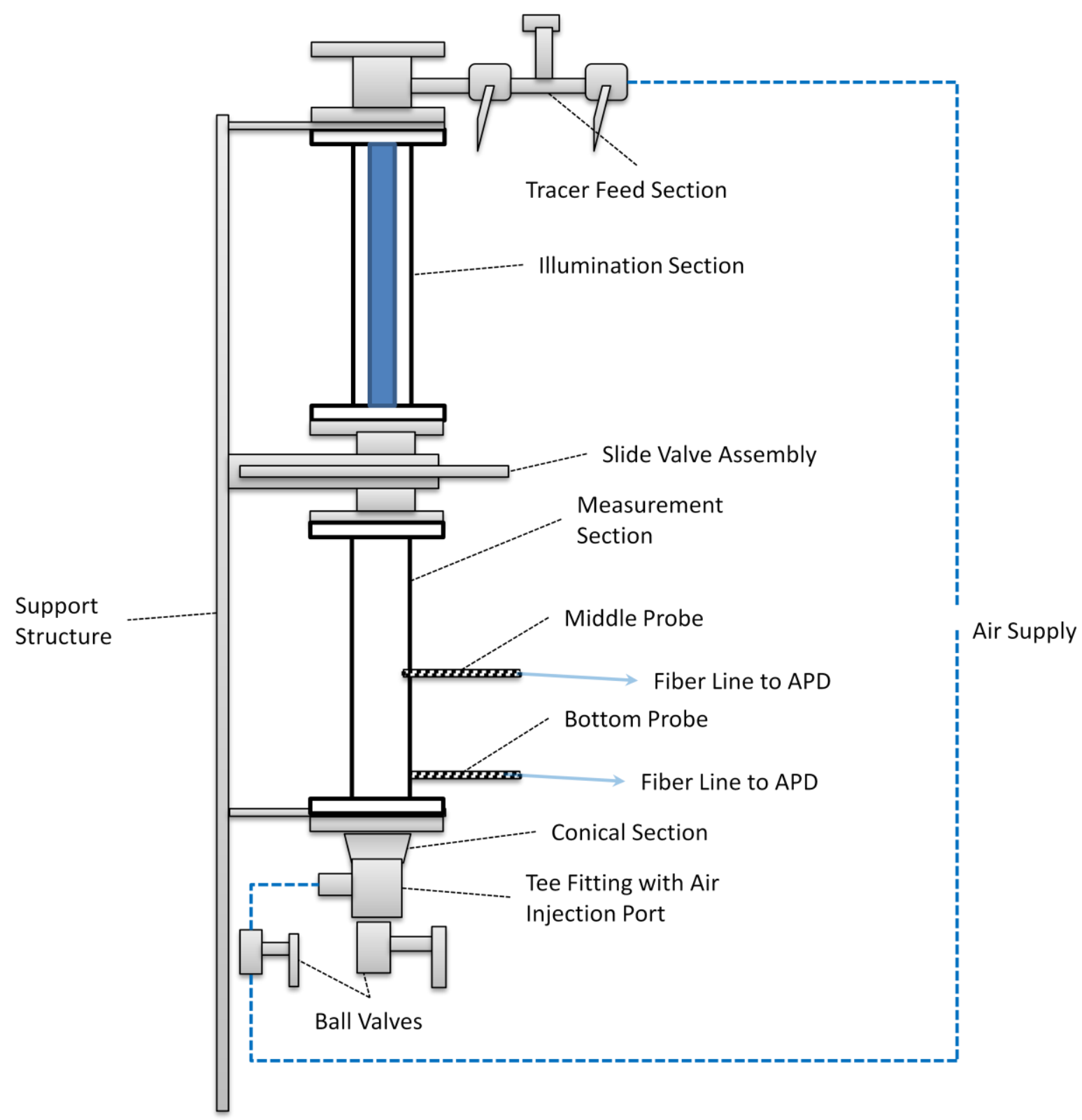

Figure 5-12: General Layout of Apparatus for Dynamic Testing

Table 5-2 contains the test matrix used to determine the minimum ratio of tracer to bed particles which could be detected. Voidage was approximated the total volume of solid material in the system. Concentration is the ratio of the weight of tracer material to the weight of bed 
material. All testing within this section was conducted at a superficial velocity of $U=1.71 \mathrm{~m} / \mathrm{s}$ and at a sensor surface temperature of $50^{\circ} \mathrm{F}$.

Table 5-2: Dynamic Testing Matrix

\begin{tabular}{|r|r|r|r|r|r|}
\hline \multicolumn{1}{|l|}{ Test } & $\begin{array}{l}\text { Tracer } \\
(\mathrm{g})\end{array}$ & \multicolumn{1}{l|}{ Bed(g) } & Concentration & $\begin{array}{l}\text { Volume } \\
\left(\mathrm{cm}^{3)}\right.\end{array}$ & Voidage $(\varepsilon)$ \\
\hline 1 & 100 & 0 & NA & 116.27 & 0.977 \\
\hline 2 & 75 & 0 & NA & 87.21 & 0.983 \\
\hline 3 & 50 & 0 & NA & 58.14 & 0.989 \\
\hline 4 & 25 & 0 & NA & 29.07 & 0.994 \\
\hline 5 & 10 & 0 & NA & 11.62 & 0.998 \\
\hline 6 & 5 & 0 & NA & 5.81 & 0.999 \\
\hline 7 & 100 & 100 & 0.5 & 232.56 & 0.955 \\
\hline 8 & 75 & 125 & 0.375 & 232.56 & 0.955 \\
\hline 9 & 50 & 150 & 0.25 & 232.56 & 0.955 \\
\hline 10 & 25 & 175 & 0.125 & 232.56 & 0.955 \\
\hline 11 & 10 & 190 & 0.05 & 232.56 & 0.955 \\
\hline 12 & 5 & 195 & 0.025 & 232.56 & 0.955 \\
\hline & & & & & \\
\hline
\end{tabular}

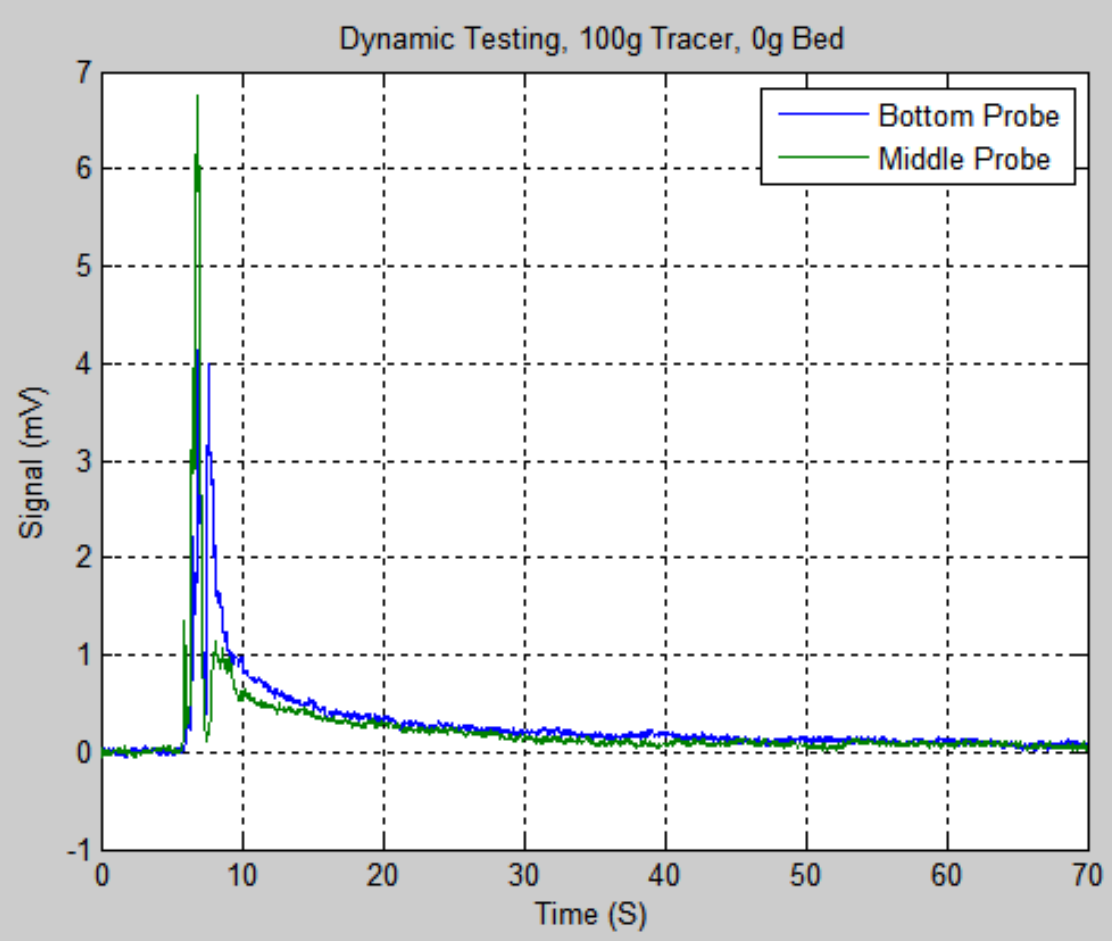

Figure 5-13: Dynamic Test 1, 100g Tracer 


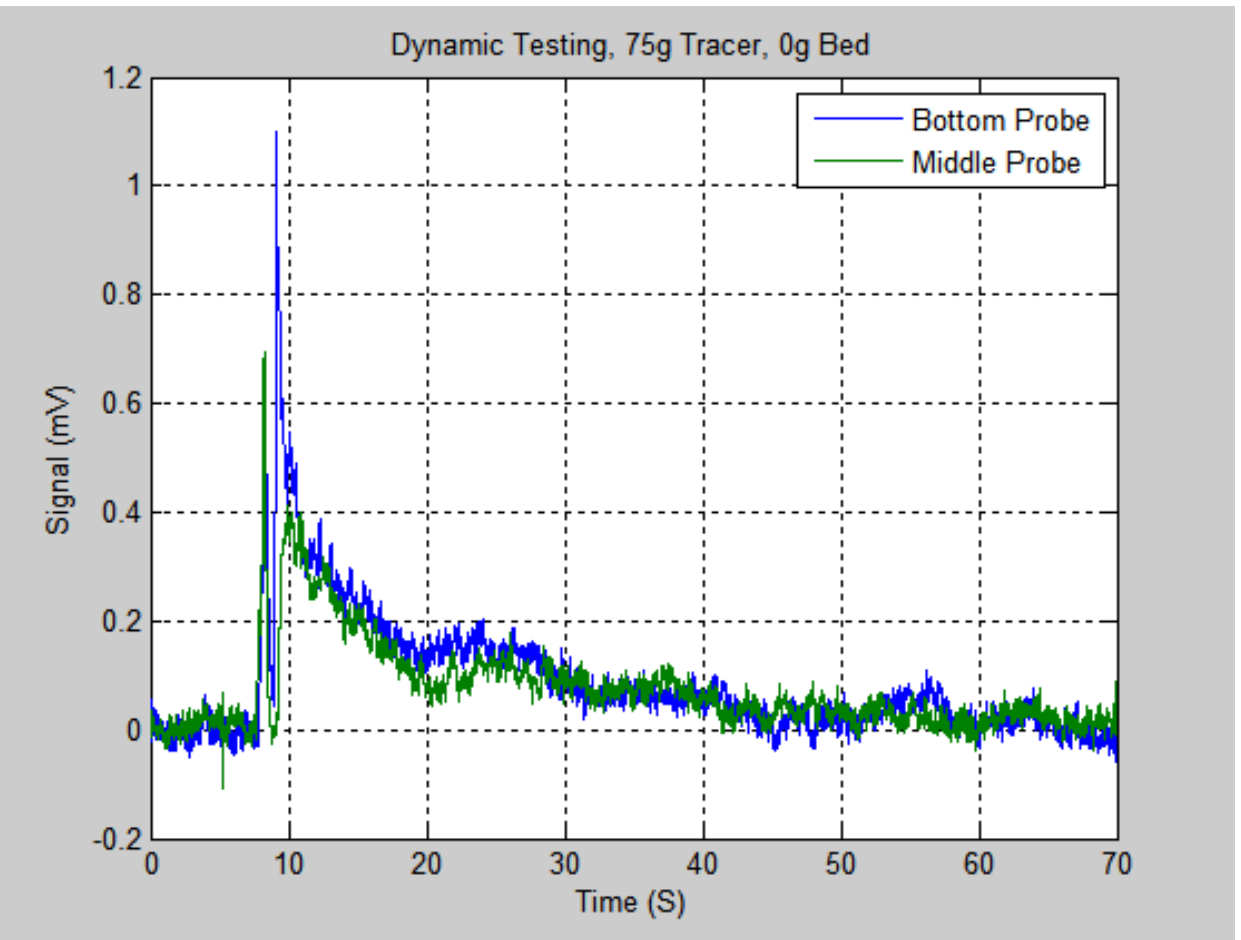

Figure 5-14: Dynamic Test 2, 75g Tracer

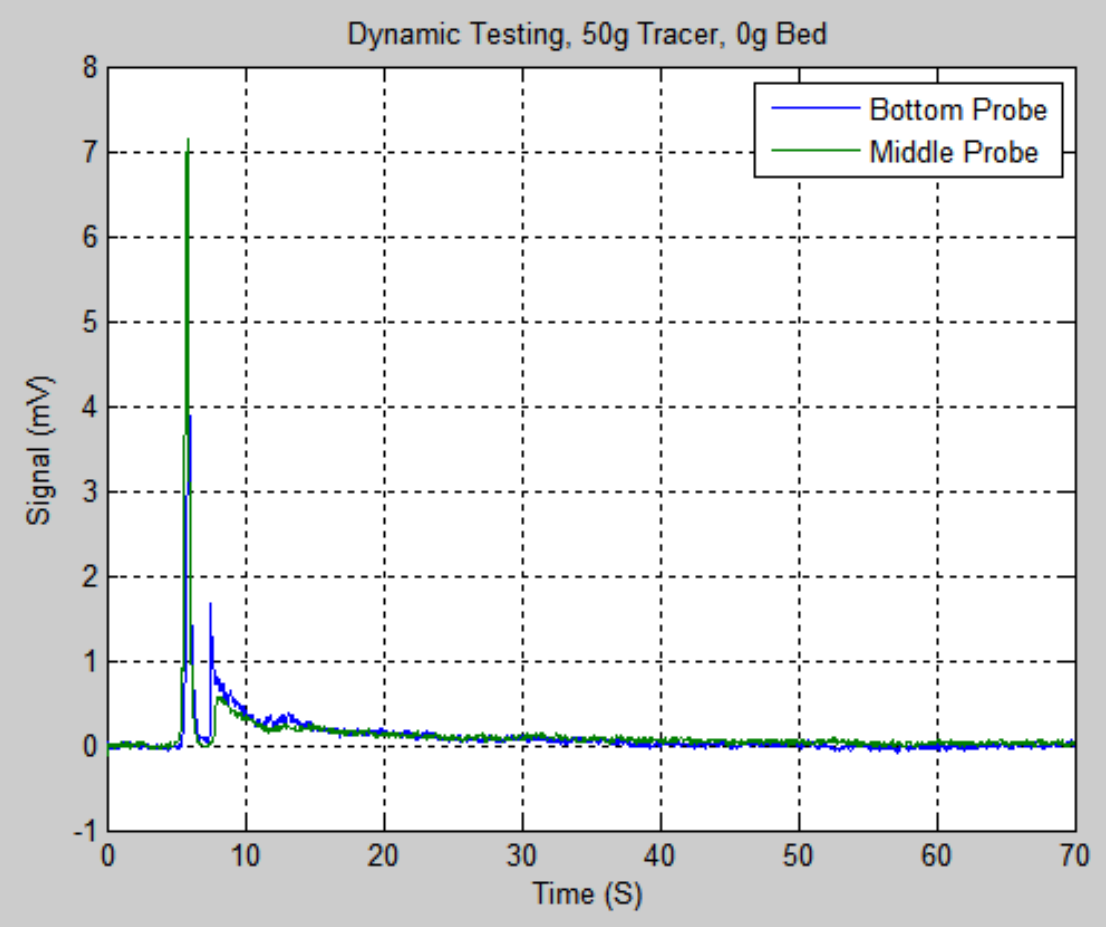

Figure 5-15: Dynamic Test 3, 50g Tracer 


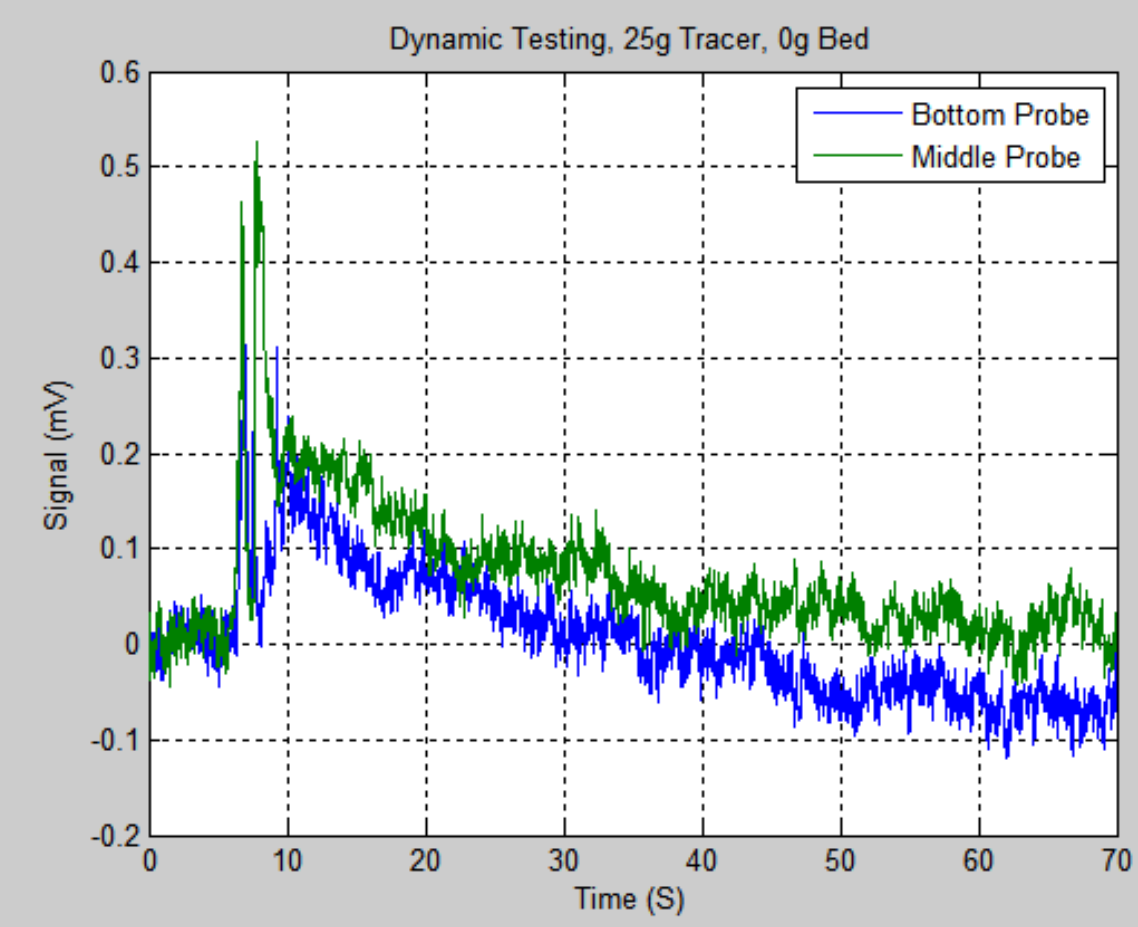

Figure 5-16: Dynamic Test 4, 25g Tracer

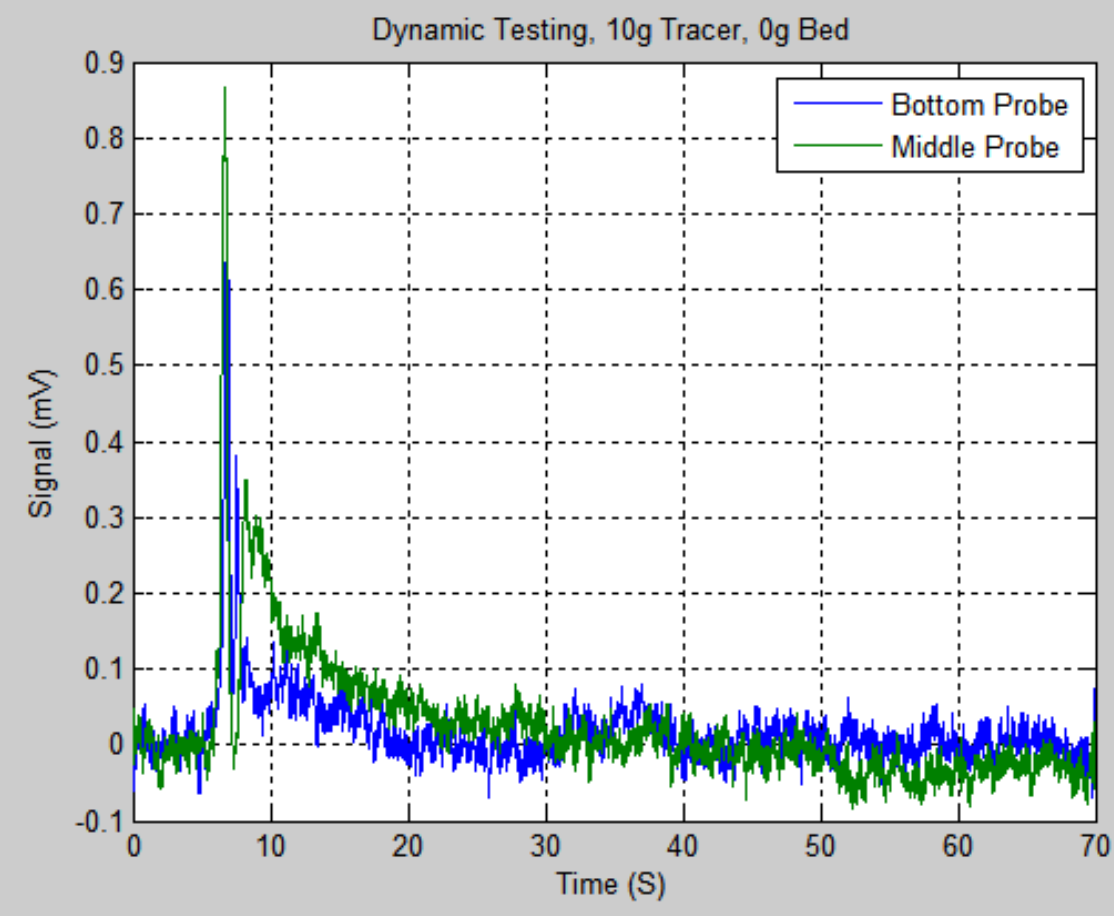

Figure 5-17: Dynamic Test 5, 10g Tracer 


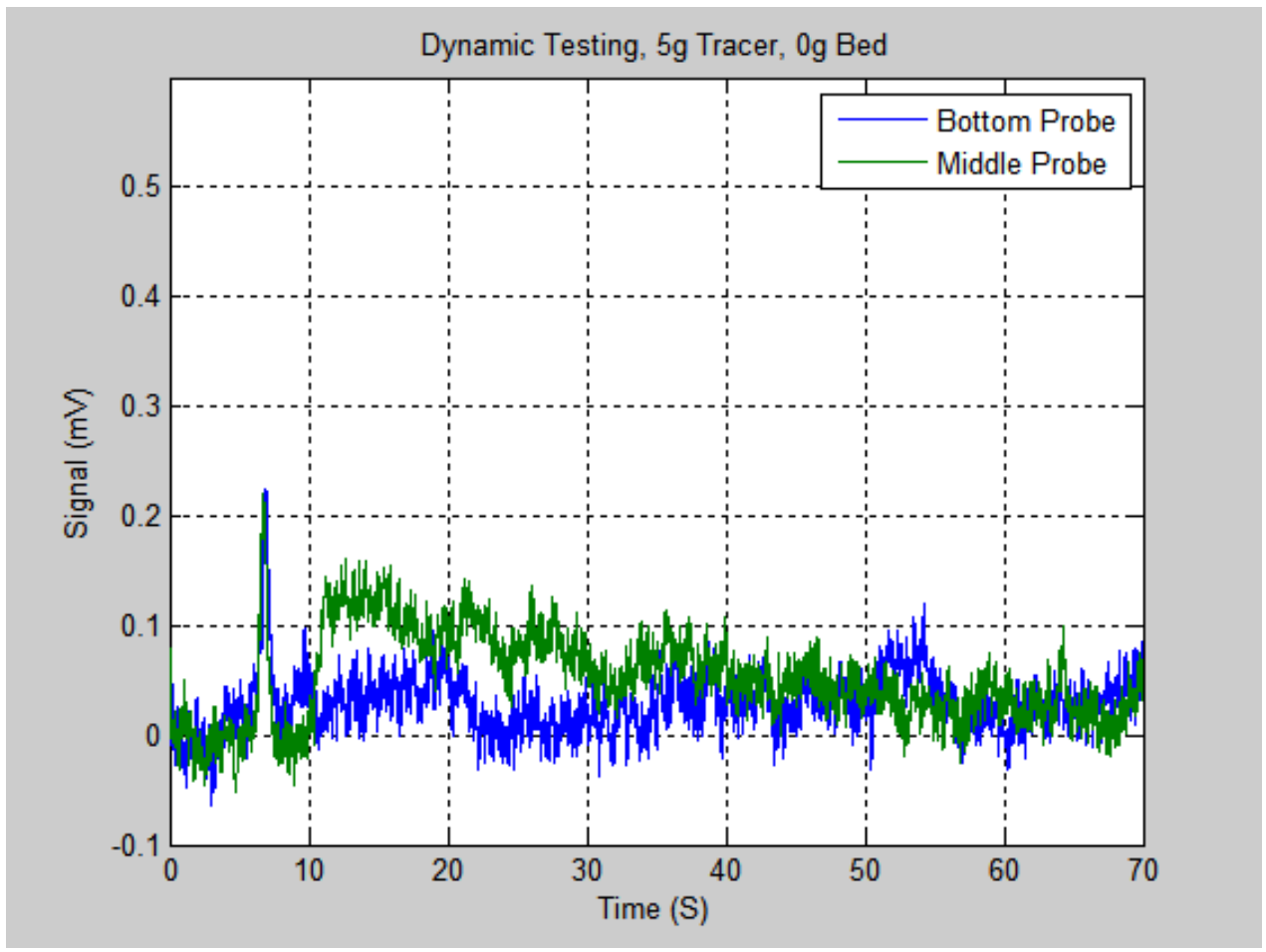

Figure 5-18: Dynamic Test 6, 5g Tracer

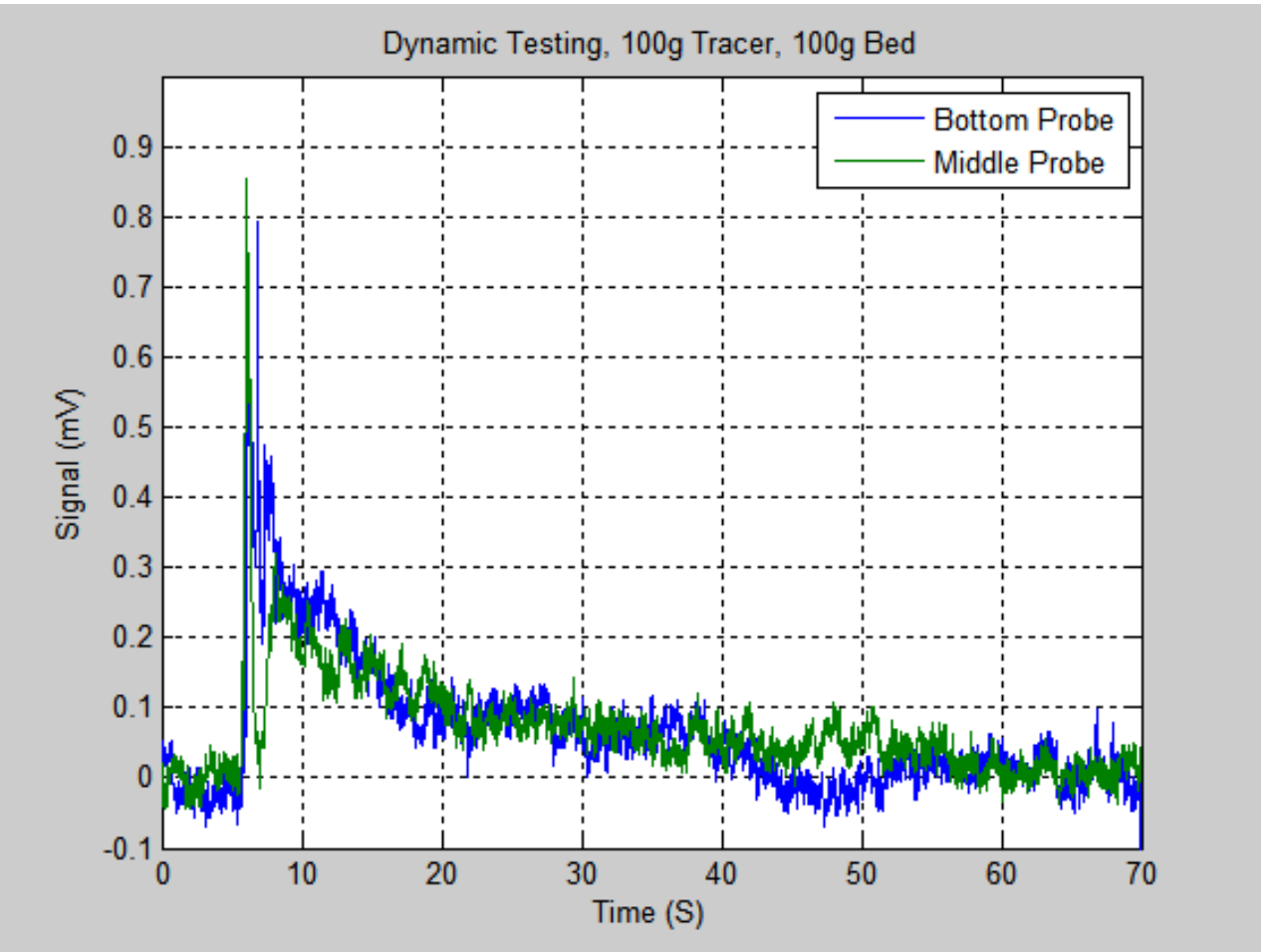

Figure 5-19: Dynamic Test 7, 100g Tracer, 100g Bed 


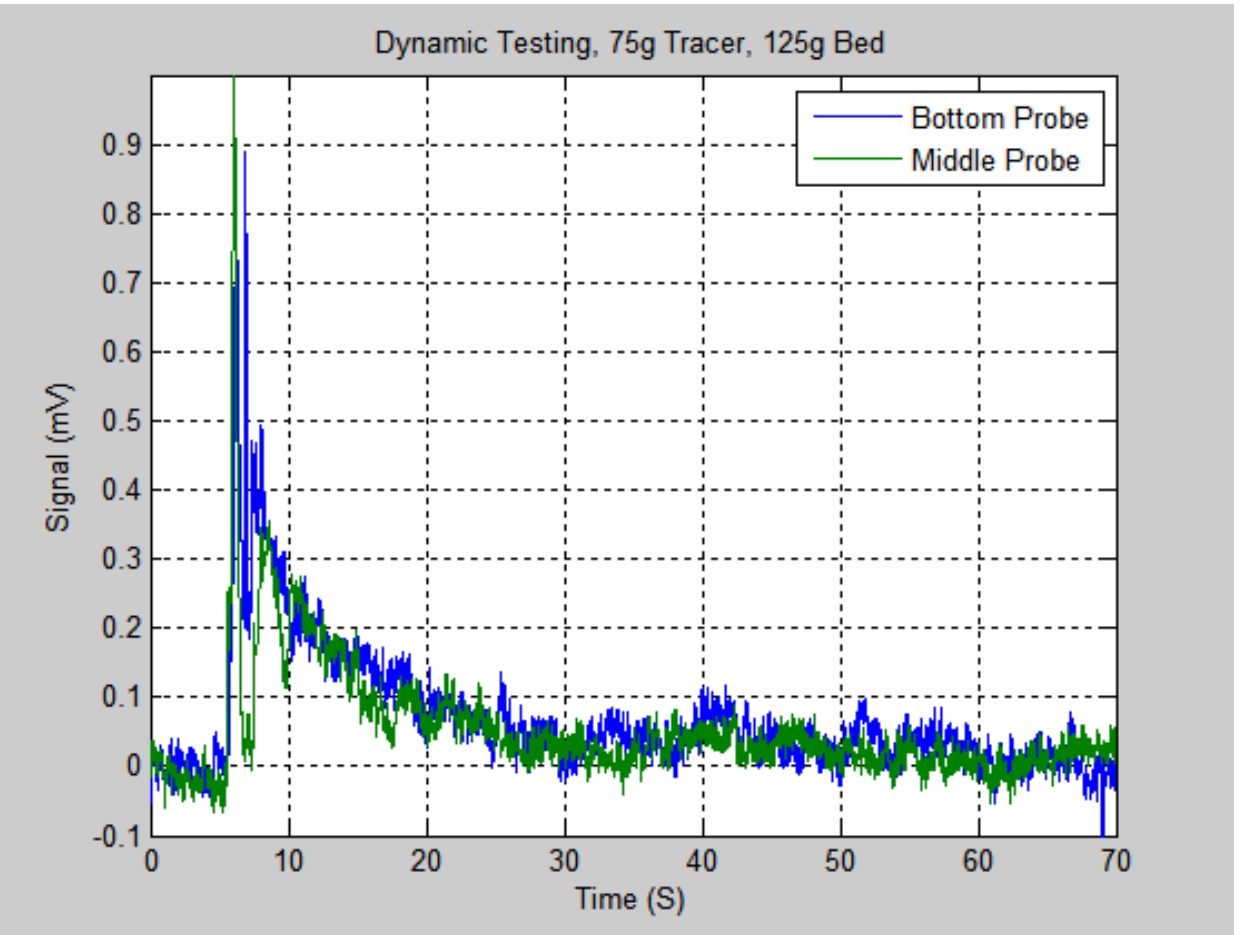

Figure 5-20: Dynamic Test 8, 75g Tracer, 125g Bed

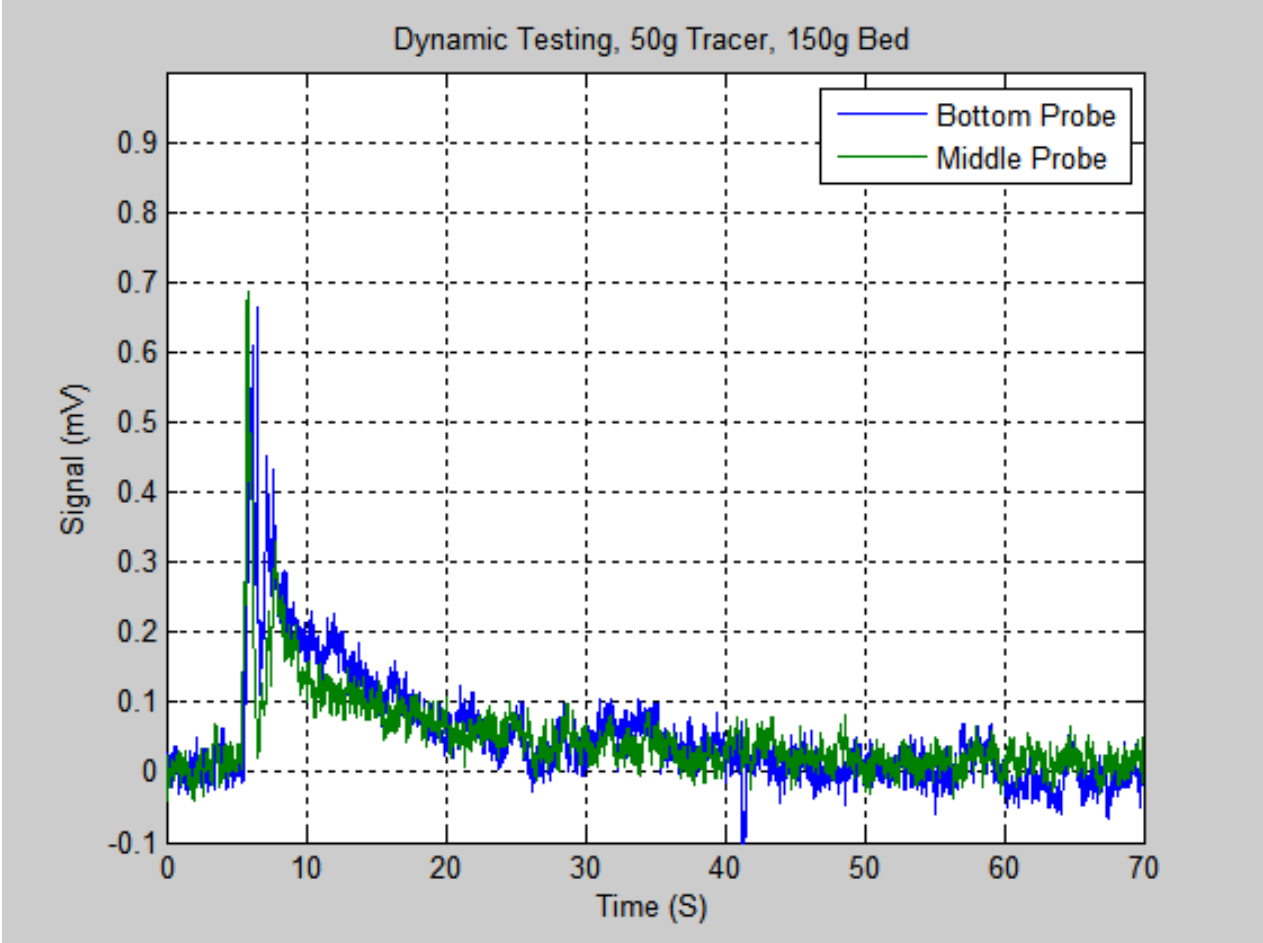

Figure 5-21: Dynamic Test 9, 50g Tracer, 150g Bed 


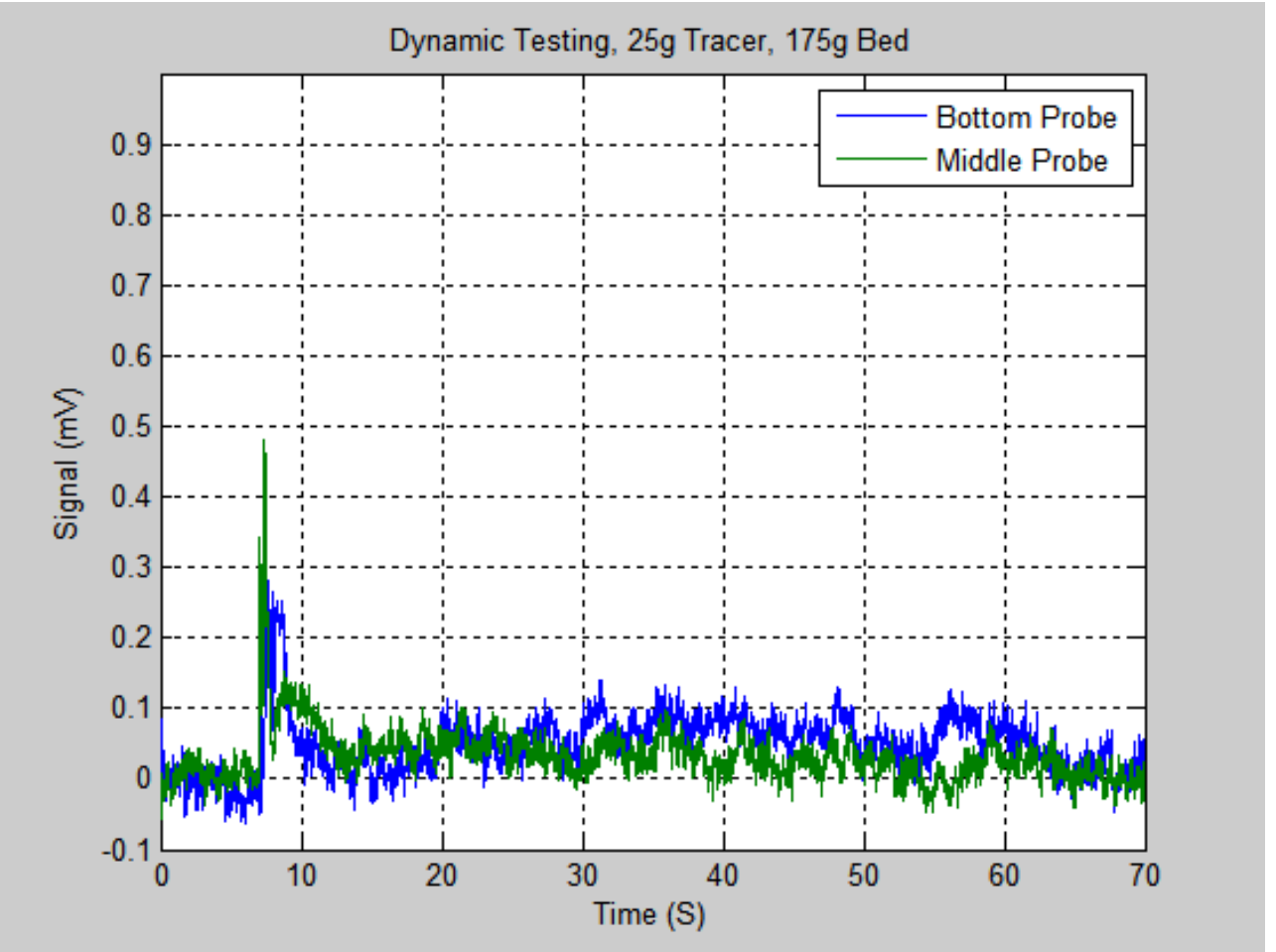

Figure 5-22: Dynamic Test 10, 25g Tracer, 175g Bed

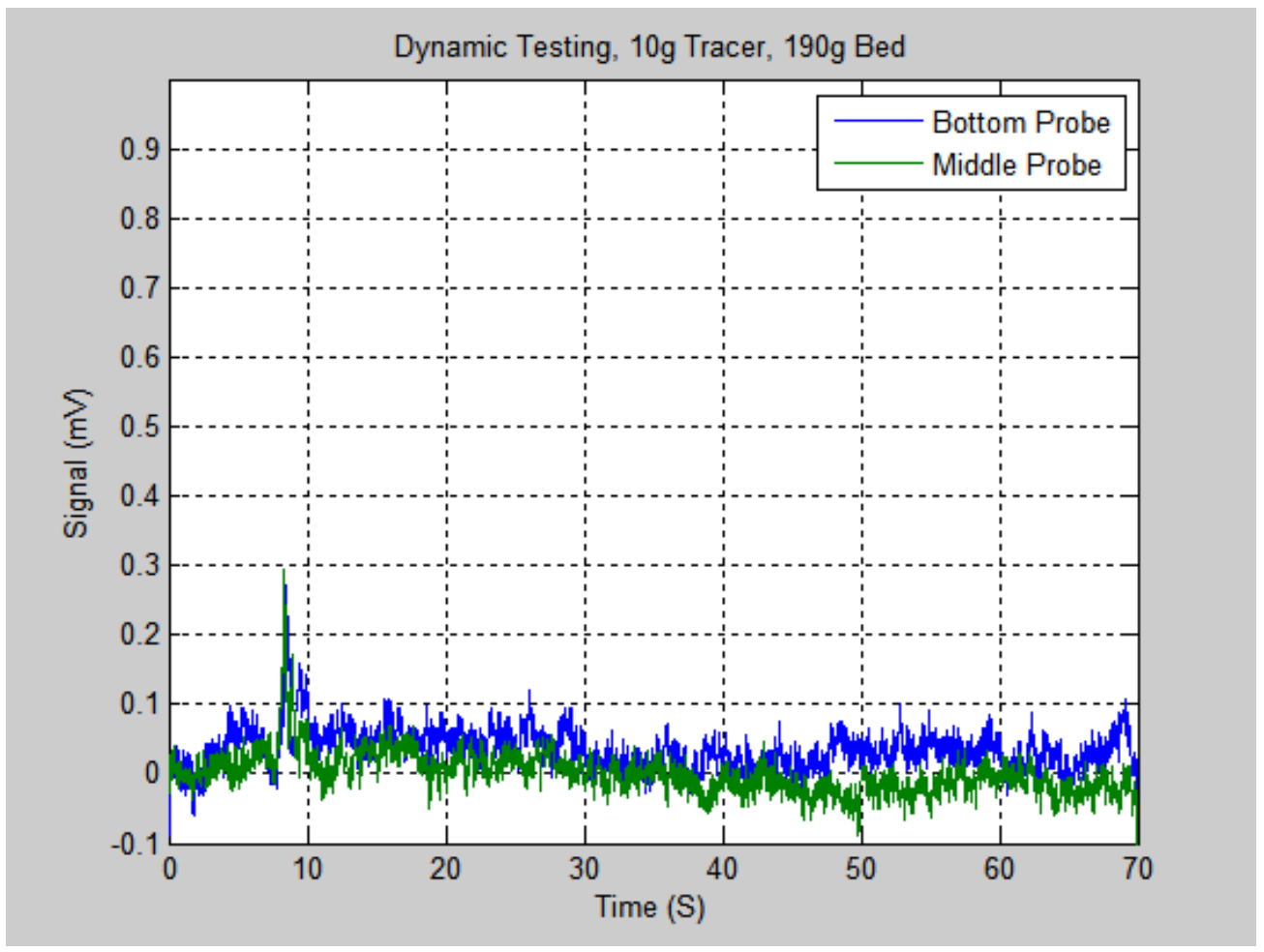

Figure 5-23: Dynamic Test 11, 10g Tracer, 190g Bed 


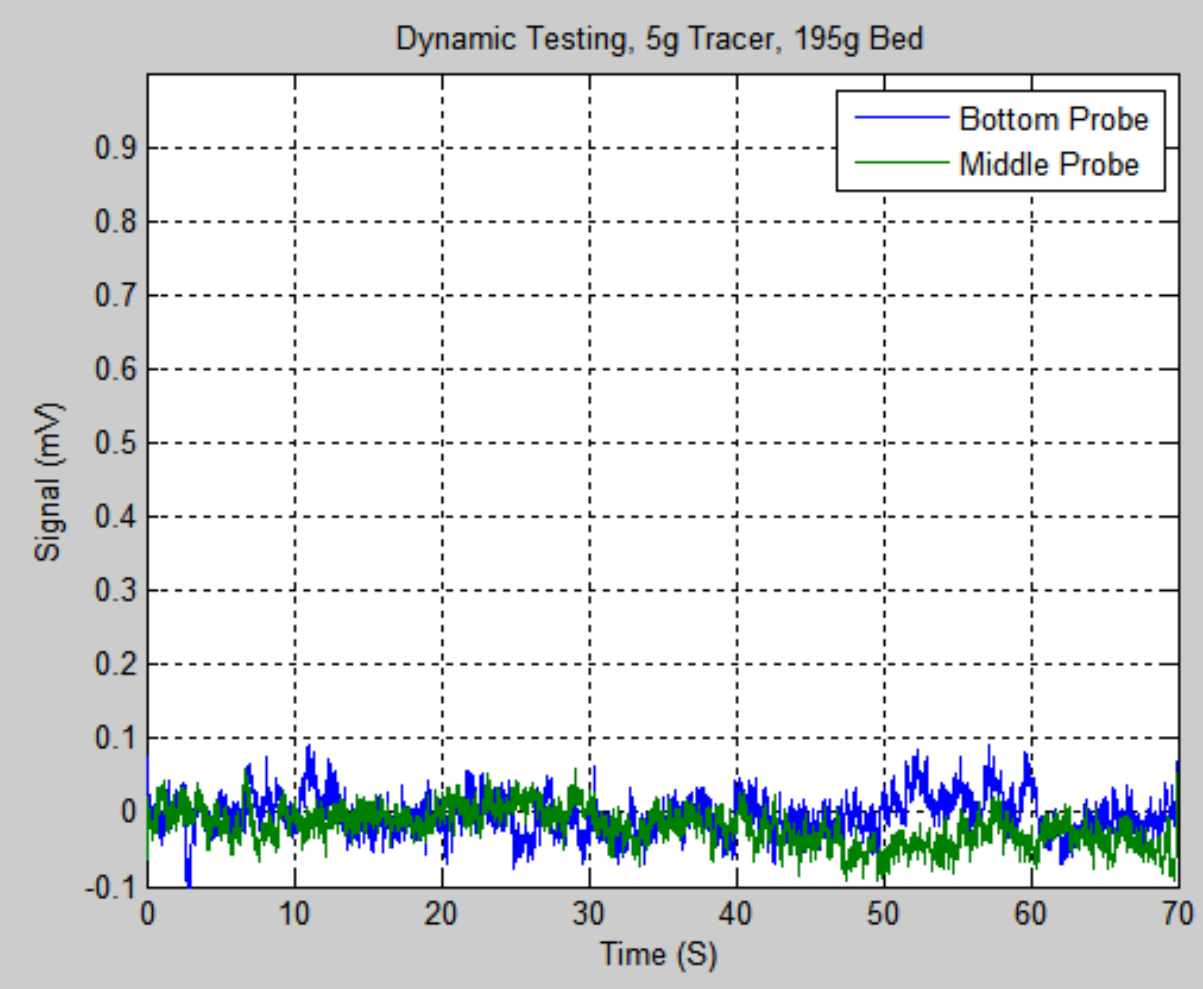

Figure 5-24: Dynamic Test 12, 5g Tracer, 195g Bed

Table 5-3: Dynamic Testing Results

\begin{tabular}{|r|l|r|r|r|r|}
\hline Test & $\begin{array}{l}\text { Detection } \\
(\mathrm{y} / \mathrm{n})\end{array}$ & $\begin{array}{l}\text { Max Signal } \\
\text { Bottom Sensor } \\
(\mathrm{mV})\end{array}$ & $\begin{array}{l}\text { Max Signal } \\
\text { Middle Sensor } \\
(\mathrm{mV})\end{array}$ & $\begin{array}{l}\text { Detection Time } \\
\text { Bottom }(\mathrm{s})\end{array}$ & $\begin{array}{l}\text { Detection Time } \\
\text { Middle (s) }\end{array}$ \\
\hline \hline 1 & $\mathrm{y}$ & 4.1322 & 6.7549 & 49.552 & 28.671 \\
\hline 2 & $\mathrm{y}$ & 1.0987 & 0.6961 & 21.804 & 20.716 \\
\hline 3 & $\mathrm{y}$ & 4.314 & 7.1431 & 17.656 & 17.169 \\
\hline 4 & $\mathrm{y}$ & 0.3748 & 0.5252 & 6.096 & 13.683 \\
\hline 5 & $\mathrm{y}$ & 0.7234 & 0.8668 & 4.859 & 7.25 \\
\hline 6 & $\mathrm{y}$ & 0.2241 & 0.2204 & 0.827 & 1.271 \\
\hline 7 & $\mathrm{y}$ & 0.793 & 0.8537 & 10.289 & 13.72 \\
\hline 8 & $\mathrm{y}$ & 0.8882 & 0.9983 & 12.997 & 9.413 \\
\hline 9 & $\mathrm{y}$ & 0.6631 & 0.6858 & 10.844 & 5.491 \\
\hline 10 & $\mathrm{y}$ & 0.3055 & 0.4792 & 1.486 & 1.797 \\
\hline 11 & $\mathrm{y}$ & 0.2722 & 0.2951 & 1.179 & 0.832 \\
\hline 12 & $\mathrm{n}$ & 0.0835 & 0.1062 & 0 & 0 \\
\hline
\end{tabular}


The results for the dynamic testing can be seen in Table 5-3 and Figure 5-13 trough Figure 5-24. Detection of the afterglow emitted from the phosphorescing particles was achieved in this scale experiment. Detection, in the absence of bed material, was achieved with 5 grams of tracer particles at a voidage of 0.999 . Detection was achieved at a mixture containing $5 \%$ tracer particles in the ratio test.

As seen in Figure 5-15, detection of the downward traveling tracer particles occurs first at the middle probe location followed by the probe at the lower location as the tracer particles fell from the upper illumination hopper. After the initial signal spike at each location, the signal sharply dropped corresponding to the particles fully passing the detection probes while the fluidization air was shut off. The next peak represents the time at which the fluidization air is reapplied, and the tracer particles are expelled upward into the view of the detection probes. Detection of the upward traveling tracer particles occurs first at the lower probe location followed by the probe at the middle location. After this secondary peak, the curves clearly exhibit the decay curve function as the tracer particles lose intensity.

\subsection{Effect of Signal Noise on Concentration Curves}

It was stated in the product manual for the APD sensors that the value of output sensor noise is approximately $1.5 \mathrm{mV}_{\mathrm{RMS}}$ [22]. A signal analysis was completed for each sensor with blackout caps installed. The maximum value of signal noise recorded was $0.1 \mathrm{mV}$ when the data is processed using a 5 point moving average filter which is used for the data processing of all signals within this study. Any recorded value below this threshold was considered noise. 
To further reduce the signal noise, low pass filters with cutoff frequencies of $1500 \mathrm{~Hz}$ were placed between the sensors and the data acquisition system. In section 5.5, the curve fit for the intensity decay of the tracer particles was created. The curve intersects the $0.1 \mathrm{mv}$ threshold at approximately 23 seconds. This limits the useful particle life of the phosphorescent to 23 seconds due to the limitations of the detection system caused by signal noise.

The useful time is further decreased when an accuracy of $10 \%$ is required. Data from sensors with blackout caps installed was used in the creation of Figure 5-25. The decrease of the value $C_{0}(t)$ with time causes the amplification of signal noise $C(t)$ for the calculation of the dimensionless concentration curve $C / C_{0}$. Figure 5-25 demonstrates this effect. The threshold value $C / C_{0}=0.1$ is exceeded before a time of 8 seconds and the value of $C / C_{0}=0.2$ is exceeded before a time of 14 seconds. Due to this effect, plots of both signal $C(t)$ expressed in $\mathrm{mV}$ and the dimensionless concentration $C / C_{0}$ are provided in Chapter 6 

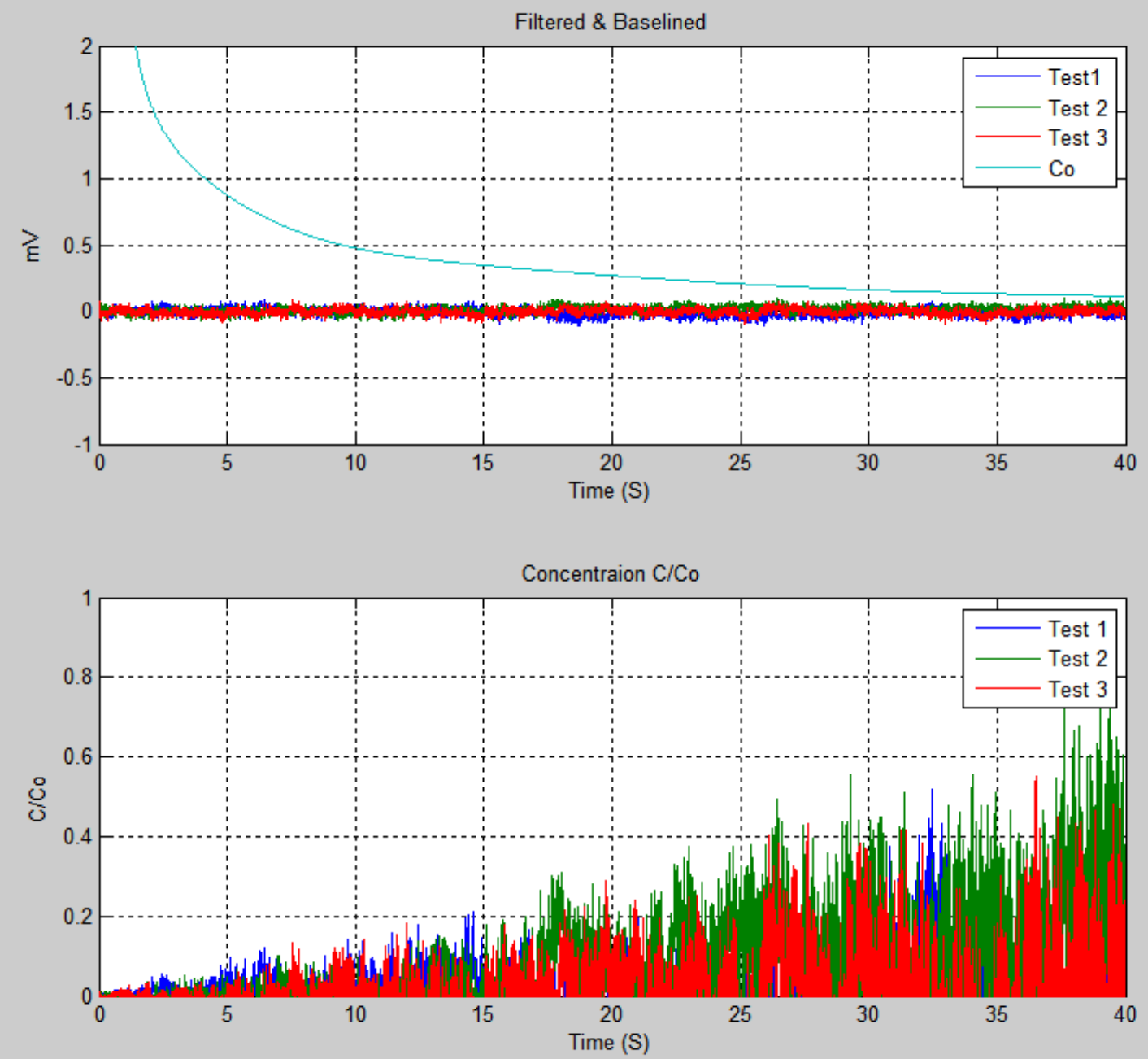

Figure 5-25: Effect of Signal Noise on Concentration Curve 


\section{Chapter 6 Results}

\subsection{Illumination System Performance}

The illumination system was designed for the uniform illumination of the phosphorescent particles. The claim for uniform illumination was substantiated by building a small test apparatus as seen in Figure 6-1 for the measurement of intensity of the particles. The testing was done in somewhat the same way as the decay testing where the particles are illuminated for a set time and dropped into a chamber for measurement after being illuminated for 5 minutes. The testing differed in that the measurement probe was inserted into the test chamber vertically through the bottom cap and the height was varied. The Arduino Uno control unit, pneumatic ball valve, and fluidization air solenoid were utilized for this test to produce consistent results. 


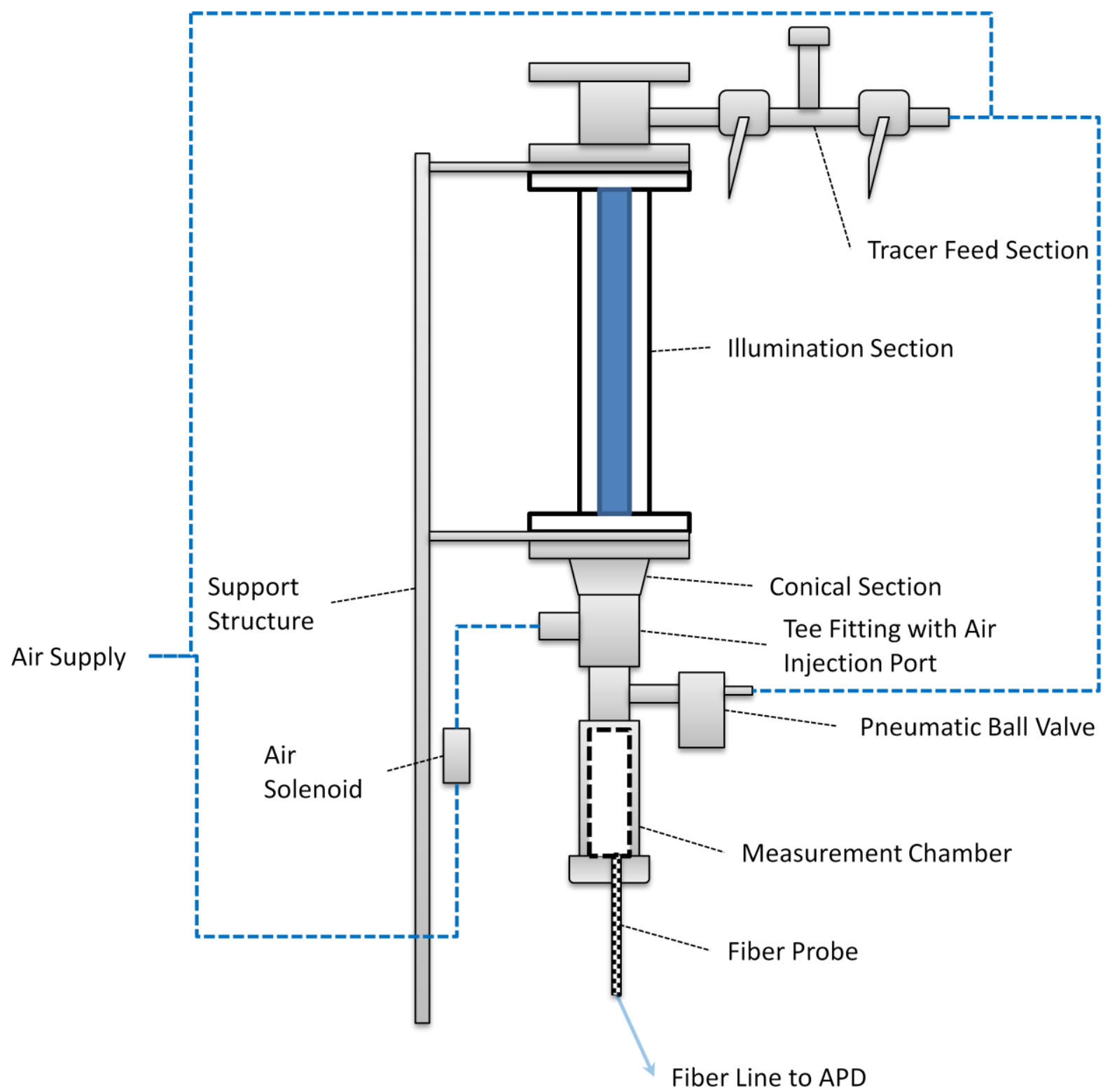

Figure 6-1: General Layout of System for Illumination Uniformity Test

The heights measured were $h=0-3.5^{\prime \prime}$ in $1 / 2$ " increments above the bottom cap of the measurement chamber. The test was performed 5 times at each height. The signal intensity at each height was measured and recorded 1.5 seconds after the fluidizing air was shut off. The delay in measurement was established so the value at each test location would not be affected 
by the tracer particles falling past the probe to lower heights within the measurement chamber. Statistical analysis of the maximum intensity value was performed to find the mean intensity and signal standard deviation. The mean value was calculated to be $4.28 \mathrm{mV}$ with a sample standard deviation of $\mathrm{s}=0.94 \mathrm{mV}$. The average signal value at each height is shown in Table 6-1. Table 6-1 shows that the particles measured at the lower portions of the test chamber had the lowest mean value followed by the location $h=0.5^{\prime \prime}$. This shows that there is a variation in the uniformity of illumination.

Table 6-1: Illumination Uniformity Test Results

\begin{tabular}{|r|r|}
\hline $\begin{array}{l}\text { Height } \\
\text { (in) }\end{array}$ & $\begin{array}{l}\text { Mean } \\
\text { Value } \\
\text { (mV) }\end{array}$ \\
\hline 3.5 & 4.27 \\
\hline 3 & 4.62 \\
\hline 2.5 & 5.21 \\
\hline 2 & 4.65 \\
\hline 1.5 & 4.56 \\
\hline 1 & 4.50 \\
\hline 0.5 & 3.62 \\
\hline 0 & 2.45 \\
\hline
\end{tabular}

The low values experienced at the lower portion of the measurement chamber were attributed to the volume of the conical section below the illumination black light. As tracer particles circulate into this area, they are no longer exposed to the irradiation light source. When the fluidization air is stopped, the solids contained within this volume fall through the conical section and end up in the lower portion of the measurement chamber. 


\subsection{Injection Unit Performance}

The injection unit performance was evaluated by the slide actuation time and particle injection time as measured by the optical sensor at the riser exit. The actuation time of the slider is a function of pressure applied to the air actuators. The actuation time is decreased with an increase of pressure, but, as a tradeoff, the increased pressure also increases momentum of the slider. With the current design, a decrease in actuation time cannot be achieved without risking damage to the threaded standoffs on the slider.

The line connected to the air actuation system was pressured to 60 psi to provide the optimal balance between actuation time and longevity. Actuation time was measured from video recordings of the slide actuation process. The video files were opened in video editing software where the video was manually manipulated on a frame-by-frame basis. The timestamp of the frame previous to the slide movement was recorded, and the timestamp of the frame where motion could no longer be detected was also recorded. The differences between the timestamps are shown in Table 6-2. 
Table 6-2: Slide Actuation Time. No Tracer Particles. 60 psi Pressurization

\begin{tabular}{|r|r|r|}
\hline \multicolumn{3}{|c|}{ Slide Actuation Time } \\
\hline Test & Down (s) & Up (s) \\
\hline 1 & 0.13 & 0.13 \\
\hline 2 & 0.10 & 0.13 \\
\hline 3 & 0.10 & 0.13 \\
\hline 4 & 0.14 & 0.13 \\
\hline 5 & 0.13 & 0.13 \\
\hline 6 & 0.14 & 0.13 \\
\hline 7 & 0.10 & 0.13 \\
\hline 8 & 0.09 & 0.14 \\
\hline 9 & 0.14 & 0.16 \\
\hline 10 & 0.10 & 0.13 \\
\hline Average & $\mathbf{0 . 1 2}$ & $\mathbf{0 . 1 3}$ \\
\hline
\end{tabular}

The injection time as measured by the optical detection probe placed in the pneumatic transport crossover just before the riser entrance. The time injection time was calculated by subtracting the time at which the particles were first detected by the sensor, $t_{1}$, from the time at which the tracer particles were no longer detected, $t_{2}$. Two tests were performed. The first was performed at conditions expected during full system testing with $30 \mathrm{~g}$ of tracer and 10.3 $\mathrm{m} / \mathrm{s}$ air velocity in the pneumatic transport line. The velocity was dropped to $8.9 \mathrm{~m} / \mathrm{s}$ for one set of testing to determine the effect of injection time due to decreased velocity. 
Table 6-3: Injection Time Study 1

\begin{tabular}{|c|c|c|c|}
\hline \multicolumn{4}{|c|}{ Injection Time Study } \\
\hline Air Velocity $(\mathrm{m} / \mathrm{s})$ & Sample Size (g) & $\begin{array}{l}\text { Solids Feed Rate } \\
(\mathrm{lb} / \mathrm{m})\end{array}$ & $t_{2}-t_{1}(s)$ \\
\hline 8.9 & 30 & 0 & 0.605 \\
\hline 8.9 & 30 & 0 & 0.731 \\
\hline 8.9 & 30 & 0 & 0.738 \\
\hline 8.9 & 30 & 0 & 0.696 \\
\hline \multirow[t]{2}{*}{8.9} & 30 & 0 & 0.682 \\
\hline & & Average & 0.6904 \\
\hline 10.4 & 30 & 0 & 0.599 \\
\hline 10.4 & 30 & 0 & 0.631 \\
\hline 10.4 & 30 & 0 & 0.622 \\
\hline 10.4 & 30 & 0 & 0.597 \\
\hline \multirow[t]{2}{*}{10.4} & 30 & 0 & 0.602 \\
\hline & & Average & 0.6102 \\
\hline 10.4 & 30 & 1 & 0.931 \\
\hline 10.4 & 30 & 1 & 0.913 \\
\hline 10.4 & 30 & 1 & 0.964 \\
\hline 10.4 & 30 & 1 & 0.825 \\
\hline \multirow[t]{2}{*}{10.4} & 30 & 1 & 1.007 \\
\hline & & Average & 0.948 \\
\hline
\end{tabular}

A second set of testing was performed to characterize the performance of the injection system based on the sample size and a set flow rate. The Delrin ${ }^{\circledR}$ bushing reducing the bore size of the slider from 2" to $3 / 4$ " was constructed with and internal volume holding approximately $50 \mathrm{~g}$ of PPE tracer material. The test was performed at an air velocity of $10.3 \mathrm{~m} / \mathrm{s}$ in the pneumatic transport line. Three test runs were measured and averaged at each test sample weight size. Figure 6-2 shows the effect of tracer quantity on the injection time. A linear trend can be seen from a sample size ranging from $10 \mathrm{~g}$ to $50 \mathrm{~g}$. Beyond the $50 \mathrm{~g}$ sample size, the injection time begins increasing exponentially. 


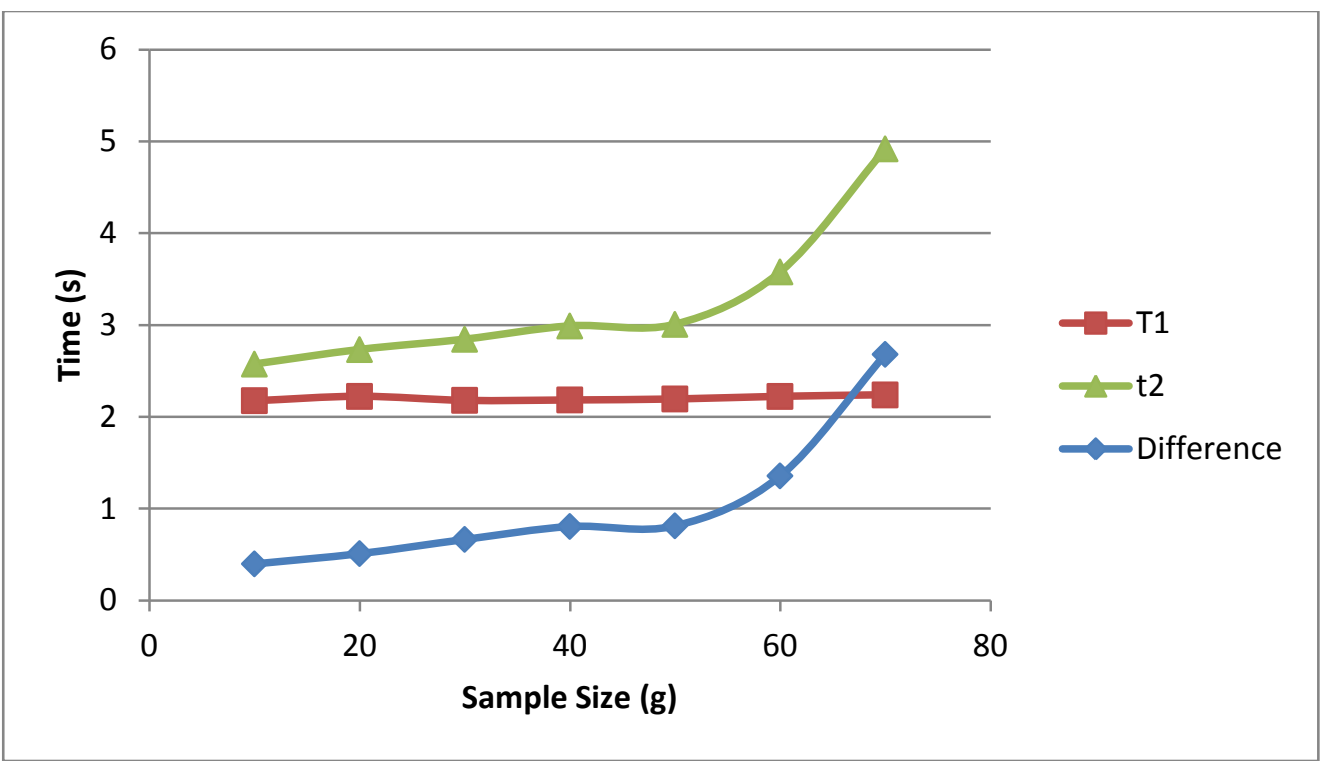

Figure 6-2: Injection Time Study 2 

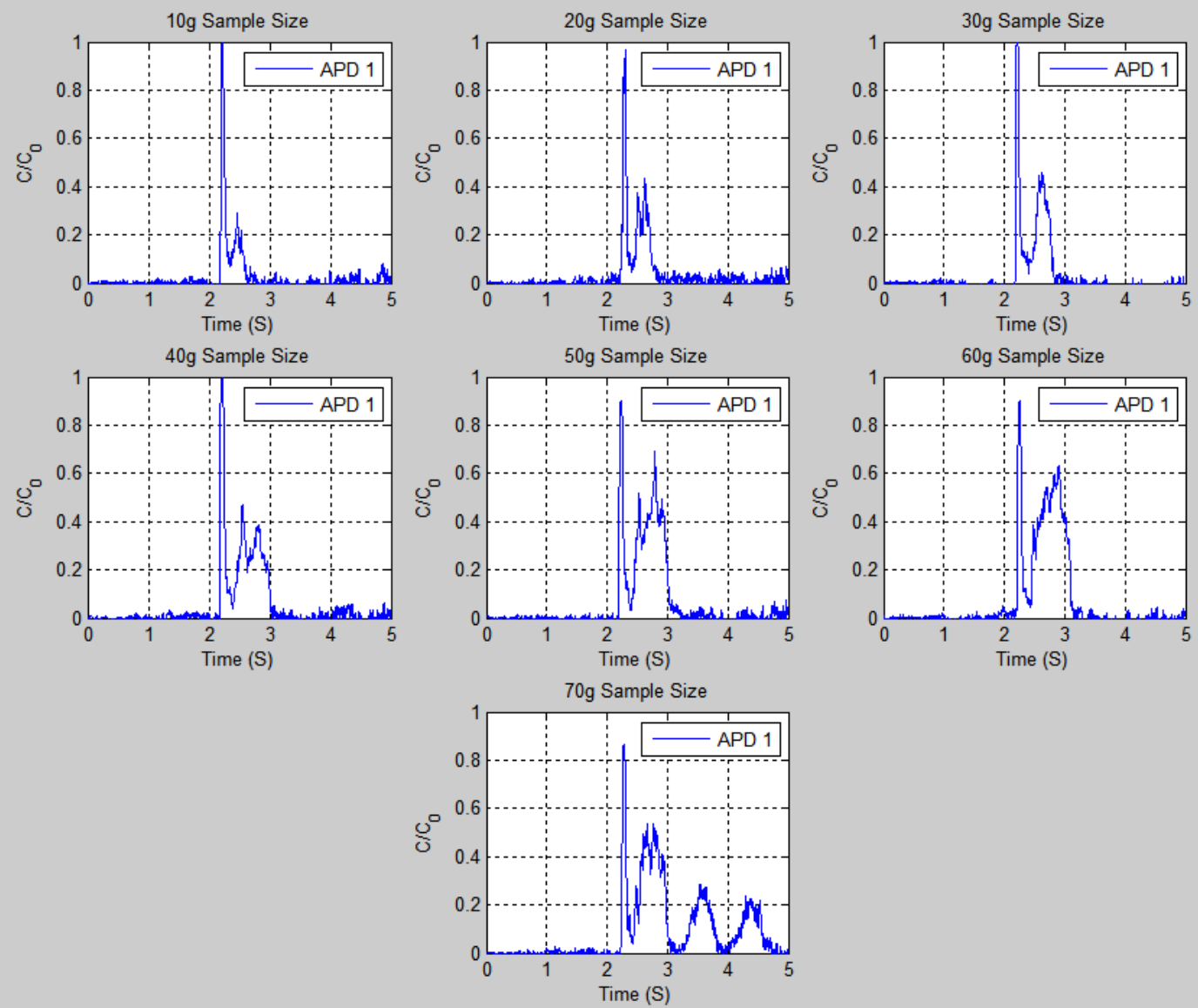

\section{Figure 6-3: Injection Time Study Signals}

Figure 6-4 shows the plot of the injection measurement compared to that of the ideal step input. The shape of the signal is caused by the geometry of the bushing and momentum effects caused by the actuation. The first peak of the signal corresponds to the group of particles that are contained within the bushing when the tracer collection bore is aligned with the pneumatic transport line. When the slider is actuated downwards, the particles that are not completely encapsulated within the bushing stay in place as the slider rapidly moves downwards. These particles then fall downwards into the now stationary slider and are injected into the 
pneumatic transport line. It is this occurrence that causes the signal to increase after the first peak.

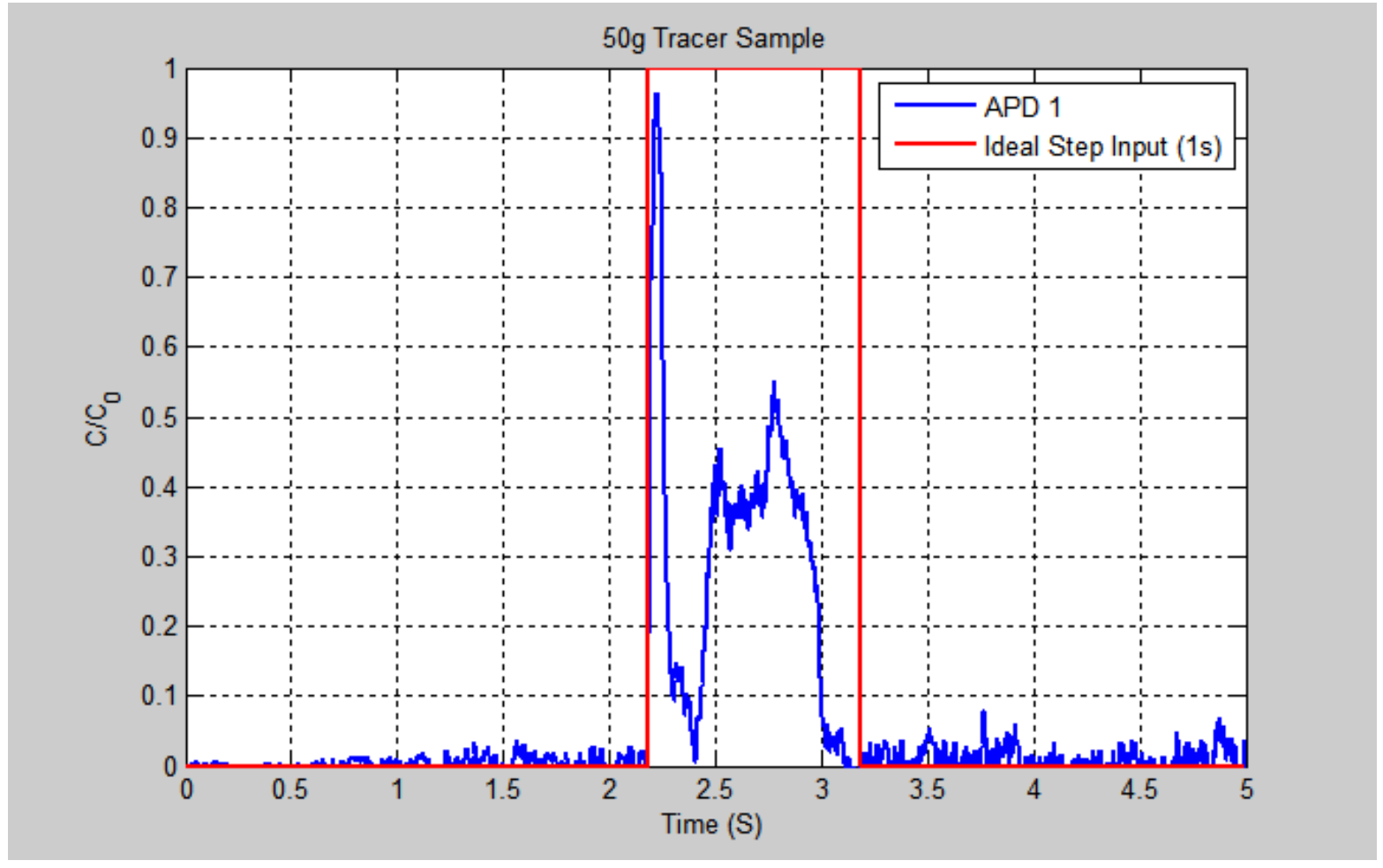

Figure 6-4: Ideal Injection

\subsection{Detection System}

The detection system was evaluated by incorporating the full RTD measurement system into the fluidized bed riser at the locations shown in Table 4-2. The tests were conducted by introducing a tracer sample into the illumination hopper, activating the switch on the Arduino control unit, and setting the DAQview software to record to a specified file when exposed to the trigger signal. After a 5 minute exposure time, the system injected the tracer particles and triggered the measurement system to initiate recording. The operation procedures can be seen in Section 3.3. Tracer detection at the exit location was problematic. Figure 6-5 details the 
various optic probe locations in the exit crossover. The following sections detail the attempt to gain a better signal for the measurement of total RTD. Operation parameters such as illumination time and tracer sample size were varied in attempt for increased detection to no effect. To keep the results consistent, testing was completed using a 5 minute illumination time and in the absence of solids feed unless otherwise noted. The system was operated in the pneumatic transport flow regime to ensure a minimum RTD for the increased the likelihood of detection.

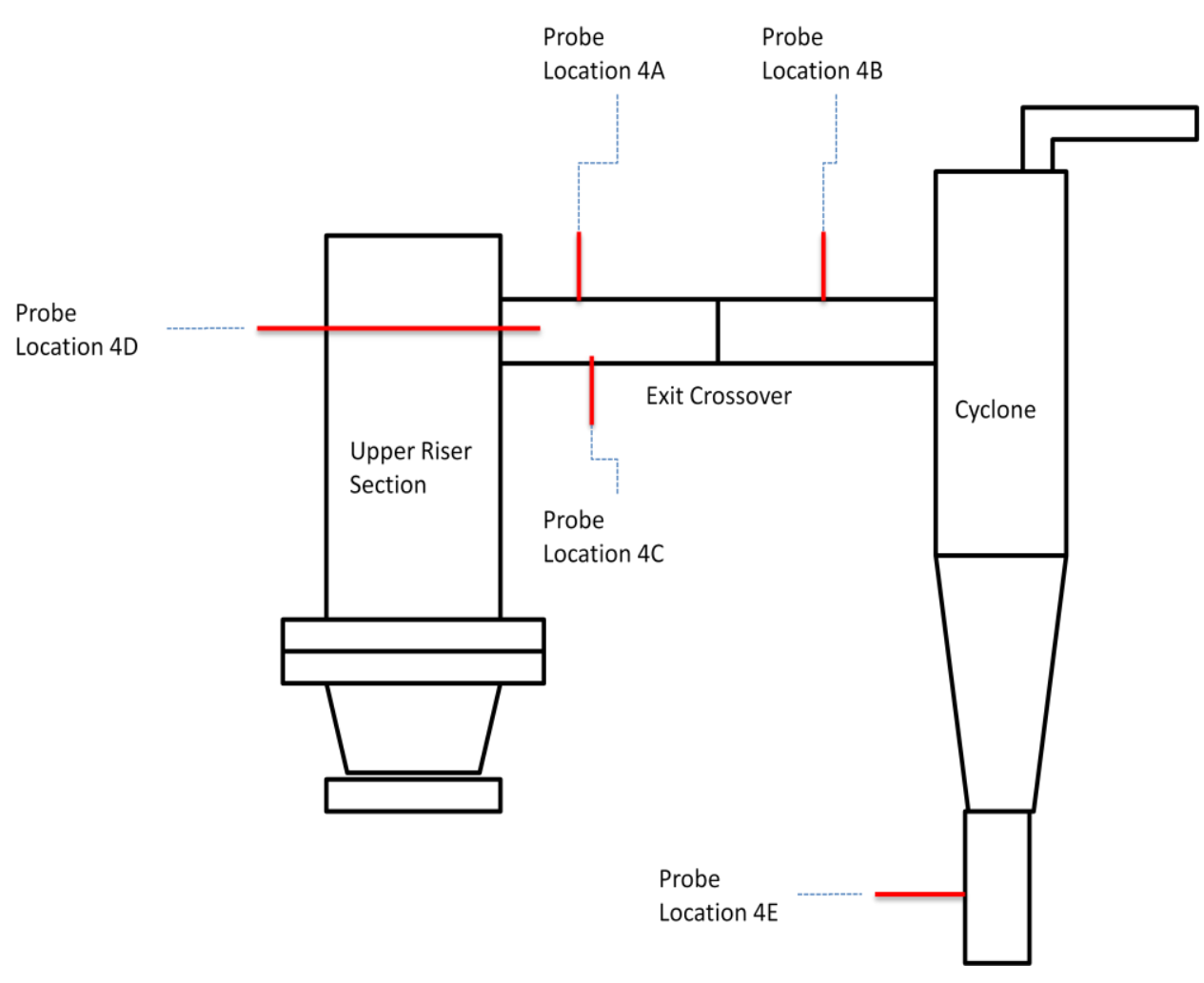

Figure 6-5: Probe Locations in Exit Crossover

The sensor and fiber optic probe combination used in the exit crossover at Location 4A failed to produce any signal above the noise level. By visual inspection, it was observed that the tracer 
particles passed through the exit crossover in very space groups at high velocity. Many modifications were attempted to increase the signal to provide useful data. The phosphorescent particles could not be further illuminated to increase the signal so other modifications were made in attempt for a usable signal. The tracer sample size was increased to $50 \mathrm{~g}$ and $100 \mathrm{~g}$ without any significant increase of detection at the exit location.

The exit sensor probe was repositioned to Location 4B in an attempt to better measure the tracer particles in the exit crossover. Visual inspection of the particles leaving the system indicated a flow pattern where the particles would make a slow bend into the exit crossover. The vertical momentum of the particles caused the particles to impact the upper part of the exit crossover near the location of the probe at the original location. Location 4A was at the top of the exit crossover 2-3/4" away from the outer wall of the upper riser stage. The distance from the exit was increased to 6" so the particles would impact the top of the exit crossover section near the original location and pass by the detection probe at a slightly increased distance. This location had negligible effect on the detection signal.

The probe was then moved to a third location, 4C, below the original location. At this position, the probe viewed upwards from the bottom of the exit crossover 3 " from the outside wall of the upper riser stage. The radial position of the probe was varied within this location in attempt to increase detection. There was an increase in signal above the noise level in Figure 6-6, but not with a sufficient duration to conclude accurate detection was made. 


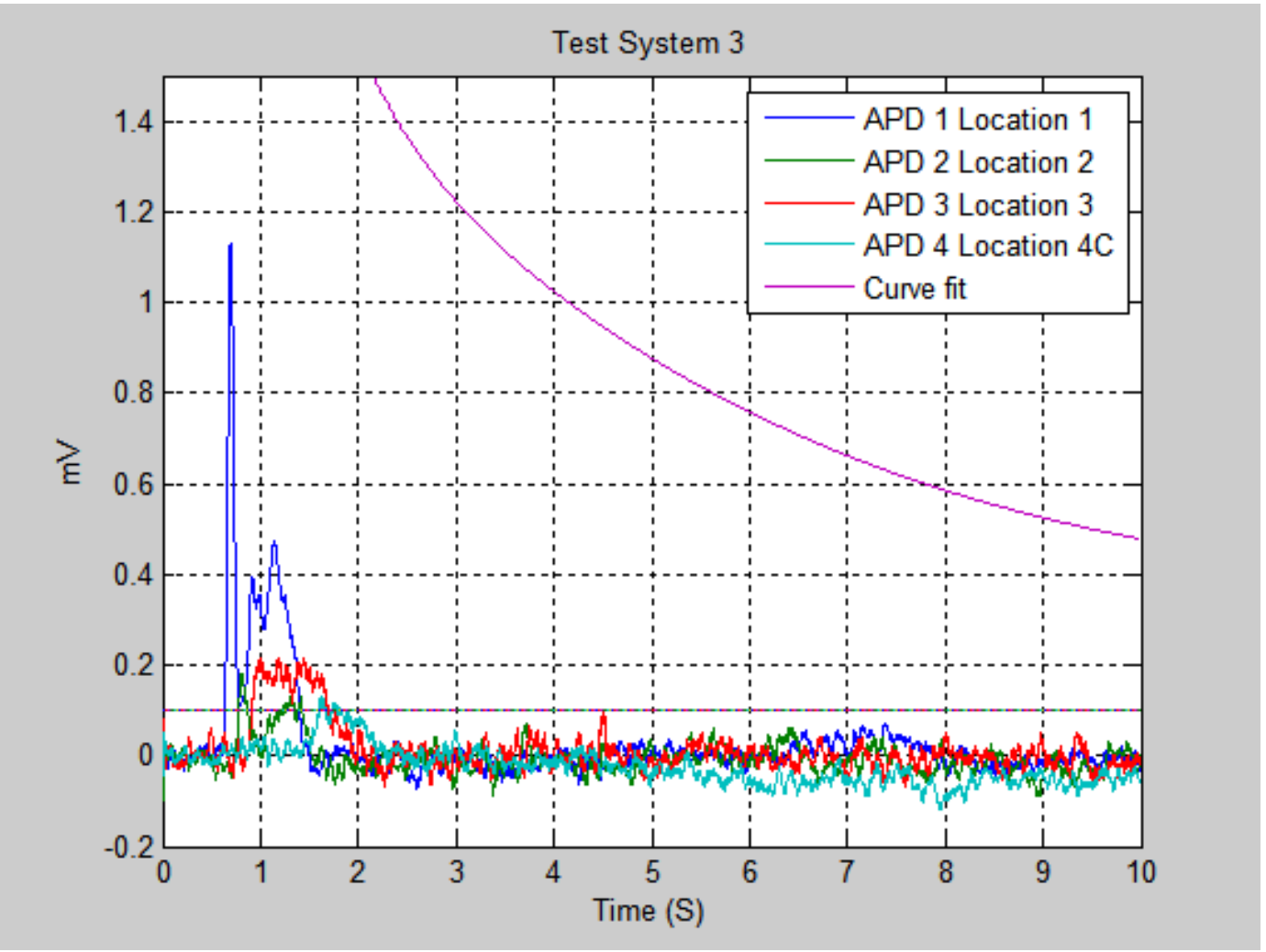

Figure 6-6: $C(t)$, APD 4 location $4 C, U_{L}=4.12 \mathrm{~m} / \mathrm{s}, U_{P}=2.87 \mathrm{~m} / \mathrm{s}$, $\mathrm{G}_{\mathrm{s}}=0 \mathrm{~kg} / \mathrm{m}^{2} \mathrm{~s}, 40 \mathrm{~g}$ Tracer

A more radical position of the exit probe was implemented so that the probe was inserted through the side of the upper riser stage directly opposite of the exit crossover and into the centerline of the exit, Location 4D. Again, no signal was recorded above the noise level of the sensor. A probe was then constructed of the 32 fiber line where the ends of the fibers were unjacketed approximately 4" past the end of the probe so that when the probe was inserted into this location, the individual fibers would be pointed in multiple directions within the exit crossover. Location 4D failed to provide increased detection of the tracer particles. 
Visual inspection in a dark environment of the various probe locations and fiber combinations was completed on the running system. The faint green afterglow could be seen through the fiber probes. The location that appeared to have the greatest intensity was at the lower upward-facing probe location 4C. This intensity indicated that the APD sensors were not sufficiently amplified to measure the light intensity passing through the fiber line.

A Photo Multiplier Tube (PMT) sensor and corresponding power supply were obtained for the measurement of the light signal. The PMT acquired for testing was a TSI Model NO. 9162 with accompanying TSI Model NO. 9165 power supply featuring anode current adjustment. A mount was made to couple the fiber optic line to the unit. Preliminary results showed that the unit was not directly compatible with measurement system and settings. A user manual for the sensor could not be located through any channels. The output of the sensor would drift upwards or downwards with time which necessitated the use of a High Pass Filter (HPF) with a very low cutoff frequency.

Simple high pass filters were constructed from simple combinations of resistors and capacitors to resolve this issue. A suitable cutoff frequency which would suppress the low frequency drift without also attenuating the useful signal could not be established. This situation was demonstrated in Figure 6-7 where both an APD and the PMT were subjected to a flashing light source. It is evident that the APD subjected to the flashing light source created a "square wave" where when the light was activated, the signal would quickly rise to the maximum intensity for as long as the light was activated. When the light was deactivated, the signal would then fall back to the zero value. This result could not be replicated with the PMT. When the light was 
activated, the PMT signal would quickly rise to a maximum and then rapidly decay to a zero value and reside there until the light was deactivated. When the light was deactivated, signal would quickly fall to a minimum value and decay back to the zero value. This trend was also seen with the absence of the HPF.

Some testing was done with the PMT which resulted in Figure 6-8, which is the raw, unfiltered data. It is evident that detection of tracer particles was occurring, but the signal could not be properly transformed to directly compare with the signals of the APD's. A time integrated intensity value cannot be calculated from the PMT signal.

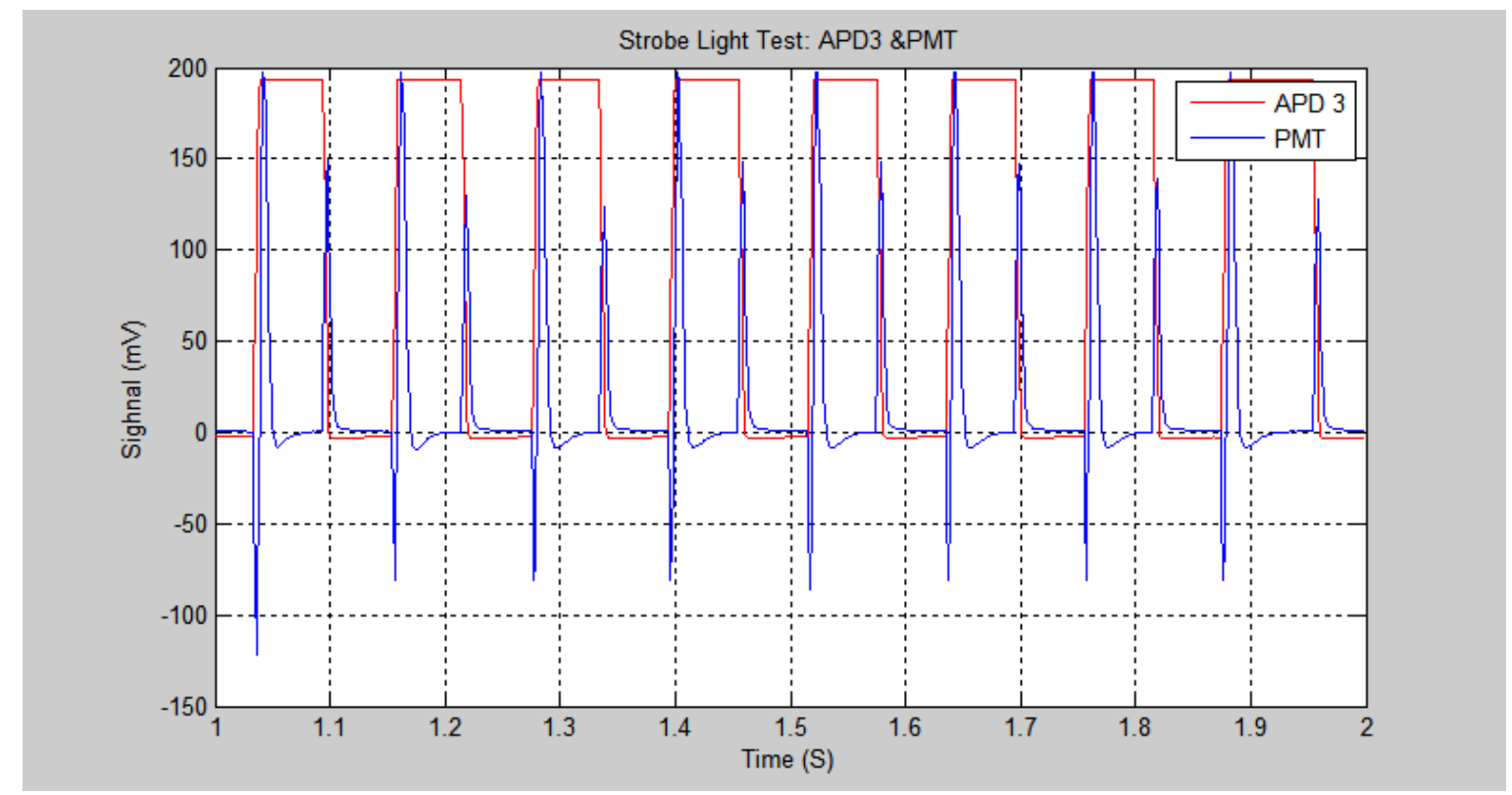

Figure 6-7: PMT APD Comparison, Strobe Light Test 


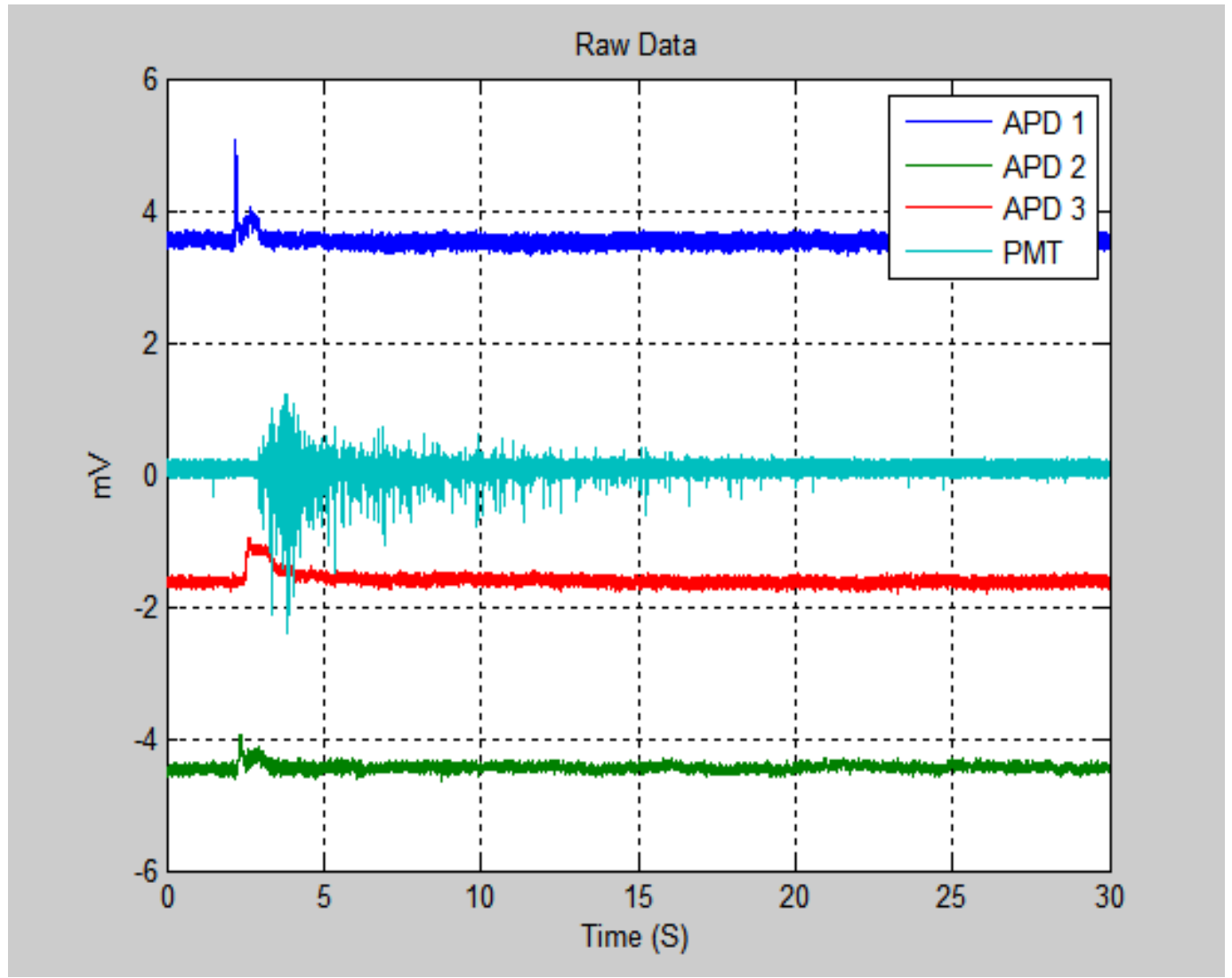

Figure 6-8: $C(t)$, $P M T$ location $4 C, U_{L}=4.12 \mathrm{~m} / \mathrm{s}$, $U_{p}=2.87 \mathrm{~m} / \mathrm{s}, G_{s}=0 \mathrm{~kg} / \mathrm{m}^{2} \mathrm{~s}, 40 \mathrm{~g}$ Tracer, Raw, Unfiltered

A probe location was added to the lower exit of the cyclone which is a vertical passage 1.5 "in diameter. It was believed that the particles would be more concentrated at this point as compared to the riser exit crossover due to the smaller cross sectional area and absence of air flow. At this location the solids are spun out of the air flow and fall into the collection hopper under the force of gravity. This arrangement does not accurately represent the RTD of the riser system due to the added time from the particle having to pass through the exit crossover and through the cyclone before detection. This measurement location could be useful for the study of RTD within the cyclone or for the study of RTD in a circulating fluidized bed riser. It should be noted that APD 4 was excluded from this test due to the connection of PMT. The results can be 
seen in Figure 6-9. Detection above the $0.1 \mathrm{mv}$ noise threshold level was recorded. The duration of detection, however, was only 0.78 seconds.

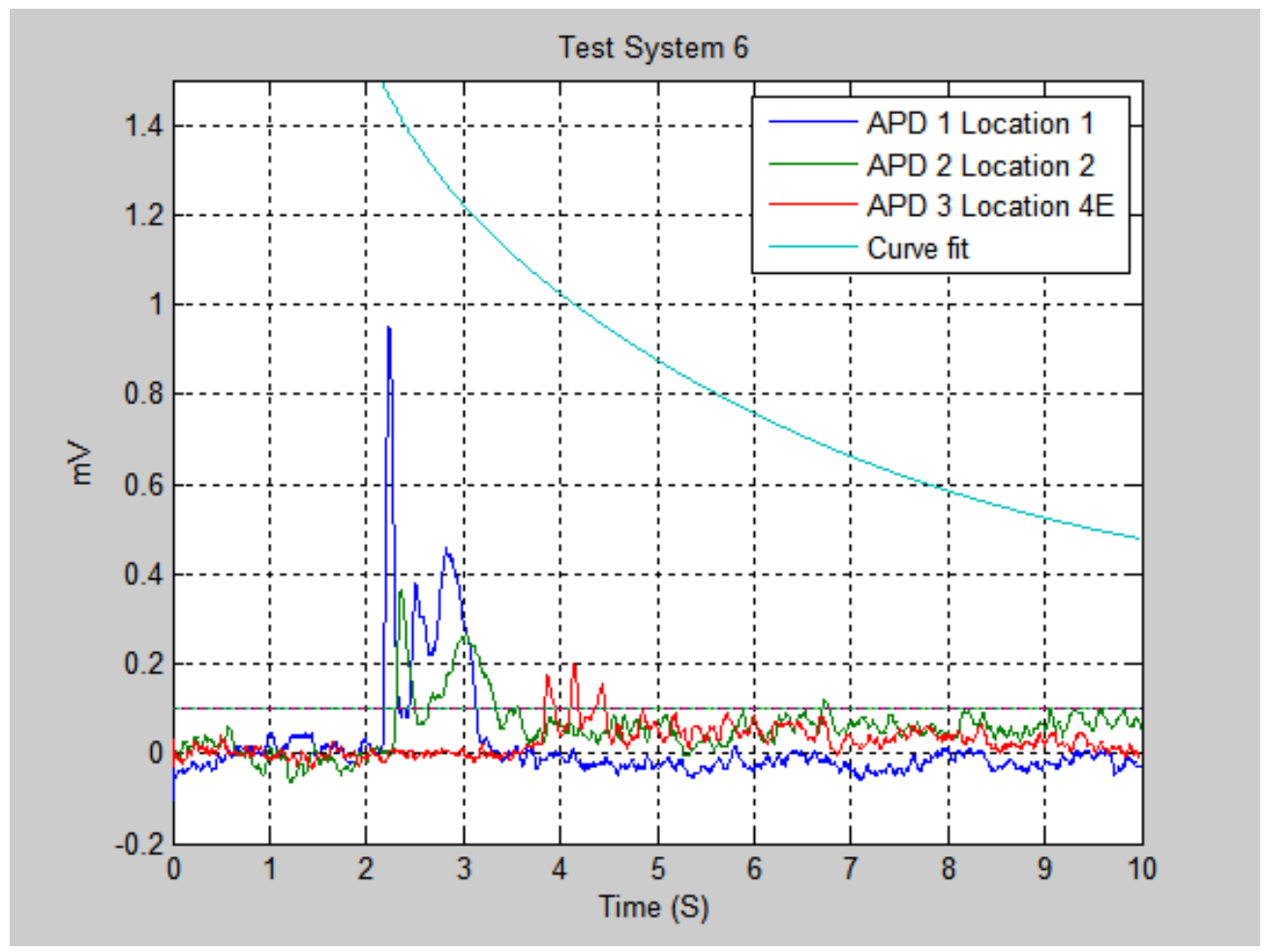

Figure 6-9: $\mathrm{C}(\mathrm{t})$, Probe Location Cyclone Exit $(4 \mathrm{E}), \mathrm{U}_{\mathrm{L}}=4.12 \mathrm{~m} / \mathrm{s}$, $U_{\mathrm{p}}=2.87 \mathrm{~m} / \mathrm{s}, \mathrm{G}_{\mathrm{s}}=0 \mathrm{~kg} / \mathrm{m}^{2} \mathrm{~s}, 40 \mathrm{~g}$ Tracer

It was then determined that the detection of the particles in the exit crossover section could not be successfully achieved with the fiber probes. A quick study was conducted where an APD was fastened to the acrylic exit crossover for the direct detection of light through the clear curved surface without the fiber optic intermediary. This proof of concept showed that detection of tracer particles was possible with this arrangement.

The main problem with the proof of concept was the distortion of light passing through the curved surface. The measurement distortion caused by the curved surface was remedied by the construction of an intermediary acrylic exit section with a flat 2 " $\times 2$ " $\times 1 / 4$ " cast acrylic window 
placed centrally along its length. The interior surface was covered in a polished aluminum film to increase internal reflectance. An APD was fastened to the surface and placed 6" from the outer wall of the upper riser section. This allows for the direct impingement of light emitted from the tracer particles onto the detection surface through a flat surface. Figure 6-10 provides a visual representation of this arrangement.

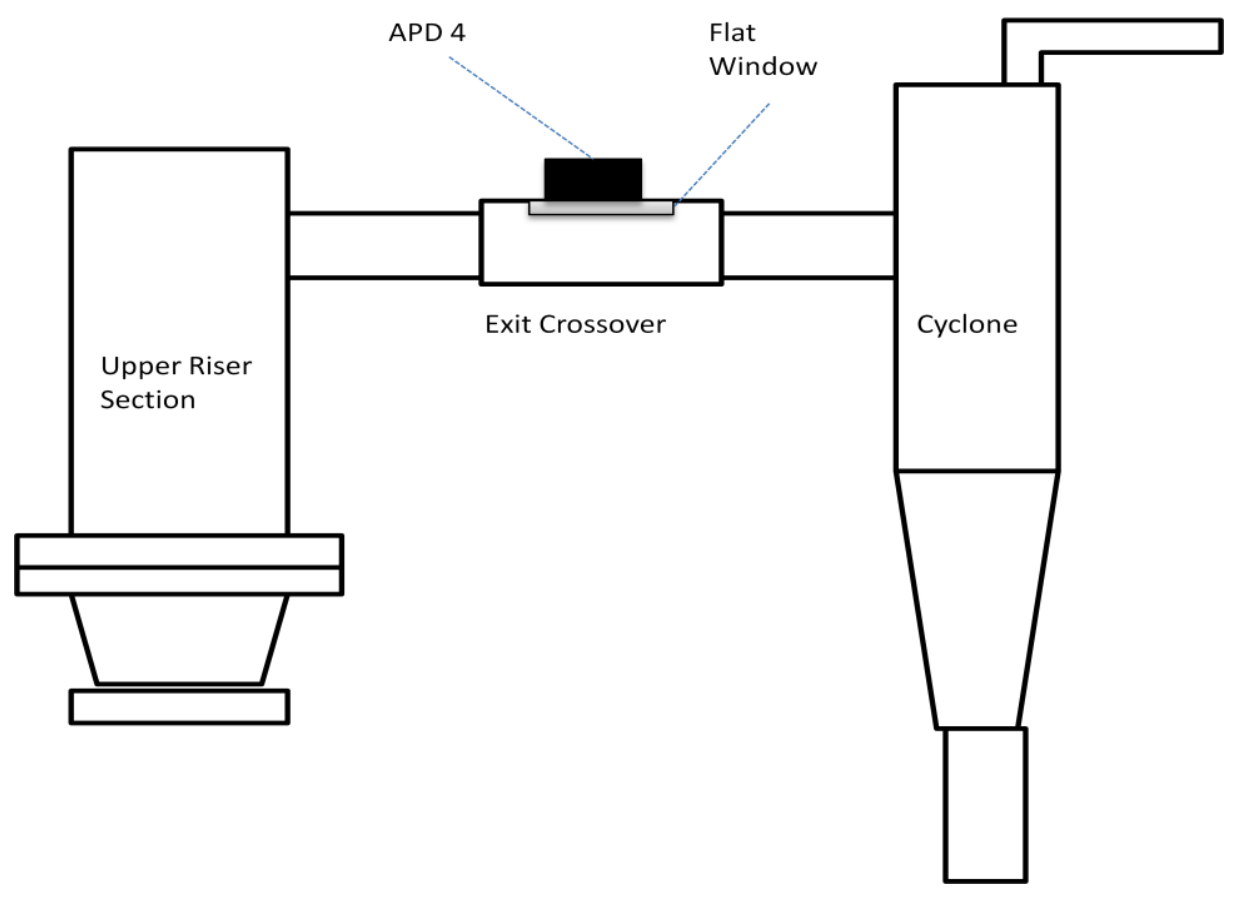

Figure 6-10: APD Location 4F

With this sensor arrangement providing the most favorable results, testing was completed at two flow regimes at two mass flux rates. The first set of tests was conducted at a superficial air velocity in the lower section of $U_{L}=2.47 \mathrm{~m} / \mathrm{s}$, a superficial air velocity in the lower section of $U_{p}=2.47 \mathrm{~m} / \mathrm{s}$, with a mass fluxes of $G_{s}=0 \mathrm{~kg} / \mathrm{m}^{2} \mathrm{~s}$ and $G_{s}=2.94 \mathrm{~kg} / \mathrm{m}^{2} \mathrm{~s}$. Figure 6-11 through Figure 6-14 represent the data collected at this air flow rate. 
A second set of testing was conducted at a superficial air velocity in the lower section of $U_{L}=4.12 \mathrm{~m} / \mathrm{s}$, a superficial air velocity in the upper section of $U_{p}=2.87 \mathrm{~m} / \mathrm{s}$, with a mass fluxes of $\mathrm{G}_{\mathrm{s}}=0 \mathrm{~kg} / \mathrm{m}^{2} \mathrm{~s}$ and $\mathrm{G}_{\mathrm{s}}=2.94 \mathrm{~kg} / \mathrm{m}^{2} \mathrm{~s}$. These velocities fall into the pneumatic transport flow regime. The results from this air flow rate can be seen in Figure 6-15 through Figure 6-18. Plots are shown with both the signal measured in $\mathrm{mV}$ and the concentration curve $\mathrm{C} / \mathrm{C}_{0}$. This result is due to the effect of signal noise described in Section 5.7. 

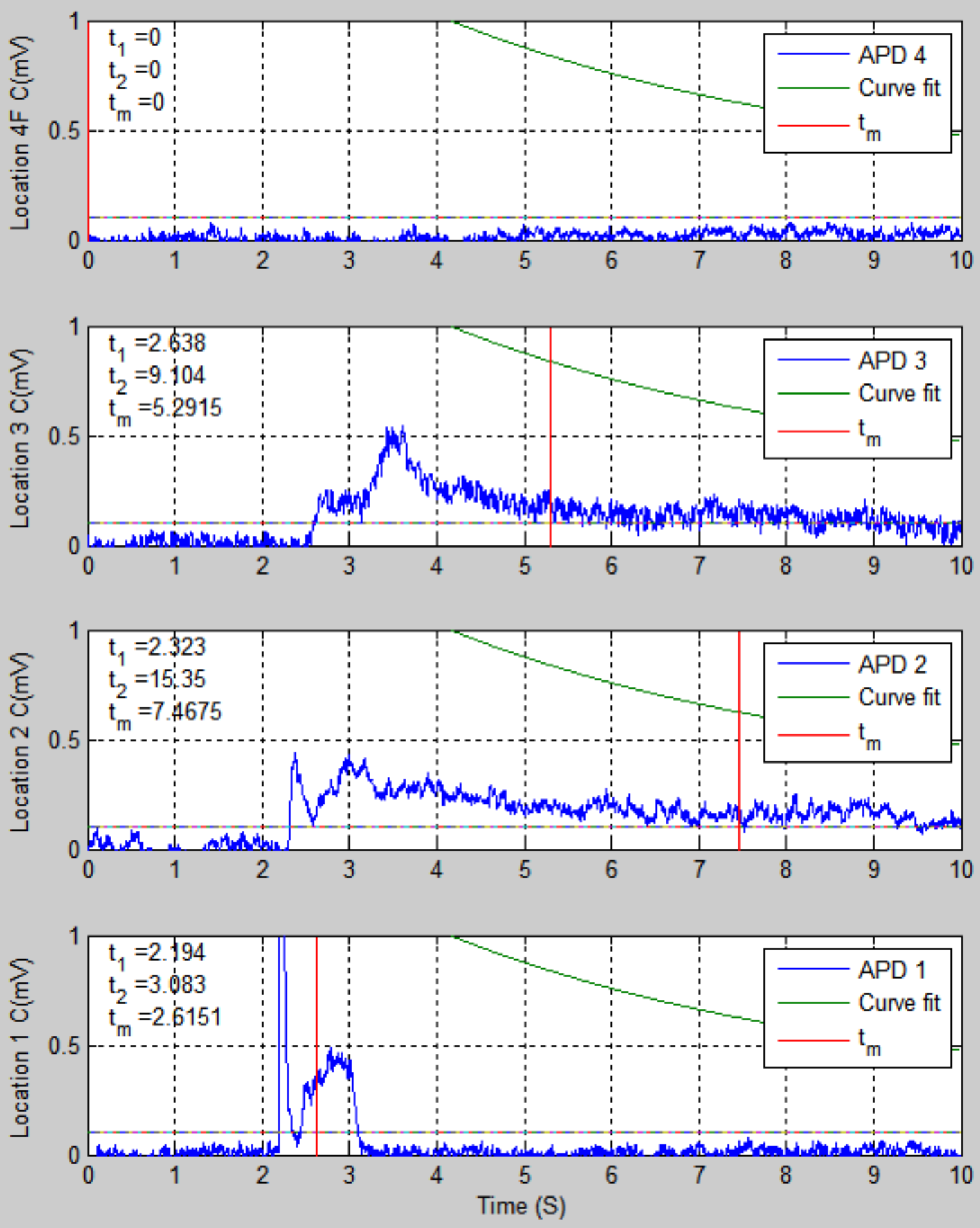

Figure 6-11: $C(t), U_{L}=2.47 \mathrm{~m} / \mathrm{s}, U_{p}=2.47 \mathrm{~m} / \mathrm{s}, G_{s}=0 \mathrm{~kg} / \mathrm{m}^{2} \mathrm{~s}, 50 \mathrm{~g}$ Tracer 

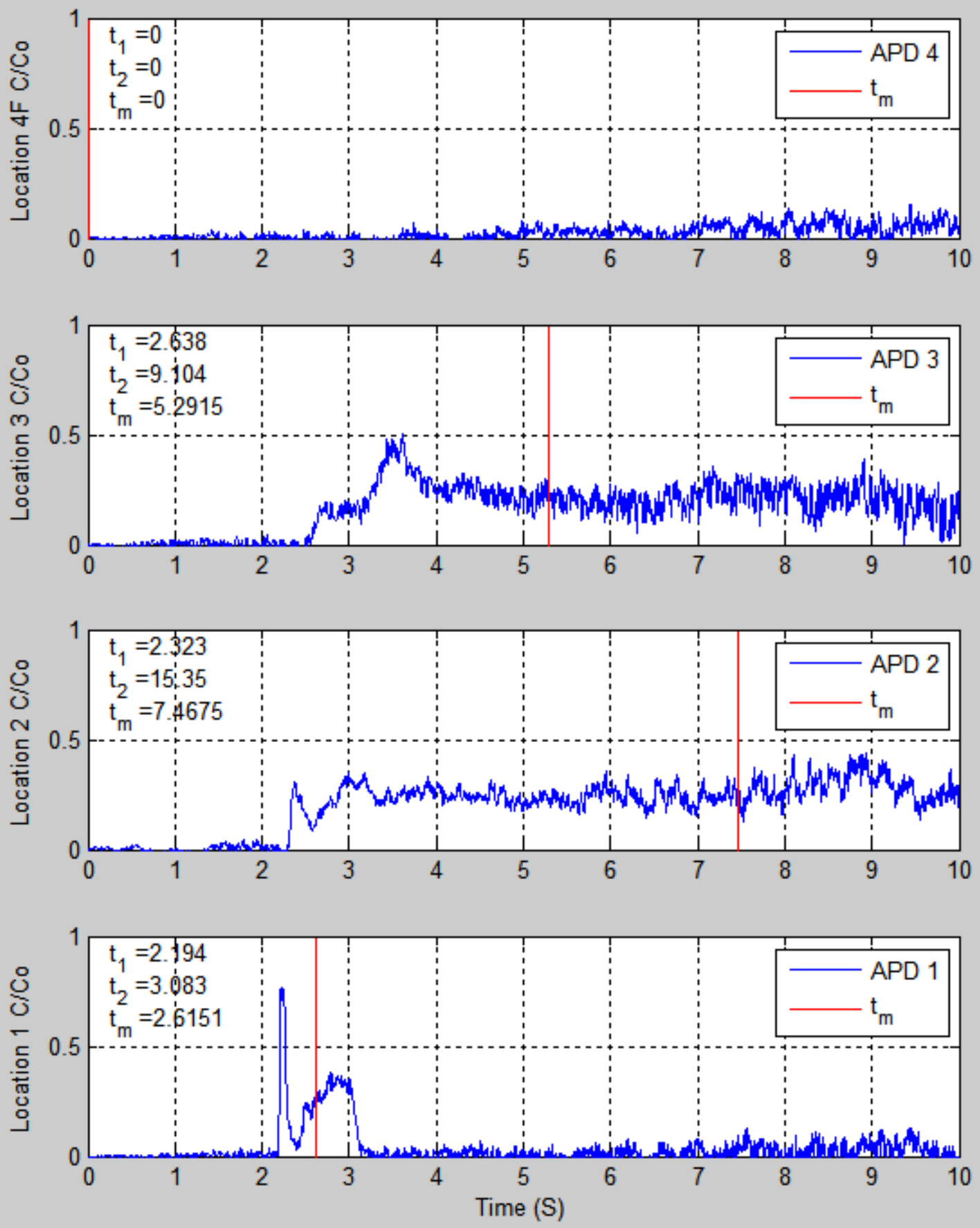

Figure 6-12: $C / C_{0}(t), U_{L}=2.47 \mathrm{~m} / \mathrm{s}, U_{p}=2.47 \mathrm{~m} / \mathrm{s}, G_{s}=0 \mathrm{~kg} / \mathrm{m}^{2} \mathrm{~s}, 50 \mathrm{~g}$ Tracer 

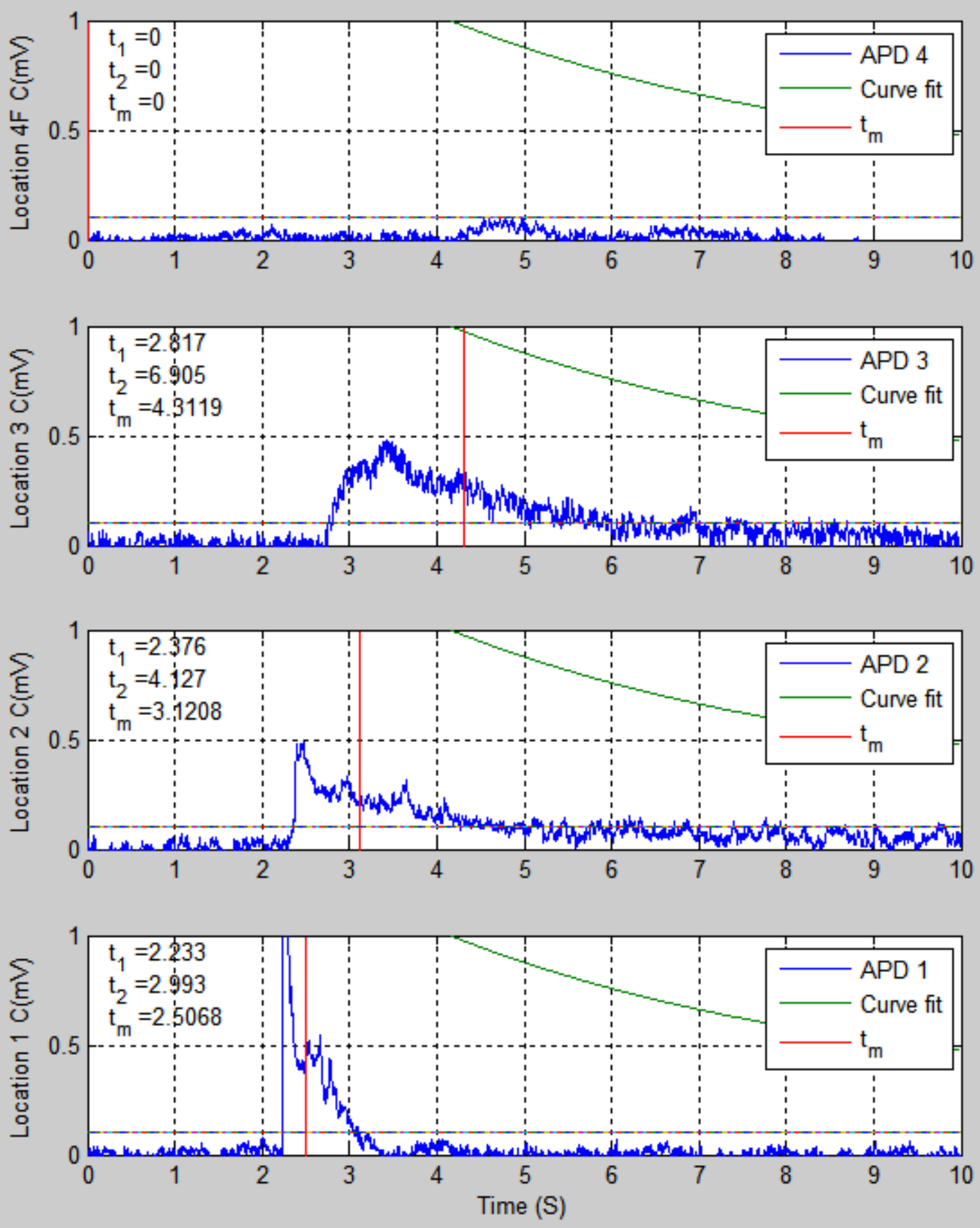

Figure 6-13: $\mathrm{C}(\mathrm{t}), \mathrm{U}_{\mathrm{L}}=2.47 \mathrm{~m} / \mathrm{s}, \mathrm{U}_{\mathrm{p}}=2.47 \mathrm{~m} / \mathrm{s}, \mathrm{G}_{\mathrm{s}}=2.94 \mathrm{~kg} / \mathrm{m}^{2} \mathrm{~s}, 50 \mathrm{~g}$ Tracer 

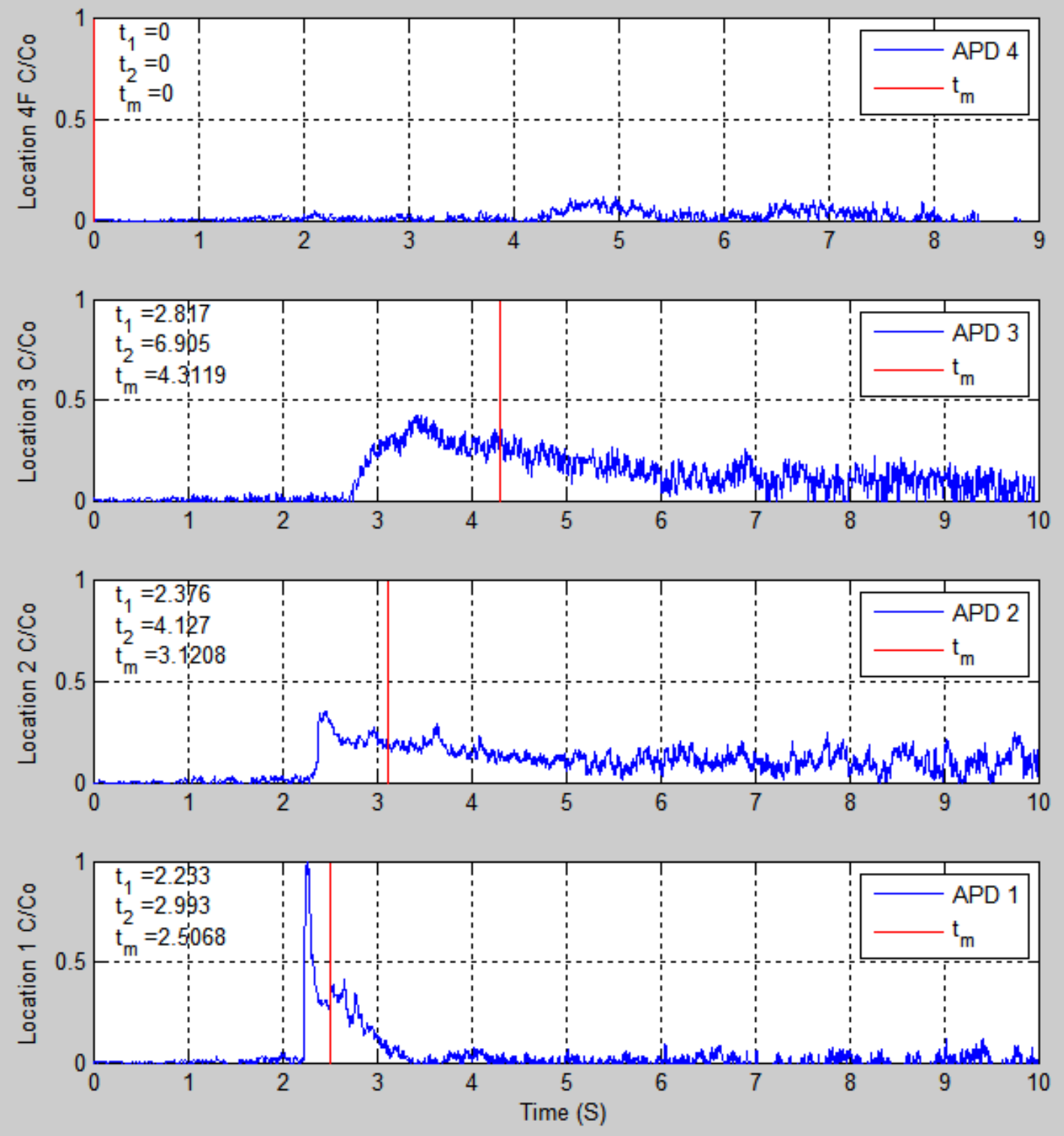

Figure 6-14: $C / C_{0}(t), U_{L}=2.47 \mathrm{~m} / \mathrm{s}, U_{p}=2.47 \mathrm{~m} / \mathrm{s}, G_{s}=2.94 \mathrm{~kg} / \mathrm{m}^{2} \mathrm{~s}, 50 \mathrm{~g}$ Tracer 

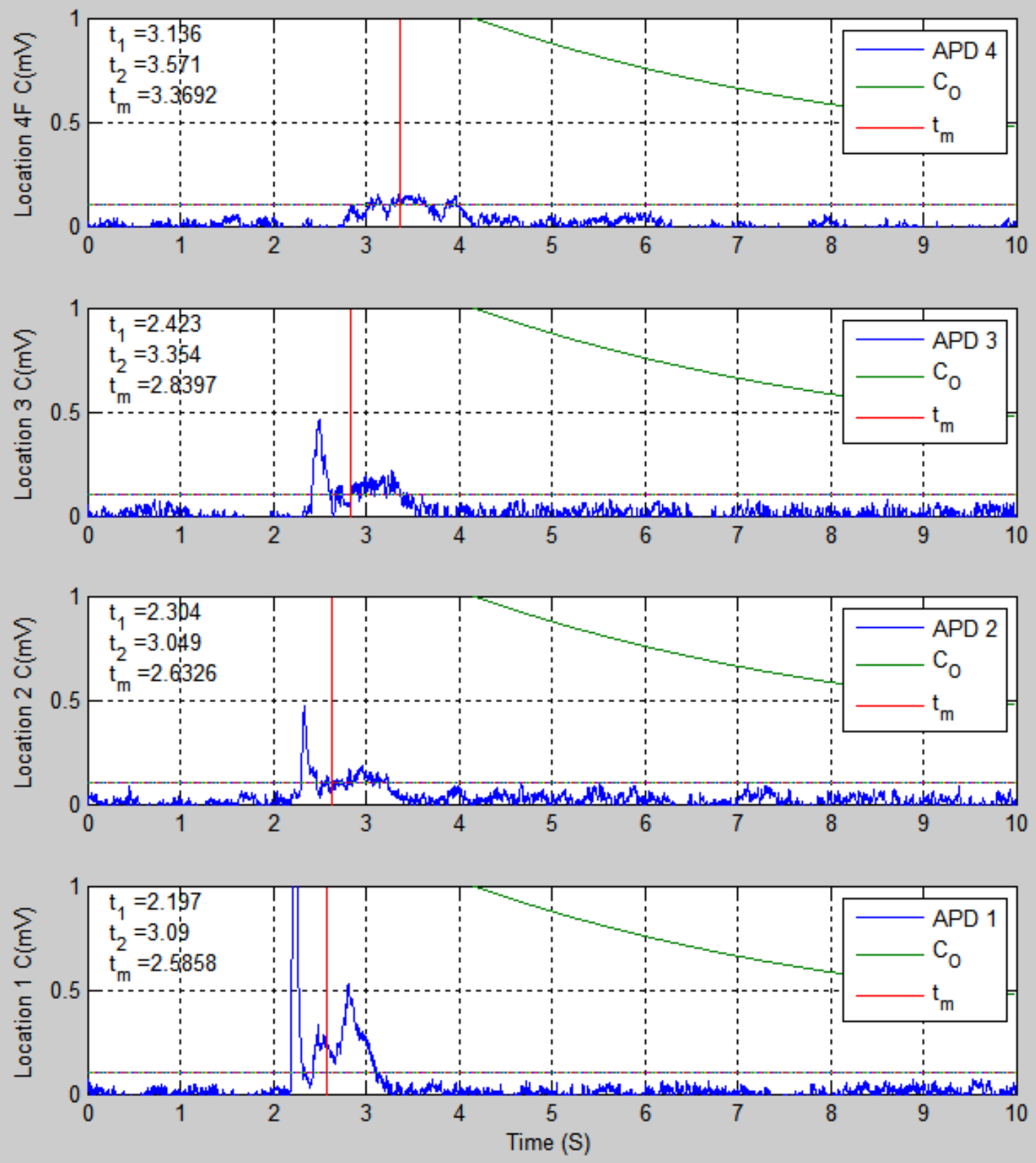

Figure 6-15: $C(t), U_{L}=4.12 \mathrm{~m} / \mathrm{s}, U p=2.87 \mathrm{~m} / \mathrm{s}$,

$\mathrm{G}_{\mathrm{s}}=0 \mathrm{~kg} / \mathrm{m}^{2} \mathrm{~s}, 50 \mathrm{~g}$ Tracer 

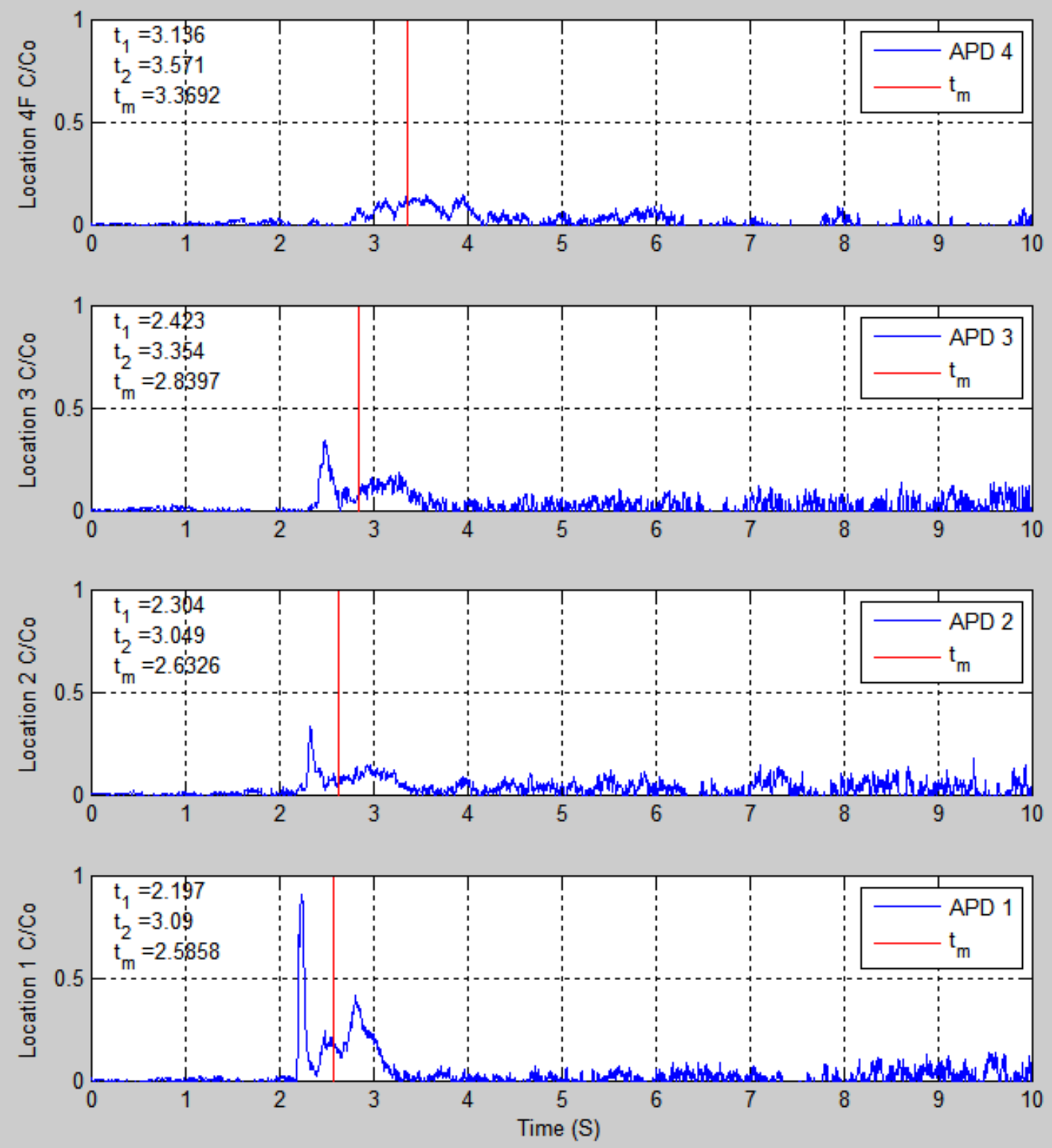

Figure 6-16: $C / C_{0}(t), U_{L}=4.12 \mathrm{~m} / \mathrm{s}, U p=2.87 \mathrm{~m} / \mathrm{s}$, $\mathrm{G}_{\mathrm{s}}=0 \mathrm{~kg} / \mathrm{m}^{2} \mathrm{~s}, 50 \mathrm{~g}$ Tracer 

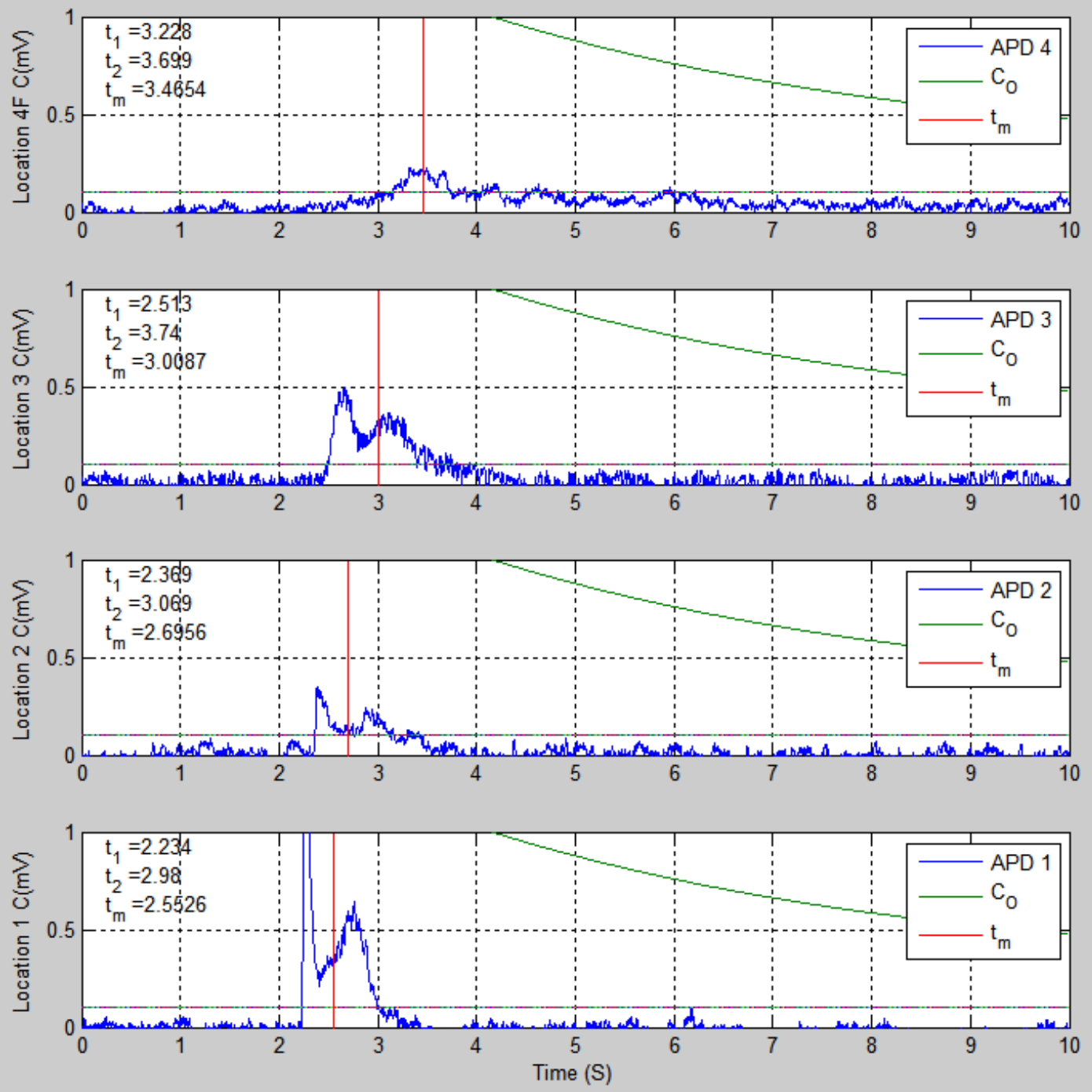

Figure 6-17: $C(t), U_{L}=4.12 \mathrm{~m} / \mathrm{s}, U p=2.87 \mathrm{~m} / \mathrm{s}$, $\mathrm{G}_{\mathrm{s}}=2.94 \mathrm{~kg} / \mathrm{m}^{2} \mathrm{~s}, 50 \mathrm{~g}$ Tracer 

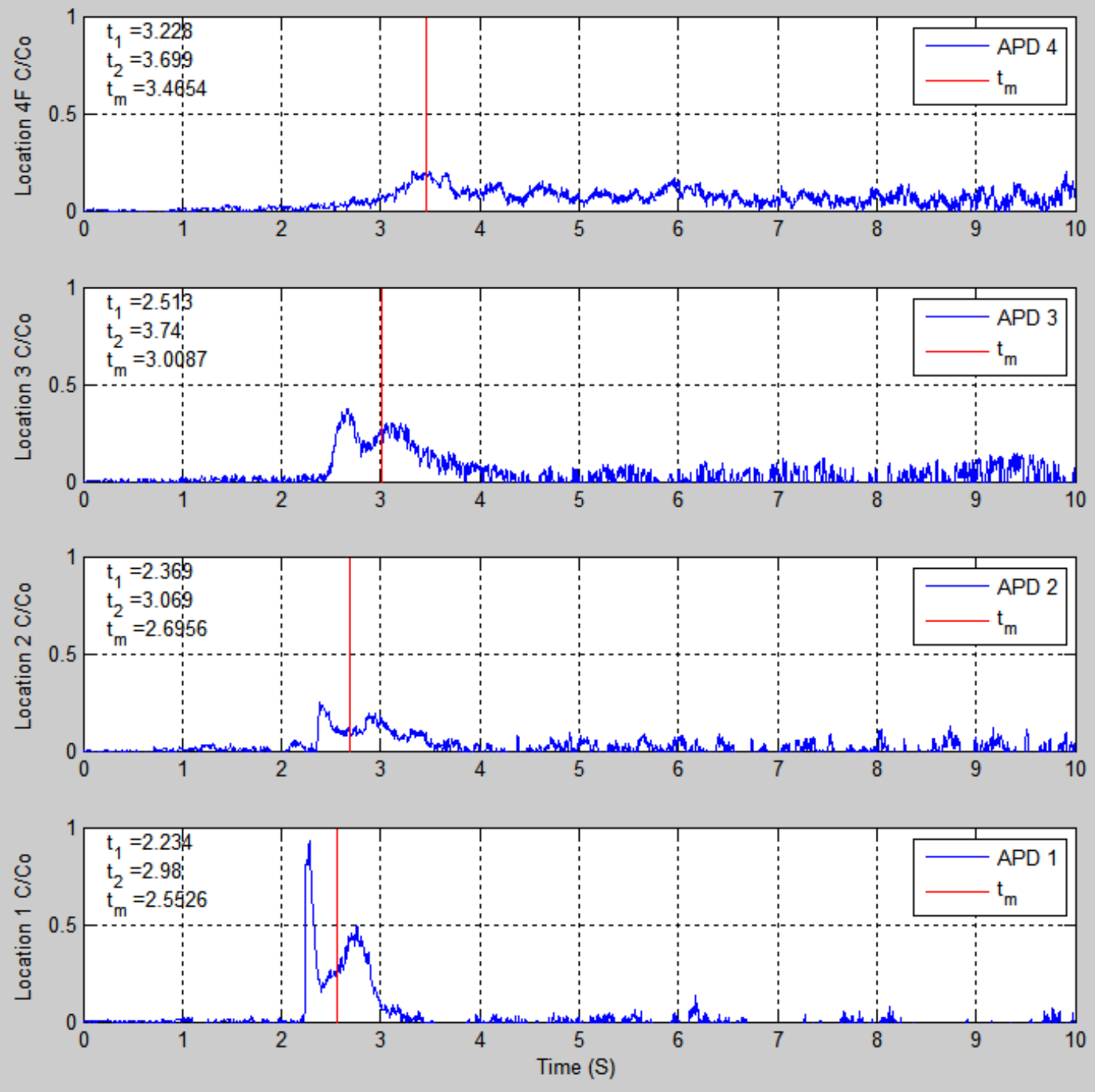

Figure 6-18: $C / C_{0}(t), U_{L}=4.12 \mathrm{~m} / \mathrm{s}, U p=2.87 \mathrm{~m} / \mathrm{s}$, $\mathrm{G}_{\mathrm{s}}=2.94 \mathrm{~kg} / \mathrm{m}^{2} \mathrm{~s}, 50 \mathrm{~g}$ Tracer

As testing progressed, it became apparent that both Sensors 2 and 3 were decreasing in performance. A test comparable to the one detailed in Section 5.2 was performed by exposing each sensor and fiber probe combination to a green LED light fitted within a compression fitting. This arrangement can be seen in Figure 5-3. The compression fitting light assembly 
securely gripped the fiber probe to assure accurate and repeatable tests. Each probe was sampled three times with the probe rotated to a different orientation between tests. The results can be seen in

Table 6-4. The difference is calculated by comparing the signal to that of the sensor providing the highest reading.

Table 6-4: Sensor Balance Results

\begin{tabular}{|r|r|r|r|}
\hline \multicolumn{1}{|r|}{ Sensor } & \multicolumn{1}{|l|}{ Probe } & \multicolumn{1}{l|}{$\begin{array}{l}\text { Signal } \\
(\mathbf{m V})\end{array}$} & \multicolumn{1}{l|}{ \% Diff } \\
\hline 1 & 1 & 1116 & \\
\hline 2 & 2 & 763 & $32 \%$ \\
\hline 2 & 3 & 759 & $32 \%$ \\
\hline 3 & 2 & 855 & $23 \%$ \\
\hline 3 & 3 & 840 & $25 \%$ \\
\hline
\end{tabular}

The balance test showed a large disparity of the recorded signal outputs for the combinations. To rule out the possibility that fiber lines were responsible for the imbalance, the fiber lines between Sensors 2 and 3 were reconditioned and switched before the tests were repeated. No significant difference was perceived after the switching of the fiber lines, which excluded the possibility of the fiber lines being the cause of the imbalance.

The balance test proved that there was a discrepancy between the sensors balance but did not quantify the change of performance for the detection of PPE particles. Decay testing detailed in Section 5.5 was repeated with Sensors 1-3 and associated fiber combination at the same conditions detailed in the preliminary works section to quantify the change in performance. The arrangement used for this test can be Figure 5-10. Sensor 4 was omitted from this testing due 
to the sensor no longer being contained within the sensor cooling unit. The results can be seen in Figure 6-19, Figure 6-20, and Figure 6-21.

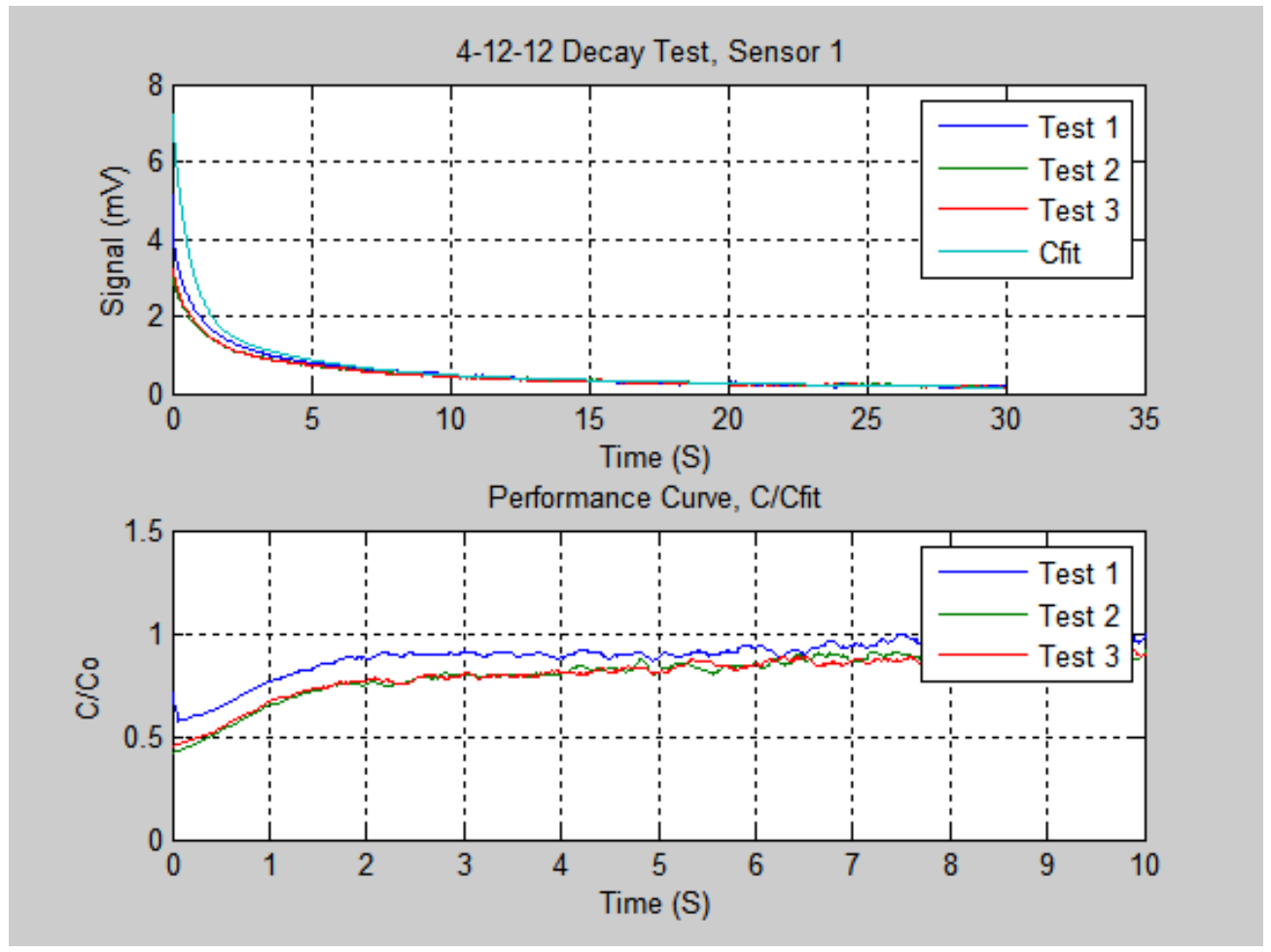

Figure 6-19: Sensor 1 Performance Analysis, Decay Test 


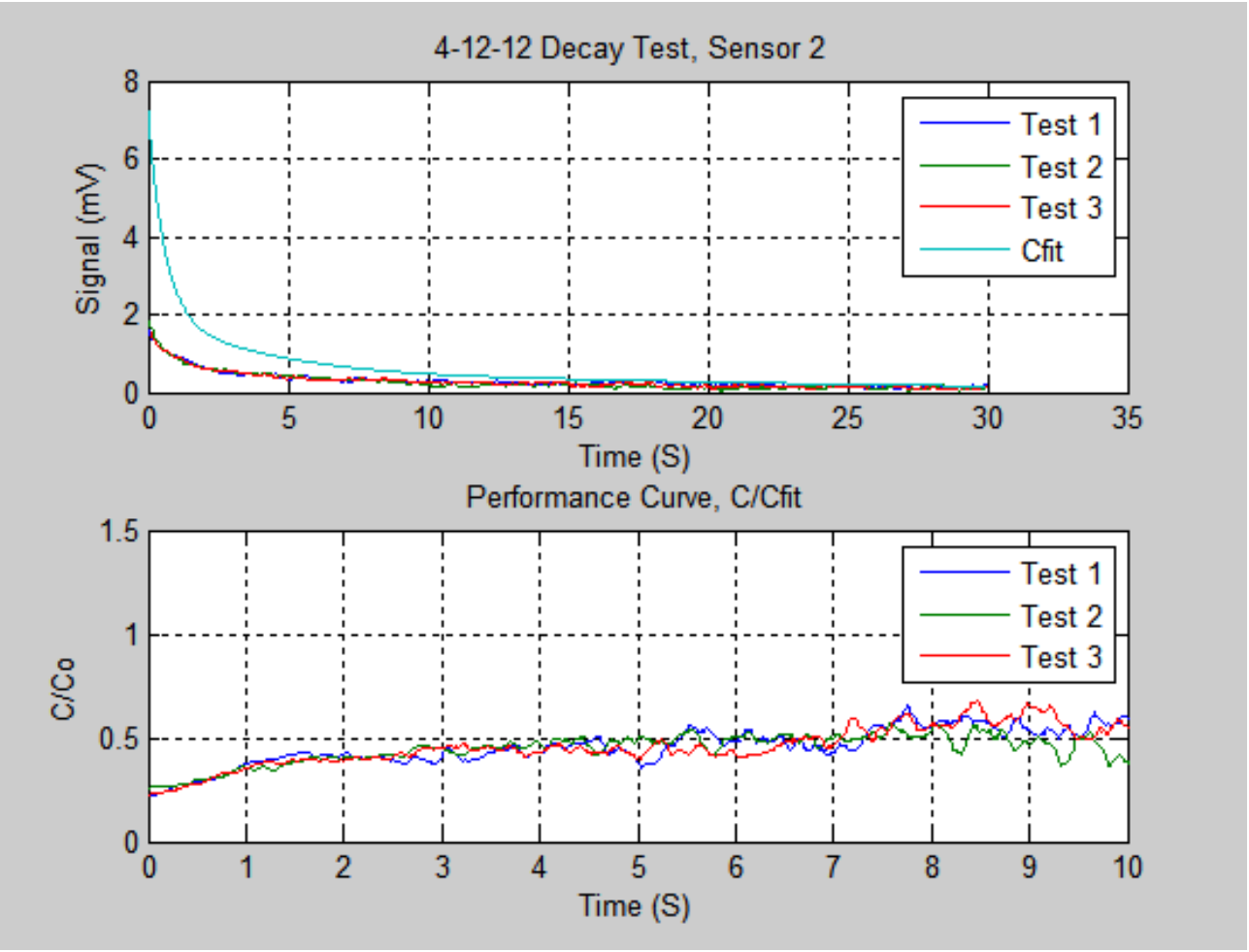

Figure 6-20: Sensor 2 Performance Analysis, Decay Test

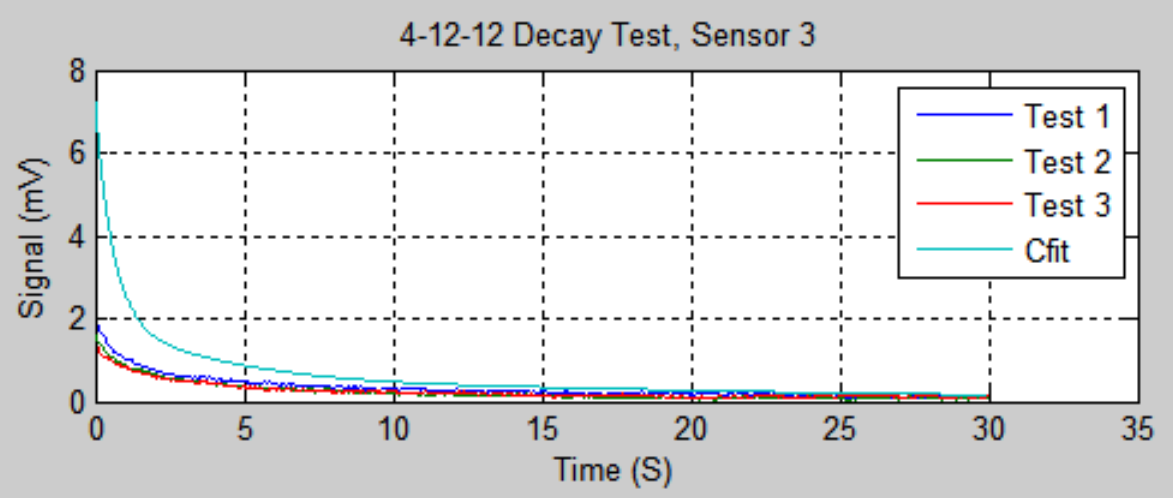

Performance Curve, C/Cfit

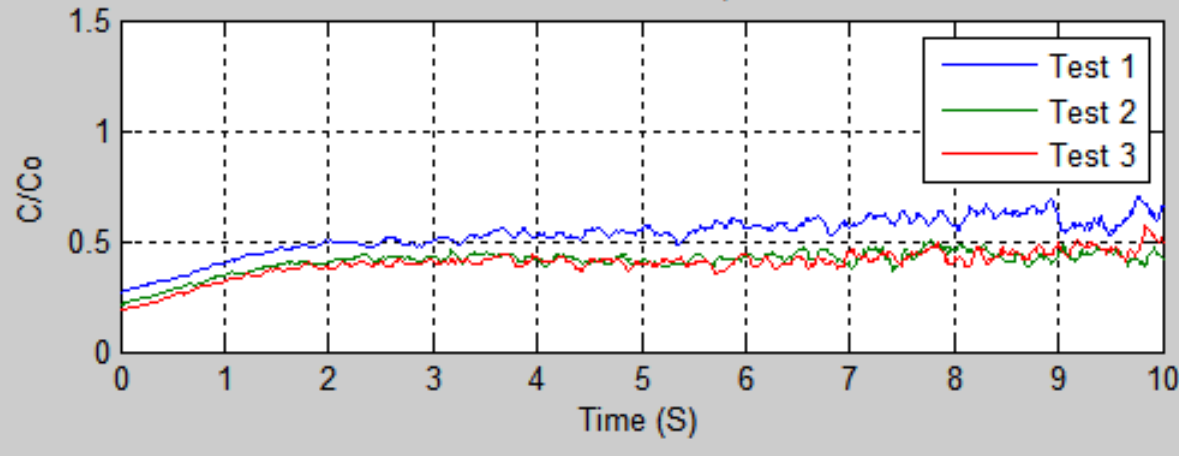

Figure 6-21: Sensor 3 Performance Analysis, Decay Test 
The dimensionless concentration curves, $\mathrm{C} / \mathrm{Co}$, from each test should theoretically form a horizontal line located at the value of 1 . The performance of Sensor 1 in Figure 6-19 is roughly comparable to the original performance of the sensor. Figure 6-20 and Figure 6-21 confirm that Sensors 2 and 3 sustained a substantial degradation in performance. Both Sensors 2 and 3 were operating at a magnification level lower than $50 \%$ of the original measured value.

It was theorized that there was degradation of performance, possibly due to condensation forming within the sealed sensors. The possibility of the sensors being exposed to a light intensity exceeding the damage threshold is quite unlikely as the ambient light only results in a reading in the $0.1 \mathrm{~V}$ range compared to the $3.6 \mathrm{~V}$ damage threshold. Multiple attempts were made to repair the sensors, after which the decay testing was performed again without an increase in performance. It was concluded that the damage sustained to the sensors was permanent. 


\section{Chapter 7 Conclusions and Recommendations}

\subsection{Conclusions}

The exploratory study for the measurement of residence time distribution, RTD, in a fluidized bed riser system was conducted. A preliminary system for the measurement of RTD was designed, fabricated, and incorporated in a small scale dual stage riser system. The RTD measurement system was separated into three categories in which performance was evaluated; 1) an illumination system for the uniform irradiation of the phosphorescent particles, 2) a unit for the injection of the irradiated tracer particles, 3) and a system for the detection and measurement of the radiating tracer particles.

The illumination system consisting of a long wave UV source contained in a fluidized hopper was shown to have uniformly illuminated the phosphorescent tracer particles and provided repeatable results. The injection system consisting of a slide mechanism and supporting control systems was shown to have injected the activated tracer particles with highly repeatable results. The actuation time of the slider mechanism was measured 0.13 seconds which was well under the expected time for actuation. The time between the ending of tracer illumination and the entrance of the tracer material into the riser was found to be 2.3 seconds, which was found to be acceptable.

The detection system, as designed, was able to accurately measure total RTD of the tracer material in the riser system at certain conditions. In controlled scale tests conducted in a 3" diameter riser section, the measurement system was able to detect tracer particles at a tracer 
sample size of 5 grams at a voidage of 0.999. Detection was also established in a bubbling bed containing a mixture of bed and tracer material with a minimum of $5 \%$ tracer particles.

The sensor and fiber optic probe combination detailed within this study provided satisfactory detection at the system entrance and lower stage riser locations. At the system exit, the detection system accurately detected the low light signature of the tracer particles in a limited range of operational conditions. The upper stage of the riser caused a breakup of the tracer particle cluster which caused the tracer particles to pass the riser exit sensor location in a dispersed fashion which made detection problematic. This condition was overcome by measuring particles by placing the detection probe in the solids exit of the cyclone or by placing the sensor directly on the exit crossover without the use of an intermediary fiber probe.

\subsection{Recommendations}

This system forms the basis for developing a more sophisticated instrument for more complex studies. The objectives of this study were met, but the RTD measurement system could be further optimized. The largest problem with the system lies within the detection system which is split into two subsystems: 1) the fiber optic probes and 2) the APD light sensors. Due to the fact that the fiber optic probe was designed to pass through $1 / 4^{\prime \prime}$ compression fittings and impart minimal disturbance to the flow within the fluidized riser, some compromises were made such as the exclusion of a focusing lens.

It is recommended that in future studies utilizing the fiber probe arrangement that the optical probes be designed with a lens to focus and direct the light photons into the fiber optic transmission line. It was originally expected that the use of lenses was not required. Therefore, 
the fiber probe was initially designed so the light would directly pass into the open end of an optic probe and be internally reflected through the fiber line. A more suitable redesigned probe with matching lens could not be constructed or purchased within the scope of the project. To further decrease optical losses from the fiber line connections, a precision base and a fiber collimination package could be used to better focus the light emission from the fiber lines onto the detection surface of the sensors.

The Thorlabs Avalanche Photodiode (APD) sensors selected for measurement of the light intensity were originally believed to meet the requirements of this study. The shortcomings of these particular sensors are highlighted within this document. The APD sensors were operated in a range near the minimum detection level where signal noise became a large hindrance. For future studies, it is recommended that photomultiplier tube sensors be utilized for the low light level detection due to their higher light amplification capabilities.

Due to the tracer particles traveling through the exit crossover in such a disperse pattern caused by the transition to the larger diameter upper stage, the detection of tracer particles required a sensor arrangement directly measuring the tracers without an intermediary fiber probe. A single PMT sensor or a series of PMT sensors with large detection areas should be utilized for this riser arrangement in future studies for a higher magnification of the light signal. The timescale of RTD in which the designed measurement system accurately recorded would be better suited for a single stage riser system with a constant diameter.

The injection system could be further optimized by changing the geometry of the bushing in the upper bore of the slider or by the addition of a valve to contain the tracer particles within 
the upper bore of the slider during actuation. The issue could also be resolved by using a pulse of air to aid the solids filling the upper bore of the slider more completely before actuation. A valve could also be attached to the top of the slider so that when the slider is actuated downwards, the tracer material would be pulled downward with the slider instead of relying on the acceleration due to gravity.

Another proposed novel method for the measurement of RTD can be found in Appendix B. The use of thermochromic pigment coated solids could be used for future studies for the measurement of RTD, solids mixing, and axial diffusion. 


\section{Bibliography}

1. Christensen, D., J. Nijenhuis, J.R. Van Ommen, and M.-O. Coppens. "Residence Times in Fluidized Beds with Secondary Gas Injection." Powder Technology 180.3 (2008): 321-31. Print.

2. Westphalen, D., and Leon Glicksman. "Lateral Solid Mixing Measurements in Circulating Fluidized Beds." Powder Technology 82.2 (1995): 153-167. Print

3. Song, Byung-Ho, Yong-Won Jang, Sang-Done Kim, and Soon-Kook Kang. "Gas Yields from Coal Devolatilization in a Bench-scale Fluidized Bed Reactor." Korean Journal of Chemical Engineering 18.5 (2001): 770-74. Print

4. Avidan, A. A. Bed Expansion and Solid Mixing in High Velocity Fluidized Beds. Diss. City University of New York, 1980. N.p.: n.p., n.d. Print.

5. Brewster, Brandon S., and J. D. Seader. "Nonradioactive Tagging Method of Measuring Particle Velocity in Pneumatic Transport." AIChE Journal 26.2 (1980): 325-27. Print.

6. Kojima, T., K. Ishihara, Y. Guilin, and T. Furusawa. "Measurement of Solids Behaviour in a Fast Fluidised Bed." Journal of Chemical Engineering of Japan 22.4 (1989): 341-46. Print.

7. Harris, A.T, J.F Davidson, and R.B Thorpe. "A Novel Method for Measuring the Residence Time Distribution in Short Time Scale Particulate Systems." Chemical Engineering Journal 89.1-3 (2002): 127-42. Print.

8. Roques, Y., T. Gauthier, R. Pontier, and M.A. Bergougnou. "Residence Time Distributions of Solids in a Gas-Solids Downflow Transported Reactor." Circulating Fluidized Bed Technology IV (1993): 555-59. Print.

9. Yan, Chaoyu, Yiping Fan, Chunxi Lu, Yongmin Zhang, Yansheng Liu, Rui Cao, Jinsen Gao, and Chunming Xu. "Solids Mixing in a Fluidized Bed Riser." Powder Technology 193.1 (2009): 110-19. Print.

10. Velden, M., J. Baeyens, and K. Smolders. "Solids Mixing in the Riser of a Circulating Fluidized Bed." Chemical Engineering Science 62.8 (2007): 2139-153. Print.

11. Godfroy, Larin, Jamal Chaouki, and Faïçal Larachi. "Position and Velocity of a Large Particle in a Gas/solid Riser Using the Radioactive Particle Tracking Technique." The Canadian Journal of Chemical Engineering 77.2 (1999): 253-61. Print.

12. Sivashanmugam, P., and S. Sundaram. "Residence Time Distribution Studies in Annular Circulating Fluidised Bed Drier." Powder Technology 107 (2000): 256-58. Print. 
13. Winaya, I Nyoman Suprapta, Tadaaki Shimizu, and Daisuke Yamada. "A New Method to Evaluate Horizontal Solid Dispersion in a Bubbling Fluidized Bed." Powder Technology 178.3 (2007): 173-78. Print.

14. Bellgardt, D., and J. Worther. "A Novel Method for the Investigation of Particle Mixing in Gas-solid Systems." Powder Technology 48 (1986): 173-80. Print.

15. Avidan, A. A., D. King, and T. Knowlton. Fluid Bed Technology. New York: American Institute of Chemical Engineers, 1988. Print.

16. Fan, Liang-Shih, and Chao Zhu. Principles of Gas-solid Flows. Cambridge: Cambridge UP, 1998. Print.

17. Monazam, E. R., and L. J. Shadle. "A Transient Method for Characterizing Flow Regimes in a Circulating Fluidized Bed." Powder Technology 139 (2004): 89-97. Print.

18. Rowan, Steve. "Analysis and Scaling of a Two-Stage Fluidized Bed for Drying of Fine Coal Particles Using Shannon Entropy, Thermodynamic Exergy and Statistical Methods." Diss. West Virginia University, 2010. WVU Scholar. 21 July 2010. Web.

19. USR Optonix Inc. Technical Data Sheet Phosphorescent Pigment 2330MBW Geen. Hackettstown NJ: USR Optonix, n.d. Print.

20. Glow Inc. "Black Lights." Glowlnc.com. N.p., n.d. Web. 22 July 2012. <http://glowinc.com/glow-in-the-dark/black-light.aspx>.

21. Hamamatsu Photronics K.K. Photomultiplier Tubes- Basics and Applications. N.p.: Hamamatsu Photronics K.K., 2006. Print.

22. Thorlabs. Operation Manual Thorlabs Instrumentation APD110x Series Avalanche Photodetectors. 1.0st ed. Newton, NJ: Thorlabs, 2009. Print.

23. Cooney, Thomas F., H. Trey Skinner, and S. M. Angel. "Comparative Study of Some FiberOptic Remote Raman Probe Designs. Part II: Tests of Single-Fiber, Lensed, and Flat- and Bevel-Tip Multi-Fiber Probes." Applied Spectroscopy 50.7 (1996): 849-60. Print. 


\section{Appendices}




\section{Appendix A: Arduino Sketch}

// Jackson Wolfe

//12-12-11

//Using Relay Shield

//Control air solenoid valves for the automation of particle injector

// Note: relay 1=relayPin3 Buzzer; relay2=relayPin2 Air Solendiod; relay3=relayPin1 Slider; relay4=relayPinO Ball Valve

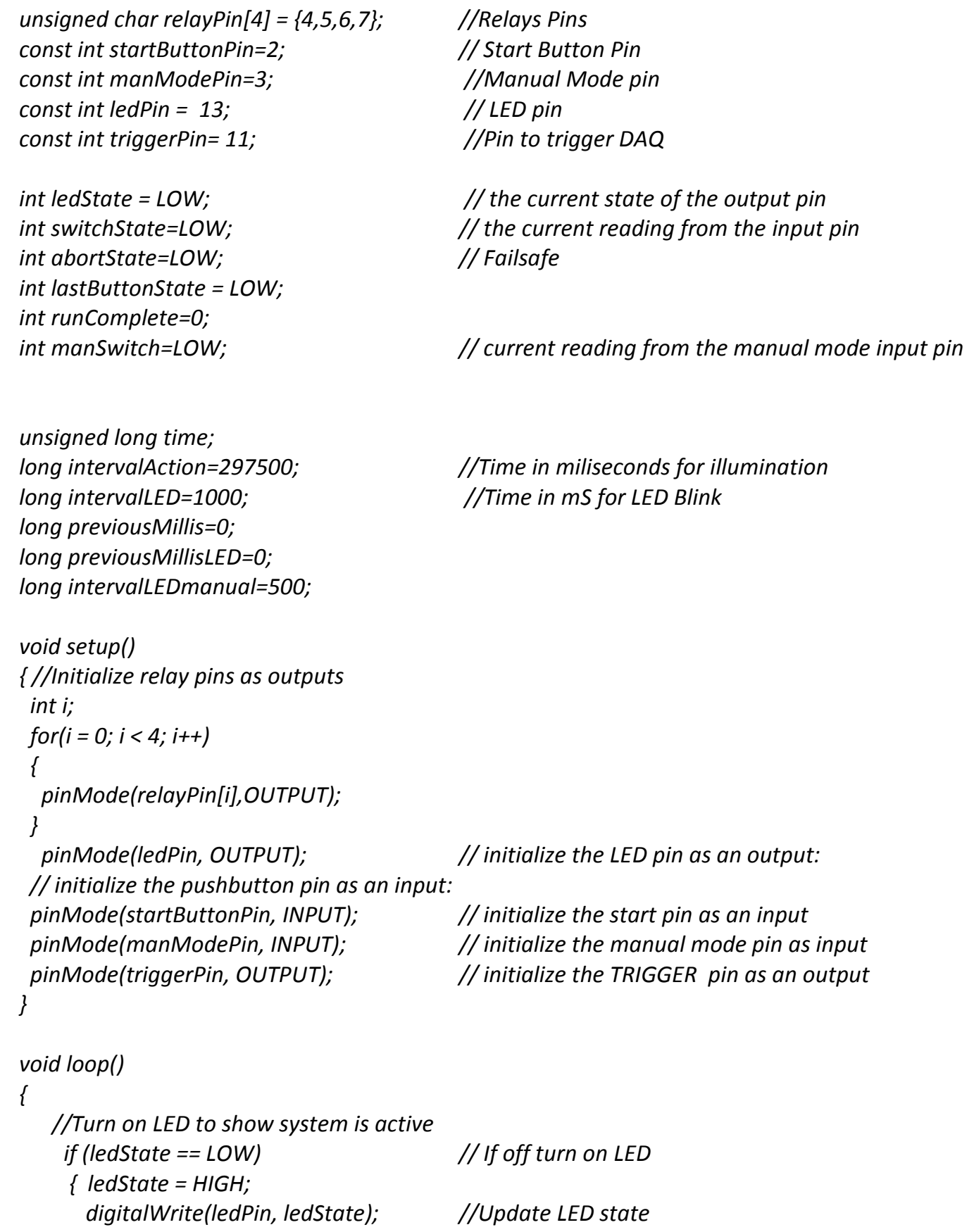




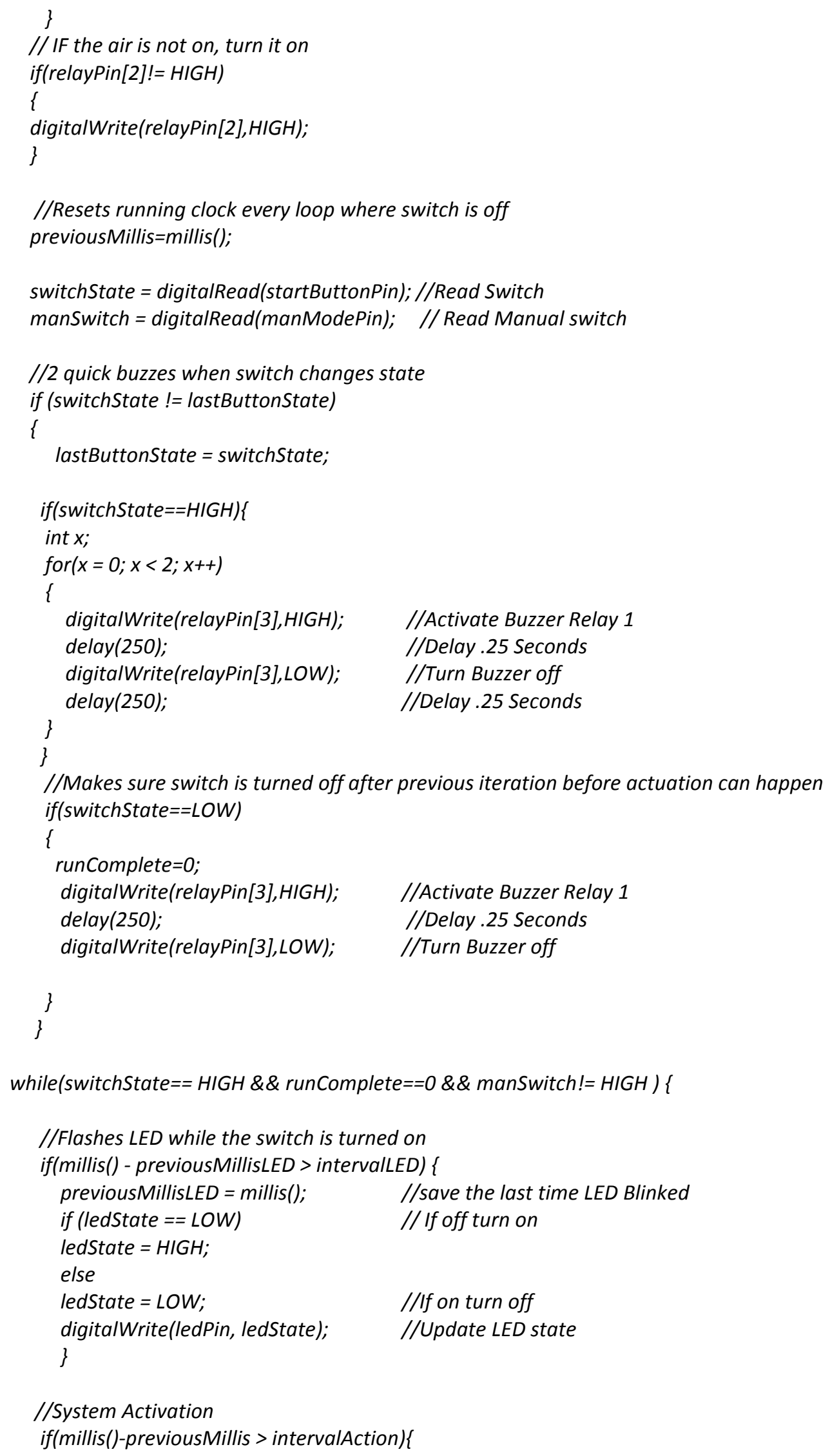




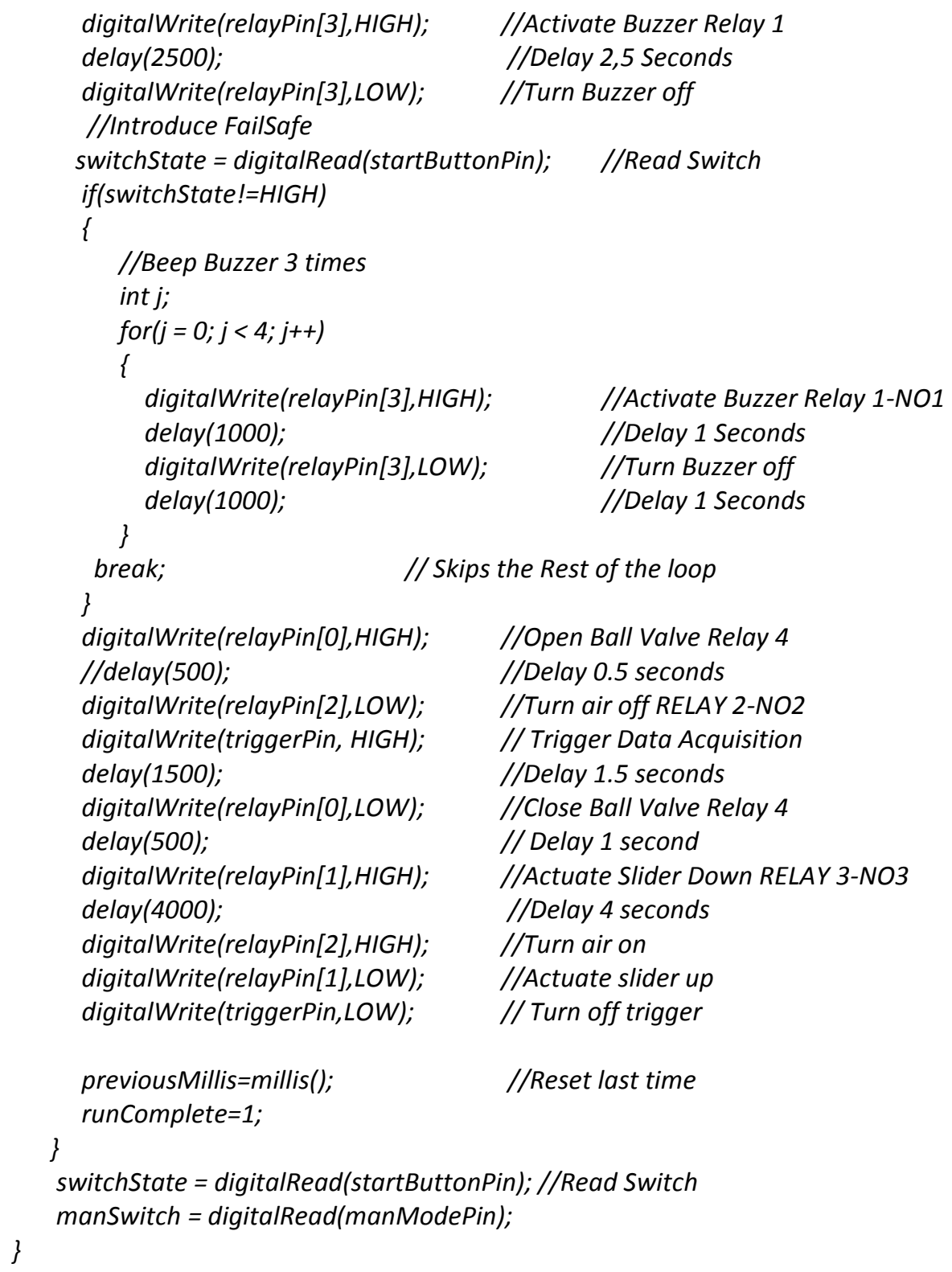




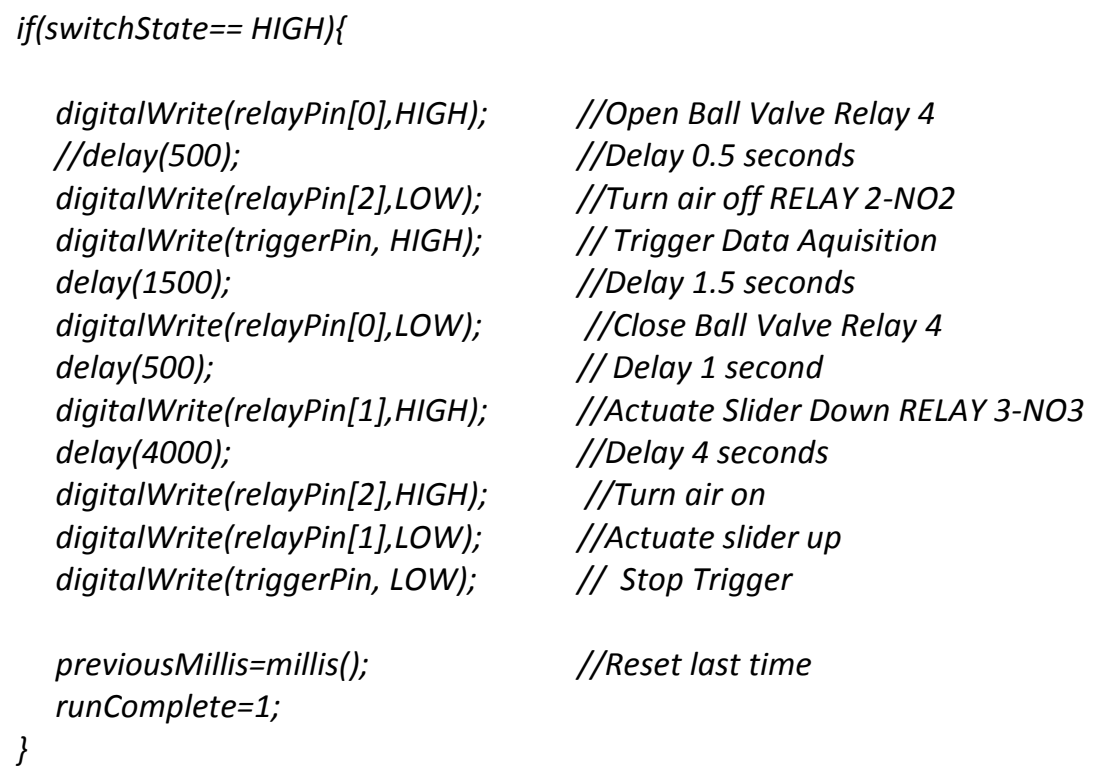




\section{Appendix B: Thermochromic Tracers}

Thermochromatic paints and dyes have the ability to reflect specific colors as a function of temperature. Thermochromic inks come in two forms, leuco and liquid crystals. Leuco dyes are easier to work with, but are not as accurate as liquid crystals. Liquid crystals also generally have a longer response time to temperature changes. Most thermochromic dyes reflect color at a warm temperature and slowly turn translucent with a temperature drop.

Coating particles in a thermochromic dye would allow the particles to change colors inside the fluidized bed riser as a function of heat transfer. If using thermochromic dye that becomes clear as it is cooled, a base dye can be applied to provide a more intense contrast to indicate a color change. Particles can be heated prior to injection into a fluidized riser to activate the pigment. The activated tracers will reflect light at a certain wavelength. After injection, the fluidizing air in the riser will begin to cool the particle which modifies the color appearance of the particle as the base dye begins to appear from under the thermochromic dye.

A wavelength shift can be measured as a function of heat transfer, but ultimately can be correlated to a change in time. A color shift versus time chart can be made for the temperature of the system and the air velocity through the riser. The dye selected for an application can vary on the type application. It is possible to use a dye that will have a temperature slightly higher than that of the operation temperature of the system so that minimal color change will occur before the exit of the particle from the riser. It is also possible to use a dye that will change color over a predetermined amount of time so that when injected, the colors will be one color, and while exiting will be almost to the color of the base dye.

This method could allow continuous injection of the tracer material unlike most RTD measurement methods. An observer would be able to clearly see a shift in color from the particles in the lower dense bed to the upper dilute phase. For localized RTD measurement, a photograph of a section of the riser can be taken when the system reaches steady state. The photograph can be analyzed in software that would produce an intensity distribution of the captured light wavelengths. Since a specific wavelength of particle can be correlated to the time of the particle in the system, the average localized RTD in the pictured section can be calculated from the intensity distribution.

There are other RTD measurement strategies could be employed as well. The more traditional method is the injection of tracers into the system as a step function. Optical measurement devices can be placed in fixed locations to measure the wavelengths of passing particles. RTD can be determined as a function of the change in time from the injection to the detection of the particles. If using this method, the thermochromic dye can be designed to change color at a temperature slightly higher than that of the air flowing through the riser. This would allow minimum color shift of the particle during the total residence time in the riser and would lead to more accurate results. 